University of South Florida

DIGITAL COMMONS

@ UNIVERSITY OF SOUTH FLORIDA
Digital Commons @ University of

South Florida

$9-1-2001$

\title{
Inventory and Analysis of Advanced Public Transportation Systems in Florida
}

CUTR

Follow this and additional works at: https://digitalcommons.usf.edu/cutr_nctr

\section{Scholar Commons Citation}

CUTR, "Inventory and Analysis of Advanced Public Transportation Systems in Florida" (2001). Research Reports. 195.

https://digitalcommons.usf.edu/cutr_nctr/195

This Technical Report is brought to you for free and open access by the National Center for Transit Research (NCTR) Archive (2000-2020) at Digital Commons @ University of South Florida. It has been accepted for inclusion in Research Reports by an authorized administrator of Digital Commons @ University of South Florida. For more information, please contact digitalcommons@usf.edu. 


\section{INVENTORY \& ANALYSISOF ADVANCED PUBUC TRANSPORTATION SYSTEMS IN FLORIDA}

Final Report 
TECHNICAL REPORT STANDARD TITLE PAGE

\begin{tabular}{|c|c|}
\hline $\begin{array}{l}\text { 1. Report No. } \\
\text { NCTR-392-04 }\end{array}$ & 3. Recipient's Catabg No. \\
\hline \multirow[t]{2}{*}{$\begin{array}{l}\text { 4. Title and Subtitle } \\
\text { Inventory \& Analysis of Advanced Public Transportation Systems in Florida }\end{array}$} & $\begin{array}{l}\text { 5. Report Date } \\
\text { September } 2001\end{array}$ \\
\hline & 6. Performing Organizaion Code \\
\hline $\begin{array}{l}\text { 7. Author(s) } \\
\text { Joel R. Rey, Shireen Chada, Chandra Foreman, Brenda Thompson }\end{array}$ & 8. Performing Organizaíon Report No. \\
\hline \multirow{2}{*}{$\begin{array}{l}\text { 9. Performing Organization Name and Address } \\
\text { National Center for Transit Research (NCTR) } \\
\text { University of South Florida } \\
4202 \text { E. Fowler Ave., CUT 100, Tampa, FL 33620-5375 }\end{array}$} & 10. Work Unit No. \\
\hline & $\begin{array}{l}\text { 11. Contract or Grant No. } \\
\text { DTRS98-G-0032 }\end{array}$ \\
\hline $\begin{array}{l}\text { 12. Sponsoring Agency Name and Address } \\
\text { Research \& Special Programs Admin., U.S. Department of Transportation, } \\
\text { RSPA/DIR-1, Room } 8417,4007^{\text {th }} \text { Street SW, Washington, D.C. } 20590\end{array}$ & 13. Type of Report and Period Covered \\
\hline $\begin{array}{l}\text { Florida Department of Transportation } \\
605 \text { Suwannee Street, MS 26, Tallahassee, FL 32399-0450 }\end{array}$ & 14. Sponsoring Agency Code \\
\hline
\end{tabular}

15. Supplementary Notes

Supported by a grant from the Florida Department of Transportation and the U.S. Department of Transportation.

16. Abstract

Through its National Center for Transit Research, and under contract with the Horida Department of Transportation, the Center for Urban Transportation Research has conducted an inventory of current and planned Advanced Public Transportation Systems (APTS) in Forida to help the Forida Department of Transportation (FDO T) develop baseline information on Intelligent Transportation Systems (ITS) transit activities around the state. Although the primary task of this effort was to develop an inventory of current and planned Florida APTS projects based on the results of a survey of Forida transit properties, the project also included two supplementary tasks related to the implementation of APTStechnologies. One of these tasks involved examining, through a literature review, 10 of the major issues that transit properties around the country have encountered during the development and/or deployment phases of their projects, and then analyzing the Florid a properties' experien ces with these issues based on their survey responses. The other, and fin al, task involved conducting an assessment of APTS benefits for a few selected transit agencies utilizing a benefits analysis spreadsheet tool (i.e., SCRITS) and documen ting the results of the assessments in ord er to provide an evaluation exam ple for oth er agencies to follow as they continue to develop and deploy APTStechnologies It is anticipated that this research will help provide further guidance to Florida and other U.S. transit properties in the formative stages of APTSinvestigation.

17. Key Words

Transit, Technology, ITS, APTS, SCRITS
18. Distribution Statement

Available to the public through the National Technical Information Service (NTIS), 5285 Port Royal Road, Springfield, VA 22161, 703-605-6000, http://www.ntis.gov/

An electronic version of this document is also available to the public in .pdf format through the NCTR web site, http://www.nctr.usf.edu/.

20. Security Classif. (of this page)

Unclassified
21. No. of pages

216

Unclassified 


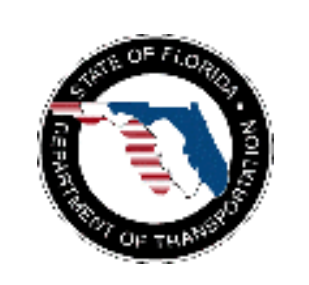

\section{State of Florida Department of Transportation}

Public Transit Office

605 Suwannee Street

Tallahassee, Fl 32399-0450

(850) 414-4500

Project Manager:

Ike Ubaka

Program Manager, Transit SystemsPlanning

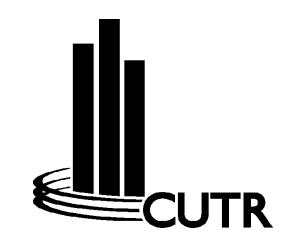

\section{Center for U rban Transportation Research}

University of South Forida

4202 E Fowler Avenue, CUT 100

Tampa, Fl 33620-5375

(813) 974-3120

Project Director: $\quad$ Dennis Hinebaugh, Transit Program Director

Project Manager: $\quad$ bel R. Rey, Senior Research Associate

Project Staff: $\quad$ Shireen Chada, Research Associate

Chandra Foreman, Research Associate

Brenda Thompson, Research Associate

The opinions, findings and conclusions expressed in this publication are those of the authors and not necessarily those of the U.S. Department of Transportation or the State of Florida Department of Transportation. 


\section{TABLE OF CONTEN TS}

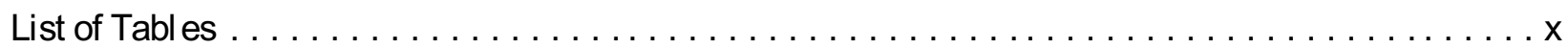

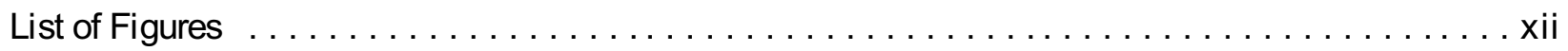

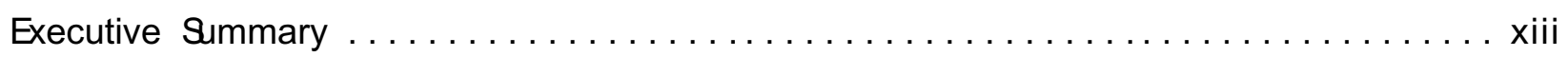

Inventory \& Analysis of Advanced Public Transportation Systems in Florida . . . . . . . . . 1

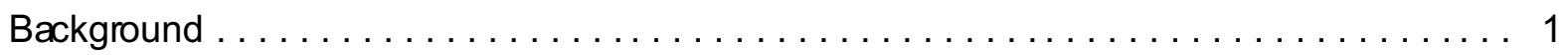

1. Inventory of Advanced Public Transportation Systemsin Florida . . . . . . . . . . . . 3

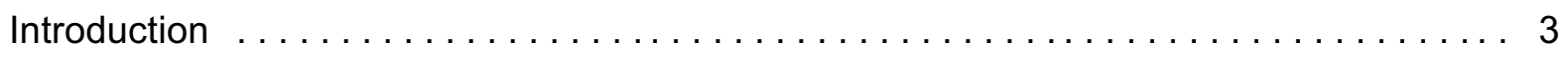

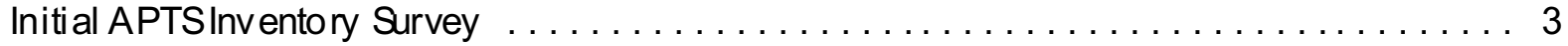

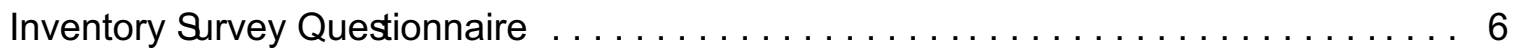

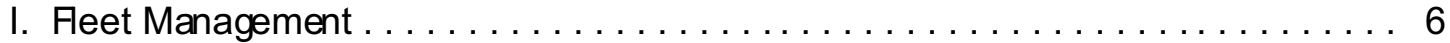

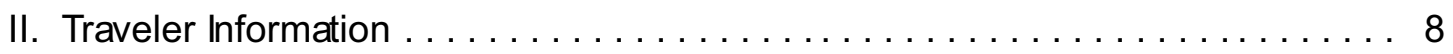

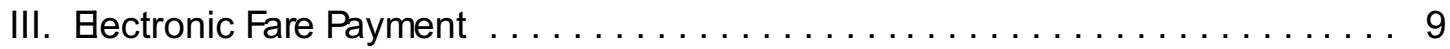

IV. Transportation Demand Management Technologies . . . . . . . . . . 9

V. Paratransit Providers . . . . . . . . . . . . . . . . . . . . 11

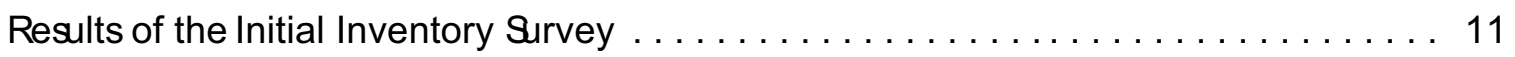

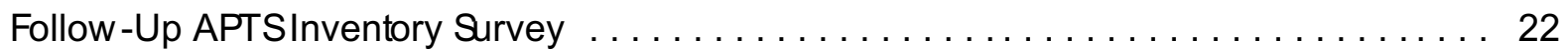

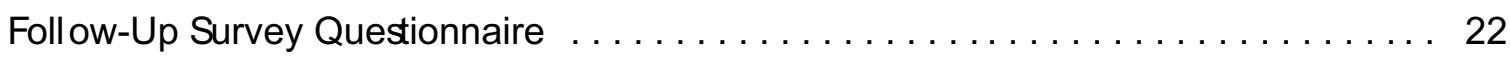

General . . . . . . . . . . . . . . . . . . . . . . . . . . . 22

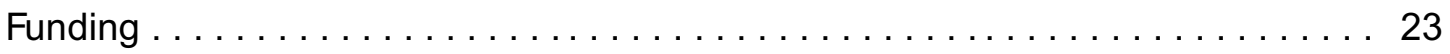

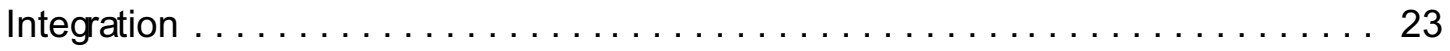

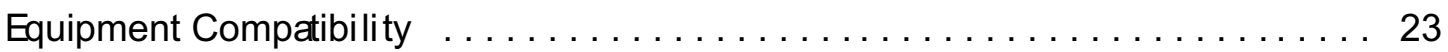

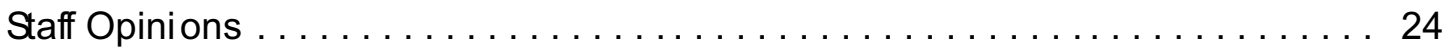

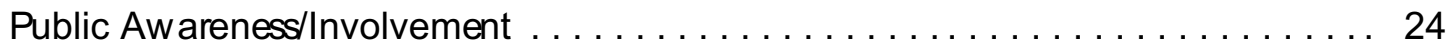

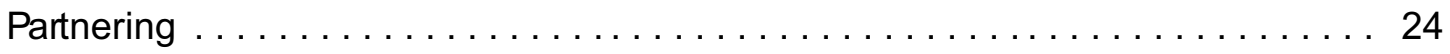

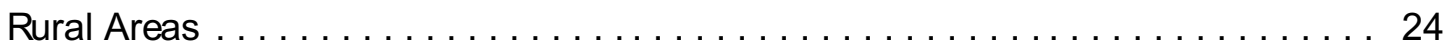

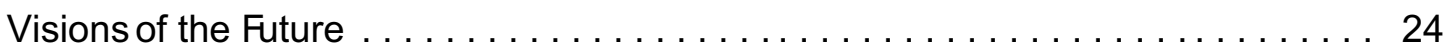

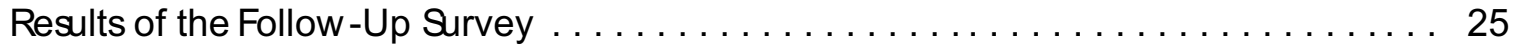

General . . . . . . . . . . . . . . . . . . . . . 25

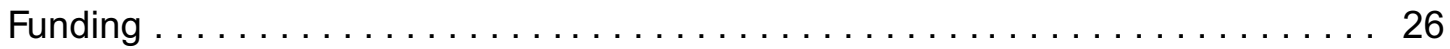

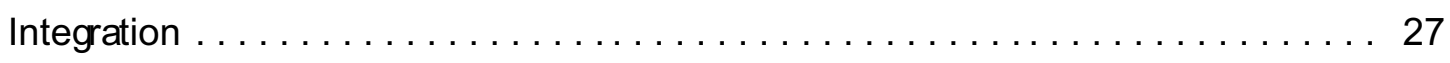

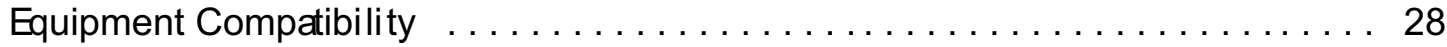

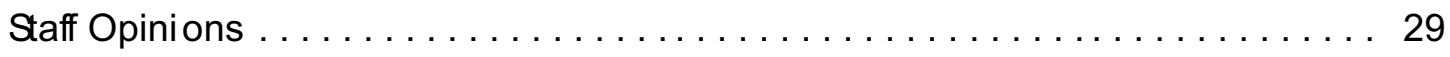




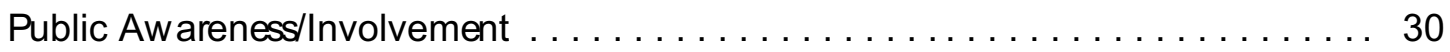

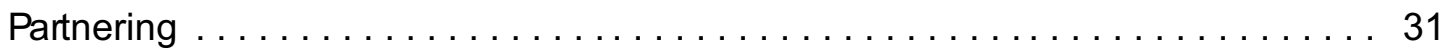

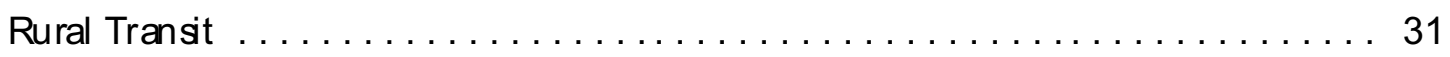

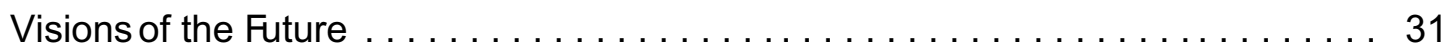

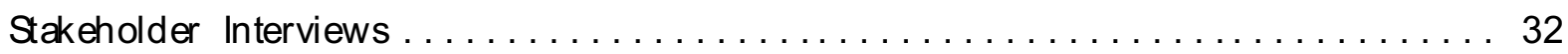

Stakeholder Interview Questionnaire $\ldots \ldots \ldots \ldots \ldots \ldots \ldots \ldots \ldots \ldots \ldots \ldots \ldots \ldots \ldots$

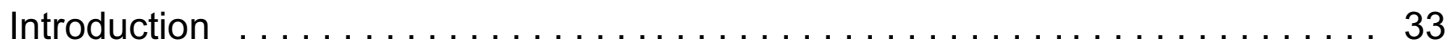

Development and Deployment ............................. 33

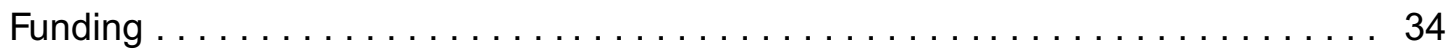

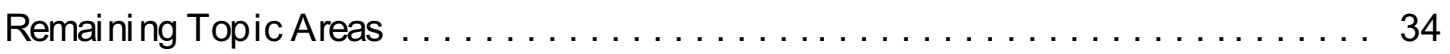

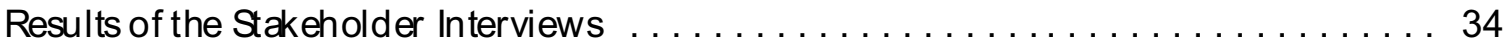

Summary of FDOT District 1 Stakeholder Interviews $\ldots \ldots \ldots \ldots \ldots \ldots \ldots, \ldots \ldots$

Summary of FDOT District 2 Stakeholder Interviews $\ldots \ldots \ldots \ldots \ldots \ldots \ldots, 35$

Summary of FDOT District 4 Stakeholder Interviews $\ldots \ldots \ldots \ldots \ldots \ldots \ldots 37$

Summary of FDOT District 6 Stakeholder Interviews $\ldots \ldots \ldots \ldots \ldots \ldots \ldots . \ldots 38$

Summary of FDOT District 7 Stakeholder Interviews $\ldots \ldots \ldots \ldots \ldots \ldots \ldots . \ldots . \ldots . \ldots$

Summary of Central Office Stakeholder Interviews . . . . . . . . . . . . . 41

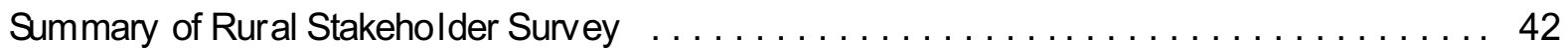

Summary of Rural Forida ITS Demonstration Project $\ldots \ldots \ldots \ldots \ldots \ldots \ldots \ldots \ldots . \ldots 4$

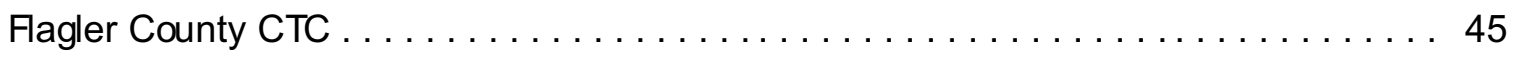

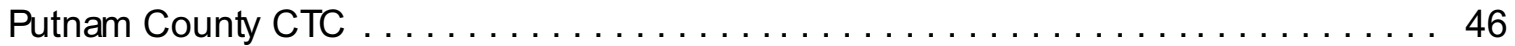

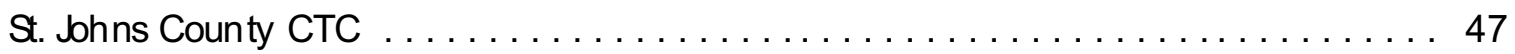

Al achua-Levy Counties CTC . . . . . . . . . . . . . . . . . . . . . . 48

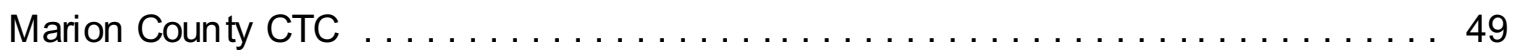

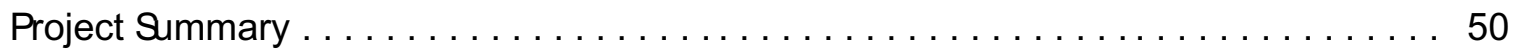

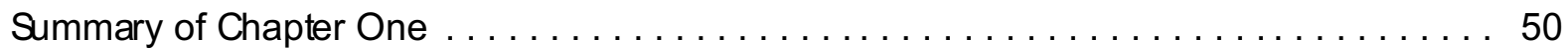

2. Issues \& Characteristics of the Development/D epl oyment of APTS A Li terature Review . . . 55

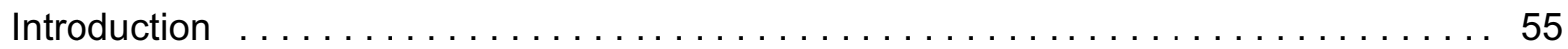

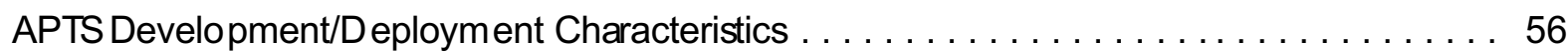

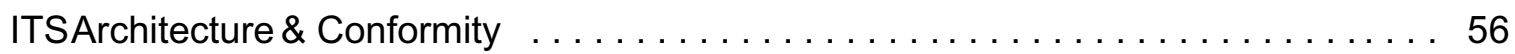

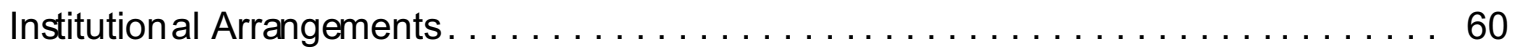

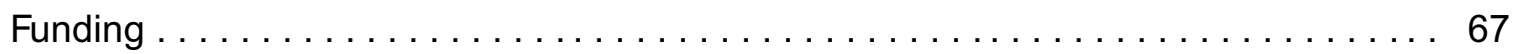

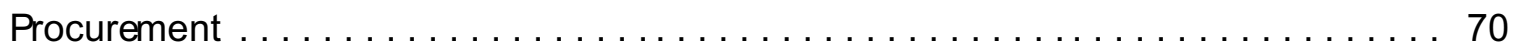

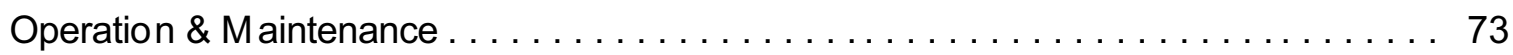

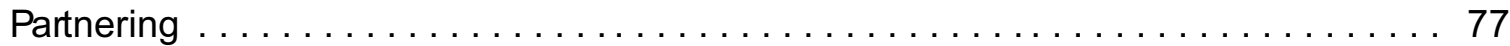

Public Involvement ................................... 84

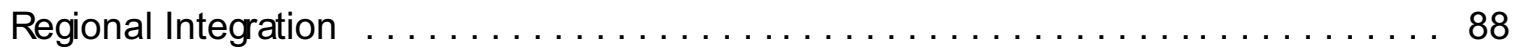

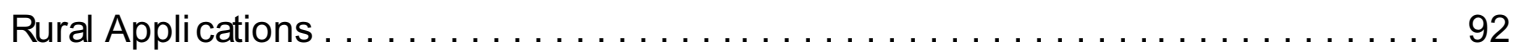


Benefits Analysis \& Performance Monitoring $\ldots \ldots \ldots \ldots \ldots \ldots \ldots \ldots$

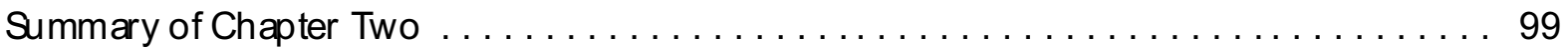

3. APTSBenefits Analysis \& Performance Monitoring $\ldots \ldots \ldots \ldots \ldots \ldots \ldots \ldots$

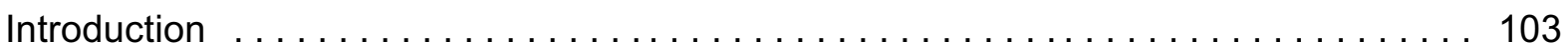

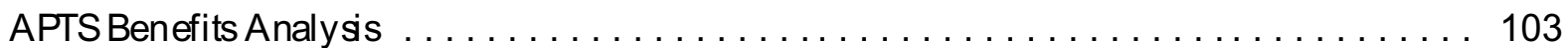

Assessment Tools . . . . . . . . . . . . . . . . . . . . . . . . . . 104

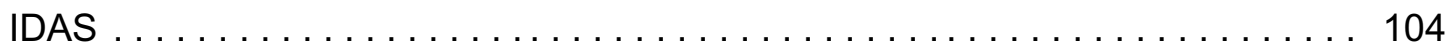

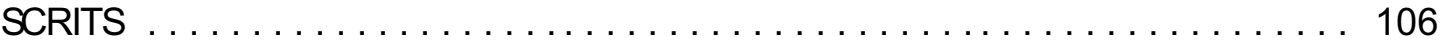

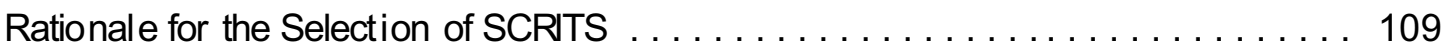

Participating Transit Agencies . . . . . . . . . . . . . . . . . . . . . 109

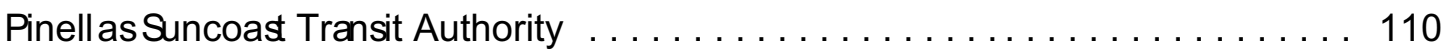

Hill sborough Area Regional Transit Authority . . . . . . . . . . . . . . 111

LYNX Transit . . . . . . . . . . . . . . . . . . . . . . . . . 112

Sarasota County Area Transit . . . . . . . . . . . . . . . . . . . 113

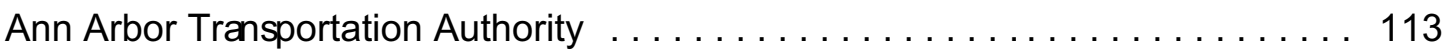

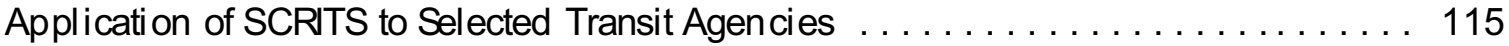

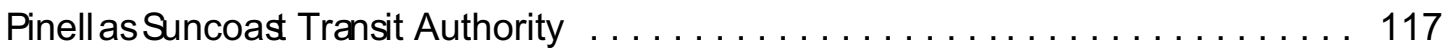

Hill sborough Area Regional Transit Authority . . . . . . . . . . . . . . . . . 122

LYNX Transit . . . . . . . . . . . . . . . . 126

Sarasota County Area Transit . . . . . . . . . . . . . . . . . . . . . 137

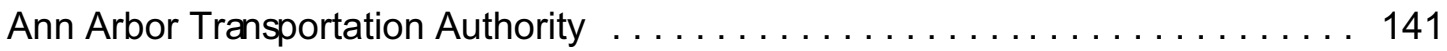

Comparison of Results . . . . . . . . . . . . . . . . . . . . . . . . 148

Assessment of the SCRITS Tool \& Analysis Process . . . . . . . . . . . 151

Recommendations for Performance Monitoring Measures . . . . . . . . . . . . . . . . 154

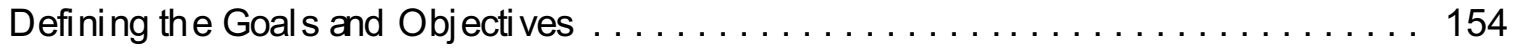

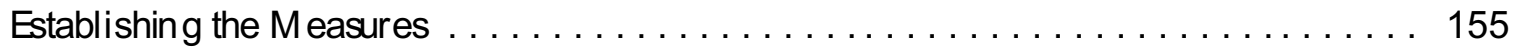

APTSApplications . . . . . . . . . . 156

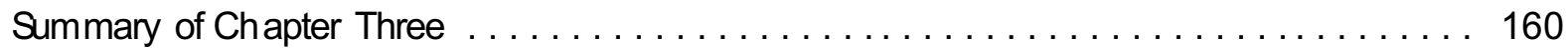

Appendix A. Initial APTSInventory Questionnaire $\ldots \ldots \ldots \ldots \ldots \ldots \ldots \ldots \ldots \ldots \ldots$

Appendix B. Follow-Up APTS Inventory Questionnaire $\ldots \ldots \ldots \ldots \ldots \ldots \ldots \ldots \ldots$ B-1

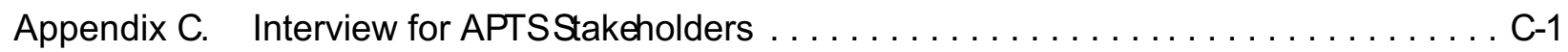

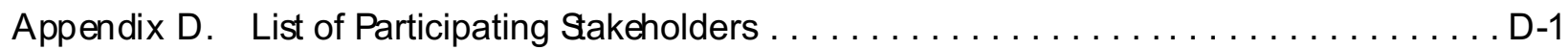

Appendix $\mathrm{E} \quad$ List of References for Literature Review . . . . . . . . . . . . . . E-1 


\section{LST OF TABLES}

Table ES-1 SCRTSEectronic Fare Collection Worksheet Analysis: Comparison of Post-Deployment Results . . . . . . . . . . . . . . . . . . . . . . xvii

Table 1-1 Florida Transit Agency Survey Participation . . . . . . . . . . . . . 5

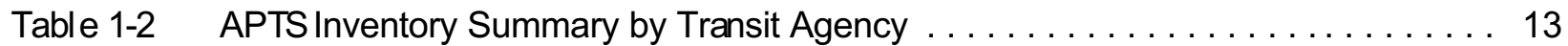

Table 1-3 APTSInventory Summary: Automated Vehicle Location Systems . . . . . . . . . . . . 14

Table 1-4 APTSInventory Summary: Automatic Passenger Counters . . . . . . . . . . . . . . . . . . 14

Table 1-5 APTSInventory Summary: Vehicle Component Monitoring Systems . . . . . . . . 15

Table 1-6 APTSInventory Summary: Automated Operations Software $\ldots \ldots \ldots \ldots \ldots$

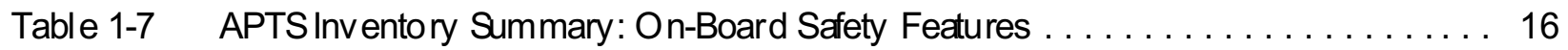

Table 1-8 APTSInventory Summary: Trip Planning Information $\ldots \ldots \ldots \ldots \ldots \ldots$

Table 1-9 APTSInventory Summary: Trip Planning Information (Single Mode/Multi-Modal) . 17

Table 1-10 APTSInventory Summary: In-Terminal Information Systems . . . . . . . . . . 17

Table 1-11 APTSInventory Summary: In-Vehicle Information Systems . . . . . . . . . . 18

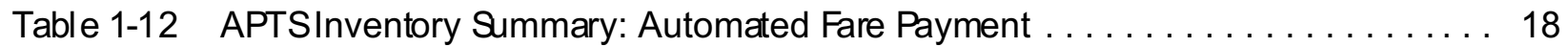

Table 1-13 APTSInventory Summary: Multi-Carrier Reservation and Billing Systems . . . . . 19

Table 1-14 APTSInventory Summary: Advanced Communications . . . . . . . . . . . . . . 19

Table 1-15 APTSInventory Summary: Automated Service Coordination . . . . . . . . . . 20

Table 1-16 APTS Inventory Summary: Transportation Management Center . . . . . . . . . 20

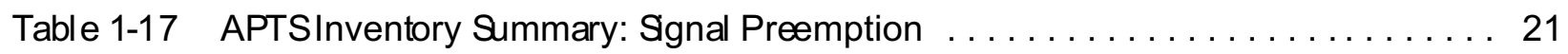

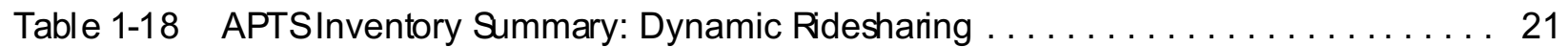

Table 1-19 APTS Inventory Summary: High Occu pancy Vehicle Lane Access . . . . . . . . . 21

Table 1-20 APTSInventory Summary: Automated Paratransit . . . . . . . . . . . . . 21

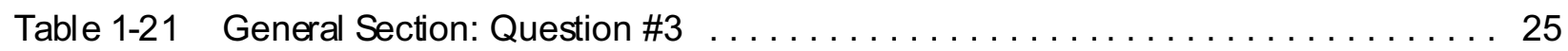

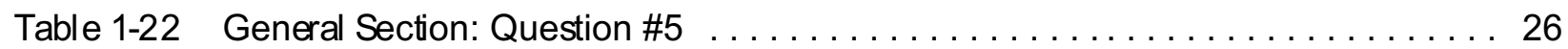

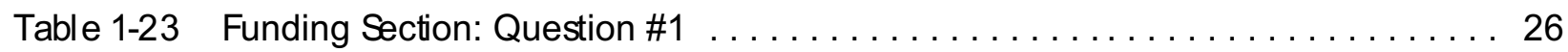

Table 1-24 Integration Section: Questions\#1, 5, \& $7 \ldots \ldots \ldots \ldots \ldots \ldots \ldots \ldots \ldots \ldots$

Table 1-25 Integration Section: Question $\# 9 \ldots \ldots \ldots \ldots \ldots \ldots \ldots \ldots \ldots \ldots \ldots$

Table 3-1 SCRITSWorksheet: Pre-Implementation Analysis of PSTA's

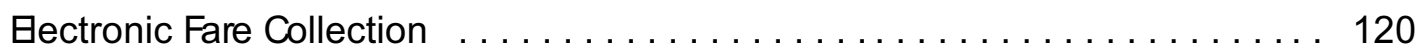

Table 3-2 SCRTSWorksheet: Post-Implementation Analysis of PSTA's

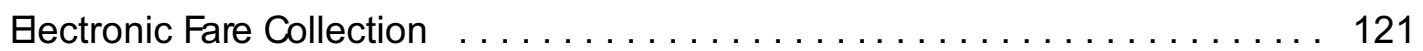

Table 3-3 SCRITSWorksheet: Pre-tmplementation Analysis of HART's

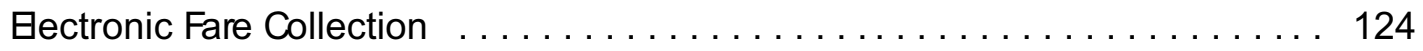

Table 3-4 SCRTSWorksheet: Post-Implementation Analysis of HART's

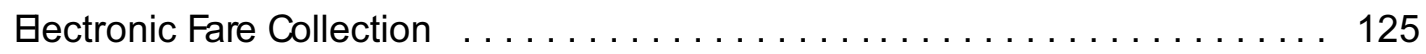


Table 3-5 SCRTSWorksheet: Pre-Implementation Analy sis of LYNX's

Eectronic Fare Collection $\ldots \ldots \ldots \ldots \ldots \ldots . \ldots \ldots \ldots$

Table 3-6 SCRTSWorksheet: Post-Implementation Analy sis of LYNX's

Eectronic Fare Collection . . . . . . . . . . . . . . . . . . . . . . . . . . 129

Table 3-7 SCRTSWorksheet: Pre-Implementation Analy sis of LYNX's

Automatic Vehicle Location . . . . . . . . . . . . . . . . . . . . . . . . . . . . . . . . . . . 131

Table 3-8 SCRTSWorksheet: Post-Implementation Analy sis of LYNX's

Automatic Vehicle Location . . . . . . . . . . . . . . . . . . . . . . . . . . . . . . . . . . . 132

Table 3-9 SCRITSWorksheet: Pre-Implementation Analysis of LYNX's

Bus Priority System . . . . . . . . . . . . . . . . . . . . . . . . . . . . 135

Table 3-10 SCRTSWorksheet: Post-Implementation Analy sis of LYNX's

Bus Priority System . . . . . . . . . . . . . . . . . . . . . . 136

Table 3-11 SCRTSWorksheet: Pre-Implementation Analysis of SCAT's

Bectronic Fare Collection . . .................................. 139

Table 3-12 SCRITSWorksheet: Post-Implementation Analy sis of SCAT's

Eectronic Fare Collection $\ldots \ldots \ldots \ldots \ldots$. . . . . . . . . . . . . . . . . 140

Table 3-13 SCRITSWorksheet: Pre-tmplementation Analysis of AATA's

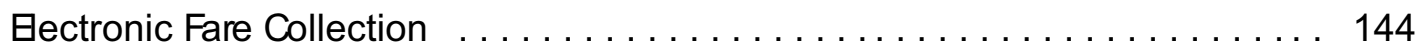

Table 3-14 SCRTSWorksheet: Post-Implementation Analysis of AATA's

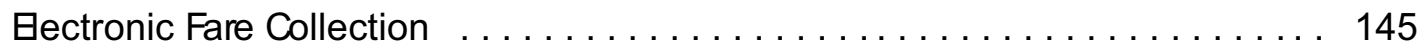

Table 3-15 SCRITSWorksheet: Pre-Implementation Analysis of AATA's

Automatic Vehicle Location . . . . . . . . . . . . . . . . . . . . . . . . . . 146

Table 3-16 SCRTSWorksheet: Post-Implementation Analysis of AATA's

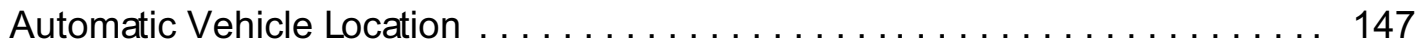

Table 3-17 SCRTSEectronic Fare Collection Worksheet Analysis: Comparison of

System Results . . . . . . . . . . . . . . . . . . . . . . . . 148

Table 3-18 SCRTSAutomatic Vehicle Location Worksheet Analysis: Comparison of

System Results . . . . . . . . . . . . . . . . . . . . . . . 149

Table 3-19 SCRITSWorksheet Analysis: Comparison of Technologies . . . . . . . . . 150

Table 3-20 Examples of APTSProgram Objectivesand Performance Measures . . . . . . . . 157

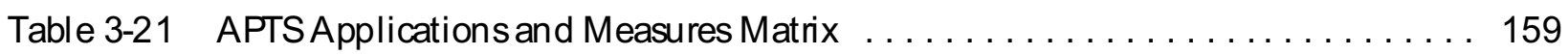




\section{LST OF FIGURES}

Figure 3-1 Benefit/Cost Summary Report - Example Output . . . . . . . . . . . 105

Figure 3-2 Performance Summary Report - Example Output . . . . . . . . . . . . . 106

Figure 3-3 Screen Capture of SCRITSEectronic Fare Collecti on Worksheet . . . . . . . . 108 


\section{EXecutive Sum M ARY}

One element of the U.S. Department of Transportation's initiative on Intelligent Transportation Systems (ITS) is the Federal Transit Admini stration's Advanced Public Transportation Systems(APTS) program. Thisprogram wasestablished to encourage the uæ of technology to improve the quality and usefulness of public transportation and ridesharing services. The Center for Urban Transportation Research (CUTR) at the University of South Forida in Tampa has conducted an inventory and analysis of APTS in Florida to help the Forida Department of Transportation (FDOT) develop baseline information on ITS transit activities around the state. This effort was comprised of three primary tasks: (1) the development of an inventory of current and planned Florida APTSprojects; (2)aliterature revi ew-based examination of 10 of the major issues/characteristics that transit propertiesaround the country have encountered during the development and/or deployment phases of their APTSprojects, supplemented by a review of the Florida properties' experiences with these sameissues, and (3)the completion of an assessment of APTSbenefits for a selection of case study transit agencies utilizing a benefits analysis spreadsheet tool in order to document an evaluation example for other agencies to follow as they continue to develop and deploy APTS technologies.

\section{APTSin Florida}

The first task utilized several surveys and sakeholder meetings to develop an inventory of the APTS activities going on around the state and compile the thoughts and comments of transit agency personnel and various statewi de stakeho Iders regarding APTSin Flo rida. Thirty Florida transit agencies that receive or will be receiving FDOT block grant funding were identified with the assistance of FDOT's Public Transportation Office for inclusion in the study. A mail-back inventory questionnaire was sent to these transit agencies. The inventory questionnaire asked the transit agencies about five main technology areas in APTS, including: fleet management, traveler information, electronic fare payment, tran sportation demand management, and technologi es associ ated with paratransit providers. Nineteen out the 30 transit agencies responded to the questionnaire.

According to the results of this initial survey, 11 of the 18 individual technologies listed in the questionnaire were still in the planning stagesfor many of the transit agencies at the time of the survey. Automated paratransit and advanced communications were the most popular technologies, with 14 transit agencies either in the planning, implementation, or fully operational stage. In addition, transit agencies have deployed advanced communication technologies more than any other technology mentioned. 
Subsequently, a follow -up questionnaire was administered via telephone and e-mail to all of the transit agencies. Ten of the agencies participated in this follow-up survey effort. According to the results of this particular survey, the majority of the respondents expect a "very high" level of efficiency from APTS. Funding was mentioned as the primary impediment to the deployment of APTS All of the respondentsstated that it is"very important" to providefundsfor APTSin public transportation projects.

For the discussion meetings that were held, CUTR invited a number of persons from around the state with a "stake" in the implementation and deployment of APTSin Florida. The stakehol ders consisted mostly of FDOT senior management staff makerssuch as the District Directors of Operations, Di strict Directors of Planning and Programming, and District Public Transportation Managers. According to the information exchange that took place at these meetings, most of the stakeholderswere enthusiastic to receive more information about ITSarchitecture and the ITSStrategic Plan. In discussing the concept of ITS architecture, all respondents indicated a belief that it is important for a regional ITSarchitecture to conform to the national ITS architecture. All of the stakeholders also believe that APTS has the potential to improve transit operations.

In addition to the aforementioned surveys and stakeholder meetings, a survey also was conducted to gain insight from rura transit providers. According to a number of Community Transportation Coordinatorsin the state, some of the APTStechnologies are expected to be tremendously beneficial to rural transit, especially in helping to better connect these services to the fixed-route services operating in urban areas. To provide some additional details about the APTSexperiencesof the rura transit providers, a general review of the Rural Forida ITSDemonstration Project being sponsored by the Federal Transit Administration (FTA) also was completed.

\section{APTSImplementation Issues \& Characteristics}

The second task of the project utilized a review of available literature to provide a variety of information on 10 specific issues (including ITS Architecture \& Conformity, Funding, Institutional Arrangements, Procurement, and Public Involvement, amongothers) related to thedevelopment and/or deployment of APTS. It also sought to document the experiences that a number of Rorida transit systems have had with these same issues, based on the results of the fol low-up APTSinventory survey and the stakeholder meetings.

From the literature review, it is evident that the decision to utilize a particular ITS technology is only the first sep of an extensive, and often challenging, process that runs from development, to deployment, and finally to the operation and maintenance of the chosen technology. Therefore, a lot 
of planning and forethought must go into the devel opment and implementation of any ITStechnology. Agencies considering the deployment of a technology first will want to understand the National ITS Architecture (or any state or local architecture that has been established) and use it as a guideline during the process. If partnering is desired, it also would be prudent for an agency to understand the issues involved with various institutional arrangements Identifying and enlisting a wide range of stakeholders in the project also will be advantageous to its success, as will ensuring that the implementation plan cl early establ ishesthe stakehol ders' rol esand responsibilities, and allows for and encourages interagency coordination.

Like most other transit projects, funding will be an important issue in the process to implement ITS. Capital funding will be needed for the acquisition and installation of equipment and supporting software applications. However, most challenging to many transit agencies will be finding the funds that will be required to upkeep and operate the ITStechnologieson a day-to-day basis. Operation and maintenance of the equipment will depend on the appropriate allocation of staff for those tasks. Staff also will be needed to deal with the timely and regular retrieval, analysis, and use of the resulting information from the operation of APTS. It is only through the appropriate levels of funding and saff resources that the full benefit of any ITStechnology application will be reached.

Simil arly, procurement of an ITStechnology can also be a complicated step in the processbecause ITS proposals are not well served by traditional procurement practices. The complexity of most technologies and the nœd to adapt to constantly evolving applications require that procurement procedures be much more flexible in nature. These more adaptive procedureswill help agencies be able to better account for desired goals, such as interoperability and the ability to be integrated with other technologies in the future, when procuring an ITStechnology.

A key element of many of the ITS proj ects that have been successfully implemented around the country is the awareness and involvement of public officials and the general public. Unfortunately, general understanding of ITS and its benefits is still quite low among decision makersand the public. Since these constituencies play an important role in setting policy and establ ishing funding priorities, it isin the best interest of agencies implementing ITS technol ogi es to ensure that they are made aw are of ITS solutions to transportation problems and other issues. If politicians and the public understand the benefits of ITSand how it can help solve existing problems, they will be more supportive of effortsto implement these technologies.

Asmore people understand ITS and how it can help solve real-world issues, it will be easier to promote the more widespread implementation of ITS technologies. Eventually, it will be possible to plan for 
deployment that will integrate services and systems across a region, thereby ensuring seamless coverage and interoperability. In terms of mobility, transportation management centers can be established that will utilize advanced ITS technologies to provide transportation information, as well as manage and control transportation networks, on a regional basis. Ulti mately, ITSwill facilitate the seamless integration of transt into the statewide transportation network.

This regional outlook for the implementation of ITStechnologies includes rural areasand the demandresponse services that are utilized in those areas, as well. ITStechnologiessuch as AVL and CAD have been utilized successfully for rural applications, and have benefitted rura transit providersby helping to improve the efficiency of demand-response service scheduling and operation. It is also anticipated that technology implementation also will help improve interagency coordination of services In fact, this is one of the specific goals of the Rural Forida ITS demonstration project, which was begun in 1998.

Finally, one of the greatest hurdles that agencies will need to overcome when implementing ITS technologiesis the justification of the costsin comparison to otherpotential improvements. Thisis why benefits analysisand performance measurement arecritical to this process. Prior to deployment, itwill be important to understand the potential benefits of the technology under consideration and demonstrate those benefits to the decision makers and all stakeholders. Performance monitoring becomes crucial during the operational testing phase of the deployment to make sure that the system is working asplanned. After that, continued monitoring of performance is necessary to ensure that al facets of the system continue to operate properly. Benefits analysis then objectively compares the results of the performance monitoring with the direct and indi rect costs of system implementation and, hopefully, justifies need for that technology. In addition, it will be important for agenciesto share the results of their analyses with others contemplating implementation. Unfortunately, the lack of qualitative and quantitative measurements of ITStechnology benefitshasbeen found to be one of the most notable hindrances to greater ITS deployment to date, especiall y for transit purposes.

\section{APTSBenefits Asessment \& Performance Monitoring}

The third task of this project conducted an assessment of the annual time savings benefits that five case study transit systems have accrued for their respective passengersthrough the implementation of one or more of thre different APTS technologies electronic fare collection, AVL, and bus priority. The spreadsheet-based, sketch-level analysis tool, SCRITS (Screening Analysis for ITS), was utilized to conduct each system's anaysis, which examined pre- and post-deployment conditions for each technology being used, or soon to be utilized, by each system. Table ES-1 presents selected post- 
deployment results for the three case study transit systems that al ready have implemented electronic fare collection systems on-board their vehicles.

Table ES-1

SCRTS Bectronic Fare Collection Worksheet Analysis: Comparison of Post-Deployment Results ${ }^{1}$

\begin{tabular}{|l|c|c|}
\hline \multicolumn{1}{|c|}{ Transit System } & Annual Value of Time Savings & Benefit/Cost Ratio \\
\hline Pinellas Suncoast Transit Authority & $\$ 2,716,732$ & 6.9 \\
\hline Hill sborough Area Regional Transit Auth ority & $\$ 1,618,087$ & 7.2 \\
\hline LYNX Transit (Orlando) & $\$ 2,136,976$ & 13.4 \\
\hline Average & $\$ 2,157,265$ & 9.2 \\
\hline
\end{tabular}

${ }^{1}$ All of the information presented in this table is for the "full w eek" case.

${ }^{2}$ Two case study systems, Sarasota County Area Transit and Ann Arbor Transit Authority, have not implemented the use of electronic fare media yet; therefore, their post-implementation resultshave not been included herein.

In addition, the topic of post-deployment performance measurement and monitoring also was introduced. The development of performance measurements for APTS technologies is extremely important because such measures enable an agency to assess how a particular technology is functioning and whether established system goals and objectives have been met by its deployment. This discussion also provided some examples of, and general recommendations for, performance measures that are applicable to the more common goals and objectives and identified specific APTS applications that may be used to achieve the objectives.

From the overall benefits analysis process, it waslearned that, despite the relative simplicity of SCRITS compared to other similar analysis tools, it is sill somewhat difficult to understand - especially some of the required user in puts for each of its technology worksheets. Other drawbacksof this analysistool are that the number of APTS-specific technologies it is designed to evaluate is extremely limited, and it can only estimate the time savings benefits that accrue to a transit agency's passengers, and not any of the potential benefits that might be realized by the agency, itself. Nevertheless, the SCRITStool is readily available, is free of charge, and is a decided step in the right direction of establishing a standardized benefits analysis process that is easily transerable between systems, regardless of size or operating environment/characteristics. Additionally, it produces results that can be understood and compared across technologies and/or agencies.

The individual system analyses also provided interesting insights as well. For the most part, the analyses found that the majority of the APTS deployments at the case study systems have indeed 
benefitted passengers of those agencies in terms of annual time savings. The resulting benefit-to-cost ratios also have been positive. Unfortunately, the analysesalso helped identify a number of issues at the systemsrelated to data collection and information availability, the estimation of user inputs for the SCRITS andysis, lack of experience with APTS technologies, and concern about comparability of analysis results across systems.

Despite the issues, however, based on the research experience with the case sudy transit systems, it would appear that personnel at the systems are aware of the importance of benefits assessment and measuring the performance of APTStechnologies. They understand the need for establishing verifiable benefits related to APTS deployment so that this information can be used to help sell their systems potential future APTS applications to their boards, local officials, and stakeholders. Being able to demonstratepositive performance of existing technologieswill help in this regard, aswell. In addition, the transit industry, itself, will be well served by the additional APTSevaluation information that will be available to be shared. 
Inventory \& Analysis of Advancto Public Transportation System sin Florida

\section{BACKGRO UND}

The Federal Transit Administration (FTA) created the Advanced Public Transportation Systems (APTS) program as part of the U.S. Department of Transportation's initiative on Intell igent Transportation Systems(ITS). The APTSprogram was established to encourage the use of technology to improve the quality and usefulness of public transportation and ridesharing services. It is believed that the implementation of variousap plicabletechnologieson transit will not only help transit systemsimprove the efficiency and effectiveness with which they provide service, but, because of these improvements, may also help to make transit more attractive to new users, such as the discretionary rider, as well. Persons interested in obtaining the most current information on the status of developments and advancements in the adoption of new technology in public transportation services in North America should refer to FTA's document, Advanced Public Transportation Systems The Stateof the Art, Update '98.

The 1999 Forida ITSStrategic Plan wasdeveloped to guide the Forida Department of Transportation (FDOT), Forida Metropolitan Panning Organizations, and local governments in the planning, programming, and implementation of integrated multi-modal ITSelementsto help maximize the safety and efficiency of Horida's Transportation System. A major provision of the ITSStrategic Plan is that the FDOT will pro-actively support the development, coordination, and deployment of public transportation ITS technology. However, it became apparent during the development of the ITS Strategic Plan that therewasno comprehensive information at thestate level regarding thelocation and operabil ity of APTS in Flori da. This is because much of the current APTS activity in Forida has been initiated and implemented at the local level. As a result, this sudy was initiated with the goa of providing FDOT with the baseline information that it will need as it becomes more involved in the development and deployment of APTSthroughout Forida. Secondarily, it isanticipated that this study will provide some level of guidance to Forida and other U.S. transit properties in the formative stages of APTSinvestigation.

This inventory and analysis of APTS in Florida is, thus, designed to help the FDOT gain a better understanding of the current ITS transit activities being undertaken around the state. The project is comprised of three primary tasks: (1) devel op an inventory of current and planned Florida APTS projects; (2) through a literature review, examine 10 of the major issues/characteristics that transit properti es around the country have encountered during the development and/or deployment phases 
of their projects, and review the Forida properties' experienceswith these issues, and (3)completeand document an assessment of APTSbenefits for afew selected transit agenciesutilizing aben efitsanalysis spreadsheet tool in order to provide an evaluation example for other agencies to follow as they continue to develop and deploy APTS technologies.

The resulting information relating to the characteristics of APTSdevelopment and deployment should be especially useful to transit properties and decision makers throughout the state and across the country. The development and deployment characteristics of APTS that this sudy will consider include:

- level of conformi ty with nati onal (and soon to be devel oped Flo rida) ITS architecture;

- institutional arrangementsneeded for multi-modal and inter-modal connectivity;

- available funding sources,

- $\quad$ procu rement methods of APTSpro ducts and services;

- impacts on agency operation, maintenance staffs, and budgets,

- extent of public-private and public-public partnering;

- extent of general public invol vement;

- integration into regional transportation servicesand systems,

- application to rural areas and/or demand responsive service; and

- extent and sophistication of benefits analysis (prior to deployment) and performance monitoring (following deployment).

It is important to note that the terms "APTS" and "ITS-transit" are used interchangeably throughout this document. Also, in those sections where survey results are discussed, direct quotes have ben included in their original form. 


\title{
CHAPTRORE
}

\author{
Inventory of Advancid Public Transportation System sin Florida
}

\section{INTRODUCTION}

Thischapter describesthe development of astatewide APTSactiviti esinventory and outlinesthe extent to whi ch new technologieshave been adopted within the public transportation industryin Florida. The primary data collection effort that was utilized to compile the information for the APTS inventory consisted of two separate transit agency surveys, a series of stakeholder meetings, and a rural stakeholder survey. The results of the surveysand the sakeholder meetings are discussed herein. In addition, information on the Rural Florida Intelligent Transportation Systemsdemonstration project is also included to provide the perspective of those who have already applied ITStransit technology to their transit systems.

It should be noted that the two transit agency surveyswere administered only to transit officials. The stakeholder interviewswere held with FDOT senior management staff primarily. In addition, the rural stakeholder survey wasadministered to Community Transportation Coordinators throughout the State with the assistance of the Commission for the Transportation Disadvantaged.

\section{InItial APTSIn Ventory SURVEY}

In conjuncti on with the FDOT Public Transportati on Office (PTO), it was determined that the Forida transit agencies that recive or will be receiving FDOT block grant funding should be surveyed with respect to APTS development/deployment. The PTO provided assistance in identifying these transit agencies, as well. A total of thirty transit agencies were included in the initial survey effort, which involved a mail-out/mail-back methodology. The inventory questionnaire that was developed for this task asked the transit agencies whether they were currently util izing or planned to utilize in the future any of anumber of APTStechnologies. The vari ous technol ogi es that were incl uded were grouped into five main APTS technology areas: fleet management, traveler information, electronic fare payment, transportation demand management, and technologi es associ ated with paratransit providers. Nineteen out the 30 transit agenci esresponded to thequestionnaire, resulting in a response rate of approximately 63 percent. 
Table 1, on the following page, presents the thi rty Florida transit properties that were selected for the survey, their system acronymsor abbreviated system namesthat will be used throughout the rest of this document whenever the systemsare referenced, and their level of participation in the two surveysthat were completed for this task. (The second survey involved a follow-up telephone interview that attempted to gather additional information on the systems' experiences with APTSdevelopment and deployment and is discussed further in a subsequent section of this document.) It should be noted that a number of the systemsthat did not participate in the surveysare not currently utilizing or planning to utilize any APTS technologies at this time. 
Table 1-1

Florida Transit Agency Survey Participation

\begin{tabular}{|c|c|c|c|}
\hline Transit Agency & $\begin{array}{l}\text { Acronym or } \\
\text { Abbreviation }\end{array}$ & $\begin{array}{c}\text { Initial } \\
\text { Inventory } \\
\text { Survey }\end{array}$ & $\begin{array}{l}\text { Follow-Up } \\
\text { Survey }\end{array}$ \\
\hline Broward County Mass Transit Divi sion & BCT & & \\
\hline Charlotte County Dial-A-Ride & Charlotte & ○ & \\
\hline Collier County Transit & Collier & ○ & $\bullet$ \\
\hline Community Services (Suart) & Stuart & & \\
\hline Council on Aging of Martin County, Inc. & Martin & ○ & ○ \\
\hline County of Volusia dbaVOTRAN & VOTRAN & & \\
\hline Escambia County Area Transit & ECAT & ○ & ○ \\
\hline Hil Isborough Area Regional Transit Authority & HART & • & \\
\hline Jacksonville Transportation Authority & ЛА & $\bullet$ & \\
\hline Key West Department of Transportation & KWDOT & & \\
\hline Lakeland Area Mass Transit District (Citrus Connection) & LAMTD & ○ & \\
\hline Lee County Transit & LeeTran & & \\
\hline LYNX Transit (Orl ando) & LYNX & & \\
\hline Manatee County Area Transit & MCAT & & \\
\hline Miami-Dade Transit Agency & MDTA & • & \\
\hline Okalo osa County Coordinated Transportation, Inc. & Okaloosa & & \\
\hline Palm Beach County Transportation Agency & Palm Tran & ○ & ○ \\
\hline Panama City U rbanized Area Metropolitan Panning Organization & Panama City & & \\
\hline Pasco County Public Transportation & PCPT & $\bullet$ & \\
\hline Pinellas Suncoast Transit Authority & PSTA & $\bullet$ & \\
\hline Polk County Transportation System & Polk & $\bullet$ & $\bullet$ \\
\hline $\begin{array}{l}\text { Regional Transit Organization, Commuter Assistance Program (F. } \\
\text { Lauderdale) }\end{array}$ & RTO/CAP & $\bullet$ & ○ \\
\hline Regional Transit System (Gain esville) & RTS & $\bullet$ & \\
\hline Sarasota County Area Transit & SCAT (Sarasota) & $\bullet$ & $\bullet$ \\
\hline Space Coast Area Transit (Brevard County) & SCAT (Brevard) & $\bullet$ & $\bullet$ \\
\hline St. Lucie County Council on Aging-Community Transit & St. Lucie & & \\
\hline SunTran (Ocala) & SunTran & $\bullet$ & ○ \\
\hline Tal lahassee Transit & TALTRAN & $\bullet$ & $\bullet$ \\
\hline Trans-Hernan do/ Mi d-Flori da Tran sit (Brooksvi lle) & Trans-Hernando & ? & \\
\hline Tri-County Commuter Rail Authority & Tri-Rail & & \\
\hline
\end{tabular}




\section{Inventory Survey Questionnaire}

The questionnaire was organized in accordance with FTA's Advanced Public Transportation Systems program. Technologies and applications were grouped under five categories:
I. Feet management
II. Traveler information
III. Bectronic fare payment
IV. Transportation demand management
V. Paratransit providers

The status of each technology that is being tested, planned, implemented, or fully operated was requested. Appendix A includes a copy of the actual questionnaire.

\section{Fleet Management}

Feet management incorporatesmany of the vehicle-based APTStechnologiesfor more effective vehicle and fleet planning, scheduling, and operations. Heet management focuses on the vehicle. It can improve the efficiency and effectiveness of the service that is being provided and can increase passenger safety, as well. The technol ogies that were listed in the questionnaire are:

Automated Vehicle Location (AVL) systems,

Automatic passenger counters,

Vehicle component monitoring systems,

Automated operations software, and

On-board safety systems.

Automated Vehicle Location, computer-based, vehicle-tracking systems, operate by measuring the actual real-time position of each vehicle and relaying the information to a central location. The transit agencies were asked to indicate which technologies related to AVL they were planning, testing, implementing, or operating, such as:

- Global positioning,

- Signpost/odometer,

- Dead-reckoning, and

- Loran-C. 
Automatic passenger counters are automated meansfor collecting data on passenger boardings and alightings by time and location. Some of the technologies that exist in the market are:

- Infra-red beams,

- Treadle mats,

- Infrared optic sensors, and

- Ultrasonic frequency sensors.

Vehicl e component mo ni toring systems perform periodic" health checks" of the transit vehicles. Transit agencies were requested to provide information on any systems that they were planning, testing, implementing, or operating to help monitor:

- High engi ne tem perature,

- Low pressure oil, and/or

- Other vehicle components/conditions.

Automated operations software hasthe capability to automate, streamline, and integrate many transit functions and modes. Transit agencies were asked to offer information about computer applications, such as:

- Computer-aided dispatch,

- Vehicle performance,

- Driver perfomance and schedule monitoring, and

- Statistics (passenger statistics, loading, and systemwide statistical information).

The transit agencies also were requested to provide information if they were planning, testing, implementing, or operating any on-board safety systems, such as:

- Silent alarms,

- Passenger clearance sensors, and/or

- Other safety systems. 


\section{Traveler Information}

Traveler information systems provide travelers with information on one or more modes of transportation. These systemsfacil itate pre-trip, as well as en-route, decision-making. The four types of traveler information systems discussed in the questionnaire are:

Trip planning information,

Single and multi-mode trip planning information,

In-terminal information systems, and

In-vehicle information systems.

The section on trip planning information listed different locationswhere pre-trip information systems can be provided and asked transit agencies whether they offer such servicesas

- Telephones,

- Intern et access,

- Fax machines, and/or

- Kiosks.

The transit agencies were asked whether they currently implement, or plan to provide, single and multimode trip information, such as:

- Schedul es and fares,

- System disruptions,

- Carpooling and parking,

- Incidents and weather,

- Routesand stop locations, and/or

- Ride-maching registration.

Transit agencies also were asked whether they have, or plan to offer, in-terminal information systems for passengers, such as:

- Eectronic signs,

- Kiosks,

- Television monitors, and/or

- Annunciators. 
Additionally, transit agencies were asked whether they plan to provide, or if they currently offer, in-vehicle information systems, such as:

- $\quad$ Eectronic signs,

- Television monitors, and/or

- Annunciators.

\section{Electronic Fare Payment}

Bectronic fare payment offers transit agencies the opportunity to integrate a new generation of electronic fare media and equipment. These systems provide more cost effective distribution of fare media and a more scure fare collection process. Transit agencies were asked whether they have or intend to provide any of the different technologies associated with electronic, or automated, fare payment, such as:

- Magnetic strip cards,

- Smart cards,

- Credit cards, and

- Proximity cards

The transt agencies also were asked whether they have or intend to offer multi-carrier trip reservation and integrated billing systems In addition, the agencies were given the opportunity to indicate the actual or potential set-up of their systems, such as:

- Between different modes,

- Util ization of ATM/credit cards, and/or

- Between different providers.

\section{Transportation Demand Management Technologies}

Transportation Demand Management (TDM) technologies are thos that combine innovative approaches and advanœd technologiesto better utilize existing infrastructure. Six TDM technologies discussed in the questionnaire are:

Advanced communications,

Automated service coordination, 
$\square$ Transportation Management Center,

Signal preemption,

Dynamic ridesharing, and

High occupancy vehicle lane access.

Advanced communication systems can include such technol ogies as:

- Analog land mobile,

- Digital,

- Trunked plus digital, and

- Other plusdigita.

Automated service coordination involves multiple transportation providers in regions that provide service with the assistance of APTStechnologies. This provides "one-stop shopping" for atraveler in a region. This is critical to integrating and coordinating the services avalable in a region. The questionnaire listed several system aspects that can be coordinated, incl uding:

- Scheduling,

- Routing,

- Information systems, and

- Billing.

"Transportation Management Center" (TMC) refersto a facility that combines traffic and public transit operations, communications, and/or control. The agencieswereasked whether thereisa TMC in their region and whether the transit agency is apart of that TMC. They were also asked which technol ogies are used to integrate and di stribute transit information from the TMC. The possible technologies that can be utilized include:

- Pagers,

- Telephones,

- Bectronic signs on board,

- Information kiosks, and

- Cable television.

Signal preemption or traffic signal priority treatment for transit is a technol ogy by which a traffic signal may be held green for longer than scheduled (or made green earlier than scheduled) so that a transit 
vehicle may pass through the intersection more quickly. Transit agencies were requested to provide information on whether they were planning, testing, implementing, or operating any intersection(s) with traffic signal priority treatment.

Dynamic ri desharing is used to obtain a ride for a single, one-way, or round trip; rather than for trips made on a regular basis. Transit agencies were requested to provide informati on about whether they were planning, tesing, implementing, or operating any dynamic ridesharing programs

The High Occupancy Vehicle (HOV) lane access technology involves a device/transponder on the vehicle that gives it accessto $\mathrm{HOV}$-only lanes Transit agencieswere requested to provide information on whether they were pl anning, testing, implementing, or operating any high occupancy vehicle lane access technology.

\section{Paratransit Providers}

Transit agencies were asked whether they currently have or intend to implement an automated paratransit system. Some of the possible automated paratransit system activities include computeraided dispatch and automated scheduling.

\section{Results of the Initial Inventory Survey}

All eightœn of the technologiesincl uded on the survey questionnaire have at l east tw o tr ansit agencies either in the planning, i mplementation, testing, and/or operation stage. Beven of the 18 technologies are still primarily in the planning stagesfor the majority of those agenciesthatare/will be utilizing them. Automated paratransit systems and advanced communi cations are the most popul ar technologies, with 14 transit agencieseither in the planning, implementation, and/or fully operational stage foe each. Trip planning information and automated operations softw are are al so qui te po pular; 12 agencies indicated some level of experience with each.

As for the level of technology deployment, more systems (nine) currently are operating advanced communications systemsthan any othertechnology mentioned. The technology with the next hi ghest level of deployment is automated fare payment, with 6 transit agencies in the fully operational stage. Only automated servicecoordination and the Transportation Management Center concept did not have any agencies in the operational phase. 
Interestingly, according to the survey results, most of the APTS technologies are either in the fully operational or planning stages, rather than the implementation or testing phases. Only three technologies (automated operations software, trip planning information, and automated paratransit systems) were found to have more than one transit agency in an implementation and/or testing phase. In addition, HOV vehicle lane access appears to be the least popular technology among the transit agencies that responded, with only two systemsindicating any level of experience with it (oneis in the planning stage and the other is operational). This is not surprising since exclusive, barrier-protected HOV lanes do not yet exist in Florida.

Table 1-2, on the following page, provides an APTSinventory summary for al of the transit agencies that participated in the survey. It details the technologies that each transit agency possesses, and what stage of development or deployment they are in currently. 
Table 1-2

APTS Inventory Summary by Transit Agency

\begin{tabular}{|c|c|c|c|c|c|c|c|c|c|c|c|c|c|c|c|c|c|c|}
\hline \multirow{2}{*}{$\begin{array}{l}\text { Transit Agency } \\
\text { (\# Veh icles in } \\
\text { Operation) }\end{array}$} & \multicolumn{5}{|c|}{ Fleet Management } & \multicolumn{4}{|c|}{ Traveler Information } & \multicolumn{2}{|c|}{$\begin{array}{c}\text { Electronic Fare } \\
\text { Payment }\end{array}$} & \multicolumn{6}{|c|}{ Transportation Demand Management Technologies } & \multirow{2}{*}{\begin{tabular}{|l}
$\begin{array}{c}\text { Paratr ansit } \\
\text { Providers }\end{array}$ \\
Automated \\
Para transit
\end{tabular}} \\
\hline & AVL & APC & $\begin{array}{c}\text { Vehic le } \\
\text { Component } \\
\text { Monitoring }\end{array}$ & $\mid \begin{array}{c}\text { Automated } \\
\text { Operations } \\
\text { Softwa re }\end{array}$ & $\begin{array}{c}\text { On-Bo ard } \\
\text { Safety } \\
\text { Systems }\end{array}$ & \begin{tabular}{|c|} 
Trip \\
Planning \\
Information
\end{tabular} & $\begin{array}{c}\text { Multi- } \\
\text { Mod al Trip } \\
\text { Planning } \\
\text { Information }\end{array}$ & $\begin{array}{c}\text { In-Termina } \\
\text { Information } \\
\text { Systems }\end{array}$ & \begin{tabular}{|c} 
In-Ve hicle \\
Information \\
Systems
\end{tabular} & $\begin{array}{c}\text { Automated } \\
\text { Fare } \\
\text { Payment }\end{array}$ & $\begin{array}{c}\text { Multi-Carien } \\
\text { Reservation } \\
\text { \& Billing }\end{array}$ & $\begin{array}{c}\text { Advanced } \\
\text { Comm mun i- } \\
\text { cations }\end{array}$ & $\begin{array}{c}\text { Automated } \\
\text { Service } \\
\text { Coordination }\end{array}$ & $\begin{array}{c}\text { Transportation } \\
\text { Management } \\
\text { Center }\end{array}$ & \begin{tabular}{|c} 
Signal \\
Preemption
\end{tabular} & \begin{tabular}{c|} 
Dyna mic \\
Ridesharing
\end{tabular} & $\begin{array}{c}\text { HOV Lane } \\
\text { Access }\end{array}$ & \\
\hline Charlotte (20) & & & & & & & & & & & & o & & & & & & $\mathrm{P}$ \\
\hline Collier (18) & & & & & & & & & & & $\mathrm{P}$ & 0 & P & & & $\mathrm{P}$ & & o \\
\hline Martin (28) & $P$ & & 0 & $P / T$ & & & $\mathrm{P}$ & & & & 0 & 0 & $\mathrm{~T}$ & & & & & $P / T$ \\
\hline ECAT (41) & & & & $\mathrm{P}$ & & $\mathrm{P}$ & & 0 & & $\mathrm{P}$ & & & & & & & & \\
\hline HART (190) & $\mathrm{P}$ & & $\mathrm{P}$ & $\mathrm{P} / \mathrm{O}^{*}$ & $P$ & $\mathrm{P} / \mathrm{O}^{*}$ & $\mathrm{P} / \mathrm{O}^{*}$ & $\mathrm{P}$ & $\mathrm{P}$ & $\mathrm{P} / \mathrm{O}^{*}$ & 0 & $\mathrm{P}$ & & $P$ & & & & 0 \\
\hline JTA (174) & $\mathrm{P}$ & 0 & $\mathrm{P}$ & 0 & 0 & $\mathrm{P}$ & $\mathrm{P}$ & o & 0 & $\mathrm{P} / \mathrm{O}$ & & $\mathrm{P}$ & $\mathrm{P}$ & $\mathrm{P}$ & $\mathrm{P}$ & $\mathrm{P}$ & & $\mathrm{P}$ \\
\hline LAMTD (50) & $\mathrm{P}$ & & & . & & & & & & & & $\mathrm{P}$ & & & & & & $\mathrm{P}$ \\
\hline MDTA (750) & o & $\mathrm{P}$ & P/T & 0 & 0 & P/IT & 0 & $\mathrm{P} / \mathrm{O}^{*}$ & 0 & 0 & & 0 & $\mathrm{P}$ & & 0 & & 0 & o \\
\hline Palm Tran (140) & & & & $\mathrm{P}$ & 0 & 0 & 0 & & 0 & 0 & & IT & $\mathrm{P}$ & & & & & IT \\
\hline PCPT (43) & & & & IT & & $\mathrm{P}$ & & & & & & 0 & & & & & & IT \\
\hline PSTA (144) & & & & & & & & & & 0 & & 0 & & & & & & \\
\hline Polk (27) & & & 0 & $\mathrm{P}$ & $\mathrm{T}$ & 0 & 1 & & & . & 0 & $\mathrm{P}$ & $\mathrm{P}$ & & & 1 & & $\mathrm{P}$ \\
\hline RTO/CAP (0) & & & & & & $\mathrm{P}$ & $\mathrm{P}$ & & & & & & & $\mathrm{P}$ & & 0 & & \\
\hline RTS (72) & & P & $\mathrm{P}$ & 1 & P & $\mathrm{P}$ & $\mathrm{P}$ & P & $\mathrm{P}$ & & & & $\mathrm{P}$ & P & $\mathrm{P}$ & P & $\mathrm{P}$ & $\mathrm{P}$ \\
\hline SCAT (Sarasota) (28) & $\mathrm{P}$ & & & $\mathrm{P}$ & $\mathrm{P}$ & $\mathrm{P}$ & $\mathrm{P}$ & & & $\mathrm{P}$ & & 0 & $\mathrm{P}$ & $\mathrm{P}$ & & & & $\mathrm{P}$ \\
\hline SCAT (Brevard) (138) & $\mathrm{P}$ & & $\mathrm{P}$ & $\mathrm{P}$ & 0 & $\mathrm{P}$ & $\mathrm{P}$ & $\mathrm{P}$ & & & & 0 & P & & & & & P \\
\hline SunTran (5) & & & 0 & & & & 0 & & & & & & & & & & & \\
\hline TALTRAN (73) & & $\mathrm{P}$ & $\mathrm{P}$ & $\mathrm{P}$ & & IT & & IT & & 0 & & 0 & & & $\mathrm{P}$ & & & 0 \\
\hline Trans-Hernando (14) & & & & & & & & & & & & & & & & & & \\
\hline
\end{tabular}

$\begin{array}{llll}\text { Legend: } & P & - & \text { Planning } \\ & \text { T } & - & \text { Testing } \\ & \text { IT } & - & \text { Implementation/Testing } \\ & \text { I } & - & \text { Implementation } \\ & O & - & \text { Fully Operational }\end{array}$

* Som e activitie s are in th e plann ing stag es, wh ile other activities are fully o peratio nal. 
Tables1-3 through 1-20 present more detailed survey results (i.e., status and sophistication) for each of the APTStechnologiesincluded in the inventory questionnaire. It should be noted that when a system hasindicated more than one satus for any of its APTSactivities, the highest status level achieved has been indicated in the tables. For example, HART indicated that some of its automated fare payment activities are in the planning stages, while other related activities are operational. In the table for this technology, then, HART is listed under the "operational" column only.

Table 1-3

APTSInventory Summary: Automated Vehicle Location Systems

\begin{tabular}{|c|c|c|c|c|c|}
\hline \multirow{2}{*}{ Technology } & \multicolumn{4}{c|}{ Status } & \multicolumn{2}{c|}{$\begin{array}{c}\text { Total } \\
\text { Systems }\end{array}$} \\
\cline { 2 - 6 } & O perational & Im plementation & Planning & -- & 7 \\
\hline GPS & 1 & -- & 6 & -- & -- \\
\hline Sign post/O dometer & -- & -- & -- & -- \\
\hline Dead-Reckoning & -- & -- & -- & -- & -- \\
\hline Loran-C & -- & -- & -- & -- \\
\hline Others & -- & -- & -- & -- & 7 \\
\hline Total Systems & 1 & -- & 6 & & - \\
\hline
\end{tabular}

NOTE Table cell in lower righthand corner indicates the total number of systems planning, testing implementing, or utilizing an AVL technology.

Table 1-4

APTSInventory Summary: Automatic Pasenger Counters

\begin{tabular}{|c|c|c|c|c|c|}
\hline \multirow{2}{*}{ Technology } & \multicolumn{4}{|c|}{ Status } & \multirow{2}{*}{$\begin{array}{c}\text { Total } \\
\text { Systems }\end{array}$} \\
\hline & O perational & Implementation & Planning & Testing & \\
\hline Infra-Red Beams & 1 & -- & 1 & -- & 2 \\
\hline Treadle Mats & -- & -- & 1 & -- & 1 \\
\hline Infra-Red Optic Sensors & - & - & - & - & - \\
\hline $\begin{array}{l}\text { Ultrasonic Frequency } \\
\text { Sensors }\end{array}$ & -- & -- & -- & -- & -- \\
\hline Others & -- & -- & 1 & -- & 1 \\
\hline Total Systems & 1 & -- & 3 & -- & 4 \\
\hline
\end{tabular}

NOTE: Table cell in lower righthand corner indicates the tota number of systems planning, tesing, implementing, or utilizing an APC technology. 
Table 1-5

APTSInventory Summary: Vehicle Component Monitoring Systems

\begin{tabular}{|c|c|c|c|c|c|}
\hline \multirow{2}{*}{ Condition } & \multicolumn{4}{|c|}{ Status } & \multirow{2}{*}{$\begin{array}{l}\text { Total } \\
\text { Systems }\end{array}$} \\
\hline & Operational & Im plementation & Planning & Testing & \\
\hline High Engine Temp. & 3 & $1^{1}$ & 3 & -- & 7 \\
\hline Low Oil Pressure & 3 & $1^{1}$ & 3 & -- & 7 \\
\hline Brake/Alternator & 1 & -- & -- & -- & 1 \\
\hline Farebox & -- & $1^{1}$ & -- & -- & 1 \\
\hline RPM & 1 & -- & -- & -- & 1 \\
\hline Others & -- & -- & 1 & -- & 1 \\
\hline Did N ot Specify & - & -- & 2 & -- & 2 \\
\hline Total Systems & 3 & 1 & 5 & -- & 9 \\
\hline
\end{tabular}

${ }^{1}$ MD TA indi cated mul tiple statuses (i.e., planning and i mpl ementatio $n / t e s t i n g$ ) for the vari ous condi tions that they are/will be mon it ori ng.

NOTE Table cell in lower righthand corner indicates the total number of systems planning, testing implementing, or utilizing vehicle component monitoring systems In this cas, thenumberdoesnot equal the sum of the row totals since most systemsare/will be measuring more than one vehicle œndition.

Table 1-6

APTSInventory Summary: Automated Operations Software

\begin{tabular}{|c|c|c|c|c|c|}
\hline \multirow{2}{*}{ Activity } & \multicolumn{4}{|c|}{ Status } & \multirow{2}{*}{$\begin{array}{c}\text { Total } \\
\text { Systems }\end{array}$} \\
\hline & O perational & Im plementation & Planning & Testing & \\
\hline $\begin{array}{l}\text { Com puter-Aid ed } \\
\text { Dispatch }\end{array}$ & $2^{1}$ & 2 & 6 & $1^{2}$ & 11 \\
\hline Vehicle Performance & 2 & -- & 1 & $1^{2}$ & 4 \\
\hline Loading & 1 & 1 & 1 & $1^{2}$ & 4 \\
\hline Driver Performance & 1 & -- & 2 & $1^{2}$ & 4 \\
\hline Schedule Monitoring & 2 & -- & 2 & $1^{2}$ & 5 \\
\hline Passenger Statistics & 1 & 1 & 4 & $1^{2}$ & 7 \\
\hline Systemw ide Statistics & $1^{1}$ & 2 & 3 & $1^{2}$ & 7 \\
\hline Others & -- & -- & -- & -- & -- \\
\hline Total Systems & 3 & 2 & 6 & 1 & 12 \\
\hline
\end{tabular}

${ }^{1}$ HART ind icated mu ltiple statuses (i. e., planning and o perati onal ) for the various acti vities that they are/w ill be in tegrating.

${ }^{2}$ Martin County in dicated multiple statuses (i.e., planning and testing) for the vari ous acti vities that they are/w il l be in tegrating.

NO TE: Table cell in lower right-hand corner indicates the total number of systems planning, testing, implementing, or utilizing automated operations software. In this case, thenumber doesnot equal the sum of the row totals since many systems are/ wil I be in tegrating more than one operations activity/function. 
Table 1-7

APTSInventory Summary: On-Board Safety Features

\begin{tabular}{|l|c|c|c|c|c|}
\hline \multirow{2}{*}{ Feature } & \multicolumn{4}{c|}{ Status } & \multirow{2}{*}{ Total } \\
Systems
\end{tabular}

NOTE Table cell in lower right-hand co rner in di cates the total number of systemsplanning, testing, implementing, or utilizing on-board sfety features. In this cas, thenumber doesnot equal the sum of the row totals since some of the systemsare/will be integrating more than one system feature.

Table 1-8

APTSInventory Summary: Trip Planning Information

\begin{tabular}{|c|c|c|c|c|c|}
\hline \multirow{2}{*}{ O utlet } & \multicolumn{4}{|c|}{ Status } & \multirow{2}{*}{$\begin{array}{c}\text { Total } \\
\text { Systems }\end{array}$} \\
\hline & O perational & Im plementation & Planning & Testing & \\
\hline $\begin{array}{l}\text { Touch-Tone } \\
\text { Telephones }\end{array}$ & $3^{1}$ & -- & 2 & -- & 5 \\
\hline Internet & $1^{1}$ & $2^{2}$ & 5 & -- & 8 \\
\hline Fax Machi nes & 1 & -- & 1 & -- & 2 \\
\hline Kiosks & $1^{1}$ & $2^{2}$ & 5 & - & 8 \\
\hline Others & -- & -- & 1 & -- & 1 \\
\hline Total Systems & 3 & 2 & 7 & -- & 12 \\
\hline
\end{tabular}

${ }^{1}$ HART indicated multiplestatuss(i.e., planning and operational) for the various outlets that they are/will be using to provide information. ${ }^{2}$ MDTA indicated multiple statuses (i.e., planning and implementation/tesing) for the various outlets that they are/will be using to provide information.

NOTE Table cell in lower righthand corner indicatesthe total number of systemsplanning, testing, implementing, or utilizing trip planning information. In this case, thenumberdoesnot equal the sum of therow totalssincesome of the systemsare/will be providing more than one information outlet. 
Table 1-9

APTSInventory Summary: Trip Planning Information (Single Mode/Multi-Modal)

\begin{tabular}{|c|c|c|c|c|c|}
\hline \multirow{2}{*}{ Information } & \multicolumn{4}{|c|}{ Status } & \multirow{2}{*}{$\begin{array}{l}\text { Total } \\
\text { Systems }\end{array}$} \\
\hline & O perational & Im plementation & Planning & Testing & \\
\hline Schedules, Fares & $4^{1}$ & - & 5 & - & 9 \\
\hline System Disruption & $2^{1}$ & -- & 1 & -- & 3 \\
\hline Carpooling \& Parking & 1 & -- & 3 & -- & 4 \\
\hline $\begin{array}{l}\text { Incidents and/or } \\
\text { Weather }\end{array}$ & -- & -- & -- & -- & -- \\
\hline Routes, Stop Locations & $3^{1}$ & 1 & 5 & - & 9 \\
\hline $\begin{array}{l}\text { Ride-Matching } \\
\text { Registration }\end{array}$ & -- & -- & 3 & -- & 3 \\
\hline Others & -- & -- & 1 & -- & 1 \\
\hline Total Systems & 4 & 1 & 6 & -- & 11 \\
\hline
\end{tabular}

${ }^{1}$ HART indicated multiple statuæs (i.e., planning and operational) for the various types of information that they are/will be providing.

NOTE Table cell in lower right-hand comer in dicates the to tal number of systems planning, testing implementing, or utilizing single mode and/or mu lti-modal trip plan ning informati on. In thi s case, the number does not equal the sum of the row totals since some of the sysems are/will be providing more than one type of system information.

Table 1-10

APTSInventory Summary: In-Terminal Information Systems

\begin{tabular}{|l|c|c|c|c|c|}
\hline \multirow{2}{*}{ Technology } & \multicolumn{3}{c|}{ Status } & \multicolumn{2}{c|}{$\begin{array}{c}\text { Total } \\
\text { Systems }\end{array}$} \\
\cline { 2 - 6 } & O perational & Im plementation & Planning & -- & 6 \\
\hline Eectronic Signs & $3^{1}$ & 1 & 2 & -- & 5 \\
\hline Kiosks & $2^{1}$ & 1 & 2 & -- & 4 \\
\hline Television Monitors & -- & 1 & 3 & -- & 4 \\
\hline Annunciators & $2^{1}$ & -- & 2 & -- & -- \\
\hline Others & -- & -- & - & - & 7 \\
\hline Total Systems & 3 & 1 & 3 & & 7 \\
\hline
\end{tabular}

${ }^{1}$ MDTA indi cated multiple statuses(i.e., planning and operational) for the various technologies that they are/will be utilizi ng.

NOTE Table cell in lower right-hand comer in di cates the total number of systems planning, testing, implementing, or utilizing in-terminal information systems In this cas, thenumber doesnot equal the sum of the row totals since some of the systemsare/will be utilizing more than one technology. 
Table 1-11

APTSInventory Summary: In-Vehicle Information Systems

\begin{tabular}{|c|c|c|c|c|c|}
\hline \multirow{2}{*}{ Technology } & \multicolumn{4}{|c|}{ Status } & \multirow{2}{*}{$\begin{array}{c}\text { Total } \\
\text { Systems }\end{array}$} \\
\hline & O perational & Im plementation & Planning & Testing & \\
\hline Electronic Signs & 2 & -- & 2 & -- & 4 \\
\hline Television Monitors & 1 & -- & 2 & -- & 3 \\
\hline Annunciators & 3 & -- & 2 & -- & 5 \\
\hline Others & -- & -- & -- & -- & -- \\
\hline Total Systems & 3 & -- & 2 & -- & 5 \\
\hline
\end{tabular}

NOTE Table cell in lower right-hand corner in dicates the to tal number of systems planning, testing, implementing, or utilizing in-vehicle information systems. In th is case, the number does not equal the sum of the row totals since some of the systemsare/will be utilizing more than one type of technology.

Table 1-12

APTSInventory Summary: Automated Fare Payment

\begin{tabular}{|c|c|c|c|c|c|}
\hline \multirow{2}{*}{ Technology } & \multicolumn{4}{|c|}{ Status } & \multirow{2}{*}{$\begin{array}{c}\text { Total } \\
\text { Systems }\end{array}$} \\
\hline & O perational & Implementation & Planning & Testing & \\
\hline Magnetic Strip Cards & $6^{1,2,3}$ & -- & 1 & -- & 7 \\
\hline Smart Cards & -- & -- & $2^{2}$ & - & 2 \\
\hline Credit Cards & -- & -- & -- & -- & -- \\
\hline Proximity Cards & -- & -- & -- & -- & -- \\
\hline Others & -- & -- & $1^{1}$ & -- & 1 \\
\hline Total Systems & 6 & -- & 2 & -- & 8 \\
\hline
\end{tabular}

${ }^{1}$ HART indicated multiple statuses(i.e., planning and operational) for the various technologies that they are/will be utilizing. ${ }^{2}$ JA indicated multiple statuses (i.e., planning and operational) for the various technologies that they are/will be utilizing. ${ }^{3}$ MD TA indi cated that the magneti $c$ strip card s are only being util ized on its rail mode.

NO TE: Table cell in lower righthand corner indicates the total number of systemsplanning, testing, implementing, or utilizing automated fare payment systems In thiscas, thenumberdoesnot equal the sum of the row totalssincesomeof the systems are/will be utilizing more than one type of technology. 
Table 1-13

APTSInventory Summary: Multi-Carrier Reservation and Bill ing Systems

\begin{tabular}{|l|c|c|c|c|}
\hline \multirow{2}{*}{ Set-Up } & \multicolumn{4}{c|}{ Status } \\
\cline { 2 - 6 } & O perational & Im plementation & Planning & Testing \\
\hline $\begin{array}{l}\text { Between Different } \\
\text { Modes }\end{array}$ & 2 & -- & 1 & -- \\
\hline $\begin{array}{l}\text { With ATM and/or } \\
\text { Credit Cards }\end{array}$ & -- & -- & -- & -- \\
\hline $\begin{array}{l}\text { Between Different } \\
\text { Providers }\end{array}$ & 2 & -- & 1 & -- \\
\hline Others & -- & -- & -- & - \\
\hline \multicolumn{1}{|c|}{ Total Systems } & 3 & - & 1 & - \\
\hline
\end{tabular}

NOTE Table cell in lower right-hand corner indi cates the to tal number of systems plan ning, testing, impl ementing, or uti li zing multi-carri er reservation and billing systems. In this case, the number does not equal the sum of the row totals since some of the systems are/will be utilizing more than one type of set-up.

Table 1-14

APTSInventory Summary: Advanced Communications

\begin{tabular}{|c|c|c|c|c|c|}
\hline \multirow{2}{*}{ Technology } & \multicolumn{4}{|c|}{ Status } & \multirow{2}{*}{$\begin{array}{c}\text { Total } \\
\text { Systems }\end{array}$} \\
\hline & O perational & Implementation & Planning & Testing & \\
\hline Analog Land Mobile & 3 & & & -- & 3 \\
\hline Digital & 1 & -- & 2 & -- & 3 \\
\hline Trunked + Digital & 3 & -- & 1 & -- & 4 \\
\hline Other + Digital & -- & -- & -- & -- & -- \\
\hline Others & 2 & 1 & 1 & -- & 4 \\
\hline Total Systems & 9 & 1 & 4 & -- & 14 \\
\hline
\end{tabular}

NOTE: Table cell in lower right-hand comer indicates the to tal number of systems planning, testing, impl ementing, or utilizing advanced communications sysems. 
Table 1-15

APTSInventory Summary: Automated Service Coordination

\begin{tabular}{|c|c|c|c|c|c|}
\hline \multirow{2}{*}{ System Aspect } & \multicolumn{4}{|c|}{ Status } & \multirow{2}{*}{$\begin{array}{c}\text { Total } \\
\text { Systems }\end{array}$} \\
\hline & O perational & Im plementation & Planning & Testing & \\
\hline Scheduling & -- & -- & 7 & 1 & 8 \\
\hline Routing & -- & -- & 7 & 1 & 8 \\
\hline Information Systems & -- & -- & 6 & -- & 6 \\
\hline Billing & -- & -- & 2 & -- & 2 \\
\hline Others & -- & -- & 1 & -- & 1 \\
\hline Total Systems & -- & -- & 8 & 1 & 9 \\
\hline
\end{tabular}

NOTE Table cell in lower right-hand corner in dicates the to tal number of systems planning, testing, impl ementing, or utilizing auto mated service coordi nation. In th is case, the number does not equal thesum of the row totas since someof thesystemsare/will be automating the coordination of more than one system aspect.

Table 1-16

APTSInventory Summary: Transportation Management Center

\begin{tabular}{|l|c|c|c|c|c|}
\hline \multirow{2}{*}{ Outlet } & \multicolumn{4}{c|}{ Status } & \multirow{2}{*}{ Total } \\
\cline { 2 - 6 } & Operational & Im plementation & Planning & Testing \\
\hline Pagers, Telephone & -- & -- & 1 & -- \\
\hline $\begin{array}{l}\text { Eectronic Signs On } \\
\text { Board }\end{array}$ & -- & -- & 3 & -- & 3 \\
\hline Information Kiosks & -- & -- & 3 & -- & 3 \\
\hline Cable Television & -- & -- & 3 & - & 3 \\
\hline Others & -- & -- & 11 & - & 1 \\
\hline \multicolumn{1}{|c|}{ Total Systems } & -- & 5 & 5 \\
\hline
\end{tabular}

${ }^{1}$ Although aTMC does not currently exist in itsregion, SCAT (Sarasota) indicated that it is involved in the planning of one and is therefore, represented in thi s table und er the "oth ers" category (si nce no speci fic info rmation ou tl ets were in di cated).

NOTE Table cell in lower right-hand comer in di cates the to tal number of systems planning, testing, implementing, or utilizing one or more out lets to integrate/d istr ib ute transit info mation as part of an exi sting TMC. 
Table 1-17

APTSInventory Summary: Signal Preemption

\begin{tabular}{|c|c|c|c|c|}
\hline \multicolumn{4}{|c|}{ Status } & $\begin{array}{c}\text { Total } \\
\text { Systems }\end{array}$ \\
\hline Operational & Implementation & Planning & Testing & 4 \\
\hline 1 & -- & 3 & -- & 4 \\
\hline
\end{tabular}

Table 1-18

APTSInventory Summary: Dynamic Ridesharing

\begin{tabular}{|c|c|c|c|c|}
\hline \multicolumn{4}{|c|}{ Status } & $\begin{array}{c}\text { Total } \\
\text { Systems }\end{array}$ \\
\hline O perational & Im plementation & Planning & Testing & $\mathbf{5}$ \\
\hline 1 & 1 & 3 & -- & . \\
\hline
\end{tabular}

Table 1-19

APTSInventory Summary: High Occupancy Vehicle Lane Access

\begin{tabular}{|c|c|c|c|c|}
\hline \multicolumn{4}{|c|}{ Status } & $\begin{array}{c}\text { Total } \\
\text { Systems }\end{array}$ \\
\hline O perational & Im plementation & Planning & Testing & $\mathbf{2}$ \\
\hline 1 & -- & 1 & -- & \\
\hline
\end{tabular}

Table 1-20

APTSInventory Summary: Automated Paratransit

\begin{tabular}{|l|c|c|c|c|c|}
\hline \multirow{2}{*}{ Activity } & \multicolumn{3}{c|}{ Status } & \multicolumn{2}{c|}{$\begin{array}{c}\text { Total } \\
\text { Systems }\end{array}$} \\
\cline { 2 - 6 } & Operational & Im plementation & Planning & $1^{1}$ & 10 \\
\hline $\begin{array}{l}\text { Computer-Aided } \\
\text { Dispatch }\end{array}$ & 2 & 1 & 6 & $1^{1}$ & 14 \\
\hline Scheduling & 4 & 2 & 7 & -- & 1 \\
\hline Comments/Complain ts & -- & -- & 1 & -- & - \\
\hline Others & -- & - & - & 1 & 14 \\
\hline \multicolumn{1}{c|}{ Total Systems } & 4 & 2 & 7 & & 14 \\
\hline
\end{tabular}

${ }^{1}$ Martin County in di cated mul tiple statuses (i.e., planning and testing) for the vari ous acti vities that they are/w il l be in tegrati ng.

NOTE Table cell in lower right-hand corner indi cates the to tal number of systems pl anni ng, testing, impl ementing, or uti li zing auto mated paratransit systems. In this case, the number does notequal the sum of the row totals since some of thesysemsare/will be automating more than one paratransit activity. 


\section{FoLLOW -UP APTSINVENTORY SURVEY}

A follow-up survey to the APTS inventory survey was administered to the transit agencies. Initially, only those transit agencies that responded to the first survey were called and the follow-up questionnaire was administered as a telephone interview with the staff members who filled out the original inventory questionnaires Eventually, all thirty of the transit agencies received acopy of the follow-up survey by e-mail to review and complete. The follow-up questionnaire sought the opinions of transt agency staff on such topics as procurement methods of APTSproducts and services, level of conformity with nati onal ITS architecture, available funding sources, extent of public awareness, and sophistication of benefits analysis, among others. Ten of the 30 transit agencies responded to the follow-up survey; these 10 agenciesall responded to the original APTSinventory survey, as well. This results in an overall agency response rate of 33 percent, and a respon se rate of about 53 percent when taking into account only the 19 original survey respondents.

\section{Follow-Up Survey Questionnaire}

The follow-up survey questionnaire consisted of nine major topic areas related to APTS and its deployment. The topic areas that were included are:

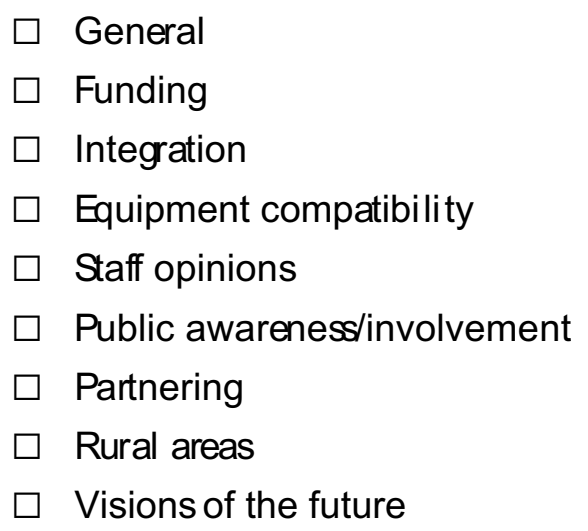

Following are brief descriptions of each of the topic areas. A copy of the follow-up APTSinventory questionnaire is included in Appendix B.

\section{General}

This first section of the survey sought information on the level of consideration given to APTSin the planning and operations of the transit agency, aswell ason the importance of and effi cienci es expected 
from APTS. Another to pic covered in th is secti on wasthe expected roles that the FDOT Central O ffi ce, FDOT District Offices, MPOs, and local government should play in the development and deployment of APTS. In addition, the transit agencies were asked which factors impede the development and deployment of APTSand how APTS can be made more effective in Forida.

\section{Funding}

This section sought the opinions of the transit agencies on funding issues related to APTS. For example, questions were asked on the importance of seeking funding and having funding provided for APTS projects. Also, agencies were asked to share any of the specific funding sources that have been used for their APTSprojects.

\section{Integration}

This 12-question portion of the survey dealt primarily with ITSarchitecture (at variouslevels-national, regional, etc.) and the integration of APTSinto it. Selected questions addressed conformity with the national ITSarchitecture, theimpli cations for APTS as a result of a statewide ITS strategic plan, and the preferred level for ITS architecture. One of the issues raised in this section is the level of importance that should be given to merging APTS into regional ITS activities (e.g., TMCs). Agencies also were given the opportunity to identify their preferred levels of integration (i.e., route, city, region, state) for each of the APTS technologies that were included in the ori ginal inventory questionnaire.

\section{Equipment Compatibility}

Thissection asked thetransit agenciesto provide their opini onson what level of uniformity should exist for each of the technologies included in the inventory survey. For example, in the case of APCs, there are a variety of technologies that can be utilized to collect the desired passenger/vehicle data. The actual mechanism used to count onsloffs can be a treadle mat, infra-red beam, or optical sensor. Locational reference of the vehicle along the route can be detected by hubometers, radio signposts, or GPS. There are even optionsfor retrieval of the stored information from the APC'scentral processing unit. Asa result, with so many possible variations to choose from when developing an APC system or some other APTSapplication, it is important to know what level of uniformity (i.e., across route, city, region, state) agencies would like to see associated with the options. 


\section{Staff Opinions}

Similar to the previous sections, this part of the survey allowed agency staff to provide their opinions on a variety of topics related to the various APTS technologies. Topics addressed in this section included: procurement methods, types of technology, manufacturers, performance ratings, recommendations for change/improvement to a technology, measurable benefits, problems, benefits analysis, and impacts to agency staff and maintenance personnel.

\section{Public AwarenessI nvolvement}

This section queried the transit agencies about their satisfaction with the levels of awaren ess of APTS on the part of the public and public officials. The agencies were also asked to provide suggestions on the appropriatemethods that could be utilized to increase theawarenessand involvement of the public and public officials.

\section{Partnering}

This part of the survey sought information on whether transit agencies currently are participating in public-public and/or public-private partnering. Also, transit agency staff were asked to discuss any opportunities that they believe exi st for public-public and/or public-private partnerships for APTS.

\section{Rural Areas}

This brief section included only one question that asked transit agency staff to provide their opinions on the benefi ts that might result from the application of APTSin ru ral areas.

\section{Visions of the Future}

Thefinal portion of the follow-up survey involved discussion of any successesthat transit agencieshave had thusfar with APTSdeployment. Agency staffalso wereasked to discuss the factorsthat fueled their success and any activities that were undertaken to ensure/maintain the success. Questionswere also included that asked about the potential impact of the ITS strategic plan on the coordination of ITStransit projects, and the long-term vision of APTS. Finally, transit agency staff were asked to provide their opinions on the Bus Rapid Transit mode and the application of the Intelligent Vehicle Initiative to transit. 


\section{Results of the Follow-Up Survey}

Following are summaries of the results for selected questions within each of the questionnaire's topic areas, as compiled from the information provided by the 10 responding transit agencies.

\section{General}

The follow-up survey revealed that only three of the transit agencies addressed APTS in their transit development plans, and a fourth incorporated it "to some degree." Another agency indicated that it plans to address the ITS-transit issue in a future meeting. Three agencies did not add ress the issue at all in their TDPs, however, one of these indicated that the topic had been discussed during the TDP process. One agency indicated that it was not sure whether this issue had been addressed in itsTDP. It shoul d be noted that the question did not apply to one particular agency, RTO-CAP, since it doesnot produce a TDP.

Seven agencies have given consideration to ITStransit in their overall operational scheme. Five of theseagencies indicated their respectivelevels of consideration to be "some" or "not much." Another of these agenciesindicated that it hasgiven "quite a bit [of consideration] right now." The last of these agencies responded that " $1-5 \%$ of [its] overall operati onal scheme" currently considers ITS.

Tabl e 1-21 presentsthe responsesfor the question in the General section that relatesto the imp ortance of incl uding ITS-transit in the transit planning process.

Table 1-21

General Section: Question\#3

\begin{tabular}{|c|c|}
\hline Question & Response \\
\hline How important is it to include APTS in the planning \\
process for transit? & Very Important -7 \\
& Somewhat Important -1 \\
& Not Important -1 \\
& No O pinion - 1 \\
\hline
\end{tabular}

According to the responding agencies, the expected levels of efficiency resulting from APTSactivities range from "marginal" to "moderate" to "very good." One respondent expects ITS-transit to produce "at least [a] 10 to 30 percent improvement in efficiency." Furthermore, one responding agency indicated that it expects its APTSactiviti es to help increase system ridership, improve its bill ing and other financial functions, and improve trip verification. 
Table 1-22 shows the responses for the fifth question in this section, which relates to the transit agencies' primary motivation(s) for implementing their ITS-transit acti vities.

Table 1-22

General Section: Question \#5

\begin{tabular}{|c|c|}
\hline \multicolumn{1}{|c|}{ Question } & Response \\
\hline What is the primary motivation for APTS? & $\begin{array}{c}\text { Service Effectiveness }-7 \\
\text { Safety }-2 \\
\text { Efficiency }-1\end{array}$ \\
\hline
\end{tabular}

When asked how ITStransit can be made more effective in Forida, sx of the responding transit agencies indicated that funding is essential for any progress to be made. Additionally, seven agencies say that the cost of APTSand/or the lack of funding isthe key factor currently impeding the deployment of ITStransit.

The agencies submitted a range of opinions regarding the roles of the "various players" (i.e., FDOT Central Offi ce, FDOT Districts, MPOs, and local government) in the development and deployment of ITS-transit. Seven of the responding agencies listed an assortment of rolesfor the "players." For the most part, education and funding were seen asbeing two of the more important rol es. Other rol es that were suggested included general support and data collection/reporting. Two of the respondents, however, indicated that the "various players" have "no rol e" in ITS-transit, with one of these agencies suggesting that it is "strictly up to the local [transit] agencies in Rorida."

\section{Funding}

The responses for the opening question of this section are provided in Table 1-23. This particular question asked the transit agencies for their respective opinions on how important it is to provide funds for ITStransit activities in public transportation projects Interestingly, the distribution of responses is identical for the question on how important it is to seek funding for these same activities.

Table 1-23

Funding Section: Question\#1

\begin{tabular}{|c|c|}
\hline Question & Response \\
\hline $\begin{array}{c}\text { How important is it to provide funds for APTSin Public } \\
\text { Transportation projects? }\end{array}$ & Very Important -8 \\
& Somewhat Important -2 \\
No O pinion -0
\end{tabular}


This section also asked the agencies what percent of the budget should be allocated for ITS-transit activities. Four of the respondents either did not know or had no opinion, and onefound the question "impossible to answer." Four of the agencies, however, did provide thei r suggested distributions. One agency indicated a transit budget allocation of 10 percent to APTS. The other three proposed allocations for both the transit agency and state budgets: 10-15 percent of each budget; 2 percent of each budget; and 5 percent and 1 percent of the sate and transit agency budgets, respectively.

\section{Integration}

The responses for three of the questions in this section of the survey are shown in Table 1-24. The questions deal with the topics of conformity and ITS architecture-specifically, conformity of the regional ITSarchitecture with that of the national ITS architecture and conformity of individual ITStransit projects with the regional archi tecture.

Table 1-24

Integration Section: Questions \#1, 5, \& 7

\begin{tabular}{|c|c|}
\hline Question & Response \\
\hline $\begin{array}{l}\text { How important is it for the regional ITS architecture to } \\
\text { con form to the nati onal ITS arch it ectu re? }\end{array}$ & $\begin{array}{c}\text { Very Important - } 8 \\
\text { Somewhat Important - } 0 \\
\text { Not Important - } 0 \\
\text { No O pinion - } 2\end{array}$ \\
\hline $\begin{array}{l}\text { How important is it for individual ITS-transit projects to } \\
\text { fit into the overal I archi tectu re? }\end{array}$ & $\begin{array}{c}\text { Very Important - } 7 \\
\text { Somewhat Important - } 2 \\
\text { Not Important - } 0 \\
\text { No O pinion - } 1\end{array}$ \\
\hline $\begin{array}{c}\text { Do you think it is important to merge APTS into the } \\
\text { regional ITS arch it ecture? }\end{array}$ & $\begin{array}{c}\text { Very Important - } 8 \\
\text { Somewhat Important - } 1 \\
\text { Not Important }-0 \\
\text { No O pinion - } 1\end{array}$ \\
\hline
\end{tabular}

Theagencieswere al so asked whether aFloridaspecific ITSarchitecture should bestatewide, regional, or local in scope. Seven of the respondentsbelieve the architecture should be statewide, with one of these indicating that "nationwide" may even be preferable. Only one agency indicated that the architecture should be regional. The other two agencies offered no opinion on this topic.

In Table 1-25, the agencies' responses for another of the questionsin this section are presented. This particular question (\#9) queried the agencies about their opinions on merging transit with regional transportation servicesand traffic operations to create regional Transportation Management Centers. 
Table 1-25

Integration Section: Question\#9

\begin{tabular}{|c|c|}
\hline Question & Response \\
\hline $\begin{array}{c}\text { Do you thin } \mathrm{k} \text { transit shoul d be comb in ed } w \text { ith region al } \\
\text { tran sportati on servi ces and traffic operation s in a regi on al } \\
\text { Transportation Management Center? }\end{array}$ & Yes -8 \\
No -1 \\
No O pinion - 1 \\
\hline
\end{tabular}

The agencies were asked next to review a variety of technologies and decide at what level (route, city, region, or state) integration shoul d occur for each. Nine of the agencies provided responses for this particular section and, for the most part, a con sensusopinion was present for many of the technologies. For example, the majority of the agencies believe vehicle component monitoring systems should be integrated at the city level (i.e., systemwide). Many of the agenciesalso think automated fare payment systems, automatic passenger counters, on-board safety systems, and automated services should be integrated at the city level, as well.

The majority of respond ents indicated auto matic vehicle location systems shoul d be integrated at the regional level. Many of the agencies also indicated that automated operations software, advanced communication systems, automated paratransit systems, and dynamic ridesharing should be regional in nature. On the issue of multi-carrier reservation and billing, therewasan equal number of votes for integrating at the city and regional levels. The issue of traffic signal priority was also split between city and region.

Interestingly, for traveler information systems, a number of agenciesindicated both "regi on" and "state" in their responses. When combined with those systemswho voted solely for state or region, a total of seven systems indicated thes higher levels of integration. This seems to indicate a particular desire to have a traveler informati on system implemented on a large scale.

\section{Equipment Compatibility}

The solequestion in this section asked the agenciesto decide at what level (route, city, regi on, or state) equipment compatibility/uniformity should occur for each APTS technology. Nine of the agencies provided responses and a consensus opinion was present for a number of the technologies. For example, uniformi ty of vehicle component monitoring systems at the city level was indicated by the highest number of transit agencies. Most of the agencies also think multi-carrier reservation and billing and traffic signal priority should be uniform at the city level, as well. 
The agenciesindicated a preference for regional uniformity for the following technologies: automatic vehicle location systems, automated operations software, traveler information systems, automated services, advanced communication systems, and automated paratransit systems. For automatic passenger counters, there was an equal number of votes for equipment compatibility at the city and regional levels. This was also the cas for automated fare payment systems In addition, dynamic ridesharing was split evenly between the regional and state levels.

It should be noted that one agency indicated both "region" and "state" in its response for the suggested uniformity of on-board safety systems. When combined with tho se systems who voted solely for state or region, a total of four systems indicated these higher levels of integration. While this may seem to indicate a desire to have on-board safety systems implemented on a larger scale, three other systems preferred the city level for this technology.

\section{Staff Opinions}

As discussed previously, this section of the questionnaire dealt wi th staff opinions on avariety of topics relating to the development and deployment of ITS-transit technologies. The agencies were queried on procurement methods, type(s) of technologies, performance ratings, measurable benefits, and related impacts, among other topics. Unfortunately, many of the agencies declared a lack of sufficient practical experience with the different technologies to form an opinion about many of the topics. Therefore, many of the questions in this section were left mostly blank.

The first question in this section asked for staff opinions on the procurement methods, type(s), and manufacturersof the various ITS-transit technologies. Responseswere provided for only half of the 14 technologies, and advanced communication systems was the only technology with widespread use: five agencies have operational systems, with four of thes utilizing 800-megahertz radio systems.

The agencies were then asked to p rovi de perfo rmance rati ngs for the various technol ogi es that they are using, as well as any recommendations for improvement(s) that they might have. The agencies provided limi ted information for only six of the technologies. However, thevast majority of the ratings are quite good. One agency scored the performance of its vehicle component monitoring system at 100 percent. The only complaint the agency had was that they would like to see more components be monitored (specifically mentioned were brake and seatbelt monitoring). Two different agencies rated their on-board safety systems. One rated itssystem as "excellent" and believed no improvements were necessary; the other rated its system at 80 percent and cited a video surveillance system that has 8-hour tapes on a 10-hour ro ute assomething in need of change. Interestingly, this second agency also 
indicated that a switch to a digital format would also improve its system since this would make piles of tapes laying around obsolete.

Travel er information systemswas the only technology that received a "poor" rating. The agency that provided this information for itselectronic signsindicated that the recommended solution wasto "buy a different system." This seems to indicate a problem with the vendor/manufacturer rather than with the technology, itself. Conversely, the other transit agency that commented on this particular technology indicated that its traveler information system was "excellent" and in need of no improvementsor changes. Automated fare payment systemsalso received an "excellent" rating from one of the agencies. Additionally, several of the agencies gave very high approval ratings to their advanced communication systems, and did not suggest any recommendations for change.

As for multi-carrier reservation and billing, one system gave the reservation portion of the technology a 95 percent rating and indicated that the bill ing portion wasoperating at 85 percent accuracy. This agency indicated a desire to improve the reservations function via automated customer dial-in (by whi ch a person could call in and make his or her ow $n$ reservati on s using au tomated touch-tone menus). It also suggested that it would like to se the accuracy of its billing function improve to 98 percent.

\section{Public AwarenessI nvolvement}

This portion of the survey concentrated on theagencies satisfaction wi th the level of public awareness for ITStransit. Seven of the agenciesindicated that they are not satisfied with the currentlevel of public awareness. Two other agencies did not have an opinion, and one indicated that it is happy with the public's awareness of APTS.

The agencies were also asked whether they believed that public officials were aware of ITS-transit. Three of the agencies indicated that they do not believe that public officials are aware of it, while two agencies think officials are indeed aware of ITS-transit. Another agency suggested that, while public official s may be aware of ITS-transit, their awareness is "very low." Additionall y, three agencies either did not have an opinion or did not know about the level of public official awareness.

Finally, the agencies were asked for their opinions on the appropriatemethods to increase thelevel of awareness for APTS Most of the respondents indicated that a process of education is needed. The various methods of educating the public and officials that were recommended included: presentations, television and radio coverage, newspaper articles, demonstrati on projects, and informati on distributed via the Internet (e.g., a Frequently Asked Questions [FAQ] page about APTS on a transit website). 
Interestingly, one of the agencies suggested standardization of the APTS technologies as a possible method for increasing awareness. This agency further indicated that funding would lead to standardization.

\section{Partnering}

On the issue of partnering, two agencies have set up partnerships with their respective counties to utilize county radio systems $A$ third system has a smil ar agreement with its city to utilize the existing radio system. This particular system has also partnered with its city for traffic engineering services. Another agency indicated having a public-public partnership (with another public transit agency)for its scheduling functions. Yet another agency is planning to partner with the public transit provider in a neighboring county to provide cross-county service; however, it was indicated that this will occur "several years down the line." Final ly, only one system indicated having a public-private partnership (with Greyhound bus service to distribute its passes), though not for any APTS-related activities.

The agencies were also asked to provide their ideas for any opportunities that may exist for publicpublicand/or public-private partnerships involving APTS Not many of the respondentshad any ideas; however, one system did menti on AVL asa possibility and another suggested traveler information and advanced communications systems as potentials for partnerships.

\section{Rural Transit}

The responding transit agencies provided a number of benefits that they believe will result from the application of APTSin rural areas. Many of the agenciesthink vehicle location, scheduling of trips, and communication will be themost significant benefits. Traveler information and thedispaching function were also seen as benefitting from the implementation of APTS. One system even pointed to the increase in overall efficiencies that would be expected to occur as an important benefit.

\section{Visions of the Future}

Many of the agencies believe that the impact of ITS-transit in their respective areas has been relatively low to moderate thus far. However, they also believe that increased success can be attained in the future through a number of important activities. Those that were mentioned include securing funding (as well as seeking to reduce the costs associated with APTS), planning, education, marketing, increasing public awareness, setting performance measures for the technologies, and establishing partnerships. Communication was one of the primary activities mentioned by a number of agencies. 
One agency indicated that it would be valuablefor agenciesto "compare notes when [they] are done," and another stressed the importance of "celebrating [their] successes."

As far as the outlook for the future, many of the responding agencies seem to subscribe to the belief that ITStransit is "very important and will happen." In fact, one agency suggested that, with APTS, "multi-modal trips should be possible from Tallahassee to Key West." It was also indicated that integration at various levels (i.e., regional, state, national) will be a necessary ingredient. Several agencies discussed the specific technol ogies that they envision utilizing in the future, incl uding AVL, automated scheduling, and customer information systems (e.g., real-time bus arrival and departure information). Some of the expected benefits of future APTSdeployment were also mentioned, such asmore effective and efficient service and reduced paperwork.

Two initi atives relating to future devel opment of ITS-transit are Bus Rapid Transit (BRT), an upgraded bus service that takes advantage of a number of APTStechnologies to im prove service efficiencies and speeds, and the Intelligent Vehicle Initiative (IVI), which attemp ts to utilize technol ogy to help buses operate more safely and effectively. All ten of the responding agencies believe that BRT should be integrated into our surface transportation system. Additionally, eight of the respondentsindicated that IVI should be incorporated into transit, as well.

\section{STAKEH OLDER IN TERVIEW S}

With the assistance of the FDOT PTO, a number of "APTS stakeholders" from around the state were identified to take part in a series of stakeholder interviews and meetings. It was determined that these stakeholders, at a minimum, should consist of FDOT senior management staff such as the District Directors of Operation, District Directors of Planning, and Public Transportation Managers. Even though these "stakeholders" are not directly dealing with transt, they were slected because they are responsible for policy and funding allocations in each FDOT district. It is also the cas that they can provide the perspective of traditional transportation professionals on the topic of ITStransit. A total of 35 stakeholders were interviewed over the course of 6 separate meetings.

A modified version of the follow-up APTS inventory survey questionnaire was administered to the stakeholders. It should be noted that the FDOT District 1 stakeholders group included several County Commissioners. Additionally, the Miami-Dade MPO was also represented in the FDOT District 6 stakeholders group. 


\section{Stakeholder Interview Questionnaire}

The stakeholder interview questionnaire consisted of eight major topic areasrelated to ITStransit. The topic areas that were incl uded are:

Introduction

$\square$ Development and deployment

$\square$ Funding

$\square$ Integration

Public awareness and involvement

$\square$ Partnering

$\square$ Rural areas

$\square$ Visions of the future

Following are brief descriptions of the topic areas. A copy of the stakeholder interview questionnaire is included in Appendix C.

\section{Introduction}

This opening section of the questionnaire attempted to determine the stakeholders' level of familiarity with the topic areas of ITS and APTS. For those sakeholders that were not very familiar with these topics, a brief synopsis of APTSwas provided that outlined its basic aspects

\section{Development and Deployment}

The Development and Deployment section asked the stakeholdersfor their views on ITS, as well as for their opinions on APTS and its importance compared to other ITS applications. They were also asked about the importance of including APTSin the project development process and whether they believe that APTS will improve the performance of public transportation. Some of the other topics covered in this section were the expected roles that the FDOT Central O ffice, FDOT District O ffi ces, MPOs, and local government should play in the development and deployment of APTS; the potential factors that may impede the devel opment and deployment of APTS, and how APTS can be made to be more effective in Forida. 


\section{Funding}

The Funding section asked the stakeholders whether the State and local governments should be investing more in APTS They were also queried on several other topics, such as how important they believe it is to sek funding for APTS how TEA-21 views funding sources for APTS, and what portion (if any) of the work program budget should be all ocated for APTS-related activities.

\section{Remaining Topic Areas}

The Int egrati on, Public Aw areness and Involvement, Partn ering, Rural Areas, and Visions of theFuture sections were, for the most part, identical to the corresponding sections in the follow-up APTS inventory survey questionnaire.

\section{Results of the Stakeholder Interviews}

Following are summaries of the discussions that occurred at the various stakeholder meetings and interviews that were held for purposes of this effort. It should be noted that Appendix $D$ contains a listing of all the individuals who participated in each of the stakeholder meetings/interviews.

\section{Summary of FDOT District 1 Stakeholder Interviews}

The first stakeholder meeting was held with the FDOT District 1 stakeholders at the County Administration building in Arcadia on Friday, May 12, 2000. The stakeholders for District 1 were identified with the help of the FDOT project manager and the district public transportation manager. A total of 10 stakeholders participated in this meeting.

The District 1 stakeholders stated that APTS is of equal importance to other ITS applications. A lack of funding wascited as the factor that impedes the development and deployment of ITS-transit. They believe that it is "imperati ve" to seek funding for ITS-transit. As a result, when asked about the role of "various players" (FDOT central office, FDOT district office, MPOs, and local governments), they indicated that the role of those groups should be to provide funding.

Most of the stakeholders were not aware of ITS architecture or the ITS Strategic Plan. After a brief explanation of ITS architecture, everyone thought it was important for the regional ITSarchitecture to conform to the national ITSarchitecture. Some stakeholders thought it was important to merge transit into TMCs. Others thought it might not be very cost effective. 
The stakeholders were satisfied with the level of public awareness of ITStransit. One method suggested to increase public awareness of ITStransit wasto put a survey on the Internet with a reward for participation. One stakeholder suggested the way to generate ridership is to "go to the source of where it is and how it is. Listen and understand it. Go on buses. Create a desire to be a part of the big solution."

Some of the suggestions that were provided for public-public and public-private partnerships included the following:

- $\quad$ sponsorship with fare cards

- advertising on kiosks

- corporate credit cards

- involvement of schools and hospitals

Some of the activities that were mentioned to assure and maintain ITS-transit success included:

- increase convenience and comfort

- increase amount of riders

- increase simpli city to use

- share experience and success stories

Everyone involved in the discussion thought Bus Rapid Transit should be included in the surface transportation system. When asked about the importance of incorporating the Intelligent Vehicle Initiative in transit, one transit representative replied, "If other areas are seeing a significant reduction in accidents, then the answer is 'yes' If not, then the answer is 'no.' Put the money in other technologies"

\section{Summary of FDOT District 2 Stakeholder Interviews}

The FDOT District 2 stakeholder meeting was held at the FDOT Urban Office in Jacksonville on Wednesday, May 24, 2000. The stakeholders for District 2 were identified with the help of the FDOT project manager. This stakeholder group consisted of only FDOT District 2 staff, with a total of three participants.

All of the participating stakeholders thought ITStransit has the potential to attract the "choice rider." Some of the issues mentioned that partici pants beli eve keep transt from attracting discretionary riders 
are land use, densities, and cheap parking. Asone sakeholder stated, "Not many people crave access to transit." To illustrate this point, the example of downtown tacksonvillewas given, where it is much cheaper to drive one's car than to ride transit because parking costs $\$ 0.25$ for two hours. One stakeholder said that the general public is "not convinced about transt, let alone ITS-transit."

When asked about the role of the "various players" in the development and deployment of ITStransit, the stakeholdersindicated that FDOT doesnot promote anything, but will supportit once initiated, i.e., FDOT is only a supporting agency. One person said, "Transit agencies should decide what they want to do and come to FDOT for funding." Additionally, the stakeholdersmentioned that FDOT should be an advocate. They also believe that FDOT would be in abetter position to fund ITStransit if a safety element, such as panic buttons, was present.

Regarding funding, the sakeholders thought that no existing funding sources should be used for ITStransit. One person also mentioned that "only existing fun ding sources shoul d be used for commuter assistance programs"

Thestakeholderswere not very famil iar with either the ITSStrategic Plan or ITSarchitecture. However, they did believe that it was necessary for individual ITS-transit projects to fit into the overall architecture. All of the stakeholders thought it was important to integrate ITS-transit into regular ITS, as well. Even though they thought transit should be included in the new TMC in lacksonville, it was indicated that there has been no discussion to include transit in that building. The stakeholdersalso mentioned that there was an ITSarchitecture workshop at the Jacksonville Transportation Authority $(\pi A)$ office at the beginning of this year. Although there were no representatives from $\pi A$ in attendance, everyone else was represented (such as emergency operations, fleet operations)and there was a lot of information sharing and opinion exchange.

The stakeholders stated that they were not satisfied with the level of public awareness of ITStransit. Having more information at Horida Transit Association conferences was one appropriate method suggested to increase awareness. In fact, one of the sakeholders thought that ITS-transit "should be at the top of the list" at Florida Transit Association conferences.

The stakeholders also indicated being disappointed with the level of ITS-transit success in their area. One of the suggestions given to grow ITS-transit was to have "better coordination" with the "DOT, MPO, and transit agencies all having a role." 


\section{Summary of FDOT District 4 Stakeholder Interviews}

TheFDOT District 4 stakeholder meeting washeld via conference telephone call on Thursday, 山ly 27 , 2000. A total of four stakeholders participated in the discussion.

The stakeholders all saw a need for ITS-transit. One stakeholder believes that "as the room for roads decreases, APTSbecomes more necessary." Asa result of this need, the District is establishing a master plan for ITS-transit. One stakeholder stated, "We are funding an AVL system, and dispatching and re routing projects" The creation of this plan wasencouraged by theideathat one stakeholderexpressed: "the longer you wait to initiate and create this, the harder it will get, and the more expensive it will get."

Integration, education, and increased communication were often stated as primary necessities for the success of ITStransit. One stakeholder said that the traditional paradigm of "just build more roads" hurts ITStransit. Another suggestion was to "provide a forum for the agencies to gather each month to help integrate each fragmented project into a single division."

On the issue of the "various players" involved with ITS-transit, all of the stakeholders agreed that ideally:

- the central office deals with policy programs;

- the districts provide experti se and guidance;

- the MPO provides coordination, endorsment, and fund approval; and

- the local level does the implementation.

One stakeholder indicated that seeking funding for ITS-transit was very important, al though another added it was important not to just "throw money at it. It needs to be planned and managed. Need the most bang for the buck. Prioritize deployment." All of the sakeholders stated that funding should be project related, not allocated specifically to ITS-transit.

All of the sakeholders believe that it is very important for ITS architecture to conform to the national ITS architecture. They stated a desire for "all systemsto be interchangeable." They also thought that it is important to combine regional transportation services and traffic operations in a regional Transportation Management Center. As a result, they are "building a traffic management center to house various providers(e.g., AHP, FDOT, traffic operations, transit, APTS)." 
The stakeholders indicated not being satisfied with the public awareness level of ITStransit. Additionally, one stakehol der said, "The officials are also not aware." In order to increase public awareness, they believe "real time information is the most useful tool and form of self-marketing."

One stakeholder said that some of the opportunities that exist for public-public and public-private partnerships for ITS-transit are "smart bus stops with real time information. Ads can be placed there." That particular stakeholder also suggested "smart cards with outside vendors" and "entering into joint development with park and ride."

On the issue of ITS-transit in rural areas, one sakeholder indicated that "scheduling and dispatch and service" were the main benefits.

To assure and maintain the success of ITS-transit, one stakeholder suggested a need to "sit down and form a master plan," then "prioritize deployment." This stakeholder further stated that "real time information is the best option to get choice riders. Smooth, clean, comfortable is needed to get commuters"

One stakeholder believes that Bus Rapid Transit should be integrated into the surface transportation system. However, it was stated that "there is aunspoken policy to try bus, then rail. We are interested in BRT." The stakeholders also agreed that it was important to incorporate the Intelligent Vehicle Initiative in transit, as well.

\section{Summary of FDOT District 6 Stakeholder Interviews}

The District 6 stakeholder meeting was held at the FDOT office in Miami on Wednesday, Jne 21, 2000. The stakeholders for District 6 were identified with the help of the FDOT project manager and the district public transportati on manager. This stakehol der group consisted of FDOT District 6 staff, a Miami-Dade Transit Authority (MDTA) representative, and an MPO representative. A total of seven stakeholders participated in the meeting. Themeeting kicked off with a 10 -minute presentation on the project by CUTRstaff.

When asked whether the roles of all the participating agencies were defined regarding ITS-transit development and deployment, the MDTA representative replied that everyonewascooperative. One of the stakeholders mentioned that a lot of progress has been made since 1997, but some things are still not clear. Another stakeholder mentioned that small cities are trying to do their own circulation. It was stated that these small cities should establish inter-local agrements with the transit agency. 
All of the stakeholdersbelievethat ITS-tran sit hasthe potential to improvetransit operations. However, it was mentioned that one obstade to the deployment of ITStransit is that transit operators are often not aware of how to operatethe technology. Additionally, it wasindicated that the County government takes a very long time to procure anything. One stakeholder said, "Dealing with bureaucracy is a major problem."

None of the sakeholders are satisfied with the level of funding for ITStransit. One stakeholder said that they "don't have money for anything. Someone has to have the vision of what the whole partnership should look like. Wehave been pushing such apartnership." It was mentioned that, since the County rolled back the gas tax, there is not enough money. One of the stakehol ders said, "FTA [Federal Transit Admini stration] and other federal agencies are expecting major portions to come from local government. It is a problem here because the $\$ 0.02$ gas tax was cut."

Most of the stakeholders indicated being aware of the ITS Strategic Plan and ITSarchitecture. There were differing opinions on the level of conformity, but the conænsus was that ITStransit architecture should be in conformity with at least the local architecture.

The participants thought that rail riders are more aware of ITStransit than other transit riders. They believe that most of the general public is only aware of what the Miami Herald reports and, because that particular newspaper only prints stories about cars, the public is not informed. It was suggested that ITStransit should come across as "moving people, rather than cars." One of the stakeholders indicated that there wasno early awareness of the technology. Variable message signs were suggested as a method to increase public awareness of ITStransit.

The stakeholders provided many visions of the future for ITStransit. One person said that the "best contribution is to provide rel iable, accurate information about transit." Other suggestions included specialized BusRapid Transit on different corridors and producing good Metro rail projects. The need for an integrated transportation system was also made clear. Some stakeholders think that ITS will be there and working 10 yearsfrom now. One person said, "Even if there is only one bus, then that bus will have all APTS"

\section{Summary of FDOT District 7 Stakeholder Interviews}

The FDOT District 7 stakeholder meeting was held at the District 7 office in Tampa on Friday, Lly 28, 2000. This stakeholder group consisted of FDOT senior management staff and members of the ITS working group. A total of five stakeholders participated in this meeting. 
Everyone in attendance saw the potential for ITS-transit. One stakeholder indicated a belief that ITStransit should be included in the transit development plan (TDP) of a transit agency. When asked about the role that the "variousplayers" should play in the development and deployment of ITS-transit, one stakeholder said that the "role of DOT is integrating transit into all transportation services. [The] DOT facilitates [The] TDP becomes an integral piece of this."

Despite the importance of ITStransit, the stakeholders do not believe that the State and local governments should be investing more in ITStransit because "the architecture is not in place." Furthermore, a sakeholder said, "Transit operation hasn't formed the process yet. We must form objectives, goals, and initiatemeasures. Oncethat happens, wewill come to the right funding levels."

The stakeholdersthought it was important to merge APTSinto the regional ITS architecture. One said, "APTSshould, at aminimum, be included in regional architecture." All of the stakeholdersalso believe that transit should be combined with regional transportation servicesand traffic operations in a regional Transportation Management Center. On that issue, one stakeholder said, "Communication is important, not cołocation."

In general, the stakeholders were not satisfied with the level of public awareness of ITStransit. One stakeholder indicated that the public wasnot even aware of transit, let alone ITStransit. To improve public awareness, they suggested the use of the Internet in addition to more standard methods of communication, such as information at malls. One stakeholder expressed the belief that "transit customers are trapped." Another said, "ITS-transit cannot be a frill. [It] should be able to capture the choice rider."

The stakeholdersdo see opportunities for public-public and public-private partnerships for ITStransit. Some of the suggestions for these partnerships included:

- commercialization of transit, featuring "televisions and moviesin buses;"

- $\quad$ partnership with fare payment services;

- website with advertising space to sell;

- partnership with Amtrak; and

- partnership with ports and airports.

The ben efits of applying ITS-transit in rural areaswere said to include "scheduling and dispatching, and electronic fare payment." 
The stakeholders had many visions of the future for ITS-transit and lamented the current state of transit in whi ch they are "serving a captive ri der." One stakeholder suggested, "Until you have communities with focal points, transit won't be successful." Another stakeholder indicated that there should be "information to make a decision about whether to use a private vehicle or transit." That stakehol der further believes that thisinformation will be available on "a device as small as our cell phones and we can access it by pushing a button." In addition to that, yet another sakeholder stressed the convenience ITStransit can offer, suggesting "express buses on exclusive lanes. [An] example is Disney. Park your car and they get you everywhere else." A fellow sakeholder echoed those views by saying that, in the future, you should be able to "go anywhere, anytime, and have access to information on how to get there conveniently."

\section{Summary of Central Office Stakeholder Interviews}

The Central Office sakeholder meeting was held in the Rhyne Building in Tallahassee on Augus 11, 2000. A total of six stakeholders participated in the meeting.

The stakeholders believe that APTS is a low priority compared with other ITS activiti es because of a lack of funding. One stakeholder said, "Finances are running thin," and another added, "Spending is very low on transit right now." However, all of the stakeholders think APTS, given the opportunity, has the ability to improve public transit.

Therol es of the "vari ous players" in APTSwere al so discussed. Whilethe stakeholdersmentioned that the roles vary from county to county, they did state that the "MPOs don't participate in rural areas." Thos within the FDOT Public Transportation Office were referred to as "gatekeepers" Additionally, the stakeholders agreed that state, local, and transit operations should be investing more in APTS They al so stated that, if work program budget items were to increase ridership, it would be a valuable tool. Overall, the view wasone of distributing funds wisely. One stakeholder suggested acourse of action that would "dedicate allocation to congestion management, which would lead to funding in transit, then to ITStransit." Another opinion wasthat a "flexibility of funding" is essential to avoid boxing in areas.

On the subject of integration, one stakeholder believes that "any time systemscan talk to each other, they should." Concerning the topic of ITSarchitecture, one person said, "People are aware, but the perception is there is no reason why it' snot integrated." One stakeholder added, "When stakeholders know what is in it for them, they get excited." 
Upon discussing whether transit should be included in a TMC, all of the stakeholders agreed with the statement that, "All transportation modes should betied together. Virtually or physically, they should be tied together."

The stakeholders also all agreed that there is not enough public awareness for APTS One suggestion was that "transit needs to take the lead. Give information for hotels and motels to inform visitors that there is atransit system." The stakeholders also mentioned the power of the Internet, suggesting links to all modes of transit and real-time travel information. One suggestion to increase public awareness was to provide information at fairs and other gathering areas for people.

The stakeholders gave many examples of partnership deals for ITS-transit, such asa partnership with local taxi service, a trolley up and dow $n$ a beach area to reduce traffic, and malls instaling variable message signs for transit near the mal stops. Advertising was also seen as a major possibility for partnerships. One stakeholder said that there should be "advertising, but also dissemination of transit information, such as 'The bus arrives in three minutes - drink Coke."”

Thevisions of the futurefor APTSincluded "a quantum leap in maintenanœ, operation and information combining vari ous modes." Other suggestions included an integration of ærvice and the production of dependable transit. "Transit should deal with service" wasone specific suggestion.

Overall, all stakeholders pointed out the importance of getting information to the users One final suggestion was to "have a transportation channel, just like the Weather Channel."

\section{SU m M ARY Of RURAL STAKeH OLder SURVeY}

In ord er to gain the perspective of ru ral transit providers, a survey based on the questionnaire uti lized for the stakeholder meetings was distributed to Community Transportation Coordinators (CTCs) throughout Foridawith the assi stance of the Forida Commission for the Transportation Di sadvantaged. The survey sought to assess the CTCs' perceptions of APTSand to determine the applications that are the most widely used and/or may be the most beneficial in the rural areas of the state. Fifteen rural agencies responded to the survey. Agency respondents are listed in Appendix D.

The survey results echo the results of the initial APTS inventory survey and the findings from the stakeholder meetings that were held. The rural participants are familiar with ITS aswell asthe more specific APTS Most of the respond ents bel ieve that ITS coul $d$ have a positive impact on effecti veness and that, if affordable, ITScould "offer a tremendousbenefit." One respondent noted that "within 10 
years, ITSAPTS will significantly restructure public transportation and blur the current distinction betw een transt and paratransit." Further, most of the respondents (specifically, 11 of 15) believe that APTS is "equally important" as other ITSapplications. Similanly, most of the respondentsbelieve that it is very important that APTSbe integrated into the regional ITSarchitecture and that transit should be combined with regional TMCs. Interestingly, while in the minority, two of the respondents expressed reservation over the integration of transit into TMCs. The first noted that, eventually, the integration should occur, but not initially. A second participant said that such integration may be appropriate in the urban setting, but not in a rural one.

When asked whether APTSwould improve the performance of public transportation, the respondents are split between APTS offering "some improvements" and "significant improvements." Of those respondentsthat identified the possible benefits of APTSto rural areas, most cite cost effectiveness and efficiency as the greatest benefits. Specifically, one rural stakeholder believes that APTSwill allow greater definition of flexible route potentials; whi le another believesthatcommunication between rural counties will be improved and transit "feed-lines" to urban areas can be created.

Of the fifteen responding rural agencies, less than half are promoting or deploying APTSapplications. Those applications being used or considered are scheduling and fleet management software, AVL, and electronic fare payment technologies. Most of the respondentseither could not describe the level of APTSin their respective areas or considered it to be low or poor. According to the survey participants, the impeding factors to more widespread use of APTSare rel ated to costs and funding, aswell asneeds assessment and reluctance of transit systems and CTCs to accept change or embrace technologies. To respond to these impediments, the respondents recommended that more information on the "financial advantages" of APTS be developed and shared to reduce the reluctance to accept the applications. Further, one participant recommended that rural or small transit systems be granted "price breaks" or "tax incentives" when choosing to deploy APTS To address the impediment of unwill ingness to embrace technologies, one respond ent recommended that APTSapplications be more user-friendly and that they are designed to be "ready-to-go" at installation.

When asked to define the role of the various players in the development and deployment of APTS, many of the responding agencies agreed that FDOT has several opportunities to facili tate deployment on the local level. Some of the respondents alluded to the need for FDOT to address its funding distribution process and assist with consensus building and cost effectiveness analysis. While not assigned to a particular transportation entity, other crucial tasksin the development and deployment of APTSthat were identified by the respondentsinclude educating the public and elected officials of 
the benefits of APTS, developing a standard architecture, providing recommendations, and assisting with training.

Over half of the respondents believe that it is important to seek funding for APTS and that state and local government should invest more in APTS. The respondents most often identified state and local government as the funding sources for their APTS projects, specifically identifying Section 5307 or Service Development funds.

None of the responding rural stakeholderswere satisfied with the level of public awarenessfor APTS (two did not answer the question and one did not feel knowledgeable enough on the subject to answer). When asked what appropriate methods of increasing public awareness might be used, the participantsmentioned disseminating information through local agencies, mail-outs, public workshops, marketing campaigns, successful demonstrati ons, and media coverage.

Regarding Bus Rapid Transit, most of the respondents agreed that it should be integrated into the surface transportation system. Specific features of BRT that were appealing to the survey respondents were vehicle location systems, low-floor buses, multi-bus strategies, and electronic fare collection. However, one of the stakeholders noted that determining which of these features should be incorporated into BRT should depend on the local agencies needs and desires rather than determined by central planning organizations.

Finally, the survey queried the rural stakeholders on how APTScan be made to be more effective in Florida. Some of the survey respondents indicated a belief that Florida's rate of growth and high transportation demands will necessitate APTS. Others responded with specific ways to ensure the effectiveness of APTS, such as through recruiting innovative field practitioners of new technology, having one architectural standard, introducing it first to major urban areas, and conducting trial and error demonstrations.

\section{Sum m ary of Rural Florida ITSDemon Stra tion Pro Ject}

According to the Rural Florida ITS demonstration project reports available on the Internet at http://www.dot.state.fl.us/ctd/fl-its.htm, thi s proj ect applies ITStechnology to selected rural areasof Florida's coordinated transportation system. (Information used in this summary is taken from the project's Year-End Report and First Quarter Report of 2000.) The project deals with transit service offered to the transportation disadvantaged, providing transport for employment or health related trips. Three rural areas in northeast Forida (Hagler, Putnam, and St. bhns Counties) were given $\$ 60,000$ 
each for start-up. Two counties(Alachua and Marion) were later add ed to the project when additional funding was awarded by FTA.

The vari ous ITStechnologies that were used incl uded Geographic Information Systems(e.g., Mapln fo), Global Positioning Systems (GPS), mobility management software (e.g., RouteLogic), and other electronic applications, such as e-mail and internet access.

Although problems did occur in the early stages of development, once a uniform architecture was established (called a "M emorandum of Understanding" [MOU], formalized in late 1998), it gave all parties involved the guidelines needed to move forward.

The technologies involved did cause some problems, although most seemed to sem from incompatibility problems with outdated hardware. Once upgrades were performed, the technology operated well. Additionally, it wasindi cated that all staffunderstood how to operate the technologies. Those involved with the project have indicated that it hashelped develop efficient transportation for citizens.

The rural areas participating in this program and their experienceswith ITSare discussed in summary fashion in the following sections.

\section{Flagler County CTC}

Flagler County Transit (FCT) is Flagler County's Community Transportation Coordinator (CTC). FCT primarily has been working with RouteLogic, an off-the-shelf transportation management software package developed primarily for routing and scheduling purposes. Since the beginning of the pilot project, FCT staff has shown the abili ty to pick up the technology quickly. Their understanding of the project'sgoals and what enhancementswould be necessary to meet those goalshasbeen amajor factor in the project's success thus far.

Working with the RouteLogic vendor, FCT has been developing various reporting and billing enhancements to the product that w ould ensure that the softw are would meet Florida-based Reporting requirements. In fact, the working relationship hasgoneso well that FCT was used as the beta test site for all upgrades and modifications to the software, and even hosted a "U sers Group" forum for users from around the U.S. Because of the attention the ITSproject has brought to RouteLogic from the state and federal level, all of the enhancements to the product were developed quickly at no additional 
charge to the users. (It should also be noted that the technical team also has been using the GIS software package, Maplnfo, to develop various reporting templates)

Interestingly, the work that went into enacting FCT's transition to the RouteLogic software has helped spur the development of the staff. Variousstaffmembersare now providing on-site technical assistance to other users and presenting on ITS technologiesat national conferences FCT also contracted with St. bhns County Council on Aging Transportation Section in 1998 to assist in that agency'sinitial start up and conversion of RouteLogic. Additionally, FCT is providing staff training and on-site technical assistance to the Alachua and Marion County CTCs (new participants in the Rural ITS project).

Overal, FCT has been operating very efficiently and has had few service problems. ITS technology hasprovided greater system sability and hasfacilitated the more efficient scheduling of resources $A$ future goal is to use theautomated scheduling feature of the software to analyze route efficiencies, with the intention of establishing fixed service routes (in order to shift away from the costlier demandresponse mode). Additionally, it should be noted that, as a result of their experience, the FCT technology team believes that the AVL technology may not be asimportant to their service delivery function as they once thought.

\section{Putnam County CTC}

The Putnam County CTC (known as the "Ride Solution") is the transportation section of the Putnam County Association of Retarded Citizens. This particul ar CTC has been recognized as being a pi oneer in rural technological and operational advancements over the last few years. As a result, the Ride Solution took a different approach in its participation in the Rural ITS project from the other two original participants.

Ride Solution already had a proprietary routing and scheduling program in place that had been developed for them by aconsultant. However, since the system was based primarily on a service route delivery model, staff believed that they needed Automated Vehi cle Locati on (AVL) technol ogy installed on their vehicles. Thistechnology would enablethem to track schedule compl iance and to gather data for client and driver tracking, vehicle maintenance, mileagecalculation for billing, and further analysis of the service routing component. (It should be noted that, despite its desire to pursue a different direction, Ride Solution did instal a RouteLogic workstation to be able to interface with the other participantsfor the coordination of inter-county trips.) 
The identification, purchase, and installation process for the AVL equipment turned out to be significantly more difficult and frustrating than RideSolution anticipated. Thesystem originally gained approval to "piggy back" on a Request for Proposal (RP) processfor AVL equi pment that had been initiated for an lowa Department of Transportation ITS project being managed by the consultant who developed RideSolution'stransportation management software. Unfortunately, Ride Solution staff had resrvations about the unanimously-selected vendor's product. Ultimately, the system identified a suitable product, manufactured by CSE (an Orlando-based company), and, after dealing with some competitive procurement issues, contracted with the company in December 1999. Installation of the AVL units was scheduled to take place in March 2000.

Overall, the Putnam County system has also been operating very efficiently, with very few day-to-day service problems. Nevertheless, management has expressed serious concern over schedule compliance, since on-time performance is key to operating in a service route environment. It is anticipated, however, that the new AVL technology will help address this problem and ensure quality service delivery.

\section{St. Johns County CTC}

St. bhns County Council on Aging, Inc., isthe county's CTC; its Transit Division is known as St. bhn's County Transit (SCT). A review of the system in April 1998, near the beginning of the Rural ITS project, showed that SCT was having serious operational problems. There had been a significant turnover in operations and management staff, and the new Executive Director wasseriously concerned with the system's efficiency and financial stability. Two major problems impacting the system at this time were its facility (all eight staff members were crammed into one small room) and the lack of adequate transportation management software. All staff responsibil ities were shared (no distribution of tasks) and the administration of the servi ce wasextremely paper intensive, with most functionsbeing completed by hand.

Since that time, though, SCT has undergone a dramatic changes. The major restructuring began in January 1999, when thetransportation department moved from its original one-roo m operations center that washoused wi thin the CTC's buil ding, to a renovated house adjacent to the CTC. Thenew facility was upgraded with computer cabling, modifications to the electrical system, and new phone lines. Even the way that the office runshasevolved, aswell. Only one of the eight original staff members remains and new staff has been hi red with more cl early delineated rol es and responsibilities. The CTC even hired Hagler County Transit's Operations Manager to serve as Assistant Executive Director (this individual has been particularly instrumental in SCJ's transition to ITS technology). 
The RouteLogic software was installed in December 1998, prior to SCJ's move. Despite a new Windows NT-based server and hardware upgrades to the existing workstations, numerous lockups occurred. This was due to the fact that SCTs original workstations (I.e., low-end Pentiums) were too outmoded, even with the upgrades, to accomplish the applications required by the software. ITS Expansion grant funding, however, madeit possible to replace the workstations, which then solved the scheduling/mapping lockup problemsthat had been occurring.

Interestingly, solving the computer woesled to the sabilization of the system's scheduling function, whi ch solved another problem SCT had been having: driversdictating their available hours. Thishad been making scheduling difficult and inefficient. However, with the ability to consistently schedule runs, SCT management was better able to make driver scheduling decisions that were in their best interests, rather than letting the "tail wag the dog."

Overal, SCT staff has found that the introduction of technology has resulted in driver costs per trip going down significantly. In addition, the system now is able to schedule more people at less hours and use cost-saving techniques such as split shifts. Vehicle time has also bœn reduced. Even the bill ing of services has been streamlined from a paper-in tensive process to a quicker, computer-based meth odology that utilizes geo-coding to calcul ate trip mileages.

Despite the successes that have been experienced to date, SCT is sill having some problems with Medicaid bill ing (i.e., a significant amount of information must be re-inputted each month for all of the Medicaid-related trips). This issue should be taken care of soon, however, by an integrated Medicaid bill ing interface that is being developed for the software. In addition, SCT believes that additional training is needed for the software, especially for the many reporting and query functions. Because of thesefunctions and the many enhancements that are add ed to the software with each version upgrade, SCT staff beli eves that the vendor should develop a step-by-step instruction book, so that users can quickly troubleshoot problems and train fellow staff.

It should be noted that, at the time of the Year-End Report, SCT's AVLs were not active and needed to be expanded to improve the functionality of the system. According to that document, this will be a primary focus of the second phase of the grant.

\section{Alachua-Levy Counties CTC}

Coordinated Transportation System, Inc., (CTS) is the designated CTC for Alachuaand Levy Counties. This CTC was selected to participate in the Rural Florida ITSDemonstration Project when the project 
was expanded in October 1999. Installation of the RouteLogic software occurred in November 1999, and CTS acquired Internet and e-mail capabilities shortly thereafter in December. Prior to implementation of the software, CTS staff were trained, client files were converted, and address information in the system's database was cleaned.

CTSwent "I ive" with the RouteLogic software on January 1, 2000. Unfortunately, servicebecamevery di srupted for the riders due to repeated omissions of scheduled ridesand the lack of city referenceson the manifests, which resulted in a large number of late appointment deliveries. To solve these initial problems, CTS updated all of its client files with city information and also had two additional staff members cross-trained in the scheduling function to provide more support.

According to CTS, the implementation period wasextremely busy, but the peer training received from Flagler County Transit (both on-site and at FCT) and the additional problem-resolution insight from the Marion County CTC proved to be very beneficial. The addition of extra staff was also helpful to them, especially since the transition to Routelogic turned out to be much more involved than they had anticipated. Despite these problems that were encountered, however, CTS still believes that the change hasmerit. (It should be noted that CTS was not using AVLs at the time of the report.) $)^{1}$

\section{Marion County CTC}

The Marion County CTC was the other CTC that was selected to participate in the Rural Florida ITS Demonstration Project when the project was expanded in October 1999. Prior to implementation of the RouteLogic software, the Marion CTC updated all of its computer equipment and its networking software in November 1999. The RouteLogic software was then installed between November and December 1999. The vendor provided on-site training during this time for Marion staff, who also received ori entation training for the software at the Flagler County Transit offices.

The Marion CTC experienced some difficulties during the implementation stage because of delays in the procurement, installation, and training process. Data entry, driver training, and community information activities that had been planned had to be curtailed. A two-week transition period using manifests from both the new and original systems was scrapped since on-line scheduling with the

\footnotetext{
${ }^{1}$ Interestingly, it is important to further note that, on October 1, 2000, ATC/Intelitran was designated as the new CTC for Alachua County. Since ATC/Intelitran has developed and sells its own mobility management software, RouteLogic did not want a competitor to have direct access to its product. As a result, ultimately it was decided to retrieve all equipment and property from CTS related to the demonstration project and install it in two smaller, more ru ral counties (Baker and Union) near the gen eral service area of St. John s and Putnam Counties.
} 
RouteLogic software began on lanuary 3,2000, and the original system was not Y2K compliant so it could not accept appointments in 2000. Instead, staff and driver memory had to be utilized in conjunction with the new manifests in order to complete trips during the first week of implementation.

Other problemsthat Marion staffhave had to deal with inclu de the lack of driver training and Medicaid bill ing issues. Because of the initial delays, official training for drivers did not occur. Thus far, training for the drivers has been one-on-one as manifest are produced and problems or questions arise. In addition, Marion hashad to utilize its old system for Medicaid billing due to some data reading issues that have delayed the conversion to direct billing from RouteLogic.

Because Marion County CTC was in the very initial stages of implementing the software when their report was filed, there is not a lot of information on their experiences in dealing with it. At the time of the Year-End Report, AVLs had not been utilized and no coordination of trips had occurred. How ever, it wasindicated that the Marion staff did receive (and were very appreciative of)considerable cooperation in orientation, training, and the answering of questions from theother project participants, Flagler County especially.

\section{Project Summary}

In conclusion, the Rural ITSDemonstration Project is significant because it deals with a number of the issues that will arise once ITS-transit is implemented across the state. Despite its relatively small scale in terms of available APTStechnologies, the project shows that concerns involving technology do, indeed, have some validity. How ever, it al so proves that they can be overcome, especi all y with a high level of coordination and support between those involved in its implementation (i.e., the agency, the State, and the vendor). Furthermore, the project shows the value of a system-wide architecture plan for agencies to follow, and the importance of funding to provide any hardware upgradesneeded to run the technology. Asfor the overall value of the technology that is being utilized, oneconclusion of the Rural ForidalTSdemonstration project FirstQuarter Reportfor 2000 isthat, while the technology does present some issues, the participating CTCs defini tely see merit in the change.

\section{SUMM ARY OF CHAPTER ONE}

This first chapter in the Inventory and Analysis of Advanced Public Transportation Systemsin Forida document hassummarized the results of two surveys that were admini stered to the 30 stateblock grantreceiving transit systemsin Florida (an initi al APTSinventory survey and a follow -up survey), a number of APTSstakeholder interviewswith FDOT senior management staff and oth ers, and a rural stakeh ol der 
survey of CTCs in the state. It has also presented a current synopsis of the Rural Florida ITS Demonstration Project.

The findings from the initial inventory questionnaire revealed that, for most transit agencies, the majority of the ITS-transit technologies that the agencies will be utilizing are currently in the planning stages. Advanced communications and automated paratransit are the most popular technologies, with 14 transit agencies either in the planning, implementation, or fully operational stage. Other popular technologi es include automated operationssoftware(12 agencies), trip planning information (12), and single-mode and/or multimodal trip planning information (11). Interestingly, every one of the APTS technologies that were discussed in the questionnaire currently is being uti lized, or will be in the near future. Nevertheless, it should be noted that high occupancy vehicle lane access is the least popular technology among the transit agencies that responded; only two systemsindicated using or planning for thistechnology. Thisisnot a surprising outcome giv en the lack of exclusive, barrier-protected HOV lanes in Florida.

As for the actual deployment of APTStechnologies, the advanced communication technology is the most frequently deployed technology being utilized by the transit agencies that responded to the survey. Nine agenciescurrently haveadvanced communicationssystemsin operation. Automated fare payment also has significant levels of deployment among the respondents six agencies have operational automated fare payment systems in place at this time.

The results of the follow-up questionnaire showed that, according to the responding transit agencies, service effectiveness is the primary motivation (with safety being a secondary motivation) for the implementation and uঙ of ITS-transit technologies. However, the vast majority of the responding transit agencies also indicated that the cost of APTSand/or the lack of funding is the key factor that currently impedes the deployment of ITS-transit. In fact, thiswas cited as the primary reason why so little ITS-transit wascurrently implemented. According to most of the respondents, funding isessential for any progress with APTS to be made, especially if the goal is to make ITS-transit more effective in Forida.

In addition to the importance of providing funds for ITS-transit activities, the transit agencies also believe in the importance of establishing an overall architecture (whether regional or statewide) to which all individual ITS-transit projects should conform. It was indicated that it is equally important that this particular architecture conform to the national ITSarchitecture, as well. Within the specific architecture, then, the individual APTSprojectscan be integrated at varying levels contingent upon the 
actual technology being deployed. Many of the agenciesalso stressed thevalue of ensuring equipment compatibility within varying levels, again based on the particular technology.

In discussing the various technologies that the responding agencies had implemented thus far, it was determined that the performance ratings of the technologies are quite good. Most only indicated a desire that their specific technologiescould do even more(e.g., vehicl e com ponent moni toring system al so keeping track of brake and seatbelt usage). Onl y one agency indicated a "poor" rating and, based on staff comments, it is evident that the rating has more to do with the vendor of the electronic signs that it is utilizing, and not the technology itself. Overall, the responding agencies seem to be quite pleased with the experienceswith ITStransit technologies, thus far.

Despite the relative successesthat have been achieved to date, it still is apparent to the transit agencies that funding is not the only obstacle that must be overcome. It is believed that a lack of awareness among the transit agencies about how to u se technol ogy is a potential stumbling block to deployment. In addition, agency staff indicated that the level of public awareness for ITS-transit improvements isstill extremel y low. Thisisalso the case for public officials, as well. One of the major ben efits of ITS-tran sit is that it can improve transit service for current passengersin a host of waysand make it moreattractive for non-users, too. However, if people are unaware of the benefits, how will the desired results of increased ridership and a broader passenger base be achieved? Without this awareness, then, the relatively large investment required for APTStechnology deployment may be for naught.

Fortunately, the agencies' vi sion for the future incl udes a belief that ITStransit is"very important and will happen." Whil e they acknowledge that the impact of APTShasbeen relatively moderate at best, so far, the agencies are positive that ITStransit's future impact can be increased through a variety of importantactiviti essuch as securing funding, planning, education, marketing, establishing partnerships, and monitoring performance (versus established standards for each technology). Communication will al so be key as agencies will need to "compare notes" and share successes with each other as more APTStechnologies are deployed and more lessons are learned.

From the various sakeholder meetings, it is apparent that a majority of the persons that were interviewed consider ITS-transit to be very important. They also indicated that technology advancements in transit did indeed warrant funding, especially given the potential to improve transit and attractnew riders. But, it wasalso cautioned that the deployment of APTSshould be " planned and managed," even prioritized-it would be folly to simply "throw money at it." To ensure the success of ITStransit in Forida, it also was stressed by a number of participants that the State's ITS architecture should conform to that of the national ITS architecture and that "all systems [should] be 
interchangeable." This means that, to the extent possible, all technology should conform to the established statewide architecture, be integrated, and have compatible equipment.

Interestingly, the stakeholders did express concern with the application of APTSto transit because of transit, itself. That is, because transit has such a low level of demand and awareness from the public, it is believed that ITS-transit, al though helpful and efficient, will not be able to solve the root of the problem-namely, that not many people have the need or desire to utilize transit. Nevertheless, most of the respondents do believe that ITS-transit-with the proper funding-can have successin attracting discretionary riders back to transit. As an example, real-time informati on was suggested asbeing one of the tools that could be useful in "self-marketing" ITS-transit while increasing the attractiveness of transit. While its impact has not been felt as of yet, the stakeholder interviews seem to indicate that traditional transportation professionals believe ITS-transit has the potential to revolutionize transit.

Some of these same sentiments and issues were echoed by the rural stakeholders in their survey responses. According to a number of CTCs in the state, certain APTS technologies should be tremendously ben eficial to rural transit and help tie much of their paratransit service to the fixed-route systems in urban areas. Some of the more applicable technologies being used or considered by the rural transit providers are scheduling and fleet management software, AVL, and electronic fare payment. However, the rural stakehol ders see a number of impediments that sill must be overcome to make the use of APTS in rural applications more widespread, such as technology costs and insufficient funding sources, lack of public and elected official awareness, and the need for training, among others. Regardless, though, the rural stakeholders see APTSasan eventual necessity for transit given Horida's continuing growth and the burgeoning demand for transportation and mobility.

Finally, the brief review of the Rural Florida ITSDemonstration Project illustrated a number of issues that will arise as ITS-transit activities continue across the state. As various technologies are implemented, it can be expected that problems will occur related to training; the procurement, delivery, and installation of new equipment; the obsolescence and/or compatibility of existing equipment; maintenance; and actual operation, among other issues. However, the demonstration project was also helpful in showing that many of these concerns can be overcome, especially with a high level of coordinati on and support between all parties involved in its implementation. The project also showed the value of a system-wide architecture plan for agencies to follow, and the importance of funding to provide any hardware upgradesneeded to operate thetechnologi es being implemented. Lastly, the project also exemplified the usefulness of one particular ITStransit application, i.e., transportation management software, and the benefits that it has brought about for several rural transportation providers. 


\section{CHAPTRTWO}

Issues \& Characteristics of the Develo pm ent/Deplo ym ent of APTS A Lteratu re Review

\section{INTRODUCTION}

The examination of 10 major APTS development and/or deployment issues and characteristics experienced by transit agencies in Florida and throughout the country is the task that is described in this second chapter. As noted previously, the development and deployment characteristics of APTS that are examined herein include:

- level of conformity with national (and soon to be devel oped Florida) ITS architecture;

- institutional arrangementsneeded for multi-modal and inter-modal connectivity;

- available funding sources,

- $\quad$ procu rement methods of APTSproducts and services;

- impacts on agency operation, maintenance staffs, and budgets,

- extent of public-private and public-public partnering;

- extent of general public invol vement;

- integration into regional transportation servicesand systems,

- application to rural areasand/or demand responsive service; and

- extent and sophistication of benefits analysis (prior to deployment) and performance monitoring (following deployment).

This chapter investigatesthes ten characteristics asthey relate to the experiencesthat transit agencies have had to date in their efforts to plan, implement, test, and/or operate any variety of APTS technologies. The primary source of information for this examination is a literature review of reports, on-line documentation, and other pertinent information available at the time of the data collection effort for this task (i.e., December 2000). The list of references utilized for this review is presented in Appendix $E$ In addition, the follow-up APTSinventory survey results that were presented in the first chapter are used, along with supplementary information drawn from the findings of the stakeholder meetings and the initial inventory survey, to examine the APTS experiences of the Forida transit agencies as they relate to these issues, aswell. 


\section{APTSDevelo pm ent/Deployment Characteristics}

As discussed in the introduction, thi s chapter will examine 10 parti cul ar issues/characteristics related to the development and/or deployment of APTStechnologies, and synopsize how they have impacted the APTS implementation efforts of transit agencies in Forida and throughout the U.S Again, the specific APTScharacteristic categories include:

- ITSArchitecture \& Conformity

- Institutional Arrangements

- Funding

- Procurement

- Operation \& Maintenance

- Partnering

- Public Involvement

- Regional Integration

- Rural Applications

- Benefits Analysis \& Performance Monitoring

The following sections discuss each of these characteristics and provide general overviews for each based on readily available li terature. Forida transit agency-specific opinions and/or experiences based on the results of the follow-up APTS inventory survey also are included as available. The goal is to provide a status report of APTS in Florida based on an analysis of each of the above issues/characteristics in the context of a broader ITS perspective.

\section{ITS Architecture \& Conformity}

The Intermodal Surface Transportation Effici ency Act (ISTEA) of 1991 identified a particular need for compatibility among the various transportation technologiesthat were being implemented throughout the U.S. Because of this need, a program began in September 1993 to develop a National ITS Archi tecture. Ultimately, a national standard for ITS was completed in lune 1996, with the specific intent of unifying a host of interrelated user services (e.g., public transportation management, emergency management, traveler services information, etc.) and promoting guidelines to ensure the "seamless" deployment and operation of ITSacross the country. 


\section{"The National ITS Architecture was developed to provide a unified framework and building blocks that agencies can use to create an integrated ITSstrategy that meets the needs of a particular state or region."}

-excer pted from Benefits of Integrated Technol ogies and the National ITSArchitecture, bhn A. Volpe National Transportation Systems Center, Policy and Technology Analysis Division, August 1998

In general , a system architecture is amodel that describeshow the particul ar components of the system will interact to achieve the system's goals. This model defines the operation of the system, the operation of each component in the system, and the information that is exchanged between the components. Thistype of "blueprint" is beneficial especi all y for larger, more complex systems li ke ITS. Fortunately for the individual agencies planning for or implementing any ITStechnologies, however, system architecture does not mean system design. While it may have an influence on design, the architecture leaves the specifics of system design (e.g., technologies, vendors, institutional arrangements, deployment approach, etc.) up to the individual agencies. Instead, it providesguidance and facilitates the devel opment of standards. The availability of such a framework hasalso been found to help minimize system costs by ensuring sensible deployment and streamlining design (e.g., minimizati on of equipment redundancy).

The expectation for the National ITS Architecture is that it will more easily enable ITS deployment throughout the U.S. that is characterized by efficiency, economies of scale, and national interoperability. The goal of "nati onal interoperability" basically seeks the establishment of a system that is compatible nationwide and links all modes of transportation. One of the primary tools the architecture will use to meet this and other goals is national standards and protocols development. While a number of standards/protocols have already been created, many others are still in different stages of development and are not yet complete. Some of the pri mary standards related to ITS-transit are as follows

- National Transportati on Communi cations for ITS Protocols (NTCIP);

- Transit Communicati ons Interface Protocols (TCIP);

- Dedicated Short Range Communications (DSRC) protocol; and

- Vehicle Area Networks (VAN).

As it specifically relates to transit and APTS, it is anticipated that these and other standards, as well as the rest of the architecture's framew ork, will all ow transit agencies to better plan and design their APTS projectsand deployment methodsto meet their immediate nœes, while still providing them with the flexibility to accommodate future system expansion and/or integration. In addition to the technical 
assistance that it provides, the architecture even documents a series of analytical tools (e.g., cost/benefit, risk assessment, communications) that can be utilized in planning for regional deployments. It should also be noted that the systems engineering approach that the architecture recommends for implementation includes an evaluation step that encourages post-deployment assessment of the application(s) to generate quantifiable information on costs, performance, and benefits, as well as to determine the degree to which project objectives were met.

\section{"The Transportation Equity Act for the $21{ }^{\text {st }}$ Century (TEA-21) contains a provision requiring Intell igent Transportation Systems (ITS) projects implemented with funds from the Highway Trust Fund (including the Mass Transit Account) to conform to the national architecture [National ITSArchitecture], applicable or provisional standards and protocols" \\ -excer pted from Interim Guidance on Conformity with the National ITSArchitecture and Standards U.S. Department of Transportation, October 2, 1998}

Unfortunately, the mere presence of a national architecture will not necessarily guarantee that ITS deployment throughout the U.S. will be seamless and interoperable. For this reason, the U.S. Department of Transportation (U.S. DOT) has tied "conformity" with the National ITSArchitecture to funding in an effort to ensure agency compliance. (It should be noted that, although "conformity" is specified in the TEA-21 language, the U.S. DOT believes that the term "consistency" better reflects its intent. Nevertheless, U.S. DOT uses the terms interchangeably for thispurpose) TheU.S DOT even developed an Interim Guidance document to " [promote] sound systems planning and design practices for ITSprojects" and "to ensure that ITSprojects meet the legislative intent."

But what does"conformity" actually mean for those agencies seeking to implement ITS technologies? According to the ITSDeployment Guidance for Transit Systems Technical Edition (which utilizes the synonymousterm, "alignment"), it means "using the National ITSArchitecture framework asguidance in designing and deploying systems." ${ }^{3}$ This particular definition and the discussion of conformity in

\footnotetext{
${ }^{2}$ Interim Guidance on Conformity with the National ITS Architecture and Standards, U.S. Department of Transp ortation, O ctober 2, 1998 , http://ww w.its.dot.go v./aconfo rm/iguid e.htm.

${ }^{3}$ Interestingly, a recent policy change has defined conformance with the National ITS Architecture as the "development of a regional ITS architecture within four years after the first ITS project advancing to final design, and the subsequent adherence of ITS projects to the regional ITS architecture." This new definition comes from the FTA National ITS Architecture Policy on Transit Projects that became effective on February 7, 2001 (Federal Register, 23 CFR Parts 655 and 940, Intelligent Transportation System Architecture and Standards, Final Rule, U.S. Department of Transportation, Federal Transit Administration, Vol. 66, No. 5, January 8, 2001). The basis for this policy, which requires that the regional architecture be based on the National ITS Architecture, is the belief that it is improbable to expect a single metropolitan area or State to fully implement all aspects of the National ITS Architecture.
} 
other architecture-related documentati on can be interpreted similarly: agencies shoul d sim ply review and understand the archi tecture's guidelines and processes, and use them as necessary to ensure that their projects comply with the ul timate goals of this effort. Again, it is not a step-by-step design that must befollowed preciæly-it isan open and flexible framework that providesdirection. For example, when an agency plans the implementation of a particular ITS subsystem or device, the concept of national architecture conformity would mean that the subsystem or device would:

- support some subset of the functions defined for that subsystem/device in the national architecture;

- support the data flows relevant to the included functions defined for that subsystem/device in the national architecture; and

- use open in terface system standards, asavail able, to ensure abi lity to communi cate with other subsystemsdevices, upgradeability, and future expandability.

\section{“The challenge of meeting Florida's transportation needsis a daunting one. ITSoffersa new set of tools for meeting these needs"}

-excer pted from Forida'sIntelligent Transportation System Strategic Plan, Final Report, Florida Department of Transportation, August 23, 1999

In Florida, the growing importance of applying technology to help meet the State's increasing transportation needs has spurred the FDOT to develop a Statewide ITSStrategic Plan. According to the plan, its purpose is "to guide the Department, Florida Metropol itan Planning Organizations, and local governments in the planning, programming, and implementation of integrated multi-modal ITS elements to maximize the safety and efficiency of Forida's Transportation System." In addition to recommendations involving the establishment of Department and District ITS Programs, staff and training requirements, and ITS procurement processes, among others, the plan also seeks the development of a statewide ITS architecture (to be based on the national architecture), along with supporting standards and specifications. It is expected that bringing this framework down to the state level will stimulate and facilitate the development of ITS programs, strategic plans, and archi tectures and standards at the regional and local levels, as well.

Al though most of the ten Florida transit agencies that responded to the follow-up APTSinventory survey have not been following the progress of the statewide architecture project (only two indicated doing so to any degree), the majority agre that it is very important for individual ITS-transit projects to fit into an established overall architecture. And, according to most of the respondents, it is preferablethat this architecture be statewide in scope. Further, there is some belief among the responding agencies that the Statewide ITS Strategic Plan will prove to be hel pful (four of the five agencies responding to this 
question indicated that it was a good idea and could help), especially asit relates to the deployment of APTS technologies.

Asfor alignment with the established architecture, it is apparent that the responding agenci es are open to the ideaof conformity and would find guidance for the deployment of APTSbeneficial. When asked to define the concept of conformity, several of the respondents provided the following thoughts:

- "user integration;"

- "integrated, intermo dal transit system;"

- " vari ous components can communicate with each other;"

- "standardization;" and

- "integration, coordination, needs(for efficiency)."

From these responses, it is evident that these agencies realize and support the importance of standardization and integration in APTS deployment. In fact, almost all of the responding agenci es believe that it is important for APTSto be merged into the regional ITSarchitecture. Unfortunately, the agencies did not offer many ideas for how thi s can be accomplished. One agency suggested "mak[ing] it a sandard; standardize systems" w wile another believes it woul d be best to do so "through [the] state DOT." Regardless of how APTS ultimately fits in with the regional or statewide architecture, the agencies were in agreement that it will be important for this architecture to conform to the national architecture.

\section{Institutional Arrangements}

The deployment and operation of ITStechnologies, especiall y at the regional or statewide level, of ten can involve a host of agencies, organi zati ons, autho rities, jurisdictions, and/or governmental enti ties. Typically, the greater the geographic coverage and/or complexity of the implementation, the greater the number of entities that must be involved and coordinated. For example, the deployment of a vehicle component monitoring system on board the vehicle fleet of a local transit agency may only require the involvement of the agency itself, or perhaps that of a few departments of the municipality in which it operates (depending on the transit agency's organizational structure and requirementsfor funding, board approval, procurement, etc.). However, a signal priority system to optimize traffic flows and provide priority for transit and emergency vehicles will expand the number of entities that must be involved (e.g., local government, State DOT, traffic operations, police, emergency services, transit agency, local news media, etc.). Involvement and coordination can become even more complex as 
the deployment crosses multiple jurisdictions (e.g., a statewide or regional commercial vehicle operations system or a corridor incident management system).

\section{"The responsibility for managing traffic in most metropolitan areas hasevolved over time in response to public needs, resources and prevailing institutional and political arrangements Withineach political jurisdiction these managerial responsibil iti esare often dispersed among separate public agencies If cooperation is lacking, thisfragmentation will inhibit chances for the successul implementation of certain elements of the national ITS program."}

-excerpted from ITS Strategic Deployment Plan, Final Report, prepared by HNTB, TRW, and TEC, for the Ohio Department of Transportation - District 12, April 1996

According to much of the ITS literature, institutional coordination has become one of the more important, and chall enging, issuesin the implementation of ITSprojects. Without cooperation between agencies involved in the deployment of a particular ITS application (often referred to as the "stakeholders"), the implementation, operation, and management of the technology will be difficult, and it may not havea chanœ to reach its full potential. But what makescoordination and cooperation so difficult? The literature raises a host of reasons, ranging from jurisdictional issues to the lack of ITSspecific technical expertise among transportation professionals. Some of the more widelyacknowledged, and experienced, impediments to coordination are introduced and bri efl y discussed below. Given the number and variety of issues that can arise, it shoul d be noted that those presented herein have been grouped into a few broad categories for simplicity's sake.

Interagency Issues - One of the largest categories of coordination impediments involves the various issues that can arise among agenci es participating in the implementation of a specific ITS technology. For the most part, agencies that typically would be involved in an ITS deployment have had relative autonomy in their respective decision-making processes. However, the centralized nature of many ITSapplications (e.g., advanced traveler information system, advanced traffic management system, commercial vehi cl e operati ons, etc.) necessitates a level of cooperation and coordination that many of these agencies may find difficult to fully accommodate because of their inherent differences.

It may be the case that the agencies have different agendas, with operational philosophiesand priorities that differ or, worse, conflict. The respective fu nctional and/or organizati onal cul tures of the agencies also can have a significant effect on coordination efforts For example, the agencies may operate, or be responsible for, different modes; they may also have independent/diverse reven ue sources, oversight boards, political accountabili ty, and, perhaps, even legislative restrictions. This is especially the cas when a deployment requires the 
involvement of both public and private entities (æe subsequent section on Public-Private Issues).

Further com pounding the pro bl em are lack of proper inter-agency communication and poorlydefined agency roles. The distinct functions and agendas of the agencies can become even more divergent if each of the agencies involved does not know or understand itsoverall role and responsibilities in the deployment effort. Therefore, it is important to institute clearlydefined roles for each of the participating agencies at the outset. Properly identified and established lines of communication are also essential in ensuring a clear understanding of agency roles, the dissmination of correct and consistent information to all partners, and, ultimately, the successful completion of the deployment.

urisdictional Issues - Asnoted previousy, the number of coordination impediments can often multiply as the deployment crosses jurisdictional boundaries. The interagency issues remain the same, but they are magnified due to the increased number of stakeholders that must be involved and coordinated. And, as the number of participants in a deployment increases, so does the likelihood of organizational, functional, and/or operational differencesamong them. It is certain that cross-jurisdictional deployment will also require significantly higher levels of intergovernmental cooperation, as well.

Consider the example of an Advanced Traveler Information System (ATIS). One particular interagency issue revolves around the ownership and control of data - both the data required for the operation of the ITS technology and the information that results from it. If LYNX and the City of Orlando decided to implement ATISwithin its immediate metropolitan area, this data-intensive application would certainly raise data control/ownership issues among the participating agencies (most likely to include LYNX, local govemment, traffic operations, police, emergency services, local toll authority, media, etc.). Now, consider how the data issue would escalate if a similar system were implemented along the $1-4$ Corridor between Orlando and Tampa. The participating agencies would increase in number and be even more decentralized in terms of responsibilities, jurisdiction, etc. Unfortunately, the success of the ATIS application, which is predicated on the centralization of its operation, could be jeopardized if a logical plan for how to handle the data function is not established, agreed upon, and followed by all stakeholders. 
"In tail oring the framework provided in the National I TSArchitecture to local needs, agencies must work together to decide what information is needed, how it will be collected and maintained, and when different agencies have access to or control over information."

-excerpted from Transportation Planning and ITS Putting the Pieces Together, prep ared by Sarah $\downarrow$ S Siwek \& Associates for the Federal Highway Administration, U.S. Department of Transportation, April 1998

Public-Private Issues - Coordination issues that can occur when public and private entities are involved jointly in the implementation of an ITS application are interagency, in nature. How ever, they can be somewhat more problematic because of the significant differencesin the cul tures and prioriti esof the public and private sectors. Generall y, pri vate agencies are market driven; profit is an important motivating factor. Conversely, the public sector is driven by the various rules and regulationsthat have been established at the local, State, and Federal levels.

This basic difference is evident in one of the primary issues that emerges when public and private enti ti es engage in ITSdeployments: the commercialization of the technology's products and services. For example, consider the sale of traffic data. According to the literature, in many cases, public sector restrictions limitor prohibit the sale of traffic information. However, private agencies involved in ITS projects that would utilize and/or produce this type of information would surely seek to capitalize on its availability. This would be a motivating factor for their involvement since it would be possible to profit from their initial investment in the venture. Without this opportunity, many private agencies may not want to commit to participating in ITS deployments because of their lack of confidence in the deployments ultimate profitability.

Another issue that must be consid ered when coordinating public-privaterel ationship sinvol ves the development of proprietary technology and the intellectual property rightsassociated with it. Similar to the case for the sale of traffic data, proprietary technology can be a significant motivating factor for private agency participation, especially since research and development costs can be offset through the sale of the ITS technology or service. This issue needs to be addressed at the outset of any agreements, though, because of the Bayh-Dole Act, which assigns the rights of inventions from federally-funded projects to the Federal Government. In addition, arelated public-privaterelation ship issuethat should beconsidered involvesanti-trust legislation. Specifically, a government agency must be cautious in establishing a relationship with a private company to ensure that an inequitable arrangement isnot made that could harm the private entity's competitors or taxpayers. Fortunately, the National Cooperative Research and Production Act of 1993 was enacted to provide a measure of protection to agencies 
collaborating for the purpose of research. Finally, it is generally believed that the time lag that can occur from an initial ITS project concept to its full deployment is an issue that also can impact $\infty$ ntinuity in private sector participation.

Technical Capability Issues - One interesting concern in coordinating the implementation of ITS technologies is the increased level of technical skills that often is requi red to be involved in such deployments. With advanced technologies comes the need for a greater "technical understanding of information, communications, and computer technologies, as well as the design and installation of new ITS technologies and applications and their integration within existing 'legacy' systems" 4 Unfortunately, previousdeployments have shown that the current engineering knowledge of many of today'stransportation professionals is not enough. In ord er to ensure the success offuture ITSdeployments, professional capacity in ITSrelated topicsmust be increased. Professionals at both public and privateagencies that will be involved with such deployments will need to build their expertise in communications, electronics, systems integration, and automation technologies, aswell as improve their basic computer skills. In addition, it will be extremely important that they keep their skills and knowledge up-to-date given the expected continual evolution of ITS technologies and innovations.

While there appears to be many impedimentsto the successful coordination of participating agenci es involved in the implementation of an ITStechnology, it must be remembered that a large number of deploymentsof varying scale have already taken place throughout the U.S. Many have been successful both becaus of an awareness of the potential pitfalls and a dedication to overcome them through careful planning and stakeholder cooperation. Among the ITS literature, there are a number of documents that have reviewed previous deployments or interviewed principal stakeholders to determine the keys to their coordination successes, aswell asthe reasons behind their setbacks. In fact, one document, Saving Lives, Timeand Money Using Intelligent Transportation Systems: Opportunities and Actions for Deployment, provides suggested actions for many different sakeholders (e.g., state governments, MPOs, transit agencies, academia, etc. ) that may be involved in an ITSimplementation. Several of the more widely-documented recommendations are bulleted below.

- Establish a general vision or plan for ITS and transportation that encourages a regional outlook.

${ }^{4}$ Building Professional Capacity in ITS: Documentation and A nalysis of Training and Education Needs in Support of ITS Deployment, U.S. De partme nt of Tran sportation, ITS Joint Program Office, IT S PCB Program, April 1999. 
- Identify and enlist a wide range of stakeholders, including those that may be somewhat nontraditional (e.g., emergency response teams, academic institutions, major employers, etc.), and ensure thei $\mathrm{r}$ involvement in the ITS planning process and their agreement on and support for the ITSvision/plan that is ultimately adopted.

- Promote activiti es that necessitate varying levels of interagency coordination for other purposes, such asconducting regi onal planni ng studies or sponsoring train ing programs that can be attended by state and local transportation officials, as well as other stakeholder representatives.

- Enco urage the emergence of a "champion" organization or convene a "cross-cutting" task force to serveasa facil itator forbringing stakeholderstogether and coordinating them. Interestingly, several documents suggest MPOs as the ideal forum for coordinating regional ITS activities. With a transportation planning process structure in place that already incorporates $3 \mathrm{C}$ (cooperative, com prehensive, and coordinated)planning, outreach, and public participation, theMPO “is being viewed asan effective mechanism to facili tate and coordinate ITS planning, across modes, across political and functional boundaries, and between public- and private-sector organizations."

- Develop an ITSoperating concept thatclearly delineatesthe stakeholders' rolesand responsibi lities during the development, implementation, and operation of the system, as well as the interagency communication structure that will be utilized throughout the process. The operating concept should also include an implementation plan that both supports and allows sufficient time for interagency involvement.

"There are many stakeholders that will play a part in the deployment, operations and management of ITS in Horida. Stakeholders include both public and private sector participants The successful participation of these stakeholders in Florida's ITS program requires two things: organization and outreach."

-excerpted from Horida's Intelligent Transportation System Srategic Pan, Final Report, Florida Department of Transportation, August 23, 1999

As ITS technologies continue to be implemented throughout Forida, it is expected that many of the same institutional coordination impediments that are being experienced elsewhere in the U.S. will be encountered here, as well. Fortunately, the FDOT is aware of many of the issuesand hasincluded a

\footnotetext{
${ }^{5}$ Nontechnical Constraints and Barriers to the Implementation of In telligent Transportation Systems, Update of the 1994 Report to Cong ress, U.S. Department of Transportation, Federal Highway Administration, Joint Program Office for Intelligent Transportation Systems, Washington, D.C., 1997.
} 
number of action items in Florida's ITS Strategic Pan to help ensure that they are appropriately addressed. For example, the Plan calls for the development of a model and process for stakeholder involvement at the statewide, regional, and individual project levels. The intent of this action is to ensure efficientworking relationships among stakeholders and maximize their ability to provide input. Other related actions include the formation of a statewide ITS stakehol der advisory committee, the development of a private sector outreach initiative, the implementation of a satewide ITS training program, and support for coordination with public transportation ITS acti vities.

In the follow-up APTSinventory survey, while a secti on was not incl uded that specifically add ressed the topic of institutional arrangements, there were several survey questions that touched upon issues related to this topic, including coordination and stakeholder roles, and a few others that engendered responsesthat also discussed similar issues. For example, one of the survey's general questions asked the respondents about the factors that have impeded the deployment of APTS. Among the transit agencies' responses were several issues that have been discussed previously as being widelyexperienced impediments to coordination and deployment: communication issues, lack of knowledge/expertise on the part of the implementing agencies, and lack of sufficient time to properly plan and coordinate the deployment.

In discussing the roles of the various "players" in the development and deployment of APTS a few of the responding transit agencies indicated that education is an important need. A number of the respondents also stressed the importance of the involvement of FDOT's Central Office, as well asits District offices, during the development and deployment process. One of the respondents indicated that local governmental so need sto be moresupportive of and involved in APTSactivities. In addition, it wasmentioned that MPO involvement could help, aswell, especially with the education processand data collection and retention.

Interestingly, these ideas coincide quite well with a few of the issues that were discussed previously in this section. In fact, in responding to a question on the activities that are necessary to ensure and maintain the success of APTS, the following were provided by the participating transit agencies: education, planning, communication, awareness, partnering, and sharing successes. These are all recommended keys to the successful planning, implementation, and operation of ITStechnologies, as identified in much of the literature. Therefore, it would ap pear that many of the Foridatransit agencies are aware of the issues that they may encounter as they attempt to implement new technologiesand coordinate stakeholdersduring the process. Fortunately, they also will have the Forida ITS Strategic Plan to assist them in their efforts. The Plan should have an additional benefit, as well: seven of the 
ten responding transit agencies indicated that they believe the Plan will encourage more coordination for ITSprojects.

\section{Funding}

The federal legislature recognized the importance of ITS and the role that it could play in the advancement of transportation efficiency when it introduced ISTEA legislation in 1991. Through ISTEA, state and local jurisdictions were specifically encouraged to use federal funds to support the research, planning, and operational testing phases of ITS deployment. Through TEA-21, possible-funded activiti es were expanded to include the support of capital aswell asoperations and maintenance costs of ITStransit projects. As a result, more ITS projects have become eligible through federal funding mechanisms

Inevitably, successful ITS deployment is directly related to many functions, including the ability to identify, secure, and utilize funds. Unfortunately, the advancement of ITS is often constrained by the complicated organization of the funding optionsavailabletolocal jurisdictionsand will greatly depend upon the ability of the federal govemment and state jurisdictions to clarify the fun ding al ternatives so that more local agencies are encouraged to solicit funds for innovative ITS technology.

The vari ous federal fun ding programs that may be used for ITS arenumerous. However, some sources may be restricted for operational testing or other phases of deployment. Federal flexible funding sources such as National Highway System (NHS) funds, Surface Transportation Program (STP) funds, Congestion Miti gation and Air Quality (CMAQ) funds, and Interstate Maintenance (IM) funds all have been made available for projects, including ITS research, development, operational testing, and operation and maintenance. The Federal Highway Administration (FHWA) is authorized to allocate ITS Integration funding, which is a dedicated source that providesassistance solely for the integration of ITScomponents

For NHS funds, infrastructure-based ITScapital improvements are eligible activities. STP funds may al so be used for projects involving infrastructure-based ITS capital improvements, as well as for other capital costsfor transit projects, highway and transit research and development, and technology transfer programs. CMAQ funds may be used for transit (new system/service and expansions or operati ons). Transportation activity in an approved State Implementation Plan and tho se projects involving publi c/private partnershi ps and initiatives also may quali fy for CMAQ funds. ITS integration funds can be used to accelerate ITS integration and interoperability in metropolitan and rura areas. In metropolitan areas, funding is primarily used for integration of previously deployed or soon-to-be 
deployed ITScomponents In rural areas, funding may also be used for installation costs. ${ }^{6}$ A primary step for any transit agency seeking federal funds for ITSprojectsmust be to determine project eligibil ity under the various federal funding programs and to seek additional funding sources to assist with the probable shortfall. While the number of funding programs for which ITSprojectsmay be eligible has grown, the funding levels remain extremely limited and acquisition of these fundsrequire that state and local jurisdictions identify alternative funding sources, such as public/private partnerships.

“. . . the state DOTs and MPOs must choose between ITSICVO [commercial vehicle operations] and competing demandsfor the obligation of these [federal aid highway] funds. Key planning and budget staff in these agencies often have limited fami liarity with ITSICVO. In addition, because the mandate and organization of ITSICVO programsare still developing in many states, ITSICVO often takes a back sat to more traditional big-ticket items such as highway and bridge construction and maintenance. . . ."

-excerpted from ITS/CVO Funding Strategies for States, Federal Highway Admini stration, March 1998

In addition to siftingthrough federal fundingalternatives, transit agenciesmust often deal with "difficult tradeoffs and choices between investing in infrastructure improvements, ITS initiatives, and/or a combination of both." ${ }^{7}$ Many states and local jurisdictions, when faced with choosing between innovative, but unfamili ar, ITSinitiativesand typical system improvements more often than not pursue funding for the usual infrastructure because they are not familiar enough with the benefits of ITS to champion deployment initiatives to the public and the people most responsible for placing a priority on such projects. While, theseagenciesmay suspect that specific technologieswould provide benefit, they are not able to translate that benefit into definable measuresof safety, efficiency, and cost savings. In addition, the relatively new presence of ITS projects compared to the inundated backlog of traditional infrastructure improvements provides further incentive for the prioritization of the typical projectsover the ITS ini tiatives. Conæquently, the low ranking of ITSdeployment projectsby state and local jurisdictions make federal funds acquisition more difficult to achieve. Until the disæmination of benefits data between the usersand potential users of ITSis consistent and the barrier of unfamiliarity is overcome, transit agencieswill continue to be poorly-equipped to successfully advocate for fun ding.

\footnotetext{
${ }^{6}$ Fact Sheet on FY'01 ITS Deployment Program, attachment to press release, U.S. Transportation Secretary Slater announces $\$ 93.9$ million in grants for Intelligent Transportation Systems, Federal Highway Adm inistration, N ovem ber 2, 2000 , http://ww w.fhw a.dot.go v/pressro om/itsfact.htm.

7 Florida's Intelligent Transportation System Strate gic Plan, Final Report, Florida Department of Transportation, August 23, 1999.
} 
Thro ugh organized attempts to establish national, regional, and state ITSarchitecture, ITSdeployment slowly is becoming better recognized asa viable and effective tool for advancing efficiency in transit. Itsacknowledgment among state and local transportation agencies hasgrown and ITSdeployment has benefitted from such advocacy.

\section{"Statewide and district deployment will not only require an increase in funding for equipment and infrastructure, but also for training and operationsand maintenance "}

-excerpted from Forida'sIntelligent Transportation System Strategic Plan, Final Report, Florida Department of Transportation, August 23, 1999

In response to the financing constraintsto ITSdeployment, theFDOT and the State of Florida has taken on a more proactive role by initiating activities that would identify it as a contender for funding of ITS projects. The development of the Florida ITS Strategic Plan is one sep toward solidifying the FDOT's role in the successful deployment of ITS technologi es acrossthe state. The Strategic Plan addresses the need for increased funding for ITStraining, operations, and maintenance, and establi shesthe objective of developing FDOT District ITSresources to encourage more local participation.

A further indication that FDOT is cognizant of the funding constraints for ITStechnology isthe candid conversationsduring the stakeholders' interviews. In particular, the FDO T stakehol ders acknowledged the funding problems and their concerns sem to compliment the findings of the follow-up APTS inventory survey. According to the results of the survey, most of the respondentsidentified costs or funding as an impediment to APTSdeployment. The follow-up survey results also indicate that all of the responding Florida transit agencies beli eve that providing funds for APTSin public transportation projects is "very" important, and that it is "somewhat" to "very" important to seek funding for APTS.

It wasmore difficult, however, for the respond ents to identify the percentage of the budget that should be allocated to APTS. One transit system indicated that one percent of the agency's budget and five percent of the state's budget should be allocated for th is purpose, while another system indicated that two percent of each respective budget would be appropriate. Two other systems suggested budget percentages that ranged from 10 to 15 percent. Unfortunately, a number of the respondentscould not identify what percentage of the budget should be allocated to APTS. It may be thecase that this results from the unfamiliarity of many transit agency personnel with the costsand benefits associated with the deployment of such initiatives - an unfamiliarity, consequently, that can impede APTSdeployment.

Asfor funding sources that have been used by Horida transit agencies thus far, the survey resul ts seem to suggest that the responding agenciesrely very little on private or innovative funding techniquesfor APTSdeployment. O nl y one responding agency indicated using pri vate funds, while another indicated 
the use of Horida Toll Revenue credit. Most acknowledged, however, that a mix of federal, state, and/or local funds were used for their respective projects.

Overall, the opinions of the responding Florida transit agencies and the stakeholder participantswere quite similar. There seems to be a general recognition of the need to actively seek funding for APTS and of how doing so might significantly improve transit efficiency. However, the actual source of that funding and how APTS deployment will fare against traditional needs in current and future budgets is less agreed upon.

\section{Procurement}

The procurement of ITStechnologies can be complicated and is worthy of extensive consideration in the overal process of deployment. ITS proposals are rarely best served by traditional procurement practices. Instead, the technological complexity and the need to adapt to the constantly evolving applications require that the procurement mechanisms be flexible to minimize institutional barriersto ITSdeployment.

\section{"The traditional procurement process for construction of a facility involvesthe letting of and completion of two separate contracts; one [for the preparation of] detailed design specifications, and . . . another for construction of the facility. . . . This traditional approach util iz ing a bifurcated processoften lackstheflexibility required when contracting for rapidly evolving technologies and systems such as ITS"}

-excerpted from Executive Summary of Innovative Contracting Practices for ITS, prepared by L.S GallegosandAssociates, Inc., for the Federal Highway Administration, April 1997

Traditional procurement practices were ori ginally devel oped to support the design and construction of infrastructure or to facili tate the purchase of equipment, such as vehicles. However, these practices present disadvantages in ITS acquisition by not allowing enough consideration for technology, discouraging those who operate and maintain theITStechnology from participating in the procurement process, and not facilitating multi-agency or private/public partnership or collaboration. ${ }^{8}$

There is a recognized need for procurement to be standard in most situations, especially when "standard" is thought to be synonymous with "fair" or "equitable." This is why the sealed low-bid

${ }^{8}$ ITS Deployment Guidance for Transit Systems, Technical Edition, U.S. Department of Transportation, Federal Highway Administration, April 1997. 
process is most often used for traditional transportation infrastructure projects. The low-bid process, however, requires that well-defined functional and/or performance-based specifications be established at the outset of the project with little, if any, room to account for adjustment. ITS products and services general ly utilize technologiesthat produce data that are independently useful, but are infinitely more useful when multiple appl icati ons are integrated. Con sequently, tho se transit agencies with little or no operational/management experience with the specific ITSapplication proposed to be deployed may find it diffi cult to establish defined specifications to all ow for future complex integration of systemsand will risk losing innovative insight and solutions that are dismissed in the low-bid process.

\section{"Thisperception [that I TSprojects must alwaysuse the same procurement approach required for construction projects hasresulted in numerousprocurement disasterswhere the 'normal' lowtbid procurement process has been inappropriately used for ITS projects. We must be more proactive in dispelling thisperception . . .."}

- excerpted from a memorandum by Anthony R Kane, Executive Director, ITS Jint Program Office, Federal Highway Administration, October 6, 1999, http://www.its.dot.gov/procure/ memo-ahtm

Most federal authorities now acknowledge that flexible procurement proceduresare required due to the complexity and quick evolution of ITS technologies and they are encouraging state and local jurisdictions to use competitive negotiation methods after conducting qualifications-based selection procedures. In addition, some jurisdictions have begun to experiment with innovative procurement methods In 1990, the FHWA established Special Experimental Project No. 14 - Innovative Contracting Practices (SE-14), which enabled transportation agencies to implement contracting practices that maintain the advantages of competition while enhancing project qual ity and timeliness to the procurement process. ${ }^{9}$

Another disadvantage that typical procurement proced ures pose for ITS projects is the requirement to maintain autonomy in the process. Most states prefer that agencies keep the procurement function independent of those who will operate and maintain the system. ITSDeployment Guidance for Transit Systems suggests that this practice exists to ensure that public funds are "properly expended and efficiently managed." However, the complexity of many ITStechnologies and the necessity of the systems to be integrated or interoperable demand that technical advice and its responsible consideration be included in the deci sion-making process. When such advice is ignored, for instance

${ }^{9}$ FHWA Federal-Aid ITS Procurement Regulations and Contracting Options, Booz Allen \& Hamilton, U.S. Department of Transportation, Federal Highway Administration, Turner-Fairbank Highway Research C enter, October 1997. 
to save money, the agency risks employing technology that is quickly approaching obsolescence or fails to integrate with existing systems, thus, preduding optimal efficiency.

In response, some transit agencies are making adjustmentsto procedures by adopting a team approach that includes, in addition to the purchasing personnel that typically may be involved in procurement, technical personnel that will be involved in the deployment of the ITSapplications. Technical advisors are able to comment on technological needswhil e purchasing advisors outline budget, financial, and procedural restrictions that impact the type of technology or service to be procured. In caseswhere personnel lack the experience in ITS to provide useful assistance to the procurement process, establishing procedures to allow review by neighboring agencies with more experience may be a viable option. Ether situation provides an opportunity to balance procedural and technological interests in the process.

Also, many successful ITSdeployments have involved interagency or multi-jurisdictional cooperation. In areas where multiple transit agencies operate, the potential for regional compatibility and interoperability of ITStechnology isgreat. However, institutional barriers associated with interagency cooperation often discourage the consideration of embarking on truly integrated ITS deployment. In ITSDeployment Guidance for Transit SystemsTechnical Edition, it issuggested that the lack of defined roles and responsibilities, difficulty in reconciling policies and procedures, and incompatible procurement regul ations most often discourage intergovernmental agreements To circumvent these problems, the authors recommend that "agencies adopt broad grants of power to perform acti vities necessary and incidental to the accomplishment of an agency's mission." They also recommend that the parties enter into intergovernmental agreements in state agency enabling legislation.

"The Florida experience, particularly in the areas of initial procurement, operations, and maintenance, clearly reveals a need for statewide procurement policies and standards for systems architecture and equipment, which FDOT is in a unique position to provide. “

-excerpted from Horida's Intelligent Transportation System Srategic Plan, Integration of ITS into the MPO Transportation Planning Process Issue Paper, prepared by TEI Engineersand Pannersfor the Forida Department of Transportation, February 1999

Like most states, Forida most often utilizesthe low-bid (Engineer/Contractor) procurement process for traditional transportation infrastructure projects. Through the ITS Srategic Plan, FDOT reiterated the advantages and disadvantages of the traditional procurement process. In addition, FDOT acknowledged in the plan that there are many local agencies who have yet to experience initial ITS deployment and that there exists a need for further guidance from the State on selecting the most appropriate and effective pro curement pro cess. In the meanti me, the M PO planning processhas been 
identified asan effective forum for state and local governments, public officials, private stakeholders, and interested citizensto discuss ITSprocurement policiesand experiences and, further, to arrange for better interagency cooperation.

In the Procurement Issue Paper for the Strategic Plan, organizational and procedural restrictions to public/private partnerships were identified as a limi tation of procurement processes in Forida. The paper noted that several states have passed legislation to allow public agencies to "accept partnership proposals from the private sector, with limited or no competition, provided thereisclear public ben efit from the arrangement." In the paper it was suggested that Forida would benefit from such opportunities.

The follow-up APTS inventory survey afforded the transit agencies the opportunity to identify the procurement methods that were used for the APTS applications they currently have in place or are implementing. Whileonly a few identified a particul ar procu rement method, the bid system appeared to be used most often. Advanced Communication Systems, for most of the respondents, were purchased through a countywide or multi ple-agency contract. Lack of local experti se was identified as an impediment to APTS advancement and this issue probably impacted the earlier phases of the projects, such as specification development and procurement. The transit agenciesseem content with using those practices with which they have the most experience and are most comfortable. Perhaps as more innovative procurement procedures are practiced in Forida and as the sate considers developing new procurement vehicles, as was suggested in the Procurement Issue Paper, more agencies will associate with procurement practices that are better suited for ITS technology.

\section{Operation \& Maintenance}

The operation and maintenance tasks associated wi th successful ITSdeployment are detailed and can be costly. If, prior to purchasing a particular APTS application, a transt agency has not thoroughly planned the appli cation' sintegration into the system' s overall current and projected planni ng schemes, the system will surely face unexpected delays, costs, and other setbacks. To ensure proper operation, management, and maintenance of ITS applications, the implementing agency will be best served if, first, an operations and mantenance plan is developed. Obviously, an agency must develop its operations and maintenance plan with its particular goalsand limitationsin mind; thus, every plan will differ. However, all plans should address, at a minimum, staff requirements and responsibilities, thorough training and support, and scheduling and procedural requirements for response and preventative maintenance. Each plan should also address financing issues, such as costs associated 
with operations and maintenance and funding opportunities that are eligible to be used for these activities.

A major aspect of an operations and maintenance plan should be to address staff requirements and responsibilities. This task obviously is determined by the various applications utilized by the agency developing the plan. In general, APTSrel ated l iterature suggests that automated vehi cle location (AVL), advanced communication systems, and computer-ai ded di spatch (CAD) are the most utilized APTS technologies by transit systems. The nature of these particular applications reduces the manual responsibilities of agency staff and provides efficient and reliable methods of data collection and storage. The operational staff needed for most APTS applications is the existing dispatch and data collection employees, when provided with additional training. According to a sudy by the Federal Transit Administration, not only did necessary fleet size decrease after implementing CAD, but the number of dispatch staff required dropped by 50 percent for most of the reviewed agencies, and dispach staff were completely eliminated by one taxi company. ${ }^{10}$

Unless an agency has had a great deal of experience with simil ar applications, most do not employ the staff readily capable of installing the APTStechnologies. Instead, the installation of APTSapplications is often done by the vendor or is included in the specifications for new vehicles, when possible. Staffing requirements for maintenance proceduresis more complicated, however. The agencieshave several staffing options for maintenance, which include vendor provided or supplied, contract maintenance with a third-party, or in-hous maintenance provisions. These options generally apply to software APTSapplications. However, when transit applications depend on shared infrastructure another option might be maintenance agreements with the partnering affiliates

It is anticipated that, asAPTSis implemented and improved operating efficiency is demonstrated, there will be a reduction in the number of operators needed to provide the samenumber of passenger trips. In addition, as fewer vehicle miles per trip are generated, maintenance requi rements may occur less frequently, thus, reducing the maintenance staff requirements. When theoperations and maintenance plan is developed, it should identify current staffing requirements and project those requirementsfor several periods, including within a few months of integration, at prescribed intervals of adjustments (such asthree, six, and twelve months), and foll owing apreestablished evaluation period. Throughout, an agency may have to modify its projected staff requirements asit finds the APTSapplications meet, exced, or fall short of their expectations.

\footnotetext{
${ }^{10}$ Personalized Public Transit, ITS De cision repo rt, http://ww w.path.b erkeley.e du/ leap/PTO/P ersonal Pub Transit/index.html, last update: November 7, 2000.
} 
Also included in an agency's operations and maintenance plan should be specific strategiesfor training the staff in implementing and maintaining the APTS applications. It is not uncommon for transit agencies to purchase APTS software only to have it sit unused because the staff is not trained or is reluctant to utilize it. If ITS is to continue its momentum in public transportation, the educational and training needs and requirements must be addressed. On the local level, an agency can begin by prescribing a training program and support system for its staff so that they can become experienced enough with the applications to recognize when they can and/or should be integrated with other technologies so that the greatest benefits are extracted.

According to Building Professional Capacity in ITS Documentation and Analysis of Training and Education Needs in Support of ITSDeployment, the key questions of a plan might be (1) who needs to know about ITS?, (2) what fundamental know ledge or skil Is are essenti al to operate and main tain ITS activities?, and (3) how are the skill s best learned?'1 An agency's operati ons and maintenance plan should address each of these key questions. First, addressing who needs to know about ITS will involve determining the staff required to effectively operate the technologies, as previously discussed. The roles and functions of each of those staff persons should then be identified so that the "what," or competencies, needed to perform the job effectively can be identified. Finally, once it isknown who will be needed and what they will need to know, the agency must determine the best way to attract workers with those particular skills and build and maintain those skills in existing staff.

Building Professional Capacities in ITS included the results of surveys conducted with various transportation entities, including transt agencies. The purpose of the surveyswas to determine how the agencieswere involved with ITS what types of staff were need ed to perform ITS tasks, what they needed to know, and how staff are trained for those roles. Typi cal ITS projects identified in the survey by transit agencies were deploying and operating transit AVL systems and automated trip planning systems, aswell as operating transit data management systems. The survey results also suggested that transit agenciesbelieve that theideal team would include project managers, operators, dispatchers, and maintenance techni cians and supervisors skilled in some form of ITS technology. While some roles may require specialized levels of knowledge, for others it may be necessary only to have a basic "awareness of the general framework." The results also identified training and education needs for ITS personnel. Those most relevant to transit includesystemsintegration, technology options, dataanalysis and management, software and hardw are operations, and systems support and main tenance. The best methodsfor delivering these skills in these areas to the appropriate staff can be achi eved in several

${ }^{11}$ Building Professional Capacity in ITS: Documentation and Analysis of Training and Education Needs in Support of ITS Deployment, U.S. Department of Transportation, ITS Joint Program Office: Washington DC, April 1999. 
ways, including traditional classroom training, job rotation or exchange programs, certificate programs for continuing education, peer-to-peer networks, and vendor-sponsored programs In an agency's operations and maintenance plan, a matrix might be developed identifying the who, what, and how of ITSeducation, training, and support.

Another major function of an agency's operations and maintenance plan should be to address proced ures for response and preventative maintenance. Effici ent maintenance procedureswill allow a transit agency to effectively react to emergency failures, maintain accurate records, and conduct preventative maintenance so that the life-cycle of the applications are extended. The document, Florida ITSStrategic Plan: Operations, Management, and Maintenance Issue Paper, suggeststhatalifecycle cost analysis be conducted "to compare using higher priced components in order to reduce regul ar maintenance costs." ${ }^{12}$ This would be an excellent task to accomplish for consideration prior to the development of an operations and maintenance plan.

In general, the plan should address what procedures will be required to maintain the ITStechnologies employed by the agency. It must also identify the maintenance-related roles of the staff. Maintenance for transit-related ITS components differs from the maintenance requirements of traffic and freeway management systems. Depending on the size of the transit agency, failure with just a small fraction of its assets could disupt service throughout the entire system. The maintenance requirements for traffic and freeway management systems are better documented and much more readily available among peers, while experience with required maintenance cycles for transit-lTS has not been welldocumented. There are, however, some smi larities in maintenance requirementsthat will allow transit agencies to make safe assumptions about their requirements. For instance, traffic signal preemption technologi esare integrated with the traffic systemsoperations and maintenance and transit systemsmay be able to adopt maintenance requirementssimil ar to, or in cooperation with, the traffic management systems.

'In areas of rapid technology change that are subject to significant pricing variations, like communications and computer systems, special attention should be directed to updating the strategy."

-excerpted from Florida ITS Strategic Plan: Operations, Management, and Mai ntenance Issue Paper, Florida Department of Transportation, June 6, 1999.

\footnotetext{
${ }^{12}$ Florida ITS Strategic Plan: Operations, Management, and Maintenance Issue Paper, Florida Department of Transportation, June 6,1999.
} 
In its operations and maintenance plan, a transit agency should estimate costs associated with response and preventative maintenance, staffing requirements, and training and support requirements. Again, these costs are highly dependent upon the types of APTS technologies deployed and whether these activities are performed in-house, by contract, through partnerships, or by other means. The plan should also address estimated costs for replacement, not only for inoperable components but also to account for technology advancement and the replacement of obsolete components.

Transit agencies must also explore, as it estimates costs and builds a need for increased funding, all possible funding sources. No one source is capable of completely meeting the funding needs of ITS operations and main tenance. In fact, after taking full advantage of federal sources such as STP, NHS, $\mathrm{IM}$, and CMAQ funds, an agency will still need to rely on local sources, partnerships, and revenue opportunities for supplementary funding.

FDOT has established, through the ITS Strategic Plan, several goals which address its role in the operations and maintenance of ITS in Florida. They are:

- The Department should develop an ITS Operations Manual. Each district will adapt the policies and procedures to their requirements.

- Each districtshould develop ITSstaffrequirementsand atraining program that will enablethem to meet the ITS servicesthey plan to deliver over the next five years

- Each district should assess staff resources to determine which, if any, operations and maintenance functions are appropriate for ou tsourcing.

If these goals are achieved, the resulting statewide or district-wi de benefits (statewi de manual, districtwide training program, and available outsourcing support) will assist state transit entities immensely. It will provide another resource to which transit agenciescan refer in an area that is sill unfamiliar to most. The lack of available resources on education, training, and "real-li fe" experiences is a concern to transit agencies in Florida. The respondents to the follow -up APTSinventory survey suggested that the education and support from FDOT districts is key. The respondents seem to agree that transit agencies are looking for alead from the FDOT Central and District Officeswith regard to training and organizing the dissmination of information among APTSparticipants

\section{Partnering}

A successful ITS program often requires cooperation between the public and private sectors. Hence, asthe implementation of ITStechnologieshasbecome more widespread, a variety of partnerships have 
been formed between publ ic-sector and private-sector entities, aswell asintergovernmentally. Thefastrack development, deployment, and operation of an ITSprogram usually relies on and can benefit from combining the strengths of each sector. While intergovernmental cooperation will help to alleviate standardization issues, public-privatepartnerships typically allow for innovative procurement and financing approaches. With encouragement, cooperative partnering will build the new ITS technology infrastructure for the $21^{\text {st }}$ century and accomplish milestones.

\section{"The Implementation Strategy of the ITSArchitecture identifiesa public-private partnership as 'an attitude leading to cooperation and trust and a productive working relationship with tangible benefit to each of the partners.' The implementation strategy views the public sector as implementers, operators, and maintainers of traffic, transit, and emergency management systems. The private sector will invest in and market private consumer products, such as vehicle navigation and traveler information units and collision avoidance technologies"}

-excerpted from Nontechnical Constraints and Barriers to the Implementation of Intelligent Transportation Systems, 1997 Update, U.S. Department of Transportation, Federal Highway Administration, bint Program Office for Intelligent Transportation Systems, Washington, D.C., 1997

The U.S. DOT has made a concerted effort to bring state and local governments, academia, and the private sector together in order to conduct basic and applied research, field testing, and deployment support. The U.S. DOT believes that, in order to successfully implement ITS technology, the transportation sector should promote cooperation among all potential partners In fact, consortia have been organized to provide a forum for potential partners, such as manufacturers, ITS suppliers, universities, and state governments. Intergovernmental cooperation and public-private partnerships can yield gains, such as cost sharing, functional standardization, and interdisciplinary teams In order to gain these benefits, the federal government especially has tried to encourage the private sector to play a larger role in advancing APTStechnology.

According to the report, Transportation Planning and ITS Putting the Pieces Together, private sector involvement may take a number of forms users, suppliers, franchises, and information service providers. While these partnership arrangements promote a variety of advantages, legal and institutional issues associated with public-private partnerships, and even with intergovernmenta cooperation, must first be resolved in order to gain the full benefit of partnering. It was indicated in the document, Public and Private Sector Roles in Intelligent Vehicle-Highway Systems (IVHS) Deployment, that there are five maj or public-private partnership barri ers that hinder APTS technology implementation: 
- unwil lingness by the publicsector to sharemanagement responsibilitieswith the private sector;

- jurisdictional fragmentation;

- legal constraints;

- procurement and contracting regulations; and

- uncertainty of the market for IVHS technology. ${ }^{13}$

It is important for agencies considering partnerships of any kind to account for and seek to address these potential pitfalls prior to and during the partnering process to avoid disagreements, delays, or other problems, and to ensure that the experience is ultimately advantageous to all parties involved. A 1993 federal study dedared that, "although public-private partnerships are cost effective, and allow the public to benefit from privatefirms' expertisein developing, marketing, deploying, and maintaining new products, diffi cul ties in the fo rmation of public-private partnerships have delayed field operational tests an average of six to twelve months." ${ }^{14}$ Interestingly, many of the early APTS technology partnerships encountered such delays. Most resulted from issues that arose due to the inexperience of the agenciesinvolved. Another causal factor wasthat the competing motivations between thepublic and private sectorswere not dealt with appropriately. Hence, dividing responsibilities between the different stakeholderswas problematic. Unfortunately, rather than enhancing theadvanœment of ITS technology, thes initial dysfunctional partnerships decreased its effectiveness by increasing project costs and time delays.

To address public-private organizational, philosophical, and/or jurisdictional differences, planning is key. Procedures and agreements need to be delineated at the outset of the partnering process. Publicprivate partnerships require innovative management; therefore, a management procedure should be established that will emphasize each of the partner's responsibilities for fulfilling planned, as well as unforeseen, project tasks. Thiswill help to avoid unnecessary confusion. Moreover, aliaison between the parties could be utilized to monitor the project schedule and ensure that all parties are fulfilling their duties.

Further, it would be wise to ascertain the desired goals of a public-private partnership before formulating any contractual agreements. In a perfect world, private funding and expertise would help provide innovative solutions at a lower cost to the taxpayer. However, this scenario is likely to occur

\footnotetext{
${ }^{13}$ It should be noted that a number of these and other related issues were introduced and discussed previou sly in the Ins titutional Arrangem ents section of this doc ument.

${ }^{14}$ Belair, Robert R., Alan F. Westin, and John J. Mullenholz, Privacy Implications Arising from Intelligent Vehicle-Highway Systems, paper prepared under Federal Highway Administration Contract No. DTFH61-93-C00087, December 8, 1993.
} 
only when each sector's needs are met. The experiences of many of the early public-private partnerships have shown that the greatest conflicts occur due to an innate difference in philosophies between the public and private sectors. While both respond to their respective stakeholders, each sector follows a different set of rules. Public sector organizations work in a political environment, requiring the efficient use of taxpayer dollars In contras, privatecompaniesare profit-driven and must be accountable to their shareholders' wants. Therefore, a suitable contract would balance the private sector's profitability standards with the public sector's "public good" needs.

In orderfor a public-privatepartnership to be effective, then, the contractual agreement should account for the participants' respective structures, needs, and strengths. Since private firms utilize profitability goal s, the projected arrangement must support an adequate return on investment. The private sector will be more willing to risk its resources when contractual arrangementssupport the advancement of new business opportunities (e.g., intellectual property rights, commercialization of ITS technologyderi ved productsand services). On the other hand, the public sector will want to be able to u tilize ITS technology - and its resulting products - in as many ways as possible for the good of its constituents, without limitations or excess costs (e.g., copyright fees) being imposed for that use. It is the belief of the public sector that the ability to benefit from the use of the intellectual property resulting from any ITS implementation is a fair and appropriate return for the investment of its taxpayers. Ultimately, this often proves to be one of the most difficult issues in which to strike the proper balance to suit both sectors

\section{"A successful I TS deployment partnership must support not only public objectives, such as reduced congestion and increased safety, but also private objectives, including recovery of development costs and profitability. In general, the basic infrastructure to support private investment must be implemented through public investment before the private sector will become involved."}

\footnotetext{
-excerpted from Nontechnical Constraints and Barriers to the Implementation of Intelligent Transportation Systems, 1997 Update, U.S. Department of Transportation, Federal Highway Administration, Joint Program Office for Intelligent Transportation Systems, Washington, D.C., 1997
}

The federal govemment hasacknowledged these barriersto partnering, but it also has recognized the progress thathas been made to date in public-private partnerships. According to several federal studies, the advantages of partnering greatly outweigh the disadvantages. Some advantages include sharing costs, obtaining expertise through interdiscipli nary teams, decreasing the time between development and deployment, and standardizing equipment and data coll ection procedures. These advantageshave impelled the U.S. DOT to dedicate resources for researching and developing best practice methods in 
order to further strengthen the partnerships between private and public entities (e.g., decreasing regulations imposed upon private firms that partner with public organizations, beneficial tax arrangements, standardi zed contracts).

It has also helped that agencies increasingly have seen the benefit of sharing their partnering experiences with others. This hasenabled agencies considering a partnership to learn from both the successes and the problems that others have already experienced. For example, the Georgia Department of Transportation initiated a project to instal 130 advanced traveler information kiosks throughout the State of Georgia prior to the start of the 1996 Summer Olympic Games that were held in Atlanta. ${ }^{15}$ During the kiosk deployment process, several important lessons about establi shing publi cprivate partnering were leamed and disseminated:

- it is often impossible to utilize traditional advertising or other labor intensive revenue sources for projects with a short development time frame;

- $\quad$ each potential partner's willingness to provide funding should be considered when pricing partnership levels; and

- the value of the project to each partner must be established, substantiated, and emphasized.

Besides public-private agreements, partnering can also involve agreements between multiple government agencies. Unlike public-private partnerships, however, intergovernmental relationships are easier to maintain. First, government agencies typically abide by similar missions and guiding principles. Second, state and local groups are used to working with each other on a variety of other issues, including transportation. Therefore, most public-public relationships already havea longterm trust factor that many public-private partnerships lack. The mutual understanding and trust found within intergovernmental relationships usually results in contractual formation taking less time and involving fewer issues. However, it is important to understand that problems between government agencies can and do occur, as well. Typically, these problems result from jurisdictional disputes, payment mechanisms, and project management issues.

A number of case sudi esshow that the successful development and deployment of ITStechnology also can benefit significantly from productive partnering arrangements between government agencies, regardless of whether they are at the federal, state, and/or local level. While the federal govemment promotes implementation guidelinesand has begun to create legislati on that promotes ITS technology

\footnotetext{
${ }^{15}$ Pohlman, Jam es M., and Elizabe th N. Williams, Public/Private Partnering for the Georgia DOT Advanced Traveler Information Kiosks, Proceedings: Intelligent Transportation Society of America $6^{\text {th }}$ Annual Meeting and Exposition, Houston, TX, April 15-18, 1996.
} 
usage, local-level problems should be addressed by community-specific ITStechnology enhancements. Usually, locally-based projects are able to utilize resources more effectively because they are closer to a community's particular problems and, hence, are better equipped to make decisions. Although projects containing local input have a better chance at resolving a community's transportation issues, local governments need to overcome nearsighted, community-centric behavior.

Beyond highlighting the need for intergovernmental cooperation at the local level is the importance associated with local communities interacting and developing regional ITStechnology planstogether. This interacti on is the best way to ensure that all ITS technology will be interoperable and continuous. Moreover, for the same reasons, state and local governments need to w ork together to establish ITS technology standards. Standardization among communities will hopefully provide citizenswith more beneficial and convenient products. For instance, astandard tran sit passenger smart card technology could be implemented across a region (or even statewide). Thiswould enable passengersto be able to ride the vehicles of all the participating transit agencies in the region (or state) through the use of a single swipe or proximity card.

Asnoted previously, intergovernmental conflicts sometimescan occur. When disagreementsbetw een local communitiesarise, conflict resolution agreementshave proven to be somewhat benefi cial. These agreements help to resolve disputes in a timely fashion. By including due process procedures, a stalemate between dissenting government sectors can be avoided. Also, complaints from each community are able to be heard and discussed openly until a suitable compromise can be reached. It is anticipated that conflict resolution agreements can and will prevent unnecessary court invol vement.

It would seem, then, from the literature that there are considerable differences between public and private missions, risk approaches, business objectives, and time frames. To obtain commitment from the private sector, profitable incentivesneed to be provided. For example, if the objective isto get the private sector to invest in research and development, one incentive would be to include the opportunity to exclusively utilize intellectual property rights over an extended period of time. To alleviate private sector apprehensions about laws requiring the surrender of these property rights, contractual agreements shoul d encom passlanguage that del ineates the rights of each party to computer programs, patent-able inventions, and proprietary technical data that are developed during the partnership. Finally, incorporating variousapproaches utilized by the Europeans and the dpanes for 
public-private partnering may also prove to be beneficial. ${ }^{16}$ Included in these approaches are the following:

- the formation of larger consortia of private sector participants;

- the use of siding publi c-private funding in IVHSprojects, with retention of intell ectual property rights by private sector firms,

- the solicitation of ideasfrom the private sector for development of projects,

- infrastructure studies by the public sector that provide a platform for private sector activities; and

- the use of codes of practice to address liability concerns and simulate product development.

"In defining ITS Program staff requirements, the D epartment should explore opportunities for public/private partnerships and partnerships with local government agencies and other state agencies (e.g., Florida Highway Patrol) to provide operational support for the Department's ITS."

-excerpted from Florida's Intelligent Transportation System Strategic Plan, Final Report, Fori da Department of Transportation, August 23, 1999

In Forida, FDOT's ITS Strategic Plan has taken into account the importance of partnering, especially public-private partnering. In the plan, one of the recommendations is that, as the State's MPOs plan for the integration of ITSinto their respective transportation planning processes, they "evaluate potential ITS projects in light of alternative roles for the public sector, private sector, or public/private partnerships." In addition, the Business Plan for the State's ITSProgram encourages the Department to develop a private sector outreach element within the ITSProgram "to actively encourage private sector participation in ITS ...." According to the Business Plan, "participation by private sector partnersiskey to the full deployment of ITSin Florida." Finally, the Plan also encourages investigating the role of public-private partnerships in the funding of individual ITS projects and the State's ITS Program.

In the follow-up APTSinventor survey, Florida transit agencies were asked whether they currently are participating in any public-publicand/or public-private partnering. According to the survey results, the primary partnering obstades that have been experi enced nati onall y appear to be occurring in Florida, aswell. Oneofthe most problematicissuesis inexperience. Without experience, transit agencieshave a difficult time devising and planning workable relationships. In fact, half of the responding Forida

\footnotetext{
${ }^{16}$ Public and Private Sector Roles in Intelligent Vehicle-Highway Systems Deployment, U.S. Department of Transportation, Federal Highway Administration, Washington D.C., August 1992.
} 
systemsreported no current or planned partnership agreements According to the responsesthat were received, none of the responding transit agencies hasestablished a public-private partnership, either. Most of those with partnering experi ence have been partners with other public entities. The APTS products and services that are currently being implemented and/or operated through public-public partnership arrangements are communications, scheduling, and traffic engineering. Two transit agenciesmentioned their county partnership arrangementsfor radio communication systems. Another transit agency proposed a partnership with a neighboring county for inter-county transit service, although this service expansion will not start for several years. Yet another agency hasan agreement with itscity for radio communicationsand traffic engineering. Finally, one agency has a public-public partnership agreement for scheduling purposes

Another prominent issue related to partnering is standardization. Currently, someagenciesare hesitant to determine partnering options without first resolving compatibility constraints, such as "system configuration [between] areas" When transit agency staff were asked to discuss any opportunities that they believe exist for public-public and/or public-private partnerships for APTS, on e-thi rd could offer no suggestions or ideas for partnering options. Of those agencies that did provide potential publicpublic and public-private partnership ventures, several technology options were described. The responding agenci es menti oned th at APTStech nology partnershi ps could enhance ride share programs, automatic vehicle location systems, traveler information systems, and advanced communication systems.

\section{Public Involvement}

According to the literature, one of the key elements common among successfully-implemented ITS projects is that, prior to and during the course of the deployment, the project team made public officials, stakeholders, and the general public aware of ITS and its benefits, especially asa solution for various transportation problems. Unfortunately, it is sill the case that, despite best efforts to date to provide education and outreach, the awareness and understanding of ITS is sill low among decision makers and the public. It is even low among many of the transportation officials and planners that should be pri me advocates for ITStechnology improvements, making it extremely difficult for them to suggest, promote, and/or evaluate such projects.

\footnotetext{
"Many key decision makers in the transportation community - including elected officials, planning and operating managers and technical staff-are generally unaware of the benefits of ITS Moreover, the general public is not aware that ITS technologies are being used to solve real transportation and social problems. To create a favorable climate for ITS products
} 


\section{and services, consumers and decision makers need to be aware and educated about the benefits of ITS"}

-excerpted from Saving Lives, Time and Money Using Intelligent Transportation Systems: Opportunities and Actions for Deployment, ITSAmerica, February 2000

Because of these low levels of awareness and understanding, it is apparent that the involvement of the public, as well as public officials and other decision makers, continuesto be an especially important aspect of the development and deployment of ITStechnologies. Most importantly, publicofficialshelp set policy and are also involved in funding decisions. Often, their decisions are based on the desires and demands of their constituents - the public. If the public understands the benefits of ITS and how it can help solve a variety of transportation issues, they will be more supportive of such solutions and more vocal in their demands for ITS implementation.

There are, however, two major issues concerning public involvement as it pertains to the implementation of ITS:

- Privacy

- Information Discrimination

The first issue, privacy, is not really unique to ITS, but it has become an increasingly problematic concem in the Information Age. In the 1993 study, Privacy Implications Arising from Intelligent Vehicle-Highway Systems, it was found that "75 percent of Americans expressed a distrust of government and concern over misuse of technology." ${ }^{17}$ Bectronic payment services, surveillance technologies, and other advanœd technologies have increased significantly the amount of personal information that is being collected and utilized for transportation purposes. This increase in the availability and use of personal data has caused public ænsitivity to privacy issues to grow, as well. Particularly, thereare concems that ITSgenerated information will be utilized for secondary purposes, such as automated enforcement of traffic laws and criminal laws, as well as in civil actions. Other concerns include the commercial use and sale of personal information for profit and the security of databases containing individual-specific data

To help deal with this issue, ITS America, through the Privacy Task Group of $i$ ts Legal Issues Committee, developed a series of Fair Information and Privacy Principles. The intent of these

\footnotetext{
${ }^{17}$ Nontechnical Constraints and Barriers to the Imp lementation of In telligent Transportation Systems, Update of the 1994 Report to Cong ress, U.S. Department of Transportation, Federal Highway Administration, Joint Program Office for Intelligent Transportation Systems, Washington, D.C., 1997.
} 
principles is to provide agencies and jurisdictions undertaking ITS projects with an advisory set of parameters for properly handling the information functions of the technologies being implemented. The princi ples, which received final approval on January 11, 2001, incl ude the following:

- Individual Centered - ITS must recognize and respect the individual's interestsin privacy and information use;

- Visible - ITS databases will be built in a manner "visible" to individuals (i.e., disclose to the public what data will be collected, how it will be collected, what its uses are, and how it will be distributed);

- Compliant - ITS will comply with applicable Federal and State laws governing privacy and information use;

- Secure- ITS will be secure;

- Law Enforcement - ITS has an appropriate role in enhancing travelers' safety and security interess, but absent consent, satutory authority, appropriate legal process, or emergency circumstancesasdefined by law, information identifying individuals will not be disclosed to law enforcement;

- Relevant - ITS will only collect personal information that is relevant for ITS purposes;

- Anonymity-ITSwill allow, where practicable, indivi dualsthe abili ty to utilize ITSapplications on an anonymous basis;

- Commercial or Other Secondary Use - ITS will ensure that information used for non-TS applications is stripped of all personal identifiers;

- FOIA - ITS database arrangements should balance the individual's interest in privacy with the public's right to know based on Federal and State Freedom of Information Act (FOIA) obligations, which require disclosure of informati on from government-maintained databases; and

- Oversight - Agencies and jurisdictions deploying and operating ITS technol ogies should have an oversight mechanism to ensure that such deployment and operation complieswith their Fair Information and Privacy Principles.

Following these princi ples can help agenciesand jurisdictions implementing ITStechnologiesensure that the misuse of data generated by ITS deployment is prevented. It is also important to note, however, that it is equally as imperative to prevent the public from fearing that the data will be misused. This especially will be key during the education process in order to help engender the public's support for ITS and prevent a potenti al backl ash because of the privacy issue. 
Related to the issue of privacy is the concern for information discrimination. Basically, thisissuedeals with the equity with which ITS-produced information is available to the public. For example, an advanced traveler information system can generate travel data for use by the public. The concern, however, is that the travel data may not be equitably available to everyone becaus of social, economic, or other demographic factors. There may even be a regional bias associated with the data's availability. If a private-sector agency involved in the deployment is tasked with the responsibil ity of distributing the travel data, it is likely that the data may have a fee associated with it, thereby discriminating against lower income travelers Theprovision of location-specific data can also impact particular segments of the population and/or specific regions in a discriminatory fashion, as well.

\section{"The process of reaching out to the traveling public should start immediately, to inform them of the benefits that can be realized from ITS. All forms of media should be used to gain the public'ssupport. When the public better understands the issues, they will be better prepared to provide feedback." \\ -excerpted from ITS Strategic Deployment Plan, Fnal Report, prepared by HNTB, TRW, and TEC, for the Ohio Department of Transportation - District 12, April 1996}

The FDOT understands the importance of sakeholder support for ITS particularly that of the public and decision makers Thisunderstanding is reflected in the Forida Statewide ITS Strategic Plan, whi ch includes the following guiding principles related to public awareness and involvement:

- Include education, training, and outreach for poli cy makers, the general publ ic, and technical staff.

- Respond to special user needs - provide for the mobility and safety needs of commuters, tourists, goods movement, pedestrians, bicyclists, older road users, and mature drivers

- Identify and support ITSadvocates'champions - seek out and promote ITSchampions in l ocal government, public agencies, academia, and the private sector, including the general public.

To help reach out to the public and other stakeholders, FDOT's ITSStrategic Plan also prescribes the development and operation of ITSweb pages for the State and each of the Districts in order to make ITSProgram information more widely available. ThePlan also callsfor the development of aStatewide ITS Training Program to provide instruction on a variety of ITSelements, such as hardware operations and maintenance, telecommunications, software operati ons and maintenance, planning, and incident management.

Programssuch as thes should be welcomed by the Florida transit agencies, especially if they truly help increase the aw areness and understanding of ITSand itsbenefits. According to the resultsof the follow- 
up APTS inventory survey, the vast majority of the responding agencies indicated that they are not satisfied with the level of public awareness of APTS In fact, only one agency indicated satisfaction with the public's current aw areness of APTS. The results were relatively simil ar for the survey question concerning the level of public official awareness of APTS Only two agencies indicated satisfaction with the awareness of these particular individuals. The responding transit agencies provided the following methods for increasing the awareness of APTS

- education;

- presntations;

- tel evision/radio coverage;

- web sites with FAQ (frequentl y asked questions) pages,

- demonstration projects; and

- newspaper articles.

It is interesting to note that, on the survey, in discussing the factorsthat have impeded the deployment of APTS, the lack of ITS knowledge on the part of the implementing agencies is one factor that was mentioned. It should come as no surprise, then, that the public still is relatively unaware and uninformed, as well. As planners, technical staff, and transportation officials become more knowledgeable about ITSIAPTS and its capabilities, then it should become easier to pass this information on to decision makersand the public in order to educatethem and engender their support for deployment activities. The results of another of thesurvey questions seems to bear this out, as well, as the responding transit agencies suggested that education and awareness were two of the activities that are necessary to ensure and maintain the success of APTS

\section{Regional Integration}

ITS can be defined by its many integral parts, such as traffic, emergency, and transit management, among others. Obviously, efficiency in all areas is required to achi eve a truly integrated and effective transportation system. Most of the literature related to ITS applications focuses more on traffic management, while not adequately addressing the role that transit plays in the overall management of transportation. Fortunately, the role that APTSplays in regional transportation management centers (TMCs) is being defined in areas across the country and the momentum to increase the role of transit as part of the solution for more efficient transportation systems is growing. 


\section{"In some cases transit was an afterthought when metropolitan areas began to approach traffic management and control from a regional perspective, and realized that transit plays a significant role in regional transportation."}

-excerpted from Review of and Preliminary Guidelines Integrating transit into Transportation Management Centers, prepared by EG\& G Dynatrend for Volpe National Transportation Systems Center, Federal Transit Administration, Jly 1994

TMCsempl oy advanced techn ol ogi esto provide transportation information and to manage and control transportation networks. Id eally, TMCs involve multiple agencies throughout a region that have an interest in and impact on transportation. For any one of these agencies to narrowly focus on transportation management from its own perspective without giving consideration to the practicesand abilities of the others to influence transportation efficiency would be a mistake. Historically, these centers were mainly traffic management in nature and they did not include transit; however, when the APTSprogram wasestablished, it became even more clear that the innovationsof advanced technology for public transportation would have profound effects on transportation management, overall. In an effort to assist those areas that are considering the integration of transit and APTS applications into TMCs, FTA developed guidelinesfor establishing the organizational and institutional mechanismsthat can assist in effecting cooperation and coordination among participating agencies.

According to the Review of and Preliminary Guidelines Integrating Transit into Transportation Management Centers, thereare a number of general guidelines, bulleted below, for the integration of APTS and transit operations into a TMC. ${ }^{18}$

- Co-location is not necessary, however, when transit dispatch and traffic operations are physically bound, the exchange of information is facilitated.

- Organizational and institutional cooperation of the transit and traffic management enti ties is more important to the success of the TMC rather than the technologies that are used.

- Roles and responsibil ities of the partici pating agenci es need not change drasti cally to be a part of the TMC.

- Each agency or organization involved in the TMC must contribute resources and expertise for the TMC to be most effective.

- Successful integration may require that non-transit agencies are educated on the importance of transit to the advancement of regional transportation efficiency.

\footnotetext{
18 Schwe iger, Caro 1 L., Review of and Preliminary Guidelines for Integrating Transit Into Transportation Management Centers, Volpe National Transportation Systems Center, Federal Transit Administration, July 1994.
} 
- Technol ogies applied in the collection of transit and traffic data by the TMC will improve the effectivenessof managing regional transportation, but will not bea substitute for transportation management.

\section{"A [TMC] employs advanced technologies to provide multimodal transportation information} and/or to manage and control transportation networks .. . The increase in coordination and information dissmination allows both for more intelligent decisions to be made on the part of trip-makers and more appropriate and timely response to incidents by transportation and emergency personnel, when they arise."

- excerpted from New Technology in Mass Transit, prepared by the Research and Special Programs Administration, Volpe National Transportation Systems Center, http://www. fta.dot.gov/transcity/its.its.html

In developing the guidelines for integrating transit into TMCs, the authors surveyed several existing TMCs to identify common factors to their success. One of the conclusions made was that the colocation of transit dispatch and operations with traffic management operations could facilitate more efficient communi cation; however, it was not necessarily required to achieve the pru dent exchange of information since advanced communication links can allow all entities to share and benefit from real -ti me data.

The participants in the study al so agreed that, while the employed technologiesplay an important part in the successful integration of transit and traffic operations in a TMC, its success depends much more on the ability to minimize organizational and institutional barriers. A suggestion from the guidelines manual was that newly formed or redeveloping TMCs should focus on goals that will dearly demonstrate the value of each entity to the TMC, further clarifying that, as a consortium, the TMC is much stronger and effective than any of the individual agencies.

Another barrier to successful integration of transit dispatch operationsand traffic operations in a TMC is not having a clear understanding of the roles and responsibilities in coordinating efforts As each organization enters the TMC as an able partner, their basic roles and responsibilities should remain unchanged. For instance, a transit agency is still responsible for organizing and providing public transportation and traffic management is still responsible for measuring freeway congestion. How ever, to optimize the impact that the enti ties could have on transportation management overall, measures can be taken to allow each entity to use itsresources to assist the other. In some areas, the busesthat are tracked in real-time by automated vehicle location technology are simultaneously used as probes by the TMC to assist the traffic managersin determining traffic congestion levels. Theexchange of data further demonstrates the value of each enti ty's purpose and resources. 
Historically, the role of transit in effective transportation management has been severely discounted. To achieve trueintegration of ITStechnology in transit and traffic management, non-transit entities may have to be educated about the roles, resources, and benefits of transit to the overall goal of optimizing transportation efficiency. Consider the case of the Greater Houston Traffic Management Center. This particular TMC is managed by an Executive Director who reports to an Executive Committee that consists of municipal, traffic, and transit representatives. This organizational scheme ensures that transit's importance is recognized and that its goals are considered in the activities of the TMC. Additionally, it is apparent from this scheme that, sometime during the process of developing the Greater Houston TMC, the participating organizations were made aware of, un derstood, and accepted the value of transit to the overal transportation management effort.

\section{"Each district should develop an ITSinfrastructure and initiate development or enhancement of a transportation management center focusing on the Interstate highways. Consideration should be given to evolving the center to have multimodal management capabilities and to be operated in urban areas at Level of Service (LOS) 3 within five years" \\ -excerpted from Florida's Intelligent Transportation System Strategic Plan, Final Report, Fori da Department of Transportation, August 23, 1999}

TheFlorida ITSStrategic Plan statesthat the "D epartment should pro-actively support the development, coordination, and deployment of public transportation ITStechnology" by involving transit agencies in the planning, development, and operation of TMCs. The Strategic Pan also suggeststhat the MPO facilitate institutional and inter-jurisdictional cooperation and coordination in the planning, deployment, and operation and management of ITS, and that policies and srategiesare developed to provide technical and financial support for thos transit agencies that wish to integrate their systems into regional architecture. Interestingly, the Sate's ITS Business Plan, which delineates how the Strategic Plan will be implemented, proposes that each FDOT District will establish and staff at least one TMC within five years

The follow -up APTSinventory survey results suggest that most of the responding transit agencies agree that transit should be combined with regional transportation services and traffic operations to form regional TMCs. However, there was some level of skepticism indicated that such integration would occur under thecurrentstateof bureaucracy. When asked what interlocal agreementsor memorandum lettersof understanding would be required to successfully integratethe advanced technologiesoftransit and traffic operations, half of the respondentsagreed that contracts between FDOT, city and county authorities, transit agencies, and MPOswould be required. The other half of the respondents did not offer any opinions on the typesof agreements that might facilitate such cooperation. Further, some of 
the stakeholders interviewed agreed that APTS systems should be interoperable and that regional transportation servicesand traffic operations combined in a regional TMC is important.

\section{Rural Applications}

While the benefits of ITSare most often touted for urban areas, it is now recognized that these benefits can easily be transated to rural areas. In fact, the U.S. DOT developed the Advanced Rural Transportation Systems (ARTS) program to "meet the needs of travelers in and through rural areas, as well as the agencies responsible for the operation and maintenance of therural transportation system." Rural America accounts for 80 percent of the tota U.S road mileage and 40 percent of the vehicle miles traveled. ${ }^{19}$ This dispersed transportation environment introduces important issues for transit providers. ITS can significantly improve the provision of transit in termsof efficiency and accessibility to rural residents, who are, by a large percentage, elderly and/or without adequate transportation. Nearly 40 percent of people in rural America have no access to public transportation and another 28 percent have inadequate servi ce. ${ }^{20}$ Therefore, technol ogy designed to reduce thelevel of isolation for thissegment of the population isimportant. Through avariety of technologies, such as vehicle-locating techniques, communi cations systems, and automated fare collection systems, public transportation in rural areas can be advanced to improve transit accessibility, dispatch and routing efficiency, and ride sharing and matching capabilities.

Of the ITS applications that are currently available, dispatch and routing technologies most often are engaged by rural transit operations. The most common of these technologies are computer-aided dispatch (CAD) and automatic vehicle location (AVL). CAD technology is also referred to as dynamic scheduling software and it automates the process of assigning ride requests to vehicles. AVL allows dispatchersto track vehicles in real-time. The obvious benefit of thes technologies is the potential to improve the cost-efficiency of trip making for paratransit/demand-responsive services through better schedule adherence, automated rescheduling, and the development of optimal dispatch strategies. Other operator benefits include a greater accountability of fleet acti vity, improved data for service planning, better interagency coordination, greater adaptability to last minute trips and cancellations, and reduced vehicle-milestraveled. User benefits include reducedadvance reservati on ti mes, reduced waiting times, and faster travel times.

\footnotetext{
${ }^{19}$ Techbrief: Rural ITS, U.S. Department of Transportation, Federal Highway Administration, TurnerFairbank Highway Research Center, April 1999.

${ }^{20}$ Intelligent Transportation Systems Ben efits: 1999 Update, U.S. Department of Transportation, Federal Highway Administration, ITS Joint Program Office, May 1999.
} 
"Fleet management systems with vehicle location capability are producing benefits in productivity, security, and travel time. In addition, several operators have reported incidents where AVL information assisted in resolving disputes with employeesand patrons A 1996 study found 22 U.S. transit systems operating more than 7,000 vehicles under AVL supervision and another 47 in various stages of procurement. The new procurements represent a tripling of the number of deployed systems...."

-excerpted from Intelligent Transportation Systems Benefits: 1999 Update, U.S. Department of Transportaion, Federal Highway Administration, ITS bint Program Office, May 28, 1999

Rural areas across the country have measured the ben efits of their ITS programs. The transit system in Sweetwater County, Wyoming, after installing CAD and AVL, increased ridership by nearly 80 percent without increasing the size of its dispatch staff. ${ }^{21}$ In Bakersfield, California, the vehicle trip length and travel time were reduced by 10 percent and in Madison County, Illinois, the cut-off time for a next-day trip request was extended by two and one-half hours. ${ }^{22}$

Thro ugh operations software systems, passengersare able to make reservations, check on ride status, and obtain billing information using touch-tone telephones, personal computers, and other methods. For many providers in ru ral areas, these ben efits have tran sated into a dramatic increase in ridership while reducing miles traveled. The improved services mean that many of the elderly or physicallychal lenged persons that util ize paratranst and demand-responsive servicesareable to makenecessary appointmentsand enjoy a more acceptable level of mobility.

In metropolitan areas, considerable attention has been given to el ectronic fare payment technol ogies such asmagnetic strip cards, smartcards, and interagency billing capabiliti es. Themagnetic strip, smart, and proximity cards are automated fare payment systems that use electronic communication, data processing, and data storage technologies to automate the collection of fares Many transit agencies, larger ones in particular, have experienced results of faster boarding, fewer instances of fare evasion, and a reduction in money handling costs with the use of automated fare payment systems. Whether automated fare payment will provide similar benefits in rural areas, or whether they are necessary, is questionable. APTSstudies have suggested that the equipment to read magnetic strip or smart cards

\footnotetext{
${ }^{21}$ Casey, Robert F., The Benefits of ITS Technologies for Rural Tran sit, Volpe National Transportation Systems Center, presented at the National Rural Intelligent Transportation Systems Conference, Spokane, WA, November 1996.

${ }^{22}$ Personalized Public Transit, ITS De cision repo rt, http://ww w.path.berkeley.e du/ leap/PTO/P ersonal Pub Transit/index.html, last update: November 7, 2000.
} 
could be more expensive than conventional fareboxes, particularly in areas using demand-responsive and paratransit services. In addition, as the fares for a great proporti on of transit users in rural areas are paid through third-party billing, the reduction in money handling costscould be minima.

How ever, another electronic farepayment application, usually designed for mul ti-carrier or interagency bill ing, can be used to afford rural transit agencies the abili ty to automate their interagency bill ing and accounting processes when third party agencies are involved. It also can be used to coordinate processesbetween multiple transit operatorsand allow the patronsto pay faresthrough use of onefare payment card. This technology simplifies coordination betwen multiple transit and social agencies, whi ch many of the elderl y riders depend upon in ru ral areas. Fare payment cardsalso have the ability to assist the rural transit agencies in maintaining user profiles on their patrons $s o$ that they are better able to adapt service to changing demographics.

A study team, spon sored by the U.S. DOT, found that, of 10 rural or small urban transit systems that had deployed or pl anned to depl oy APTStechnology, only 2 planned to eventual ly deploy electronic fare systems $^{23}$ Through the same U.S. DOT study, many of the constraints to deploying ITSin rural areas were identified. Rural Public Transportation Technologies User Needsand Applicationsfound that few rural transit systemshad implemented or were famil iar with ITS technologies. The study also stated that smaller transit systemsfaced moredifficul ty championing thebenefits and justifying the costs of ITSastheir budgets were more constrained or limited. In addition, the same constraints to ITSthat effect urban areas also apply to rural areas (e.g., limited funding, poor integration, ineffective procurement, unsuccessful communication of benefits, etc.).

"The overall economic vitality of Florida also requires that safe and efficient movement of people and goods be maintained within and through the rural and inter-urban areas of Florida. However, unlike most urban areas, rural mobility and safety needs are relatively isolated or dispersed. ITSapplicationsin rural and inter-urban areas can therefore be viewed as a tool for providing contiguoustrafficmonitoringand traveler information only if specific problem areas can be identified, and cost-sharing and real-time information-sharing can be maximized."

-excer pted from Horida's Intelligent Transportation System Srategic Plan, Rural/InterUrban ITSApplications Issue Paper, Forida Department of Transportation, March 8 , 1999

${ }^{23}$ Techbrief: Rural Public Transportation Technologies: User Needs and Applications, U.S. Department of Transportation, Federal Highway Administration, Turner-Fairbank Highway Research Center, September 1998. 
A goal in Florida, according to the Rural and Inter-Urban ITSApplications /ssuesPaper of FDOT's ITS Strategic Plan, is to advanœ ITSin rural communitiesfrom operational testing in select areas to full ITS deployment across the sate. The objectives are to improve the efficiency, accountability, and interagency coordination of services, particularly for thetran sportation disad vantaged. The ITSStrategic Plan also specifically addresses the need to encourage federally-designated rural enterprise communities to include ITS in their development goals.

FDOT has identified the Forida Commission for the Transportation Disadvantaged and paratransit Community Transportation Coordinators as valuable resources for increasing the awareness and utilization of ITS in ru ral areas. The constraints to implementing ITSin rural areas mirrors those of the metropolitan areas. The unfamili arity of rural transit operators with the benefits of and opportunities for ITSdeployment in rural Florida can dow the advancement of rura ITS. However, asmore rura areas encounter successful experiences with ITS applications, such as the coordinated AVL project in Putnam, St. bhns, and Flagler Counties, and as the costs and benefi ts of these experiencesare more consistently documented and shared, more transit operators in rural areas will be encouraged to implement ITS technologies, as well.

In the initial APTS inventory survey, most of the 19 respondents indicated that they were pl anning, testing, or operating an automated paratransit scheduling system. Thisis not surprising since, according to much of the ITSliterature, automated scheduling appears to be one of themost popular introductory APTSapplications among paratransit providers. None of the systems that primarily service rural areas acknowledged having automated fare payment technology, but three operate or are planning a multicarrier reservations and billing system. The lack of participation in automated fare payment technol ogy may be reflective of the perceived lack of necessity by the transit operators since there usually exists a greater presence of third party billing incidences over actual fare collection.

From the follow-up APTS inventory survey responses, it is apparent that the responding agencies believe automated vehicle location, automated trip scheduling, and advanced communicationswill be the most ben efi cial APTStechnologiesfor application in rural areas-a finding thatcorrespondswith the initial inventory results that identified these particular applications as being popular among the responding agencies. This result is evident in the agencies responses to the survey question that asked for the potential benefits that could result from applying APTSto rural areas. The benefits that were indicated are as follows:

- vehicle tracking;

- scheduling/dispatching of paratransit trips; 
- communications;

- traveler information; and

- improved efficiencies.

One system even indicated that "liveswill bemadeeasier" and that "all possiblebenefits" could aœrue from the use of APTStechnologies.

\section{Benefits Analysis \& Performance Monitoring}

One of the most notable hindrances to greater APTS deployment is the lack of qualitative and quantitative measurements of benefits to the transit industry when APTS technologies are applied. Performance measu rement and ben efitsanal ysisarecritical because they acknowledgeefficienciesand aid in justifying costs. When new technology is introduced, no matter what the industry, the key to acceptance is demonstrating that its use will yield better service at lower costs. Decision makers need to have objective eval uati ons of ITS operations that cl early delineate the benefits so that, during this time of limited funding, positive gainsfor the industry, transit agencies, and transit usersare achieved. ITS deployment is relatively new and an extensive history of data on either the cost or benefit doesnot exist. Presumably, this lack of data has prom pted a demand for transit agencies to more consistently share performance evaluations and benefit data with one another.

"Funding for Intell igent Transportation System (ITS) projects is becoming scarcer, and this trend will continue unless ITS proponents are able to demonstrate gain from on-going ITS projects The problem isnot insurmountable. There are demonstrable gainsfrom current ITS projects, and many of these gains are of significant interest to public policy makers and potential ITSsponsors However, asa community, we have failed to effectively communicate ITS achievements to the public."

- excerpted from ITS Evaluation: A New Framework, an abstract by Richard Harris, Richard Staats, and Ronal d Bailey, Logistics Management Institute, viewed onl ine at http://www.itsonline.com//mi/isatax.htm

Performance monitoring is first introduced during the operational testing phase of ITSdeployment and should continue throughout to ensure that the system is responding as desired. Performance monitoring provides the agency with an idea of how the system is working defined by preset measures of effectiveness. The benefits of performance monitoring and evaluation transcend solely justifying costs, however, as it identifi es areas in which the system needs improvement. 
Benefit analysis, on the other hand, is done by objectively comparing the results of performance monitoring with the direct and indirect costs of implementing the system. This is most often used by state and local agencies when justifying the need for ITS technology with public and private funding providers. While the U.S. DOT, through the ITS bint Program Office (PO), has gathered information on the impacts of ITS projects, it acknowledges that there exists an unacceptable lack of benefits data available for transit agencies to use in this justification process. The lack of data sources is partly a result of the failure of those sate and local agencies that have implemented ITS to adequately monitor the performance of the applications and to promptly publish the resulting benefits demonstrated through any performance monitoring that has been done.

The development of a performance monitoring plan is crucial when deciding to implement ITS technology. To successfully identify the true benefits and even the shortcomings of a system, the evaluating agency must identify the criteria to be measured and the units of measurement. The Technical Edition of the ITS Deployment Guidance for Transit Systemsidentifies suggested "measures of effectiveness," or MOEs, and recommends that they be used as indicators in the evaluation of a system's performance. ${ }^{24}$ Ideally, the MOEs should represent the concems of the stakeholders, who might include transit operators, riders, and private partners. They might measure safety, cost, capacity, satisfaction, and delays. Examples of measures identified in the ITSDeployment Guidance for Transit Systemsinclude:

- number of transit riders/year;

- transit vehicle occupancy;

- travel times (minutes);

- queue lengths;

- total annual transit miles, and

- transit revenue.

"Evaluations are critical to understanding the value, effectiveness, and impacts of the ITS program activities Significant policy issues can only be addressed if the benefits, costs, and risks can be identified for each project. Indeed the lack of or failure to use aids that help guide the public use of scarce resources will threaten the quality of decisions"

-excerpted from Cost/Benefit Analysis, ITS Decision resources, http://www.path. berkeley.edu/-eap/itsdecision resourcescost benefit.html, last update: Jly 15, 2000

${ }^{24}$ ITS Deployment Guidance for Transit Systems Technical Edition, U.S. Department of Transportation, April 1997. 
Whileperformance monitoring can provide immeasurable benefit to the implementing agency, ben efit analysis is also of great use to other agencies that are planning to use a simil ar technology. The value of the ITS application in relation to costs is an invaluable tool for justification. By identifying the shortcomings of an ITSapplication, an implementing agency can make adjustments and can share those shortcomings with other agencies that are undertaking similar endeavors

In connection with the Mly 12, 2000, ITSBenefits Data NeedsWorkshop, Mitretek Systems prepared a report entitled, ITS Benefits: Data Needs Update 2000. The purpose of the document is "to summarize and highlight where gaps or limited knowledge exists concerning the benefits of ITS services" so that additional evaluation of those services can be encouraged and so that the JP might best determine "where limited evaluation resources may provide the most advantage." 25 The information presented in the report resulted from the work of the data needstask force that participated in the workshop and were tasked with developing, reviewing, and rating a listing of data neds. A survey was used to accomplish the rating of the data needs. One general finding from the survey included overall higher priority rankings for data issues within metropolitan application areas versus those within rural application areas. Among the metropolitan ITS application issues, incident management on arterial systems, data archiving, and operations and maintenance recei ved the highest priority scoresfor requiring additional benefits analysis. Among the rural-based issues, high priority for more benefits analysis was given to emergency services, operation and maintenance, and crash prevention and security. Finally, in specific relation to transit, the task force indicated considerable interest in acquiring more benefits data for the impact of ITSon transit management systems(e.g., AVL and computer-aided dispatch), maintenance, transit information systems, and security.

The Florida ITS Strategic Plan does not directly acknowledge a goal of improved performance monitoring or benefits analysis. However, it states that an essential element of management and operation of ITSprojectsis the "moni toring of transportation facilities performance on a real-time basis ... to provide informati on for improved operati ons." The Economic Impacts Issue Paper for the plan addressed transportation system efficiency gains (found on the national level) attributable to the ITS deployment and then extrapolated thos gains to predict impacts of ITSon Forida. Unfortunately, neither the plan nor the issue paper addressed the underlying shortcoming of not having adequate benefits anal ysis and evaluation at the stateand local level. This deficiency wasmentioned by æeveral of the transit agencies that responded to the follow-up APTSinventory survey.

\footnotetext{
${ }^{25}$ Proper, A llen T. and Rob M accubin, ITS Ben efits: Data Needs Update 2000, prepared in connection with the 12 July ITS Benefits Data Needs Workshop, Mitretek Systems, August 29, 2000.
} 
None of the respondentsto the survey acknowledged that a benefits analysis was done prior to or after their respective deployments. However, many agencies recognized that "comparing notes" and "celebrating your successes" were activiti es necessary to ensuring or maintaining the success of ITS deployments. The transit agencies seem to be receptive to sharing their ITS experiences with other agencies in Florida; however, without consistent guidelines for performance monitoring and benefit analysis, the successes of these deployments may not be recognized asan objective representation of the technology's effectiveness and efficiency.

\section{SUM MARY OF CHAPTER TWO}

This second chapter of the Inventory and Analysis of Advanced Public Transportation Systems in Forida report has provided a variety of information on 10 specific characteristics related to the development and/or deployment of APTS It also has documented the experiencesthat a number of Forida transit systemshave had with these particul ar issues, based on the results of the fol low-up APTS inventory survey and the stakeholder meetings.

"For ITS to be succesful, the many partnersin the transportation system - including highway and transit officialsin Federal, State, and local governments- must coordinate their efforts and work as a team. Public-private partnerships and participation by urban and rural organizations are also necessary, as is the support of the public."

-excer pted from Safer, More Efficient Travel with Intelligent Transportation Systems, an ITSwhite paper produced by the Federal Highway Administration and the Federal TransitAdmini stration for use bymembers of theNational Associations Working Group for ITS, Pub. No. FHWA-SA-97-087

From the literature review, it is evident that the decision to utilize a particul ar ITS technol ogy is only the first step of an extensive, and often challenging, process that runs from development, to deployment, and finally to the operation and maintenance of the chosen technology. For example, if a transt system wants to incorporate APCs on a portion of its fleet for data collection purposes, the decision making does not end with the selection of a particular APC technology and vendor. A host of other considerations must be taken into account, incl uding:

- Will this component be able to beintegrated with othersshould the need or desire arisefor the implementation of other APTS technologies (e.g., AVL)?

- How will the APCs be procured? 
- How will all aspects of the technology befunded, including installation, maintenance, and data compilation and analysis?

- Will it be beneficial to partner with other agencies, public or private, and how will those relationships be established and structured?

- What level of involvement, or "buy-in," will be needed from board members, local officials, and/or the public?

- What impact will the increased influx of data have on planning staff? Will it be possible to utilize the data in a timely and beneficial manner to positively support agency operations?

- What impact will upkeep and repair of the APC equipment have on maintenance staff?

Therefore, a lot of planning and forethought must go into the development and implementation of any ITS technology. Agencies considering the deployment of a technology will want to understand the National ITSArchitecture (or any state or local architecture that has been established) and use it as a guideline during the process. If partnering is desired, it also would be prudent for an agency to understand the issues involved with various institutional arrangements(i.e., interagency, jurisdictional, public-private, and/or technical capability issues). Identifying and enlisting a wide range of stakeholders in the project also will be advantageous to its success, as will ensuring that the implementation plan clearly establ ishesthe stakeholders' roles and responsibil ities, and all ows for and encourages interagency coordination.

Like most other transit projects, funding will be an important issue in the process to implement ITS. Capital funding will be needed for the acquisition and installation of equipment and supporting software applications. However, it is the funding that will be needed to upkeep and operate the ITS technology on a day-to-day basisfor which most agencies will struggle to identify a source. Operation and maintenance of the equipment will depend on the appropriate allocation of staff for those tasks. Staff also will be needed to deal with the timely and regular retrieval, analysis, and use of the resulting information from the operation of the technology. It is only through the appropriate levels of funding and staff resources that the full benefit of any ITStechnology application will be reached.

Simil arly, pro curement of an ITS technology can al so be a complicated step in the process becaus ITS proposals are not well served by traditional procurement practices. The complexity of most technologies and the nœed to adapt to constantly evolving applications require that procurement proced ures be much more flexible in nature. These more adaptive procedures will help agencies be able to better account for desired goals, such as interoperability and the ability to be integrated with other technologies in the future, when procuring an ITStechnology. 
A key element of many of the ITSprojectsthathavebeen successfully implemented around the country is the awareness and involvement of public officials and the general public. Unfortunately, understanding of ITS and its ben efits is still quite low among decision makers and the public. Since these constituenciesplay an important rol e in setting policy and establishing funding priorities, it isin the best interest of agencies implementing ITS technol ogies to en sure that they are made aware of ITS solutions to transportation problems and other issues If politicians and the public understand the benefits of ITS and how it can help solve existing problems, they will be more supportive of effortsto implement these technologies.

Asmore peo ple understand ITS and how it can help solve real-world issues, it will be easier to promote the more widespread implementation of ITStechnologies. Eventually, it will be possible to plan for deployment that will integrate services and systems across a region, thereby ensuring seamless coverage and interoperability. In terms of mobility, transportation management centers can be established that will utilize advanced ITS technologies to provide transportation information, as well as manage and control transportation networks, on a regional basis. Ulti mately, transportation will be able to be integrated at the statewide level for the seamless connection with transportation systemsin neighboring states and across the country.

This regional outl ook for the implementation of ITS technologies incorporates rural areas and the demand-response services that are utilized in those areas, aswell. ITStechnologies such as AVL and CAD have been utilized successfully for rural applications, and have benefitted rural transit providers by helping to improve the efficiency of demand-response service scheduling and operation. It is al so anticipated that technology implementation also will help improve interagency coordination of services. In fact, thisis one of the specific goals of the Rural Forida ITS demonstration project, which was begun in 1998 .

Finally, one of the greatest hurdles that agencies will need to overcome when implementing ITS technologiesisthe justification of thecostsin comparison to other potential improvements. Thisis why benefits andysis and performance measurement are critical to this process. Asnoted previousy, prior to deployment it will be important to understand the potential benefits of the technology under consideration and demonstrate those benefitsto the decison makersand all stakeholders. Performance monitoring becomescrucial during the operational tesing phase of the deployment to make sure that the system is working as planned. After that, continued monitoring of performance is necessary to ensure that all facets of the system continue to operate properly. Benefits analysis then objectively compares the results of the performance monitoring with the direct and indirect costs of system implementation and, hopefully, justifies need for that technology. In addition, it will be important for 
agencies to share the results of their analyses with others contemplating implementation. Unfortunately, the lack of qualitative and quantitative measurements of ITS technology benefits has been found to be one of the most notable hindrancesto greater ITSdeployment to date, especially for transit purposes 


\section{CHAPTRTHRE}

\section{APTSBenefts An alysis \& Perfo rm ance Monitoring}

\section{INTRODUCTION}

As noted in the previous chapter, it is extremely important for a transit agency considering the implementation of, or actually deploying, a particular APTStechnology to assess its potential benefits prior to implementation and monitor its performance after deployment. These analyses are beneficial because they can help highlight efficiencies and can aid in the justification of costs. Another major benefit is that these analysescan al so provide an agency with important support informati on asit shares its deployment/operation experiences wi th other agencies and the transit ind ustry, as a whole. This sharing of qualitative and quanti tati ve measurements of APTSbenefits with the industry is considered to be an important key to increased APTSdeployment throughout the U.S.

In this third chapter, a spreadsheet-based analysis tool is utilized to assess the benefit(s) that a selected group of transit systemshave accrued through the implementation of an APTStechnology. Four Forida transit agencies and one agency from outside the state have ben selected by CUTR, and approved by FDOT, for inclusion in this particular analysis. To conduct theanalysis, the tool utilizespre-and postdeployment data provided by these agencies for specific performance variables. In addition, a discussion of post-deployment performance monitoring also is included herein, with some general recommendations for performance measures that shoul $d$ be considered by transit agencies.

\section{APTSBenefits Analysis}

To conduct an APTSbenefits analysis for the purpose of exemplifying this type of review process for transit agencies throughout Forida, it was first necessary to determine the tool(s) that would be used and the transit system(s) that would be analyzed as case studies. During the scoping stage of the project, two different computer-based analysis tools were identified that would be considered for use in this analysis, SCRTS(Screening Analysis for ITS) and IDAS (ITS Deployment Analysis System). In addition, CUTR identified several in-state and out-of-state transit agencies that would be promising candidates for inclusion in the study.

Ultimately, with the assistance of FDOT, it was decided that the SCRTStool would be utilized in the case studies and five systems were selected for analysis: Pinellas Suncoast Transit Authority, Hillsborough Area Regional Transit Authority, LYNX Transit, and Sarasota County Area Transit in 
Florida, and Ann Arbor Transportation Authority in Mi chigan. Thefollowing sections briefly describe the two analysis tools that were considered and the reasons for the decision to utilize SCRTS instead of IDAS, as well as the participating transit agencies.

\section{Asesment Tools}

As discussed previousy, two assessment toolswere suggested in the original project scope for revi ew to determine which could best be utilized to conduct APTS related benefits analyses for a selection of transit agencies. Both tools, SCRITS and IDAS, are computer-based and were developed to provide sketch-level planning analysis capabilities for ITS applications, including the assessment of potential benefits. These tools are described more in-depth in the next two sections, followed by a brief discussion of the rationale for ul ti matel y selecting SCRTS to com pl ete the analysesdocumented herein.

\section{IDAS}

According to i nformation from a promotional brochu re, the ID AS prod uct website (http://www .camsys. com/tod/idas/index.html), and the McTrans website (http://mctrans.ce.ufl. edu/featured/idas/), IDAS, or the ITS Deployment Analysis System, is a sketch-planning analysis tool that can be used to estimate impacts, benefits, and costs associated with the implementation of ITStechnologies. Developed by a team led by Cambridge Systematics, Inc., for the Federal Highway Administration (FHWA), this software is intended to assist public agenciesand consultantsin integrating ITSinto the transportation planning process. To this end, IDAS relies on the modal split and traffic assignment outputs from existing travel demand forecasting models(e.g., FSUTMS) to estimate changes in the modal, route, and temporal decisions of travelersthat occur due to ITSdeployment. Utilizing this software, it is possible to predict relative costs and benefi ts for more than 60 types of ITS investments, incl uding automated scheduling and automatic vehicle location for both fixed-route transit and paratransit services and five other transit-specific components.

IDAS is also capable of evaluating and quantifying the impacts of ITS infrastructure improvements throughout a transportation network. These impactscan include user mobility, travel time and speed, travel time reliability, fuel costs, operating costs, accident costs, emissions, and noi se, among others. It also is possible to view the performance of particular ITS options by mode, facility type, and/or district. Analysis results are output to a benefit/cost summary report and a series of performance summary reports. Examples of these reports are il lustrated in Figures 1 and 2. In addition, ID AS can be utilized to analyze how an ITS project can affect agency efficiency and/or system reliability. As a sketch-planning analysis system, it is important to note, however, that the program is intended to be 
used as a tool for alternatives analysis and not for the optimization of ITSoperations. According to documentation, some of the other capabilities of the softw are incl ude:

- compari son and screening of ITS alternatives;

- estimation of life-cycle costs;

- inventory of ITSequipment;

- identification of cost-sharing opportunities;

- sensitivity and risk analysis;

- ITSimprovement scheduling; and

- documentation for transition into design and implementation.

IDAS is designed to operate in the Windows NT 4.0 environment; however, it can also run in a Windows 95 environment (despite issues with network-viewing capabilities that may result from incompatible hardware configurations). A fully functional Windows 95/98 version was due on the market in July 2000, although the current availability of this version could not be verified. IDASs graphical interface and its use of complex algorithms in its traffic assignment process necessitate the utilization of at least a 300 megahertz Pentium II processor to run the software. The system requirementsalso recommend the availability of at least 128 megaby tes of RAM and at least 2 gi gabytes of free disk space to properly run the IDAS program.

Figure 3-1

\section{Benefit/Cost Summary Report - Example Output}

\begin{tabular}{|c|c|c|c|c|c|}
\hline \multicolumn{6}{|l|}{ Alternative Comparison Module } \\
\hline $\begin{array}{c}\mid \text { ITS Option Comparison } \\
\text { Cost Adjustment } \\
\text { Value of Time } \\
\text { In-Vehicle }\end{array}$ & $\begin{array}{l}\text { BenefitiCost Summary } \\
\text { Project: Demo } \\
\text { Benefits are reported in } 1995 \text { dollars } \\
\text { Annual Benefits } \\
\end{array}$ & \multicolumn{3}{|r|}{$\begin{array}{l}\text { Winnipeg } \\
\text { Transit AVL }\end{array}$} & $\Delta$ \\
\hline Out-of-Vehicle & Change in Costs Paid by Users & & & & \\
\hline Travel Time Reliability & Fuel Costs & 1.00 & $\Phi$ & 678 & \\
\hline Cost of Fuel & Non-fuel Operating Costs & 1.00 & $\Phi$ & 22,987 & \\
\hline Non-Fuel Vehicle Operating Costs & Accident Costs (Internal Only) & 1.00 & $\Phi$ & 36,443 & \\
\hline Emission Costs & Change in External Costs & & & & \\
\hline Accident Costs & Accident Costs (External Only) & 1.00 & $\$$ & 6,431 & \\
\hline Fatality & Emissions & & & & \\
\hline Injury & HCROG & 1.00 & $\Phi$ & 2,861 & \\
\hline Property Damage Only & NOX & 1.00 & $\Phi$ & 4,701 & \\
\hline Noise Damage Costs & $\mathrm{CO}$ & 1.00 & $\Phi$ & 48,855 & \\
\hline Other Mileage Based Costs & PM10 & 1.00 & $\$$ & 0 & \\
\hline Other Non-Mileage Based Costs & $\mathrm{CO} 2$ & 0.00 & $\$$ & 0 & \\
\hline Risk Analysis & Global Warming & 0.00 & $\Phi$ & 0 & \\
\hline Select Ranges & Noise & 1.00 & $\Phi$ & 943 & \\
\hline $\begin{array}{l}\text { Select Ranges } \\
\text { Run Analysis }\end{array}$ & Other Mileage-Based External Costs & 1.00 & $\$$ & 0 & \\
\hline $\begin{array}{ll}\text { Run Analysis } \\
\text { View Results }\end{array}$ & Other Trip-Based External Costs & 1.00 & $\Phi$ & 0 & \\
\hline $\begin{array}{c}\text { View Results } \\
\text { View Outputs }\end{array}$ & Change in Public Agencies Costs (Efficiency Induced) & 1.00 & $\Phi$ & 39,643 & \\
\hline Benefit/Cost Su & Other Calculated Benefits & 1.00 & $\$$ & 0 & \\
\hline $\begin{array}{c}\text { Performance Summary } \\
\text { by Market Sector } \\
\text { by Facility Type }\end{array}$ & $\begin{array}{l}\text { Total Annual Benefits } \\
\text { Annual Costs }\end{array}$ & 1.00 & & $3,525,288$ & \\
\hline by District & Average Annual Private Sector Cost & & $\$$ & $\overline{0}$ & \\
\hline & Average Annual Public Sector Cost & & $\$$ & 506,534 & \\
\hline & Total Annual Cost & & & 506,534 & \\
\hline 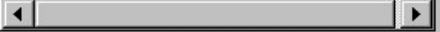 & & & & & \\
\hline & Benefit/Cost Comparison & & & & \\
\hline Done & $\begin{array}{l}\text { Net Benefit (Annual Benefit - Annual Cost) } \\
\text { B/C Ratio (Annual Benefit/Annual Cost) }\end{array}$ & & & $\begin{array}{r}3,018,754 \\
6.96 \\
\end{array}$ & 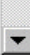 \\
\hline & 4 & & & & \\
\hline
\end{tabular}


Figure 3-2

Performance Summary Report - Example Output

\begin{tabular}{|c|c|c|c|c|c|c|}
\hline \multirow{24}{*}{\begin{tabular}{|c|c|} 
ITS Option Comparison \\
Cost Adjustment \\
Value of Time \\
In-Vehicle \\
Out-of-Vehicle \\
Travel Time Reliability \\
Cost of Fuel \\
Non-Fuel Vehicle Operating Costs \\
Emission Costs \\
Accident Costs \\
Fatality \\
Iniury
\end{tabular}} & \multicolumn{4}{|c|}{$\begin{array}{l}\text { Performance Summary } \\
\text { Project: Demo, Alternative: Winnipeg, ITS Option: Transit AVL }\end{array}$} & \multirow{2}{*}{\multicolumn{2}{|c|}{ Total }} \\
\hline & By: Market Sector & Auto & Transit & Truck & & \\
\hline & Vehicle Miles of Travel & & & & & \\
\hline & Control Alternative & 628,656 & & 71,950 & 700,606 & \\
\hline & ITS Option & 626,033 & & 71,911 & 697,944 & \\
\hline & Difference (\%) & $-2,624(-0.48)$ & & $-39(-0.1 *)$ & $-2,662(-0.4$ 娄 $\}$ & \\
\hline & Vehicle Hours of Travel & & & & & \\
\hline & Control Alternative & 28,956 & & 3,347 & 32,303 & \\
\hline & ITS Option & 28,721 & & 3,332 & 32,052 & \\
\hline & $\begin{array}{r}\text { Difference (\%) } \\
\text { Average Speed }\end{array}$ & $-235(-0.83)$ & & $-16(-0.5 *)$ & $-251(-0.8 *)$ & \\
\hline & Control Alternative & 21.7 & & 21.5 & 21.7 & \\
\hline & ITS Option & 21.8 & & 21.6 & 21.8 & \\
\hline & Difference (\%) & $0(0.4 \%)$ & & $0(0.48)$ & $0(0.4 *)$ & \\
\hline & $\begin{array}{l}\text { Control Alternative } \\
\text { Conel }\end{array}$ & 37,642 & 7,872 & 3,347 & 48,862 & \\
\hline & ITS Option & 37,337 & 7,447 & 3,332 & 48,116 & \\
\hline & Difference (\%) & $-306(-0.84)$ & $-425(-5.48)$ & $-16(-0.5 *)$ & $-746(-1.5 *)$ & \\
\hline & Number of Person Trips & & & & & \\
\hline & Control Alternative & 146,877 & 18,211 & 11,702 & 176,790 & \\
\hline & ITS Option & 146,375 & 18,714 & 11,702 & 176,790 & \\
\hline & $\begin{array}{l}\text { Difference (\%) } \\
\text { Number of Fatality Accio }\end{array}$ & dents ${ }^{-502(-0.3 \%)}$ & $502(2.8 *)$ & $0(0.08)$ & $0(0.0 *)$ & \\
\hline & Control Alternative & $2.4402 \mathrm{~B}-03$ & & $2.8377 \mathrm{~B}-04$ & $2.72408-03$ & \\
\hline & ITS Option & $2.4299 \mathrm{E}-03$ & & $2.8361 \mathrm{~B}-04$ & $2.7135 \mathrm{E}-03$ & \\
\hline & Difference (\%) & L. $031 \mathrm{E}-05(-0.4 \%)$ & & L. $562 \mathrm{~B}-07(-0.18)$ & $-1.047 \mathrm{~B}-05(-0.48)$ & \\
\hline & Number of Injury Accide & & & & & \\
\hline 4 & Control Alternative & $4.3108 \mathrm{~B}-01$ & & $4.8298 \mathrm{~B}-02$ & $4.7938 \mathrm{~B}-01$ & \\
\hline Done & $\begin{array}{l}\text { IS Uption } \\
\text { Difference (\%) }\end{array}$ & $\begin{array}{r}4.2891 \mathrm{~B}-01 \\
-2.17 \mathrm{~B}-03(-0.5 *)\end{array}$ & & $\begin{array}{r}4.8236 \mathrm{~B}-02 \\
5.268 \mathrm{~B}-05(-0.1 *)\end{array}$ & $\begin{array}{r}4.7715 \mathrm{~B}-01 \\
-2.233 \mathrm{~B}-03(-0.54)\end{array}$ & \\
\hline & Number of PDO Acciden & & & & - & \\
\hline & $4 \mid \cdot \Lambda$ Transit AVL & & & 41 & • & 1 \\
\hline
\end{tabular}

\section{SCRITS}

Screening Analysis for ITS(SCRTS) is a spreadsheet-based analysis tool that can be utilized to estimate the user benefits of particular ITS applications, according to the user's manual and other information provided at FIWA's SCRITSwebsite (http://www .fhwa.dot.gov/steam/scrits.htm). SCRITSisintended to be used as a sketch fevel analysis tool that will enable plannersand consultants to identify some of the possible benefits that would accrue dueto the depl oyment of one of the incl uded ITS technologies; as such, it is not intended for detailed analysis. When greater accuracy is necessary, the manual suggests the utilization of more sophisticated analysis tools such as simulation models or IDAS.

SCRITSwasoriginally developed to address "the need for simplified estimates in the early stages of ITSrelated planning, in the con text of either a focused ITSanalysis, a corridor/subareatransportation study, or regional planning analysis." ${ }^{26}$ The following principles guided the development process of this particular tool:

${ }^{26}$ User's Manual for SCRITS, SCReening Analysis for ITS, prepared by Science Applications International Corpo ration for the U.S. D epartment of Transportation, Federal Highw ay Adm inistration, O ffice of Tra ffic Management and ITS Applications, January 1999. 
- results should becompatible with transportation analyæs conducted using other types of tools, such as travel demand models or simulation applications;

- analysis should be adaptable to regional, facility, and subarea scales;

- analysis should produce estimates of benefits on a daily basis (as opposed to estimates for individual peak periods or peak hours); and

- andyst must recognize that there is a great deal of uncertainty regarding the effects of ITS applications.

Microsoft Excel for Office 97 was used to create the SCRTS andysis tool, which is structured in a workbook format that consists of a series of workshets. One workshet is provided for uærs to provide a st of baseline data, such as a definition of the sudy area and related travel statistics (e.g., VMTestimates). Several other work sheetsincl ude lookup tables from whi ch information isdrawn that is util lized in the various analyses of the ITSapplications. The remaining worksheetsin the workbook are used to analyze and estimate benefits for the 16 individual ITS applications contained in the spreadsheet tool. Among the ITS technologies included in the SCRITS tool are Closed Circuit TV, Highway Advisory Radio, Variable Message Sgns, and Bectronic Toll Collection. Three of the application spreadsheets are related specifically to transit: Automatic Vehicle Location System for Buses, Bectronic Fare Collection for Buses, and Sgnal Priority Systems for Buses. Unfortunately, as it is currently structured, the SCRTS tool does not accommodate analysis for combinations of ITS strategies.

To analyze a particular ITS application, the uæer must input baseline data into the appropriate worksheet, then fill in all of the required data items on the worksheet associated with the application being analyzed. It al so is necessary to provide all cost esimates (e.g., construction, installation, and/or operations/maintenance) and the service life of the technology. Utilizing this information, SCRTS then calcul ates a number of measures of effectiveness (which vary by ITS appl ication), incl uding:

- changes in VHT (for most applications);

- changes in VMT, where applicable;

- changes in emissions (CO, Nox, $\mathrm{HC}$ ), where applicable;

- changes in vehicle operating costs, where applicable;

- changes in energy consumption, where applicable;

- changes in the number of accidents, where applicable; and

- economic ben efit and benefit $t$ cost ratio (for most applications). 
The SCRTTSdocumentation does stress two caveatsrelated to the use of the tool. First, it is important to recognize that SCRTSoutput is app roxi mate and shoul $\mathrm{d}$ be used for general planni ng purposesonly. As mentioned previously, it is strictly a sketch-level planning tool. Given the uncertainty associated with travel delay and the numerousassumptions that are required in the worksheets and calculations to reasonably assess the accrual of ITSbenefits, SCRITScan produce only a general approximation of these benefits. Second, it is important to note that SCRTSfocuses on user benefitsonly. Resulting benefits to agency operations, such as labor efficiency and/or management effectiveness, are not accounted for in any of the workshøes, despite the fact that these benefits may be the most important reason for implementing the technology. This is especially the case for various transit management applications. For example, while electronic fare collection may provide passengers with a greater variety of fare options and faster boarding times, a transit agency will benefit significantly from the reduction of cash transactions and the increased automation of its accounting system.

An example of one of the SCRITSandysis worksheets is shown in Figure 3. The figure depicts the worksheet that can be utilized to assess the benefits of Electronic Fare Collection for Buses.

Figure 3-3

\section{Screen Capture of SCRITS Bectronic Fare Collection Worksheet}

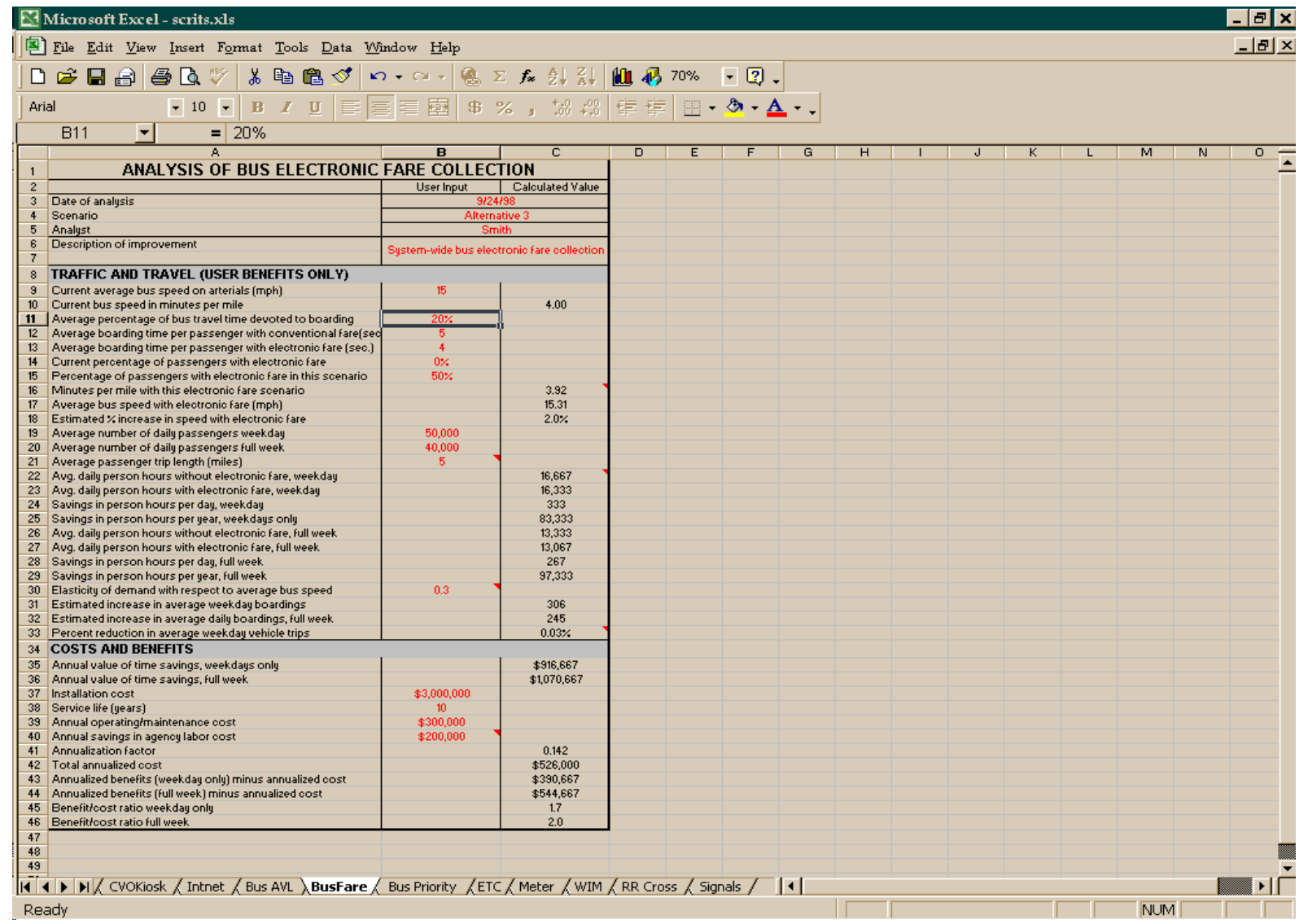




\section{Rationale for the Selection of SCRITS}

Asmentioned previousy, it was determined that the SCRITStool would be util ized to conduct the case study anal yses for the five transit systems. Although it is a less sophisticated sketch-level analysistool, SCRITS was chosen over IDAS for a number of reasons, incl uding the following:

- IDAS is a more complex analysis tool that will require a higher learning curve for proper utilization;

- IDAS requires more intensive datainputs, including modal split and traffic assignment outputs from existing travel demand forecasting models;

- the SCRTS tool, available fre of charge, is an Excel-based spreadsheet - software that is readily available at most, if not all, transit systems in Florida;

- the IDAStool is a stand-alone software package that costs $\$ 795$; and

- the IDAS software requi res more signi ficant base computer requi rements than does SCRITS.

The general review of the tools' capabilities, asindicated in their respective documentation, suggests that the IDAS tool is the more valuable and in-depth planning and assessment tool, assuming that a transit agency is will ing to spend the time, money, and effort to acquire it, learn to use it, and apply it properly. However, it is anticipated that the SCRTStool will be more well-received at the individual transit agencies asa potential pre-deployment planning analysis tool. It will be easier to acquire and will not require nearly as much staff time asIDAS to understand make uঙ of the tool. Nevertheless, it is important to remember that the SCRTStool is only able to analyze "user" benefits, and only for three different APTS components (automatic vehicle location, electronic fare collection, and signal priority).

\section{Participating Transit Agencies}

As indicated previousy, it wasdecided that five separate case studies would be conducted involving the following systems: Pnellas Suncoast Transit Authority, Hillsborough Area Regional Transit Authority, LYNX Transit, and Sarasota County Area Transit in Florida, and Ann Arbor Transportation Authority in Michigan. Four of the five systems currently utilize electronic fare collection, and the other system (Sarasota) is in the process of implementing it. In addition, LYNX and Ann Arbor also have in place AVL systems and utilize buspriority. The following sections provide brief synopses of the systems and their respective ITS com ponent(s). 


\section{Pinellas Suncoast Transit Authority}

Pinellas Suncoast Transit Authority (PSTA) is an independent authority and was created by special act of the Horida Legislature (Chapter 70-907, House Bill No. 5465). The system provides fixed-route motorbusand demand-response servicesthroughout most of Pinellas County, with Kenneth City, Bellair Beach, Bellair Shores, Treasure Isand, and St. Pete Beach as the only exceptions. NTD information for the 1999 fiscal year indicates that PSTA's service area encompasses approximately 209 square miles, with a total population of 833,500 persons. Fixed-rou te mo torbus service is provided seven days per week through the us of 115 vehicles operating in peak service. In FY 1999, PSTA bu sescarried a total of 9.3 million passenger trips while operating nearly 6.6 million revenue mi les of service.

According to the initial APTS inventory survey, PSTA currently is not in the planning stages for the implementation of any new APTS technologies. However, the system al ready has in place an electronic fare payment system and anadvanced communicationssystem. PSTA isutilizing a Motorola (anal og land mobile) radio system on its vehicles, and expects to eventually upgrade that system to a more advanced one from Motorola that will incorporate AVL, as well. The system also has CENTSaBILL electronic registering farebox units from GF Genfare on its entire fleet, along with accompanying GFI TRM (Ticket Reader/lssue Machine) units.

The farebox units, which have been in use since 1989, enable the rapid collection and registering of cash and token fares. An integrated keypad also allows driversto record special fares, aswell. PSTA added the TRiM units in 1995 and began utilizing magnetic stripe cards at that time. The TRiM unit is able to process (i.e., read/validate, print/issue) all types of magnetic documents, including magnetic ti ckets/passes and transfers. The capabilities of the units also allow a transit system to add stored-value or stored-ride tickets to their fare media mix. PSTA has made use of the units' capabilities by offering roll ing 7-day and 31-day fare cards (i.e., cards that do not register the start date for valid use until the first ti me that they are utilized in a TRiM unit).

According to PSTA, the CENTSaBIШ fareboxes and accompanying TRiM units currently are being upgraded. The system is replacing them with GFI's new Genfare Odyssey Electronic Revenue Center fareboxes (all-in-one registering farebox and ticket reader unit). Genfare product information for the Odysæy indi catesthat this system providesimproved dataregistration, security, and ease of operations. It also supports the optional use of credit cards, proximity smartcards, and employer ID programs. Some of the GFI O dyssy's features incl ude:

- acceptsand validates coins and bills; returns unacceptable coins and bills to passengers, 
- accepts and processes all types of magnetic stripe paper and plastic farecards and passes,

- issues, prints, and encodes machine readable transfersfrom blank stock stored internally;

- accepts and automatically validates tranfersissued by other Odysæy units;

- hasbuilt-in provisions for non-contact smartcard operations,

- has provision for credit card fare payment options, such as VisalMasterCard;

- allowsfor multi-level fare tables for passenger categories, time differentials, zone options and fare media type;

- provides change and on-board card upgrades by cash-to-card conversion;

- includes passenger displays to show transactions and remaining card value; and

- provides optional interface to destination/next stop electronic signsaudio annunciator system; GPS; passenger counters; and on-board bus computer systems

\section{Hillsborough Area Regional Transit Authority}

The Hill sborough Area Regional Transit Authority (HART) is an independent authority that provides fixed-route motorbus and demand response services to all of Hillsborough County (excluding Plant City). According to FY 1999 National Transt Database (NTD) information (the most recent year for whi ch validated NTD dataareavailable), HARTs service areaencompassesapproximately 273 square miles, with a service area population totaling over 922,000 persons. Fixed-route motorbus service is provided seven days per week using a peak fleet of 158 vehicles. HART's fixed-route service provided more than 5.4 million revenue miles of service in FY1999, generating a total of 9.3 million passenger trips.

The results of the initial APTS inventory survey indicate that HART is in the planning stages for a number of APTStechnologies, some of which are al ready moving to the operational phase. Some of these technologies include AVL, vehicle component monitoring, automated operati ons software, onboard safety systems, trip planning information, and advanced communications, among others. Two technologies that are fully operational are HARTs multi-carrier reservation and bill ing system and its automated pararansit system (which includes automated scheduling and computer-aided dispatch). In addition, HART is utilizing an electronic fare payment system on board itsvehicles. Similar to PSTA, the system isutilizing CENTSaBILL electronic regi stering fareboxes from GFI Genfare on its motorbuses

Theelectronic farebox units, which repl aced the system' s Dun can drop-styl e cash boxes, were installed in 1989. The GF TRiM unitswere integrated in 1998 (HART is utilizing the updated, second-design units, TRM 2). With the advent of the TRiM units, HART began making magnetic stripecards available for use. Currently, a one-day unlimited ride fare card can be purchased on any bus. In addition, HART 
also offers non-rolling 5-day and 31-day unlimited use fare cards; however, these fare media are available only at authorized sales outlets.

\section{LYNX Transit}

LYNX Transit is an independent authority that provides fixed-route motorbus, demand response, and vanpool servicesto a three-county region that includes Orange, Seminole, and Osœola Counties. The system also coordinates a five-county regional ridesharing assistance program and transportation disadvantaged services for the region. According to FY 1999 NTD data, LYNX's service area covers more than 2,500 square miles and has a population of almost 1.4 million persons. Fixed-route motorbusservice is provided seven days per week using a peak fleet of 168 vehicles. LYNX provided a total of 19.8 mill ion passenger trips on its fixed-route service and more than 10.4 million revenue miles of service in FY 1999.

While LYNX did not participate in the initial APTS inventory survey, it is known that the system is utilizing electronic fare collection on its motorbuses, and $A V L$ and bus prioritization for its $L Y M M O$ downtown circulator service. The electro nic fare collecti on system consists of Genfare CENTSaBILL electronic registering fareboxes, which were installed in 1990. The system currently is taking advantage of the farebox's swipe card reader, offering both weekly and monthly (non-rolling) swipe passes. However, LYNX has not implemented TRiM units in any of its vehicles to date.

The LYMMO service is free, so the GFI fareb oxes on board the LYMMO busesare used only to count passengers(i. e., a driver usesthe keypad on the unit to enter in the number of personsboarding at each stop). LYMMO, however, does make use of AVL and buspriority technologies. A computerized bus detection system utilizing vehicle-basd transpondersand loop detectorsat various locations along the route is used to I ocate LYMMO busesalong the circulator ali gnment. Information from th is system then is used as input for the passenger advisory system (i.e., station kioskswith electronic mapsand variable message signs, and an audio broadcast system), which provides persons waiting at stations with realtime bus information.

In addition, loop-actuated busonly signals have been integrated with traffic $\infty$ ntrol at 11 intersections along the circulator alignment for the provision of signal priority for LYMMO. The loop detectors in the excl usive bus lane activate a special bus-onl y phase at those signalized intersections where the bus cannot proceed al ong the exclusive bus lane with the general traffic phase. 


\section{Sarasota County Area Transit}

Sarasota County AreaTransit (SCAT) is the informal designation for the Sarasota County Transportation Authority, which functionally operates as the Transit Department of Sarasota County government. SCAT is governed by the Sarasota County Board of County Commissioners and provides fixed-route motorbus and demand-response services to the urbanized portion of the county, incl uding the cities of Sarasota, Venice, Englewood, and North Port, and the Town of LongboatKey. Information from the FY 1999 NTD indicates that SCATs service area has a total population of 272,000 persons and is approximately 159 square miles in size. Fixed-route motorbus service is provided Monday through Saturday from 5:00 a.m. to 8:00 p.m., using a peak fleet of 26 vehicles. In FY 1999, a tota of 1.6 mill ion passenger trips were carried on SCAT buses, which operated a total of 1.5 million revenue miles of service during this fiscal year.

As noted in the first chapter, SCAT is in the planning stages for a number of APTS technologies, including automated operations software, AVL, trip planning information, automated service coordination, and the development of a TMC, among others. The only technology that currently is fully operational is SCATs advanced communications system (Motorola $800 \mathrm{MHz}$ trunked radio system). How ever, SCAT is now in the process of implementing an electronic fare payment system on its entire fleet. In October 2000, the system replaced the GF Genfare non-registering farebox units (i.e., simple drop box for cash fare collection) on its42-vehicle fleet with validating farebox units from Agent Systems, Inc. The new units, called the SmartBox, electronically validate both coins and bills, rejecting counterfeits and slugs, and stack and face bills in the cashbox.

While thes new fareboxesare operational now, SCAT will not be installing the companion SmartBox Magnetic Ticket Units (i.e., the electronic ticket reader) until the end of Summer 2001, at the earliest. One of the major benefits of these units is the ability to issue change in the form of reusable cash cards - a capabil ity that SCAT looks forward to utili zing. The ticket units will be able to accept all forms of tickets and passes, and will even be able to issue and accept transfers In effect, the integrated SmartBox farebox and ticket un it will all ow each ind ivi dual bus to become a full-service ticket and pass sales outlet.

\section{Ann Arbor Transportation Authority}

Ann Arbor Transit Authority (AATA, and also known as "The Ride") is an independent authority that was authorized by an act of the Michigan State Legislature in 1968 to provide public transportation 
services within Washtenaw County. ${ }^{27}$ The system's Articles of Incorporation were created by the City of Ann Arbor, which authorized AATA to provide its servicesthroughout Ann Arbor and beyond its corporate limits. Currently, AATA provides fixed-rou te mo torbus and demand-response services within the Ann Arbor and Ypsilanti urbanized areas and in portions of the Ypsilanti, Pittsield, and Superior Townships. AATA also coordinates a RdeShare program, which facilitates carpool and vanpool services for commuterstraveling within Washtenaw County, aswell as for those persons traveling into the county from Southeast Michigan/Northwest Ohio. FY1999 NTD dataind icate that AATA's service area is 71 square miles in size with a total population of 189,200 persons. Fixed-route motorbus service is provided seven daysper week with a peak vehicle requirement of 59 vehicles. In FY 1999, AATA provided a total of 4.0 mill ion passenger trips on its fixed-route motorbus service; the system operated almost 2.3 million revenue miles of service during this time, as well.

According to information provided on AATA's web site (http://www .theride.org/aoshtml), the system began implementing an Advanced Operating System (AOS) in the fall of 1996. This AOS, a fully integrated public transit communication, operation, and maintenance system, incl udes elements such as advanœed communications, AVL, onboard emergency system, onboard en-route information, computer-assisted transfer management, automated paratransit reservations/scheduling, vehicle component monitoring, video surveillance, automated passenger counting, and electronic fare collection, among others.

According to staff, AATA currently is using Genfare CENTSaBILL electronic registering fareboxes on its vehicle fleet. These units were ori ginally installed in 1984 and were utilized successfully through 1999, when AATA decided to upgrade its system. In February 2000, new electronic fareboxes from another vendor replaced all of the GFI units. Unfortunately, AATA had numerous operational and maintenance issues with the new units that were not satisfactorily addressed. Ultimately, the system had all of $i$ ts ori ginal CENTSaBILL fareb oxes rehabilitated by GFl; these were reinstalled on the bus fleet in January 2001. AATA hasnot implemented TRiM unitsin any of its vehiclesto date, nor is the system taking advantage of the farebox's swipe card reader. Instead, AATA utilizes various multi-ride flash passes in addition to accepting cash for fare payment.

For vehicle location, the system is using Siemens GPS technology. The position of each vehicle can be calculated within one to two meters util izing this system. The GPS signal also provides accurate time to the vehicles so that scheduled times and locations can be compared with actual times and

${ }^{27}$ AATA Strategic Plan: Destination 2010, Ann A rbor Transportation Auth ority, http://www.theride.org/ StragegicPlanText.html, adopted October 1999. 
locationsto determine real-time, on-ti me performance. The bus operator can be notified viaa mobile display terminal (part of the advanced communications system) and the onboard computer whenever a bus is running late; the system is set up to notify AATA'sOperation Center, as well. The AVL system al so is st up to trigger external destination signs/announcementsand the internal next-stop signs and announcements. In addition, it integrateslocation datawith information from other onboard systems, such as fare collection, passenger counters, and component (i.e., engine) monitoring.

\section{Application of SCRITS to Selected Transit Agencies}

In this section, the data inputs for and the resulting outputs from the transit systems' SCRTS analyses are presented. Also discussed are any rati onale provided by the systemsfor their respective user input estimates. The three transit-specific SCRTS worksheets, electronic fare collection, AVL, and bus priority, all are examined. The el ectronic fare collection analysis worksheet has been completed and is presented for all five case study transit systems HART, PSTA, LYNX, SCAT, and AATA. The busAVL analysis worksheet has been completed for LYNX and AATA, and the bus priority analysis worksheet has been completed for LYNX only; these are also presented in this section. To the extent possible, comparisons of the systems' cost/ben efit results have been made and are provided in this section, as well.

As a caveat, it is important to keep in mind that SCRITSis supposed to be a sketch tevel planning tool, as noted previously in its description. That is, it should be utilized to help estimate potential user-side benefits that may result from the implementation of a particular ITS technology - not necessarily for post-deployment evaluation. In this analysis, four of the five systemsincluded as case studies already havein place the technologiesthat are being examined. Only SCAT is sill in the process of deploying a particular technology (i.e., electronic fare collection). Therefore, with direction from FDOT, assessment of the SCRTStool, by necessity, has had to utilize a methodology that does not conform to its original intended use.

This methodology consists of a pre- and post-deployment assessment of the SCRITS-derived user benefits associated with the implementation of the three transit-related ITStechnologies. To this end, each case study transit system was asked to provide information for each of the worksheet data inputs for the pre-deployment and post-deployment casesof their respective ITStechnologies For the systems with technologiesalready in place, inputs for the pre-deployment case required staff to "assume" that a given technology wasnot yet in operation. They then were asked to provide best estimates for those inputs related to the technology's function based on their original expectations. For example, in the case of electronic fare collecti on, on e of the inputs the systems were asked to provide is the percentage 
of passengersusing electronic fare media. For this input, system saff had to disregard actual current electronic fare usage and, instead, provide what their expectation wasfor utilization before the new farebox system was implemented. The post-deployment case simply required the systems to provide actual data based on their current operating experience with a particular technology. ${ }^{28}$

It should be noted that in each of the technology worksheets, therearea number of operational inputs on which the three ITStechnologieswould be expected to have a less immediate impact. Variables such as average percentage of bustravel time devoted to boarding, average number of dail y passengers, and daily vehicle trips on bus corridor, then, were kept constant between the two deployment cases to mitigate their impact on the benefits results (especially since numerousother factorsunrelated to the deployment also could have had an impact on these variables). For example, the availability of electronic fare media ultimately may have an impact on daily ridership, but this effect would not be as immediate asthat on average boarding times for passengers, which more directly affects the benefit of passenger time savings. As a result, in each of the worksheets the variable(s) most closely related to the function of the ITS technology were the only ones that were modified to represent "predeployment expected" and "post-depl oyment actual" values. In the case of electronic fare collection, these vari ables include average passenger boarding times (with conventional and electronic fare) and percentage of passengers with electronic fare. In the case of $A V L$, these variablesincl ude average wait time per passenger, average wait time with AVL, and percentage of passengersusing AVL information. Finally, in the case of bus priority, these variables include percentage of bustravel time due to signal delay and percentage reduction in signal delay from pre-emption.

A final note involvesa variablethat isused in the electronic farecollection and buspriority w orksheets, elasticity of demand with respect to average bus speed. This variable represents the estimated percentage increase in transit ridership that would be expected for each one percent increase in average bus speed. The default value utilized by SCRITSis 0.3 (according to FHWA staff, this value is based on national experience, but areference for its origin could not be provided). This means that, if a system were able to implement improvements to its service that would increase average bus speed by 10 percent, ridership would be expected to increase by approximately 3 percent as a result. Since none of the systemsincluded in this analysis have completed any elasticity studiesrelated to busspeed, it was determined that each system's applicable analysis should utilize the default value of 0.3.

\footnotetext{
${ }^{28}$ Since SCAT and AATA have not had any operational experience with electronic fare collection yet, the methodology for their analyses had to be modified further. SCAT and AATA staff still were required to provide pre-deployment estimates for the worksheet data inputs, but averages from the post-deployment experiences of the other thre e case study transit system s were utilize d to estima te the key inputs for SCAT's and A ATA 's postdeployment condition. This variant methodology is discussed further in the sections detailing the SCRITS analyses for SCAT and AATA.
} 


\section{Pinellas Suncoast Transit Authority}

PSTA planning staffwasprovided with the SCRTSspreadsheet tool and asked to provide pre and postimplementation data for the system's electronic fare collection system for the tool's requi red user inputs. After PSTA staff provided the necessary information, a follow-up phone interview wasutilized to validate and/or darify the system's user inputs and to collect descriptive information about the electronic fare collection system (i.e., manufacturer, model, when implemented, electronic fare media being utilized, etc.). During that conversation, data were verified, corrected as needed, and finalized for inclusion in this analysis.

It should be noted that the SCRTS tool uti lizes a number of baseline inputs (whose values are based on national norms, but can be modified to account for local/regional characteristics) that are utilized throughout the various ITStechnology worksheets. One of thes, the value of time per person hour, is used in the electronic fare collection worksheet. For the purpose of this analysis, a value of $\$ 10.85$ per person hour wasused for PSTA. This value reflects 80 percent of the 1998 average wage rate in the Tampa-St. Petersburg-Clearwater Metropolitan Statistical Area, based on average annual pay data from the 2000 Florida Statistical Abstract (Table 6.57). ${ }^{29}$

Tables 3-1 and 3-2 reflect the user inputs and resulting calculated values for PSTA's pre- and posdeployment conditions, respectively. According to PSTA saff, average busspeed is 15 milesper hour, average passenger trip length is 5 miles, and the average perœnt of bus travel time that is devoted to boarding is approximately 50 percent. Thislast input value wasestimated based on the revenue hours of service, ridership levels, and assumed passenger boarding times for several typical routes in the system. Averageweekday ridership was indicated to be 35,000 and average daily ridership (including weekends) is about 29,400 . PSTA also provided financial information for its electronic fareb ox system implementation. The total cost, including installation, was $\$ 2,055,000$ and a useful service life of 10 years is expected for the equi pment. PSTA staff estimated an annual operating/main tenance cost of

\footnotetext{
29 Accord ing to the report, Assessing the Benefits and Costs of ITS Projects: Volume 1 Methodology (Gillen, Li, Dahlgren, and Chang, California PATH Program, Institute of Transportation Studies, University of California, Berkeley, UCB-ITS-PRR-99-9, March 1999), one of the alternative techniques that the Texas Transportation Institute recommends for estimating the value of time for evaluating projects is using 70 to 80 percent of the wage rate. Similarly, a model used by the Federal High way Ad ministration (FH WA) su ggests the use of 80 percent of the average wage rate for both work and non-work travel (from An Appraisal of Candidate Project Evaluation Measures, an appendix to the FTA Policy Paper, Revised Measures for Assessing Major Investments: A Discussion Draft, September 1994). In this appendix, given the wide range in approaches to valuing travel time savings, FTA proposed valuing time at 80 percent of loc al wage rates to be consistent with FHW A practic es until a uniform approach could be developed.
} 
$\$ 200,000$ for the system, but believe that the new system has resulted in $\$ 100,000$ per year in labor cost savings.

The majority of the discussion with PSTA staff revolved around average boarding times and electronic fare utilization. Among the Forida systems analyzed herein, PSTA is unique in that the system implemented electronic fareboxes and integrated TRM units at the same time to replace its nonregistering drop boxes (which required a significantly higher level of driver involvement to complete each faretransaction). Asa result, PSTA's average boarding time per passenger with conventional fare (e.g., cash, coins) dropped significantly from an estimated 9 seconds per transaction prior to implementation, to an estimated 5 seconds per tran saction after deployment. For average boarding time per passenger with electronic fare, pri or to depl oyment of the new fareboxes, PSTA had assumed a 50 percent reduction in boarding ti me for those passengers using el ectronic fare media ascompared to those with conventional fare (i.e., 4.5 seconds, or 9 seconds $\times$ [1 - 0.5]). In reality, PSTA staff believe that boarding times for those using electronic fare media are even lower than anticipated: 3 seconds per transaction.

As for utilization of electronic fare media by its passengers, PSTA's pre-implementation estimate was relatively close to that which actually occurred after deployment. Prior to implementation, PSTA staff believed that approximately 30 percent of their passengerswould make use of electronic fare media. Actually, after deployment of the new fareboxes and TRiM units, about 35 percent of ridership is paying for trips with electronic fare.

As shown in Table 3-1, application of PSTA's pre-deployment user inputsresults in an annual value of time savingsfor its passengers of more than $\$ 2.9$ million (over $\$ 2.4$ million if only weekday service is included). The benefit/cost ratio for this technology for a full week is 7.4 (6.2 for weekdays only). These figures, then, are the estimated results thatPSTA could expect from implementing electronic fare collection on board its vehicle fleet. Comparatively, using PSTA's post-deployment user inputs, it is evident in Table 3-2 that the actual value of time savings for the system's users is about $\$ 2.7$ million (about $\$ 2.3$ million for weekdaysonly). In addition, the ben efit/cost ratio for afull week is6.9 (5.8 for weekdays only).

These figures indicate that, when considering the cas for a full week, PSTA's annual value of time savingsand benefit/cost ratio both decreased ap proximately 6.7 percentbetween the "pre-deployment expected" and "post-deployment actual" values. The primary reason for this decline is the differences in the pre- and post-implementation average passenger boarding time estimates. For the predeployment condition, PSTA staff esti mated 9-second boarding timesfor passengerswith conventional 
fareand 4.5-second boarding timesfor passengerswith electronic fare-adifference (i. e., time savings) of 4.5 seconds. In reality, PSTA staffbelieve that the incremental difference in boarding ti mes betw een passengerswith conventional fare and those with electronic fare is only about two seconds (5 æconds for conventional fare versus 3 seconds for electronic fare). This means that the time savings per electronic fare transaction decreased 1.5 sconds between what was expected and what was actually experienced after implementation. Nevertheless, these results indicate that all of PSTA's passengers are accruing significant benefits in terms of time savings because of the implementation of the electronic fare collection system and the resulting availability of electronic fare media. 
Table 3-1

SCRITS Worksheet: Pre-Implementation Analysis of PSTA's Bectronic Fare Collection

\begin{tabular}{|c|c|c|}
\hline & User Input & Calculated Value \\
\hline \multicolumn{3}{|l|}{ TRAFIC AND TRAVE (USR BENEFITSON LY) } \\
\hline Current average busspeed on arterials (mph) & 15 & \\
\hline Current bus speed in minutesper mile & & 4.00 \\
\hline Average percentage of bustravel time devoted to boarding & $50 \%$ & \\
\hline Average boarding time per passenger with conventional fare(sec.) & 9 & \\
\hline Average boarding time per passnger with electronic fare (æec.) & 4.5 & \\
\hline Current percentage of passengers with electronic fare & $0 \%$ & \\
\hline Percentage of passengers with edectronic fare in this scenario & $30 \%$ & \\
\hline Minutesper mile with this electronic fare scenario & & 3.70 \\
\hline Average bus speed with electronic fare (mph) & & 16.22 \\
\hline Estimated \% increase in speed with electronic fare & & $8.1 \%$ \\
\hline Average number of $d$ ail y passengers weekd ay & 35,000 & \\
\hline Average numb er of dail y passengers full w eek & 29,400 & \\
\hline Average passenger trip length (mi les) & 5 & \\
\hline Average dail y person hours wi thout el ectronic fare, weekday & & 11,667 \\
\hline Average dail y person hours with electronic fare, weekday & & 10,792 \\
\hline Savingsin person hoursper day, weekday & & 875 \\
\hline Savings in person hours per year, wœkdays only & & 224,875 \\
\hline Average dail y person ho urs withou t electro nic fare, ful I w eek & & 9,800 \\
\hline Aver age dail y person ho urs with el ectro nic fare, ful I w eek & & 9,065 \\
\hline Savingsin person hoursper day, full week & & 735 \\
\hline Savingsin person hoursper yea, full week & & 268,275 \\
\hline Elasticity of demand with respect to aver age bus speed & 0.3 & \\
\hline Estimated increase in average w eekday board ings & & 851 \\
\hline Estimated increase in average dail y bo ardings, full week & & 715 \\
\hline Percent reduction in average weekday vehicle trips & & $0.09 \%$ \\
\hline \multicolumn{3}{|l|}{ COSTSAND BENEFITS } \\
\hline Annual value of time savings, weekdays only & & $\$ 2,439,894$ \\
\hline Annual value of ti me savings, full w eek & & $\$ 2,910,784$ \\
\hline Installation cost & $\$ 2,055,000$ & \\
\hline Service life (years) & 10 & \\
\hline Annual operating/maintenancecost & $\$ 200,000$ & \\
\hline Annual savings in agency labor cost & $\$ 100,000$ & \\
\hline Annualization factor & & 0.142 \\
\hline Total annualized cost & & $\$ 391,810$ \\
\hline Annualized benefits (weekday only) minus annualized cost & & $\$ 2,048,084$ \\
\hline Annualized benefits (full week) minus annualized œst & & $\$ 2,518,974$ \\
\hline Benefit/cost ratio wœkday only & & 6.2 \\
\hline Benefit/co st ratio full week & & 7.4 \\
\hline
\end{tabular}


Table 3-2

SCRITS Worksheet: Post-Implementation Analysis of PSTA's Bectronic Fare Collection

\begin{tabular}{|c|c|c|}
\hline & User Input & Calculated Value \\
\hline \multicolumn{3}{|l|}{ TRAFIC AND TRAVE (USRR BENEFITS ON LY) } \\
\hline Current average busspeed on arterials ( $\mathrm{mph}$ ) & 15 & \\
\hline Current busspeed in minutesper mile & & 4.00 \\
\hline Average percentage of bustravel time devoted to boarding & $50 \%$ & \\
\hline Average boarding time per passenger with conventional fare(æc.) & 5 & \\
\hline Average boarding time per passenger with electronic fare (sec.) & 3 & \\
\hline Current percentage of passengers with electronic fare & $35 \%$ & \\
\hline Percentage of passengers with dectronic fare in this scenario & $35 \%$ & \\
\hline Minutesper mile with this electronic fare scenario & & 3.72 \\
\hline Average bus speed with electronic fare ( $\mathrm{mph}$ ) & & 16.13 \\
\hline Estimated \% increase in sped with electronic fare & & $7.5 \%$ \\
\hline Average number of dail y passengers weekday & 35,000 & \\
\hline Average numb er of dail y passengers ful I w eek & 29,400 & \\
\hline Average passenger trip length (mi les) & 5 & \\
\hline Average dail y person hours wi thout el ectronic fare, weekday & & 11,667 \\
\hline Average dail y person hours wi th electronic fare, weekday & & 10,850 \\
\hline Savingsin person hoursper day, weekday & & 817 \\
\hline Savings in person hours per year, wœkdays only & & 209,883 \\
\hline Average dail y person hours without el ectro nic fare, full w eek & & 9,800 \\
\hline Average dail y person ho urs with el ectro nic fare, ful I w eek & & 9,114 \\
\hline Savingsin person hoursper day, full week & & 686 \\
\hline Savingsin person hoursper yea, full week & & 250,390 \\
\hline Elasticity of demand with respect to aver age bus speed & 0.3 & \\
\hline Esimated i ncrease in average w eekday b oard in gs & & 790 \\
\hline Esimated increase in average dail y boardings, full week & & 664 \\
\hline Percent reduction in average weekday vehicle trips & & $0.08 \%$ \\
\hline \multicolumn{3}{|l|}{ COSTSAND BENEFITS } \\
\hline Annual value of timesavings, wekdays only & & $\$ 2,277,234$ \\
\hline Annual value of ti me savings, full w eek & & $\$ 2,716,732$ \\
\hline Installation cost & $\$ 2,055,000$ & \\
\hline Service life (years) & 10 & \\
\hline Annual operating/maintenance cost & $\$ 200,000$ & \\
\hline Annual savings in agency labor cost & $\$ 100,000$ & \\
\hline Annualization factor & & 0.142 \\
\hline Total annualized cost & & $\$ 391,810$ \\
\hline Annualized benefits (weekday only) minus annualized cost & & $\$ 1,885,424$ \\
\hline Annualized benefits (full week) minus annualized œst & & $\$ 2,324,922$ \\
\hline Benefit/cos ratio wœkday only & & 5.8 \\
\hline Benefi t/co st rati o full week & & 6.9 \\
\hline
\end{tabular}




\section{Hillsborough Area Regional Transit Authority}

The SCRITStool wasprovided to HART planningstaff, who was then asked to review the spreadsheet's electronic fare collection worksheet and provide pre and post-implementation datafor that particular worksheet'srequ ired u ser in puts. After HART staff provided some preliminary information, a follow -up meeting was held at HART to review this information and collect other necessary input data for the analysis (at this meeting, a plan for HART to collect actual boarding time data also was discussed; subsequently implemented, results of this effort are discussed later in this section). Subsequent phone contact wasneeded to finalize the system'suser inputsand to collect descriptive information about the electronic fare collection system (i.e., man ufacturer, model, when implemented, electronic fare media being utilized, etc.). Additionally, as was the case for PSTA, the HART analysis utilized $\$ 10.85$ to represent the value of time per person hour (i.e., 80 percent of the 1998 average wage rate in the Tampa-St. Petersburg-Clearwater M etropol itan Stati stical Area).

The user inputs and resulting cal cul ated values for HARTs pre- and post-deployment conditions are shown in Tables 3-3 and 3-4, respecti vely. HART staff indicated that average bus speed is 13 mi les per hour, average passenger trip length is 4.33 miles, and the average percent of bus travel time that is devoted to boarding is approximately 20 percent. The first two of these inputs are based on system operating data, whil e the third figure is an estimate HART staff based on knowledge of bus operations. Average weekday ridership was indicated to be 28,500 and average daily ridership (including weekends) is 23,100 . The total cost, including installation, of HART's electronic farebox system implementation was $\$ 650,000$. The anticipated useful service life of the equipment is five years and HART staff estimated an annual operating/maintenance cost of $\$ 65,000$ for the system. HART staff did not bel ieve that the new system resulted in any measurable labor cost savings.

Similar to the PSTA case study experience, most of the discussion of user inputs with HART involved average boarding ti mes and el ectronic fare utilization. Unl ike PSTA, HART implemented its TRiM units (in 1998) a number of years after installation of its electronic fareboxes (in 1989), so the disparity between conventional and electronic fare boarding times is not significant in the pre-deployment condition. According to estimates from HART staff, the average boarding time per passenger with conventional farefor thiscase was assumed to be about six secondsper transaction, while the average boarding time per passenger with electronic fare was assumed to be five seconds per transaction. However, further discussion of average boarding times, in genera, and boarding time inputs for the post-deployment condition led HART staff to believe that they did not really have a grasp on actual passenger boarding times, regardless of payment method used. Therefore, HART volunteered to conduct a boarding time analysis (based on a process developed by CUTR) to develop improved 
estimates for the SCRTS analysis, as well as a better understanding of the boarding/fare payment process. According to the documentation ${ }^{30}$ of HARTs boarding time analysis, the boarding time average for passengers paying by cash was 11.56 seconds and for passengerspaying by fare card was 7.25 seconds. ${ }^{31}$ These, then, were the average boarding time inputs utilized for the post-deployment condition.

In discussing electronic fare utilization, HART staff indicated that, prior to implementation, it was expected that 30 percent of passengerswould make use of electronic fare media. In actuality, after deployment of the TRiM units, 70 percent of HART's ridership is paying for trips with electronic fare.

Asshown in Table 3-3, application of HART's pre-deployment uær inputs results in an annual value of time savings for its passengers of more than $\$ 300,000$ (about $\$ 263,000$ if only week day service is included). The benefit/cost ratio for this technology for a full week is 1.4 (1.2 for weekdays only). These are the estimated results that HART could expect from implementing electronic fare collection on board itsvehicle flet. Comparatively, HART'spost-deployment user inputsresult in anactual value of time savings for the system's users of about $\$ 1.6$ million (about $\$ 1.4$ mill ion for weekdaysonly), as shown in Table 3-4. In addi tion, the benefit/cost ratio for a full week is 7.2 (6.2 for weekdays only).

When considering the case for a full week, HART's annual value of time savings and ben efit/cost ratio both increased significantly (400+ percent in each case) between the "pre-deployment expected" and "post-deployment actual" values. The primary reasons for the increase are the differences in the preand post-implementation average passenger boarding time and electronic fare use estimates. For the pre-deployment condition, the difference in estimated average boardingtimes(i.e., time savings) isonly one second, while the differencein post-deployment averageboarding timesis more than four seconds. This means that the time savings per electronic fare transaction increased more than three seconds betw een what wasexpected and what was actually experienced after implementation. In addition, the percent of passengerswith electronic fare more than doubled from 30 percent to 70 percent between what was expected and what actually occurred. Regardl ess of these differences, though, like PSTA's situation, HARTs passengers are benefitting in terms of time savings becauæ of the electronic fare collection system deployment and the resulting availability of electronic fare media.

\footnotetext{
${ }^{30}$ Impact of Electronic Fare Card on Boarding Times, Hillsborough Area Regional Transit Authority, Tampa, FL, July 13, 2001.

${ }^{31}$ Interestingly, it was determined that the typical fare transaction took several seconds longer than staff anticipated because of the number of transaction s that involved a conversation between the passenger and the driver. The av erage bo arding time for transactions with out conversation was 6.25 second s, while tran sactions with conversation took 13.55 seconds, on average.
} 
Table 3-3

SCRITS Worksheet: Pre-Implementation Analysis of HART's Bectronic Fare Collection

\begin{tabular}{|c|c|c|}
\hline & User Input & Calculated Value \\
\hline \multicolumn{3}{|l|}{ TRAFIC AND TRAVE (USRR BENEFITSON LY) } \\
\hline Current average busspeed on arterials ( $\mathrm{mph}$ ) & 13 & \\
\hline Current bus speed in minutesper mile & & 4.62 \\
\hline Average percentage of bustravel time devoted to boarding & $20 \%$ & \\
\hline Average boarding time per passnger with conventional fare(æec.) & 6 & \\
\hline Average boarding time per passnger with electronic fare (æec.) & 5 & \\
\hline Current percentage of passengers with electronic fare & $0 \%$ & \\
\hline Percentage of passengers with electronic fare in this scenario & $30 \%$ & \\
\hline Minutesper mile with this electronic fare scenario & & 4.57 \\
\hline Average bus speed with electronic fare (mph) & & 13.13 \\
\hline Estimated \% increase in speed with electronic fare & & $1.0 \%$ \\
\hline Average number of $d$ ail y passengers weekd ay & 28,500 & \\
\hline Average number of dail y passengers ful I w eek & 23,100 & \\
\hline Average passenger trip length (mi les) & 4.33 & \\
\hline Average dail y person hours wi thout el ectronic fare, weekday & & 9,493 \\
\hline Average dail y person hours wi th electronic fare, weekday & & 9,398 \\
\hline Savingsin person hoursper day, weekday & & 95 \\
\hline Savings in person hours per year, wœkdays only & & 24,206 \\
\hline Average dail y person hours without el ectro nic fare, full w eek & & 7,694 \\
\hline Average dail y person ho urs with el ectro nic fare, ful I w eek & & 7,617 \\
\hline Savingsin person hours per day, full week & & 77 \\
\hline Savingsin person hoursper yea, full week & & 28,083 \\
\hline Elastici ty of demand with respect to average bus speed & 0.3 & \\
\hline Estimated i ncrease in average w eekday b oard in gs & & 86 \\
\hline Esimated increase in average dail y boardings, full week & & 70 \\
\hline Percent reduction in average weekday vehicle trips & & $0.01 \%$ \\
\hline \multicolumn{3}{|l|}{ COSTSAND BENEFITS } \\
\hline Annual value of timesavings, wekdays only & & $\$ 262,639$ \\
\hline Annual value of ti me savings, ful I w eek & & $\$ 304,705$ \\
\hline Installation cost & $\$ 650,000$ & \\
\hline Service life (years) & 5 & \\
\hline Annual operating/maintenance cost & $\$ 65,000$ & \\
\hline Annual savings in agency labor cst & $\$ 0$ & \\
\hline Annualization factor & & 0.244 \\
\hline Total annualized cost & & $\$ 223,600$ \\
\hline Annualized benefits (weekday only) minusannualized cost & & $\$ 39,039$ \\
\hline Annualized benefits (full week) minus annualized ost & & $\$ 81,105$ \\
\hline Benefit/cost raio wœkday only & & 1.2 \\
\hline Benefi tco st rati o full week & & 1.4 \\
\hline
\end{tabular}


Table 3-4

SCRITS Worksheet: Post-Implementation Analysis of HART's Bectronic Fare Collection

\begin{tabular}{|c|c|c|}
\hline & User Input & Calculated Value \\
\hline \multicolumn{3}{|l|}{ TRAFIC AND TRAVB (USR BENEFITSON LY) } \\
\hline Current average busspeed on arterials (mph) & 13 & \\
\hline Current bus speed in minutesper mile & & 4.62 \\
\hline Average percentage of bustravel time devoted to boarding & $20 \%$ & \\
\hline Average boarding time per pasænger with conventional fare(æc.) & 11.6 & \\
\hline Average boarding time per passnger with electronic fare (æec.) & 7.2 & \\
\hline Current percentage of passengers with electronic fare & $70 \%$ & \\
\hline Percentage of passengers with edectronic fare in this scenario & $70 \%$ & \\
\hline Minutesper mile with this electronic fare scenario & & 4.37 \\
\hline Average bus speed with electronic fare (mph) & & 13.73 \\
\hline Estimated \% increase in speed with electronic fare & & $5.6 \%$ \\
\hline Average number of $d$ ail y passengers weekd ay & 28,500 & \\
\hline Average numb er of dail y passengers full w eek & 23,100 & \\
\hline Average passenger trip length (mi les) & 4.33 & \\
\hline Average dail y person hours wi thout el ectron ic fare, weekday & & 9,493 \\
\hline Average dail y person hours with electronic fare, weekday & & 8,989 \\
\hline Savingsin person hours per day, weekday & & 504 \\
\hline Savings in person hours per year, wœkdays only & & 128,544 \\
\hline Average dail y person ho urs withou t electro nic fare, ful I w eek & & 7,694 \\
\hline Average dail y person hours with el ectro nic fare, ful I w eek & & 7,285 \\
\hline Savingsin person hoursper day, full week & & 409 \\
\hline Savingsin person hoursper yea, full week & & 149,132 \\
\hline Elastici ty of demand with respect to aver age bus speed & 0.3 & \\
\hline Esimated increase in average w eekday b oard in gs & & 479 \\
\hline Estimated increase in average dail y boardings, full week & & 389 \\
\hline Percent reduction in average weekday vehicle trips & & $0.05 \%$ \\
\hline \multicolumn{3}{|l|}{ COSTSAND BENEFITS } \\
\hline Annual value of time savings, weekdays only & & $\$ 1,394,704$ \\
\hline Annual value of ti me savings, full w eek & & $\$ 1,618,087$ \\
\hline Installation cost & $\$ 650,000$ & \\
\hline Service life (years) & 5 & \\
\hline Annual operating/maintenance cost & $\$ 65,000$ & \\
\hline Annual savings in agency labor $\infty s t$ & $\$ 0$ & \\
\hline Annualization factor & & 0.244 \\
\hline Total annualized cost & & $\$ 223,600$ \\
\hline Annualized benefits (weekday only) minus annualized cost & & $\$ 1,171,104$ \\
\hline Annualized benefits (full week) minus annualized œst & & $\$ 1,394,487$ \\
\hline Benefit/cos ratio wœkday only & & 6.2 \\
\hline Benefi t/co st ratio full week & & 7.2 \\
\hline
\end{tabular}




\section{LYNX Transit}

The SCRTS tool also wasprovided to LYNX planning staff; however, they were asked to review three of the tool's worksheets(electronic fare collection, automatic vehicle location and information, and bus priority systems) and provide pre- and post-implementation datafor the required user inputsfor each. Initially, a meeting washeld at LYNX to provide the SCRTSspreadsheet and discuss the uঙ of the tool. Subsequent phone contact with various saff was necessary to collect and/or verify the system's user inputs, as well as to gather descriptive information about the electronic fare collection system (i.e., manufacturer, model, when implemented, electronic fare media being utilized, etc.)and the other two technologies. It was even the case that City of Orlando Traffic Department staff was contacted to retrieve various traffic and cost datafor the AVL and priority technologies. It also is important to note that this andysisutilizes $\$ 10.68$ to represent the value of time per person hour (i.e., 80 percent of the 1998 average wage rate in the Orlando Metropolitan Satistical Area) and 1.2 to represent the average daily vehicle occupancy for daily automobile trips (needed as a baseline input for the bus priority worksheet, this value was estimated by LYNX staff and supported by City of Orlando Traffic Department staff).

Theuser inputsand resulting calculated valuesfor the pre-and post-deployment conditionsfor LYNX's electronic fare payment system are shown in Tables 3-5 and 3-6, respectively. LYNX staff indicated that average bus speed is 15 miles per hour, the average passenger trip length is 6.4 miles, and the average percent of bus travel time that is devoted to boarding is approximately 25 percent. The first two of these inputs are based on system operating data, while the third figure is a LYNX staff estimate based on knowledge of the system's bus operations. Average weekday ridership was indicated to be 70,000 and average daily ridership (including weekends) is 59,300 . The total cost, including installation, of LYNX' selectronic registering fareboxeswas estimated atabout $\$ 900,000$ (recall that the system currently is not utilizing integrated TRiM units). The anticipated useful service life of the equipment was estimated to be between 10 and 12 years, so a value of 11 years was utilized in the analysis. In addition, LYNX staff estimated an annual operating/maintenance cost of $\$ 40,000$ for the system, but were not sure if its use resulted in any measurable labor cost savings (therefore, a value of zero dollars was used).

Average boarding timesand extent of electronic fare utilization were also discussed with LYNX staff. According to their estimates, the average boarding time per passenger with conventional fare is six seconds per transaction. For the pre-deployment case, staff indicated that about a two-second time savings was anticipated with the use of the swi pe passes, so the average boarding ti me per passenger with electronic fare for this case was assumed to be four seconds per transaction. Additionally, staff 
believe that this estimate also is representative of post-deployment average boarding times for passengersusing electronic fare media, so the four-second per transaction figure was utilized for this case, as well.

As for the percentage of passengers utilizing electronic fare, LYNX staff indicated that the preimplementation expectation for the proportion of ridership that would make use of electronic fare media was 40 percent. In actuality, after deployment of the electronic fareboxes, only 26 percent of LYNX's ridership is paying for trips wi th electronic swipe passes.

According to the information in Table 3-5, application of LYNX's pre-deployment user inputs results in an annual value of time savings for its passengers of more than $\$ 3.3$ million (about $\$ 2.7$ million if only weekday service is included). The benefit/cost ratio for this technology for a full week is 20.6 (17.1 for wekdaysonly). These are the estimated results that LYNX could expect from implementing electronic fare collection on board itsvehicle fleet. Comparatively, as indicated in Table 3-6, LYNX's post-deployment user inputs result in an actual value of time savings for the system's users of about \$2.1 million (about \$1.8 million forweekdaysonly). In addition, the post-deployment benefit/cost ratio for a full week is 13.4 (11.1 for weekdays onl y).

Examination of the case for afull week shows that LYNX' sannual value of time savings and benefit/cost ratio both decreased about 35 percent between the "pre-deployment expected" and "post-deployment actual" values. Since the average boarding times for conventional and electronic fare usage are identical between the two cases, the reason for this decline is LYNX's electronic fare use estimates. Originally, LYNX expected swipe pass utilization to reach 40 percent. However, after deployment of the new fareboxes, the percent of passengerswith electronic fare is only 26 percent, a 35 percent drop between the anticipated utilization level and that which actually occurred. Regardless of this issue, though, it is still the case that, according to the post-deployment SCRITSanalysis, LYNX's passengers are benefitting in termsof time savings because of the electronic fareboxes and the resulting availability of the weekly and monthly swipe passes. 
Table 3-5

\section{SCRITS Worksheet: Pre-Implementation Analysis of LYNX's Bectronic Fare Collection}

\begin{tabular}{|c|c|c|}
\hline & User Input & Calculated Value \\
\hline \multicolumn{3}{|l|}{ TRAFIC AND TRAVE (USRR BENEFITS ON LY) } \\
\hline Current average busspeed on arterials ( $\mathrm{mph}$ ) & 15 & \\
\hline Current bus speed in minutesper mile & & 4.00 \\
\hline Average percentage of bustravel time devoted to boarding & $25 \%$ & \\
\hline Average boarding time per passenger with conventional fare(sec.) & 6 & \\
\hline Average boarding time per passenger with electronic fare (sec.) & 4 & \\
\hline Current percentage of passengers with electronic fare & $0 \%$ & \\
\hline Percentage of passengers with dectronic fare in this scenario & $40 \%$ & \\
\hline Minutesper mile with this electronic fare scenario & & 3.87 \\
\hline Average bus speed with electronic fare (mph) & & 15.52 \\
\hline Estimated \% increase in sped with electronic fare & & $3.4 \%$ \\
\hline Average number of d ail y passengers weekd ay & 70,000 & \\
\hline Average numb er of dail y passengers full w eek & 59,300 & \\
\hline Average passenger trip length (mi les) & 6.4 & \\
\hline Average dail y person hours wi thout el ectronic fare, weekday & & 29,867 \\
\hline Average dail y person hours with electronic fare, weekday & & 28,871 \\
\hline Savingsin person hoursper day, weekday & & 996 \\
\hline Savings in person hours per yœar, wœkdaysonly & & 255,858 \\
\hline Average dail y person ho urs withou t el ectro nic fare, full w eek & & 25,301 \\
\hline Aver age dail y person ho urs with el ectro nic fare, ful I w eek & & 24,458 \\
\hline Savingsin person hoursper day, full week & & 843 \\
\hline Savingsin person hoursper year, full week & & 307,833 \\
\hline Elastici ty of demand with respect to average bus speed & 0.3 & \\
\hline Estimated increase in average w eekday board ings & & 724 \\
\hline Estimated increase in average dail y bo ardings, full week & & 613 \\
\hline Percent reduction in average weekday vehicle trips & & $0.07 \%$ \\
\hline \multicolumn{3}{|l|}{ COSTSAND BENEFITS } \\
\hline Annual value of timesavings, weekdays only & & $\$ 2,732,561$ \\
\hline Annual value of ti me savings, full w eek & & $\$ 3,287,655$ \\
\hline Installation cost & $\$ 900,000$ & \\
\hline Service life (years) & 11 & \\
\hline Annual operating/maintenancecost & $\$ 40,000$ & \\
\hline Annual savings in agency labor cost & $\$ 0$ & \\
\hline Annualization factor & & 0.133 \\
\hline Total annualized cost & & $\$ 159,700$ \\
\hline Annualized benefits (weekday only) minus annualized cost & & $\$ 2,572,861$ \\
\hline Annualized benefits (full week) minus annualized oost & & $\$ 3,127,955$ \\
\hline Benefit/cos ratio wœkday only & & 17.1 \\
\hline Benefi tco st ratio full week & & 20.6 \\
\hline
\end{tabular}


Table 3-6

SCRITS Worksheet: Post-Implementation Analysis of LYNX's Bectronic Fare Collection

\begin{tabular}{|c|c|c|}
\hline & User Input & Calculated Value \\
\hline \multicolumn{3}{|l|}{ TRAFIC AND TRAVE (USR BENEFITSON LY) } \\
\hline Current average busspeed on arterials (mph) & 15 & \\
\hline Current bus speed in minutesper mile & & 4.00 \\
\hline Average percentage of bustravel time devoted to boarding & $25 \%$ & \\
\hline Average boarding time per passenger with conventional fare(sec.) & 6 & \\
\hline Average boarding time per passnger with electronic fare (æec.) & 4 & \\
\hline Current percentage of passengers with electronic fare & $26 \%$ & \\
\hline Percentage of passengers with dedronic fare in this scenario & $26 \%$ & \\
\hline Minutesper mile with this electronic fare scenario & & 3.91 \\
\hline Average bus speed with electronic fare (mph) & & 15.33 \\
\hline Estimated \% increase in speed with electronic fare & & $2.2 \%$ \\
\hline Average number of $d$ ail y passengers weekd ay & 70,000 & \\
\hline Average numb er of dail y passengers full w eek & 59,300 & \\
\hline Average passenger trip length (mi les) & 6.4 & \\
\hline Average dail y person hours wi thout el ectronic fare, weekday & & 29,867 \\
\hline Average dail y person hours with electronic fare, weekday & & 29,220 \\
\hline Savingsin person hoursper day, weekday & & 647 \\
\hline Savings in person hours per year, wœkdays only & & 166,308 \\
\hline Average dail y person ho urs withou t electro nic fare, ful I w eek & & 25,301 \\
\hline Average dail y person ho urs with el ectro nic fare, ful I w eek & & 24,753 \\
\hline Savingsin person hoursper day, full week & & 548 \\
\hline Savingsin person hoursper yea, full week & & 200,091 \\
\hline Elasticity of demand with respect to average bus speed & 0.3 & \\
\hline Estimated increase in average w eekday board ings & & 465 \\
\hline Estimated increase in average dail y boardings, full week & & 394 \\
\hline Percent reduction in average weekday vehicle trips & & $0.05 \%$ \\
\hline \multicolumn{3}{|l|}{ COSTSAND BENEFITS } \\
\hline Annual value of time savings, weekdays only & & $\$ 1,776,165$ \\
\hline Annual value of ti me savings, ful I w eek & & $\$ 2,136,976$ \\
\hline Installation cost & $\$ 900,000$ & \\
\hline Service life (years) & 11 & \\
\hline Annual operating/maintenancecost & $\$ 40,000$ & \\
\hline Annual savings in agency labor cost & $\$ 0$ & \\
\hline Annualization factor & & 0.133 \\
\hline Total annualized cost & & $\$ 159,700$ \\
\hline Annualized benefits (weekday only) minus annualized cost & & $\$ 1,616,465$ \\
\hline Annualized benefits (full week) minus annualized œst & & $\$ 1,977,276$ \\
\hline Benefit/cost ratio wœkday only & & 11.1 \\
\hline Benefit/co st ratio full week & & 13.4 \\
\hline
\end{tabular}


LYNX staff also was asked to assist with a SCRTS analysis of the AVL system being utilized on the LYMMO downtown circulator service. The user inputsand resulting calculated valuesfor the pre-and post-deployment conditions for the automatic vehicle location and information worksheet are shown in Tables 3-7 and 3-8, respectively. LYNX staff indicated LYMM O's average weekday dail y boardings to be 4,000 and average daily boardingsfor a full week (i.e., including weekends) to be 3,100.

According to the City of Orlando Traffic Divi sion and LYNX staff, the tota cost (including installation) of LYNX's AVL and bus priority systemswas approximately $\$ 1,000,000$. Snce the systems use a lot of the same infrastructure and equipment and were purchased together, it was difficult for staff to provide a cost breakdown for the two systems. The best estimate that could be provided is that each represented about 50 percent of the initial total cost. Therefore, $\$ 500,000$ was used as the total cost for the LYMMO AVL system. The anticipated useful service life of the equi pment $w$ as estimated to be between 8 and 10 years, so a value of 9 years was utilized in the analysis. Additionally, LYNX saff could not provide any information on annual operating/maintenance costs for the system, so a value of zero dollars wasused. Smil arly, a value of zero dollars also was used for annual savingsin agency labor cost since staff did not bel ieve that the use of $A V L$ resul ted in any measurable labor cost savings.

The three other user inputs needed for the AVL analysis worksheet include current average wait time per passenger, average wait time per passenger with the AVL system, and percent of passengers utilizing information from the AVL system (i.e., real-time information resulting from the AVL system that is displayed at various stopsand/or transfer stations). These variables were also discussed with LYNX staff. For the pre-deployment case, LYNX had originally planned for 10-minute headways, so it was assumed that average wait time would be 10 minutes By using the AVL-derived real-time information at the LYMMO stops, it was expected that passengerswould wait only two minutes, on average. LYNX staff also expected that all (i.e., 100 percent) LYMMO passengers would make use of the available information.

During discussion of the post-deployment case, LYNX staff indicated that average wait times after deployment of the AVL system are actually around two minutes, regardless of whether the AVL-deri ved information is utilized or not. According to staff, the reason for this is that the LYMMO system is operating on such short (four-minute) headways. Because of the rel atively short ti me span between successive vehicles, staff believe that passengers will not need or want to make use of the real-time information since the wait time is already so short. They believe the information kiosks now have become more of novelty than a needed source of real-time information for LYMMO vehicle arrival times. As a result, the post-deployment input for percent of passengers utilizing the AVL-derived information at the stops is only 60 percent. 
Table 3-7

SCRITS Worksheet: Pre-Implementation Analysis of LYNX's Automatic Vehicle Location

\begin{tabular}{|c|c|c|}
\hline & User Input & Calculated Value \\
\hline \multicolumn{3}{|l|}{ TRAFIC AND TRAVE (USR BENEFITS ON LY) } \\
\hline Current average wait time per passenger (min.) & 10 & \\
\hline Average wait time with AVL system (min.) & 2 & \\
\hline Average number of week day dail y bo ardings & 4,000 & \\
\hline Average number of dail y boardings, full week & 3,100 & \\
\hline Percent of passengers that use the information & $100 \%$ & \\
\hline Hours of time saved per weekday & & 533 \\
\hline Ho urs of time saved per average day, full w eek & & 413 \\
\hline Hours of timesaved per yœar, wœkdays only & & 137,067 \\
\hline Hours of time saved per year, total & & 150,867 \\
\hline \multicolumn{3}{|l|}{ COSTSAND BENEFITS } \\
\hline Annual value of time savings, weekdays only & & $\$ 1,463,872$ \\
\hline Annual value of ti me savings, ful I w eek & & $\$ 1,611,256$ \\
\hline Installation cost & $\$ 500,000$ & \\
\hline Service life (years) & 9 & \\
\hline Annual operating/maintenancecost & $\$ 0$ & \\
\hline Annual savings in agency labor $\infty$ st & $\$ 0$ & \\
\hline Annualization factor & & 0.153 \\
\hline Total annualized cost & & $\$ 76,500$ \\
\hline Annualized benefits (weekday only) minus annualized cost & & $\$ 1,387,372$ \\
\hline Annualized benefits (full week) minus annualized œst & & $\$ 1,534,756$ \\
\hline Benefit/cos ratio wœkday only & & 19.1 \\
\hline Benefi t/co st ratio full week & & 21.1 \\
\hline
\end{tabular}

According to Table 3-7, LYNX's pre-deployment user inputs result in an ann ual value of ti me savings for itspassengers of more than $\$ 1.6$ million (about $\$ 1.5$ million if only weekday service is included). The benefit/cost rati o for this technol ogy for a full week is 21.1 (19.1 for weekdays only). These are the estimated results that LYNX could expect from the implementation of AVL and provision of realtime information. Comparatively, the data in Table 3-8 show that LYNX's post-deployment user inputs result in no time savings for its usersand a ben efit/cost ratio of 0.0 . These significant differences result from the fact that LYNX does not see any time savingsfor its passengers, in terms of average wait time, as aresult of LYMMO'sAVL system and the real-time information kiosks located at the LYMMO stations (i.e., average wait time is two minutes regardless of whether real-time information is available for LYMMO service). 
Table 3-8

SCRITS Worksheet: Post-Implementation Analysis of LYNX's Automatic Vehicle Location

\begin{tabular}{|c|c|c|}
\hline & User Input & Calculated Value \\
\hline \multicolumn{3}{|l|}{ TRAFIC AND TRAVE (USR BENEFITSON LY) } \\
\hline Current average wait time per passenger (min.) & 2 & \\
\hline Average wait time with AVL system (min.) & 2 & \\
\hline Average number of week day dail y boardings & 4,000 & \\
\hline Average number of dail y boardings, full week & 3,100 & \\
\hline Percent of passengers that use the information & $60 \%$ & \\
\hline Hours of time saved per weekday & & 0 \\
\hline Ho urs of time saved per average day, ful I w eek & & 0 \\
\hline Hours of time saved per yœar, wœkdays only & & 0 \\
\hline Hours of time saved per year, total & & 0 \\
\hline \multicolumn{3}{|l|}{ COSTSAND BENEFITS } \\
\hline Annual value of timesavings, weekdays only & & $\$ 0$ \\
\hline Annual value of ti me savings, ful I w eek & & $\$ 0$ \\
\hline Installation cost & $\$ 900,000$ & \\
\hline Service life (years) & 11 & \\
\hline Annual operating/maintenance cost & $\$ 40,000$ & \\
\hline Annual savings in agency labor cost & $\$ 0$ & \\
\hline Annualization factor & & 0.153 \\
\hline Total annualized cost & & $\$ 76,500$ \\
\hline Annualized benefits (weekday only) minusannualized cost & & $-\$ 76,500$ \\
\hline Annualized benefits (full week) minus annualized ost & & $-\$ 76,500$ \\
\hline Benefit/cos ratio wœkday only & & 0.0 \\
\hline Benefi t/co st ratio full week & & 0.0 \\
\hline
\end{tabular}

However, it is important to note that, since the average wait times used in this particular analysis are estimates based on staff experience and knowledge, it is possible that some time savings actually are accrued by passengers that rely on LYMMO's AVL-based rea-time information. As seen in the HART case study, the perception of time (whether boarding time, wait time, or otherwise) may not always approximate the reality. For example, even if the information kiosks at the LYMMO stationswere only utilized by 60 percent of passengers, but their use of this information saved them just one minute of wait time, then an annual time savings of nearly $\$ 121,000$ would result for the full-week case, with a benefit/cost ratio of 1.6. In order to achieve the breakeven point between the total costs resulting from the AVL and information system and the users' time savings benefits (i.e., benefit/cost ratio of 1.0), LYMMO's passengerswould need to save only 38 seconds of wait time from their use of the real-time information. 
The LYMMO's bus priority system also was analyzed using the SCRTS tool. The user inputs and resulting calculated values for the pre- and post-deployment conditions for the bus priority system worksheet are shown in Tables 3-9 and 3-10, respectively. The number of miles on which priority treament is implemented is three miles, since the LYMMO route is three miles long and it has bus priority signalization for various intersections along its entire length. A total of seven buses operate each weekday on the LYMMO route, and current average bus speed is approximately 7.5 milesper hour. LYNX staff also indicated that average passenger trip length for LYMMO service is 1.5 miles and that the service carries 4,000 weekday daily passengers, on average.

As discussed previousy in LYNX's AVL analysis, the City of Orlando Traffic Division and LYNX staff indicated the tota cost (including installation) of LYNX's AVL and bus priority systems to be approximately $\$ 1,000,000$. Snce 50 percent of this initial total cost was applied to the AVL system, the other half (i.e., $\$ 500,000$ ) was used as the total cost for the bus priority system. The anticipated useful service life of the priority equipment was estimated to be between 8 and 10 years, so a value of 9 years was utilized in the analysis. Again, LYNX staff and Traffic Divi sion staff could not provide any information on annual operating/maintenance costsfor thissystem, so a value of zero dollarswas used. In addition, LYNX staff indicated that LYMMO's current operating cost per bus route-hour is approximately $\$ 46$.

Unli ke the other two worksheets analyzed thusfar, the bus priority worksheet also requiresuser inputs related to various traffic operations characteristics of the route(s) being analyzed. The four traffic operations variablesthat are needed asinputs include the number of daily vehicle tripson the corridor served by the priority route(s), the weekday daily vol ume of cross street traffic for the priority route(s), the percentage of traffic that incurs preemption delay, and the average delay time per pre-empted vehicle (in seconds). LYNX staff deferred to the expertise of the City of Orlando Traffic Division for this information. Discussion with Traffic Division staff found that about six percent of traffic incurs preemption delay due to the LYMMO priority system, and that the average delay time is around 15 seconds per pre-empted vehicle. For the traffic volume data, a website (http://www.ci.orlando.fl.us/ departments/public works/trans/countsadt.pdf) was provided that included the most recent (i.e., October 4, 2000) available traffic approach counts for selected intersections throughout the City of Orlando. From thisinformation, then, daily vehicle tripson the LYMMO corridor and weekday daily cross street volumes were estimated $(62,700$ and 66,400 , respecti vely).

Only two other user inputs are needed for the buspriority analysis worksheet: the percentage of bus travel time that can be attributed to signal delay and the estimated percent reduction in signal delay that would result from the uæ of a priority system. Thes variables were discussed with LYNX saff, 
who indicated that, typically, about 35 percent of bustravel time results from having to wait at signals. This value was used in both the pre and post-deployment cases since, like all of the other inputs discussed previously, it is assumed to remain constant betw een the two cases. In this worksheet, only the input for estimated reduction in signal delay actually varies. For the pre-deployment condition, LYNX staff indicated that, during development of the LYMMO system, the original expectation was a 50 percentreduction in signal delay becaus of the uঙ of buspriority. In reality, however, staff believe that they have been able to achieve only a 25 percent reduction in signal delay.

Tabl e 3-9 indicates that LYNX's pre-deployment user inputs result in a combined annual time savings for bus passengers and vehicle passengers (i.e., thos persons in vehicles affected by the priority system'soperation) of approximately $\$ 450,000$. Thecorresponding benefit/cost ratio is6.4. These are the estimated results that LYNX could expect from the implementation of a bus priority system. Comparatively, Table 3-10 shows that LYNX's post-deployment uঙr inputsresult in almost $\$ 180,000$ in total bus passenger and vehicle passenger time savings, and abenefit/cost ratio of 2.4 .

The pre-and post-deployment results indicate that the tota annual time savings and ben efitcost ratio both decreased at least 60 percent between the "pre-deployment expected" and "post-deployment actual" values. This decline is directly attributable to the decrease in the estimated percent reduction in signal delay due to bus priority. As noted previousy, LYNX expected a 50 percent reduction in signal delay, but actually only experienced about a 25 percent reduction after implementation of the priority system. Despite this decrease, though, LYMMO's priority system still is benefitting bus passengers in terms of their overall time savings. 
Table 3-9

SCRITS Worksheet: Pre-Implementation Analysis of LYNX's Bus Priority System

\begin{tabular}{|c|c|c|}
\hline & User Input & Calculated Value \\
\hline \multicolumn{3}{|l|}{ BUS OPERATIONS, WEEKDAY ONLY } \\
\hline Mi les on which prio rity treatment is implemented & 3 & \\
\hline Nu mber of buses per weekday on priority routes & 7 & \\
\hline Current average busspeed on arterials ( $\mathrm{mph}$ ) & 7.5 & \\
\hline Percen tage of bu s travel time attrib utable to signal d elay & $35 \%$ & \\
\hline Estimated \% reduction in signa delay from preemption & $50 \%$ & \\
\hline Average minutes per mile for buses without priority & & 8.00 \\
\hline Average minutes per mile for buses with pri ority & & 6.60 \\
\hline Average bus speed with priority (mph) & & 9.09 \\
\hline Percentage increase in bus speed & & $21.2 \%$ \\
\hline Number of route-hours saved per day & & 0.5 \\
\hline Number of route-hours saved per year, wøkdays only & & 126 \\
\hline Nu mber of dail y passengers on affected routes & 4,000 & \\
\hline Average passenger trip length (mi les) & 1.5 & \\
\hline Person hours without priority, weekday only & & 800 \\
\hline Person hours with priority, weekday only & & 660 \\
\hline Savings in person hours per weekday & & 140 \\
\hline Savings in person hours per year, wœkdays only & & 51,100 \\
\hline Elastici ty of demand with respect to average bus speed & 0.3 & \\
\hline Estimated increase in average weekday passengerson route & & 255 \\
\hline Dai ly vehi cle tri ps on corridor served by bus route(s) & 62,700 & \\
\hline Percent reduction in vehicle trips in bus corridor & & $0.41 \%$ \\
\hline Annual value of time savingsfor bus passengers & & $\$ 545,748$ \\
\hline \multicolumn{3}{|l|}{ TRAFHC O PERATIONS } \\
\hline Weekday daily volume of cross street traffic for entire route & 66,400 & \\
\hline Percen tage of traffic that incu rs pre-emption del ay & $6 \%$ & \\
\hline Average delay time per pre-empted vehicle (sec.) & 15 & \\
\hline Additional vehicle hours delay per day to cross stret trafic & & 17 \\
\hline Additional person hours delay per day & & 20 \\
\hline Additional person hours delay per year & & 7,271 \\
\hline Annual value of vehicle passenger time savings, weekdays only & & $-\$ 93,183$ \\
\hline \multicolumn{3}{|l|}{ COSTSAND BENEFITS } \\
\hline Total of bus passenger and veh icle passenger ti me savings & & $\$ 452,565$ \\
\hline Installation cost & $\$ 500,000$ & \\
\hline Service life (years) & 9 & \\
\hline Annual operating/maintenancecost & $\$ 0$ & \\
\hline Operating cost per bus route-hour & $\$ 46$ & \\
\hline Annual bus operating cost savings & & $\$ 5,793$ \\
\hline Annualization factor & & 0.153 \\
\hline Total annualized cost & & $\$ 70,707$ \\
\hline Annualized benefits (weekday only) minus annualized cost & & $\$ 381,858$ \\
\hline Benefit/cos raio wøkday only & & 6.4 \\
\hline
\end{tabular}


Table 3-10

SCRITS Worksheet: Post-Implementation Analysis of LYNX's Bus Priority System

\begin{tabular}{|c|c|c|}
\hline & User Input & Calculated Value \\
\hline \multicolumn{3}{|l|}{ BUS OPERATIONS, WEEKDAY ONLY } \\
\hline Mi les on which prio rity treatment is implemented & 3 & \\
\hline Nu mber of buses per weekday on priority routes & 7 & \\
\hline Current average busspeed on arterials ( $\mathrm{mph}$ ) & 7.5 & \\
\hline Percen tage of bu s travel time attrib utable to signal d elay & $35 \%$ & \\
\hline Estimated \% reduction in signa delay from preemption & $25 \%$ & \\
\hline Average minutes per mile for buses without priority & & 8.00 \\
\hline Average minutes per mile for buses with pri ority & & 7.30 \\
\hline Average bus speed with priority (mph) & & 8.22 \\
\hline Percentage increase in bus speed & & $9.6 \%$ \\
\hline Number of route-hours saved per day & & 0.2 \\
\hline Number of route-hours saved per year, wœkdays only & & 63 \\
\hline Nu mber of dail y passengers on affected routes & 4,000 & \\
\hline Average passenger trip length (mi les) & 1.5 & \\
\hline Person hours without priority, weekday only & & 800 \\
\hline Person hours with priority, weekday only & & 730 \\
\hline Savings in person hours per weekday & & 70 \\
\hline Savings in person hours per year, wœkdays only & & 25,550 \\
\hline Elastici ty of demand with respect to average bus speed & 0.3 & \\
\hline Estimated increase in average weekday passengerson route & & 115 \\
\hline Dai ly vehi cle tri ps on corridor served by bus route(s) & 62,700 & \\
\hline Percent reduction in vehicle trips in bus corridor & & $0.18 \%$ \\
\hline Annual value of time savingsfor bus passengers & & $\$ 272,874$ \\
\hline \multicolumn{3}{|l|}{ TRAFHC O PERATIONS } \\
\hline Weekday daily volume of cross street traffic for entire route & 66,400 & \\
\hline Percen tage of traffic that incu rs pre-emption del ay & $6 \%$ & \\
\hline Average delay time per pre-empted vehicle (sec.) & 15 & \\
\hline Additional vehicle hours delay per day to cross stret trafic & & 17 \\
\hline Additional person hours delay per day & & 20 \\
\hline Additional person hours delay per year & & 7,271 \\
\hline Annual value of vehicle passenger time savings, weekdays only & & $-\$ 93,183$ \\
\hline \multicolumn{3}{|l|}{ COSTSAND BENEFITS } \\
\hline Total of bus passenger and veh icle passenger ti me savings & & $\$ 179,691$ \\
\hline Installation cost & $\$ 500,000$ & \\
\hline Service life (years) & 9 & \\
\hline Annual operating/maintenancecost & $\$ 0$ & \\
\hline Operating cost per bus route-hour & $\$ 46$ & \\
\hline Annual bus operating cost savings & & $\$ 2,896$ \\
\hline Annualization factor & & 0.153 \\
\hline Total annualized cost & & $\$ 73,604$ \\
\hline Annualized benefits (weekday only) minus annualized cost & & $\$ 106,088$ \\
\hline Benefit/cos raio wøkday only & & 2.4 \\
\hline
\end{tabular}




\section{Sarasota County Area Transit}

Similar to the other systems, SCAT planning staff was provided with the SCRITS spreadsheet tool and asked to review the tool's electronic fare collection worksheet. However, since the system has not yet implemented the compani on electronic ticket reader units to its new Agent fareboxes, staff provided only pre-implementation data for that worksheet's required user inputs. SCAT was able to provide some of the necessary information initially, but several follow-up phone discussions were needed to coll ect the rest of the user inputs. This phone contact also provided an opportunity to validate and/or clarify the system's initial information, as well as to collect descriptive information about the new electronic fareboxes and planned ticket reader units (i.e., manufacturer, model, when implemented, plansfor electronic fare media, etc.). For the purpose of SCAT sanalysis, $\$ 9.70$ was used to represent the value of time per person hour (i.e., 80 percent of the 1998 average wage rate in the SarasotaBradenton Metropolitan Statistical Area).

Table 3-11 presents the user inputs and resulting calculated values for SCATs pre-deployment condition. According to SCAT staff, average bus speed is 20 miles per hour, average passenger trip length is 6.53 miles, and the average percent of bus travel time that is devoted to boarding is approximately 15 percent. Thefirst two of these inputsare based on system operating data, while the third figure is an estimate SCAT staff basd on knowledge of bus operations. Average weekday ridership was indicated to be 5,500 and average daily ridership (including weekends) is 5,250. SCAT also provided the total cost, including installation, for its electronic farebox system implementation $(\$ 540,000)$, aswell as the expected useful service life of the equipment (10years). However, since the fareboxes have only been in place for lessthan a year (and are still under warranty), staff did not have an estimate for what the annual operating/maintenance cost of the equipment would be in subsequent years. Since the system's current cost is zero, that is the value that was used in the worksheet. Similarly, zero dollars was used for the annual labor cost savings since SCAT staff expected that increased maintenance requirements would negate any potential savings from decreased fare admi ni strati on requi rements (e.g., cash handling/counting, security, etc.).

With regard to average boarding times, SCAT staff believe that the average boarding ti me per passenger with conventional fare isabout seven seconds. Conversely, it wasestimated that the averageboarding time for passengerswith electronic fare would be around 5 seconds. In addi tion, SCAT staff indicated that 20 percent of system ridership is expected to make use of electronic fare media once it isavailable for use on the SCAT system. 
Asmentioned previously in a footnote, analysisof SCATs post-deployment condition required avariant meth odol ogy since the system has not had any operational experience with electronic fare collection yet. Like the other systems, many of the user inputs from the pre-deployment case were utilized for the post-deployment analysis without modification (e.g., ridership and financial information). However, the values for average boarding time with electronic fare and the percent of electronic fare use were derived using corresponding data from the post-deployment experiencesof the other three Florida transit systems. For example, post-deployment average boarding times for passengers with electronic fare for PSTA, HART, and LYNX are 3 seconds, 7.2 seconds, and 4 seconds, respectively. The average of these values is 4.7 seconds; therefore, this is the value that was used for SCATs postdeployment average boarding time for passengers with electronic fare. The systems average for percent of passengers with electronic fare is approxi matel y 44 percent. These values are refl ected in SCATs user inputs for its post-deployment analysis shown in Table 3-12.

In Table 3-11, it is evident that application of SCATs pre-deployment user inputs results in an annual value of time savings for its passengers of just over $\$ 52,000$ (about $\$ 38,000$ if only weekday service is included). The benefit/cost ratio for this technology for a full week is 0.7 ( 0.5 for weekdays onl y). These values represent the estimated results that SCAT could expect from the implementation of electronic fare collection on its system. Comparatively, using post-depl oyment user inputs averaged from the experiences of the other three Forida properties, Table 3-12 shows that SCAT actual ly may attain almost $\$ 132,000$ in time savings for its users (about $\$ 96,000$ for weekdays only), once its electronic ticket readers are installed and operational. The benefit/cost ratio for this post-deployment case for a full week is 1.7 (1.3 for weekdays onl y).

These figures indicate that, when considering the cas for a full week, SCATs annual value of time savings and benefit/cost ratio both will be expected to increase more than 140 percent between the "pre-deployment expected" and "post-deployment actual" values if the system's experience with electronic fare media is simil ar to that of the average experience of the other Florida systems analyzed herein. Since SCAT's estimate of average boarding time for passengerswith electronic fare (5 seconds) is quite similar to the average boarding time derived from the other three systems (4.7 seconds), the major reason for expecting such an increase is a higher el ectronic fare use estimate. SCAT expects a 20 percent utilization of electronic fare media; however, the other Florida systems experienced electronic fare usage ranging from 26 to 70 percent, with an average of 44 percent. Even if SCAT actual ly experiences electronic fare u sage at the low end of this range(i.e., 26 percent), the benefit/cost ratio for the full w eek case would still be 1.0 - the breakeven point betw een the cost of the fare system and the time savings benefits accrued by system uærs. 
Table 3-11

\section{SCRITS Worksheet: Pre-Implementation Analysis of SCAT's Bectronic Fare Collection}

\begin{tabular}{|c|c|c|}
\hline & User Input & Calculated Value \\
\hline \multicolumn{3}{|l|}{ TRAFIC AND TRAVE (USRR BENEFITS ON LY) } \\
\hline Current average busspeed on arterials ( $\mathrm{mph}$ ) & 20 & \\
\hline Current busspeed in minutesper mile & & 3.00 \\
\hline Average percentage of bustravel time devoted to boarding & $15 \%$ & \\
\hline Average boarding time per passenger with conventional fare(æc.) & 7 & \\
\hline Average boarding time per passnger with electronic fare (sec.) & 5 & \\
\hline Current percentage of passengers with electronic fare & $0 \%$ & \\
\hline Percentage of passengers with dectronic fare in thisscenario & $20 \%$ & \\
\hline Minutesper mile with this electronic fare scenario & & 2.97 \\
\hline Average bus speed with electronic fare ( $\mathrm{mph}$ ) & & 20.17 \\
\hline Estimated \% increase in speed with electronic fare & & $0.9 \%$ \\
\hline Average number of dail y passengers weekday & 5,500 & \\
\hline Average number of dail y passengers full w eek & 5,250 & \\
\hline Average passenger trip length (mi les) & 6.53 & \\
\hline Average dail y person hours wi thout el ectronic fare, weekday & & 1,796 \\
\hline Average dail y person hours with electronic fare, weekday & & 1,780 \\
\hline Savingsin person hoursper day, weekday & & 15 \\
\hline Savings in person hours per year, wœkdays only & & 3,910 \\
\hline Average dail y person hours without el ectro nic fare, full w week & & 1,714 \\
\hline Aver age dail y person ho urs with el ectro nic fare, ful I w eek & & 1,699 \\
\hline Savingsin person hoursper day, full week & & 15 \\
\hline Savingsin person hoursper yea, full week & & 5,363 \\
\hline Elasticity of demand with respect to aver age bus speed & 0.3 & \\
\hline Esimated i ncrease in average w eekday b oard in gs & & 14 \\
\hline Estimated increase in average dail y boardings, full week & & 14 \\
\hline Percent reduction in average weekday vehicle trips & & $0.00 \%$ \\
\hline \multicolumn{3}{|l|}{ COSTSAND BENEFITS } \\
\hline Annual value of timesavings, weekdays only & & $\$ 37,923$ \\
\hline Annual value of ti me savings, ful I w eek & & $\$ 52,019$ \\
\hline Installation cost & $\$ 540,000$ & \\
\hline Service life (years) & 10 & \\
\hline Annual operating/maintenance cost & $\$ 0$ & \\
\hline Annual savings in agency labor $\infty s t$ & $\$ 0$ & \\
\hline Annualization factor & & 0.142 \\
\hline Total annualized cost & & $\$ 76,680$ \\
\hline Annualized benefits (weekday only) minusannualized cost & & $-\$ 38,757$ \\
\hline Annualized benefits (full week) minus annualized ost & & $-\$ 24,661$ \\
\hline Benefit/cos ratio wœkday only & & 0.5 \\
\hline Benefi tco st ratio full week & & 0.7 \\
\hline
\end{tabular}


Table 3-12

SCRITS Worksheet: Post-Implementation Estimates for SCAT's Bectronic Fare Collection

\begin{tabular}{|c|c|c|}
\hline & User Input & Calculated Value \\
\hline \multicolumn{3}{|l|}{ TRAFIC AND TRAVE (USRR BENEFITS ON LY) } \\
\hline Current average busspeed on arterials ( $\mathrm{mph}$ ) & 20 & \\
\hline Current bus speed in minutesper mile & & 3.00 \\
\hline Average percentage of bustravel time devoted to boarding & $15 \%$ & \\
\hline Average boarding time per passnger with conventional fare(æec.) & 7 & \\
\hline Average boarding time per passenger with electronic fare (sec.) & 4.7 & \\
\hline Current percentage of passengers with electronic fare & $0 \%$ & \\
\hline Percentage of passengers with dectronic fare in this scenario & $44 \%$ & \\
\hline Minutesper mile with this electronic fare scenario & & 2.93 \\
\hline Average bus speed with electronic fare ( $\mathrm{mph}$ ) & & 20.44 \\
\hline Estimated \% increase in sped with electronic fare & & $2.2 \%$ \\
\hline Average number of dail y passengers weekday & 5,500 & \\
\hline Average numb er of dail y passengers ful I w eek & 5,250 & \\
\hline Average passenger trip length (mi les) & 6.53 & \\
\hline Average dail y person hours wi thout el ectronic fare, weekday & & 1,796 \\
\hline Average dail y person hours wi th electronic fare, weekday & & 1,757 \\
\hline Savingsin person hoursper day, weekday & & 39 \\
\hline Savings in person hours per year, wœkdays only & & 9,891 \\
\hline Average dail y person hours without el ectro ni c fare, full w eek & & $\begin{array}{r}1,714 \\
\ldots\end{array}$ \\
\hline Aver age dail y person hours with el ectro nic fare, ful I w eek & & 1,677 \\
\hline Savingsin person hoursper day, full week & & 37 \\
\hline Savingsin person hoursper yea, full week & & 13,568 \\
\hline Elasticity of demand with respect to aver age bus speed & 0.3 & \\
\hline Esimated increase in average w eekday board in gs & & 37 \\
\hline Esimated increase in average dail y boardings, full week & & 35 \\
\hline Percent reduction in average weekday vehicle trips & & $0.00 \%$ \\
\hline \multicolumn{3}{|l|}{ COSTSAND BENEFITS } \\
\hline Annual value of timesavings, weekdays only & & $\$ 95,946$ \\
\hline Annual value of ti me savings, ful I w eek & & $\$ 131,608$ \\
\hline Installation cost & $\$ 540,000$ & \\
\hline Service life (years) & 10 & \\
\hline Annual operating/maintenance cost & $\$ 0$ & \\
\hline Annual savings in agency labor $\infty$ st & $\$ 0$ & \\
\hline Annualization factor & & 0.142 \\
\hline Total annualized cost & & $\$ 76,680$ \\
\hline Annualized benefits (weekday only) minus annualized cost & & $\$ 19,266$ \\
\hline Annualized benefits (full week) minus annualized ost & & $\$ 54,928$ \\
\hline Benefit/cos ratio wœkday only & & 1.3 \\
\hline Benefi tco st ratio full week & & 1.7 \\
\hline
\end{tabular}




\section{Ann Arbor Transportation Authority}

To gain the perspective of a transit agency outside of Forida, AATA planning staff was provided the SCRITStool and asked to review two of the tool'sworksheets(electronic fare collection and au tomatic vehicl e location and information) and provide pre-and post-implementation datafor the requ ired u ser inputs for each. The SCRITS spreadsheet was provided via e-mail and a phone interview was held to discuss the use of the tool and its variousinputs. During this initial discussion, descriptive information about the electronic fare collection system (i.e., manufacturer, model, when implemented, electronic fare medi a being utilized, etc.) and the AVL system was gathered, as well. Subsequent phone contact was used to collect and/or verify the system's user inputs. For purposes of this analysis, \$13.21 was used to represent the value of time per person hour (i.e., 80 percent of the 1998 average wage rate in the Ann Arbor, Michigan, Metropolitan Stati stical Area). ${ }^{32}$

The user inputsand resulting cal cul ated valuesfor the pre-and post-deployment conditionsfor AATA's electronic fare payment system are shown in Tables3-13 and 3-14, respectively. AATA's user inputs related to the operation of its bus service include an average bus speed of 13.9 miles per hour, an average passenger trip length of 3.34 miles, and an average percent of bus travel time that is devoted to boarding of approximately 25 percent. The first two of these inputs are based on system NTD operating statistics, while the third figure is an AATA saff estimate based on reven ue hou rs of servi ce, number of busstops, number of round trips, and an average dwell time for boarding passengersateach stop for a typical route in the system. Average weekday ridership was indicated to be 15,000 and average daily ridershi $p$ (incl uding weekends) is 12,000. Thetotal cost, includinginstal lation, of AATA's electronic registering fareboxes was estimated at about $\$ 782,000$. The anticipated useful service life of the equipment was indicated to be 10 years. It was estimated by AATA staff that the annual operating/maintenance cost of the fareboxes is $\$ 183,000$; however, it was indicated that there are no labor cost savings associated with the implementation (in fact, it was believed that the system actually may have resulted in some additional labor costs, though this increase could not be estimated so a value of zero dollars was used nonethel ess).

Next, AATA staffwere queried concerning the system'spre-implementation averageboarding time and electronic fare utilization inputs. Since AATA makesuse of avariety of multi-ride flash passes, it was necessary to account for their use in estimating the average boarding time per passenger with conventional fare. According to AATA staff, cash transacti ons average about 10 seconds while flash

${ }^{32}$ Statistical Abstract of the United States: 2000, $120^{\text {th }}$ Edition, U.S. Censu s Burea u, Wa shington, D.C., 2000 . 
pass transactions average only 2 seconds Based on the current distribution of cash and pass users (about 50-50), the average boarding time for passengers with conventional fare is sx seconds (i.e., $0.5 \times 10+0.5 \times 2$ ). Saff then indicated that it was expected that the average boarding time per passenger with electronic fare would be approximately six seconds per transaction. As for the percentage of passengers utilizing electronic fare, AATA staff indicated that the pre-implementation expectation for the proportion of ridership that would make use of electronic fare media is 50 percent, or about the same proportion that iscurrently utilizing flash passes. The reason for thisexpectation is that AATA staff believe that all current flash pass users will switch over to electron ic fare cards since the passes will be discontinued upon implementation of the electronic fare media.

Simil ar to the andysis for SCAT, a variant methodology had to be utilized for the analysis of AATA's post-deployment case since the system has not had any operational experience with electronic fare collection yet. Assuch, for thiscase, the values for average boarding time with electronic fare and the percent of electronic fare use were derived using corresponding data from the post-deployment experiences of the thre case study transt systemsalready utilizing electronic fare media. Again, the average value for post-deployment average boarding timesfor passengerswith electronic farefor PSTA, HART, and LYNX is 4.7 seconds. In addition, the systems' average for percent of passengers with electronic fare is approximately 44 percent. These values have been incorporated into AATA's postdeployment analysis and are reflected in the user inputs shown in Table 3-14.

The only other change in the inputs between the pre-and post-implementation analyses involves the average boarding time for passengerswith conventional fare. As mentioned previously, it is expected that electronic fare media will replace AATA's current flash passes. This means that the definition of conventional fare will change for AATA in the post-deployment case (i.e., will only include cash). Therefore, a value of 10 seconds per transaction is utilized in this case to represent the average boarding time for passengers with conventional fare user input.

Table 3-13 shows that application of AATA's pre-deployment uær inputs results in no annual time savings for its passengersand, therefore, a benefit/cost ratio for this technology of 0.0 . This outcome is due to no expected time savings between conventional fareand electronic fare. According to AATA staff, one major concern of implementing electronic fare media is that, if it does replace the flash passes, it actually may serve to slow down overal average boarding ti mes since the expectation is that having to swipe a card or insert it into a reader will take more time than simply "flashing" a pass at the driver. This expectation isrevealed in AATA's estimations of average boarding times two seconds for the flash pass and six seconds for an electronic fare card. 
The AATA post-deployment analysis presented in Table 3-14, which utilizes post-deployment user inputs averaged from the experiences of the three case study transit systemscurrently using electronic fare media, indicates that AATA actually may attain more than $\$ 810,000$ in time savings for its users (about $\$ 711,000$ for wekdays only), once electronic fare media is made available. The benefit/cost rati o for this case for a full week is 2.8 ( 2.4 for weekdays onl y).

Based on these figures, then, if the system's experience with electronic fare media is similar to that of the average experience of the three "experienced" cas sudy systems, AATA actually should realize annual time savings for its passengers and a positive benefit/cost despite the discontinuation of flash passes. The primary reason for this favorable projection is that the differential in average boarding times for passengers with conventional and el ectronic fare should be greater than AATA staff expects. Without flash pass use, average conventional fare boarding times should increase and the average electronic fareboarding time experienced at the other systems ( 4.7 seconds) is lower than that expected by AATA ( 6 seconds). Interestingly, AATA's actual results ultimately may even be higher than that shown in Table 3-14 snce theother systems averageelectronic fare utilization is 44 perœnt and AATA expects at least 50 percent electronic fare usage based on its passengers current utilization of flash passes. 
Table 3-13

SCRITS Worksheet: Pre-Implementation Analysis of AATA's Bectronic Fare Collection

\begin{tabular}{|c|c|c|}
\hline & User Input & Calculated Value \\
\hline \multicolumn{3}{|l|}{ TRAFIC AND TRAVE (USRR BENEFITS ON LY) } \\
\hline Current average busspeed on arterials ( $\mathrm{mph}$ ) & 13.9 & \\
\hline Current bus speed in minutesper mile & & 4.32 \\
\hline Average percentage of bustravel time devoted to boarding & $25 \%$ & \\
\hline Average boarding time per passenger with conventional fare(æc.) & 6 & \\
\hline Average boarding time per passenger with electronic fare (sec.) & 6 & \\
\hline Current percentage of passengers with electronic fare & $0 \%$ & \\
\hline Percentage of passengers with dectronic fare in this scenario & $50 \%$ & \\
\hline Minutesper mile with this electronic fare scenario & & 4.32 \\
\hline Average bus speed with electronic fare ( $\mathrm{mph}$ ) & & 13.90 \\
\hline Estimated \% increase in sped with electronic fare & & $0.0 \%$ \\
\hline Average number of $d$ ail y passengers weekday & 15,000 & \\
\hline Average numb er of dail y passengers ful I w eek & 12,000 & \\
\hline Average passenger trip length (mi les) & 3.34 & \\
\hline Average dail y person hours without el ectronic fare, weekday & & 3,604 \\
\hline Average dail y person hours wi th electronic fare, weekday & & 3,604 \\
\hline Savingsin person hoursper day, weekday & & 0 \\
\hline Savings in person hours per year, wœkdays only & & 0 \\
\hline Average dail y person hours without el ectro nic fare, full w eek & & 2,883 \\
\hline Average dail y person ho urs with el ectro nic fare, ful I w eek & & 2,883 \\
\hline Savingsin person hoursper day, full week & & 0 \\
\hline Savingsin person hoursper yea, full week & & 0 \\
\hline Elastici ty of demand w ith respect to aver age bus speed & 0.3 & \\
\hline Esimated i ncrease in average w eekday board ings & & 0 \\
\hline Esimated increase in average dail y boardings, full week & & 0 \\
\hline Percent reduction in average weekday vehicle trips & & $0.00 \%$ \\
\hline \multicolumn{3}{|l|}{ COSTSAND BENEFITS } \\
\hline Annual value of timesavings, weekdays only & & $\$ 0$ \\
\hline Ann ual value of ti me savings, ful I w eek & & $\$ 0$ \\
\hline Installation cost & $\$ 782,000$ & \\
\hline Service life (years) & 10 & \\
\hline Annual operating/maintenance cost & $\$ 183,000$ & \\
\hline Annual savings in agency labor cost & $\$ 0$ & \\
\hline Annualization factor & & 0.142 \\
\hline Total annualized cost & & $\$ 294,044$ \\
\hline Annualized benefits (weekday only) minus annualized cost & & $-\$ 294,044$ \\
\hline Annualized benefits (full week) minus annualized œst & & $-\$ 294,044$ \\
\hline Benefit/cos ratio wœkday only & & 0.0 \\
\hline Benefi t/co st rati o full week & & 0.0 \\
\hline
\end{tabular}


Table 3-14

SCRITS Worksheet: Post-Implementation Analysis of AATA's Bectronic Fare Collection

\begin{tabular}{|c|c|c|}
\hline & User Input & Calculated Value \\
\hline \multicolumn{3}{|l|}{ TRAFIC AND TRAVE (USRR BENEFITS ON LY) } \\
\hline Current average busspeed on arterials ( $\mathrm{mph}$ ) & 13.9 & \\
\hline Current bus speed in minutesper mile & & 4.32 \\
\hline Average percentage of bustravel time devoted to boarding & $25 \%$ & \\
\hline Average boarding time per passenger with conventional fare(æc.) & 10 & \\
\hline Average boarding time per passenger with electronic fare (sec.) & 4.7 & \\
\hline Current percentage of passengers with electronic fare & $0 \%$ & \\
\hline Percentage of passengers with dectronic fare in this scenario & $44 \%$ & \\
\hline Minutesper mile with this electronic fare scenario & & 4.06 \\
\hline Average bus speed with electronic fare ( $\mathrm{mph}$ ) & & 14.76 \\
\hline Estimated \% increase in sped with electronic fare & & $6.2 \%$ \\
\hline Average number of $d$ ail y passengers weekday & 15,000 & \\
\hline Average numb er of dail y passengers full w w eek & 12,000 & \\
\hline Average passenger trip length (mi les) & 3.34 & \\
\hline Average dail y person hours wi thout el ectronic fare, weekday & & 3,604 \\
\hline Average dail y person hours wi th electronic fare, weekday & & 3,394 \\
\hline Savingsin person hoursper day, weekday & & 210 \\
\hline Savings in person hours per year, wœkdays only & & 53,794 \\
\hline Average dail y person hours without el ectro nic fare, full w week & & 2,883 \\
\hline Average dail y person ho urs with el ectro nic fare, ful I w eek & & 2,715 \\
\hline Savingsin person hoursper day, full week & & 168 \\
\hline Savingsin person hours per yea, full week & & 61,358 \\
\hline Elastici ty of demand w ith respect to aver age bus speed & 0.3 & \\
\hline Esimated increase in average w eekday board in gs & & 279 \\
\hline Esimated increase in average dail y boardings, full week & & 223 \\
\hline Percent reduction in average weekday vehicle trips & & $0.03 \%$ \\
\hline \multicolumn{3}{|l|}{ COSTSAND BENEFITS } \\
\hline Annual value of timesavings, weekdays only & & $\$ 710,615$ \\
\hline Ann ual value of ti me savings, ful I w eek & & $\$ 810,545$ \\
\hline Installation cost & $\$ 782,000$ & \\
\hline Service life (years) & 10 & \\
\hline Annual operating/maintenance cost & $\$ 183,000$ & \\
\hline Annual savings in agency labor cost & $\$ 0$ & \\
\hline Annualization factor & & 0.142 \\
\hline Total annualized cost & & $\$ 294,044$ \\
\hline Annualized benefits (weekday only) minus annuadized cost & & $\$ 416,571$ \\
\hline Annualized benefits (full week) minus annualized oost & & $\$ 516,501$ \\
\hline Benefit/cos ratio wœkday only & & 2.4 \\
\hline Benefi t/co st rati o full week & & 2.8 \\
\hline
\end{tabular}


Since AATA currently hasimplemented AVL on itsentire fleet, the system al so wasasked to assist with a SCRTSanalysis of this particular technology. The uær inputsand resulting calculated values for the pre-and post-deployment conditions for the automatic vehicle location and informati on worksheet are shown in Tables 3-15 and 3-16, respectively. Datafor average weekday daily boardings $(15,000)$ and average daily boardings for a full week $(12,000)$ were replicated from the electronic fare collection system analysis presented previousy.

AATA staff estimated the total cost (including installation) of its AVL system to be about $\$ 2,100,000$. The anti cipated useful service life of the equi pment was indicated to be 8 years. An annual operating/ maintenance cost for the system of $\$ 203,000$ was provided; however, like the case for its electronic fare system, a value of zero dollarswasused for annual labor cost savingssince AATA staff believe that the AVL implementation also may have resulted in additional labor costs (though, as for the other technology, this potential increase could not be estimated).

Table 3-15

SCRITS Worksheet: Pre-Implementation Analysis of AATA's Automatic Vehicle Location

\begin{tabular}{|c|c|c|}
\hline & User Input & Calculated Value \\
\hline \multicolumn{3}{|l|}{ TRAFIC AND TRAVE (USRR BENEFITS ON LY) } \\
\hline Current average wait time per passenger (min.) & 5 & \\
\hline Average wait time with AVL system (min.) & 2 & \\
\hline Average number of week day dail y bo ardings & 15,000 & \\
\hline Average number of dail y boardings, full week & 12,000 & \\
\hline Percent of passengers that use the information & $40 \%$ & \\
\hline Hours of time saved per weekday & & 300 \\
\hline Ho urs of time saved per average day, ful I w eek & & 240 \\
\hline Hours of time saved per year, wœkdays only & & 76,800 \\
\hline Hours of time saved per year, total & & 87,600 \\
\hline \multicolumn{3}{|l|}{ COSTSAND BENEFITS } \\
\hline Annual value of time savings, weekdays only & & $\$ 1,014,528$ \\
\hline Annual value of ti me savin gs, ful I w eek & & $\$ 1,157,196$ \\
\hline Installation cost & $\$ 2,100,000$ & \\
\hline Service life (years) & 8 & \\
\hline Annual operating/maintenance cost & $\$ 203,000$ & \\
\hline Annual savings in agency labor cost & $\$ 0$ & \\
\hline Annualization factor & & 0.167 \\
\hline Total annualized cost & & $\$ 350,700$ \\
\hline Annualized benefits (weekday only) minus annualized cost & & $\$ 663,828$ \\
\hline Annualized benefits (full week) minus annualized œst & & $\$ 806,496$ \\
\hline Benefit/cos ratio wœkday only & & 2.9 \\
\hline Benefi t/co st ratio full week & & 3.3 \\
\hline
\end{tabular}


Table 3-16

SCRITS Worksheet: Post-Implementation Analysis of AATA's Automatic Vehicle Location

\begin{tabular}{|c|c|c|}
\hline & User Input & Calculated Value \\
\hline \multicolumn{3}{|l|}{ TRAFIC AND TRAVE (USR BENEFITS ON LY) } \\
\hline Current average wait time per passenger (min.) & 5 & \\
\hline Average wait time with AVL sysem (min.) & 2 & \\
\hline Average number of week day dail y boardings & 15,000 & \\
\hline Average number of dail y bo ardings, full week & 12,000 & \\
\hline Percent of passengers that use the information & $40 \%$ & \\
\hline Hours of time saved per weekday & & 300 \\
\hline Ho urs of time saved per average day, full w eek & & 240 \\
\hline Hours of time saved per year, wœkdays only & & 76,800 \\
\hline Hours of time saved per year, total & & 87,600 \\
\hline \multicolumn{3}{|l|}{ COSTSAND BENEFITS } \\
\hline Annual value of timesavings, weekdays only & & $\$ 1,014,528$ \\
\hline Annual value of ti me savings, ful I w eek & & $\$ 1,157,196$ \\
\hline Installation cost & $\$ 2,100,000$ & \\
\hline Service life (years) & 8 & \\
\hline Annual operating/maintenance cost & $\$ 203,000$ & \\
\hline Annual savings in agency labor cost & $\$ 0$ & \\
\hline Annualization factor & & 0.167 \\
\hline Total annualized cost & & $\$ 350,700$ \\
\hline Annualized benefits (weekday only) minus annualized cost & & $\$ 663,828$ \\
\hline Annualized benefits (full week) minus annualized cost & & $\$ 806,496$ \\
\hline Benefit/cos ratio wœkday only & & 2.9 \\
\hline Benefit/co st ratio full week & & 3.3 \\
\hline
\end{tabular}

As noted before in the LYNX AVL analysis, there are three other user inputs needed for the AVL analysisworksheet: current average wait time per passenger, average wait time per passenger with the AVL system, and percent of passengers utilizing real-time information from the AVL system. For the pre-deployment case, AATA staff estimated current average wait time to be about five minutes. By using the AVL-derived real-time information at AATA's transfer stations (the only stops currently providing thisinformation), it was expected that passengerswould wait only two minutes, on average. Additionally, AATA staff originally estimated that about 40 percent of its patrons would make uæ of the available information.

Next, the post-deployment case was discussed with AATA staff. Interestingly, it isstaff's belief that the actual input valuesfor thistechnology are identical to those that wereestimated for the pre-deployment case. That is, average wait time after deployment of the AVL system is about two minutes for those 
utilizing the AVL-derived information and approximately 40 percent of AATA's passengersare making use of the information.

As shown in Tables 3-15 and 3-16, then, the results for the pre-and post-implementation analyses are identical. AATA's user inputs result in an annual value of time savingsfor its passengersof nearly $\$ 1.2$ million (about $\$ 1.0$ million if only weekday service is included). The benefitcost ratio for this technology for a full week is 3.3 (2.9 for weekdays only). It should be noted, however, that staff believe that greater user benefitscould be achieved if real-time information wasavailable through more outlets (e.g., telephone, television, Internet, all bus stops, etc.), instead of just at the system's transfer stations.

\section{Comparison of Results}

Although changes did occur between the pre-and post-deployment results for each of the systems analyzed using the three transit-related SCRTS worksheets, for the most part, it is evident in the previous analyses that benefits (in terms of user time savings) have resulted from the various implementations. As presented in Table 3-17, time savings (13 percent) and benefit/cost ratios (6 percent) have increased between expected and achieved results, on average. Based on the postdeployment results, average annual time savings related to the deployment of electronic fare collection at the five systems totals nearly $\$ 1.5$ million, and the average benefit/cost ratio achieved for this technology is 6.4 .

Table 3-17

SCRTS Bectronic Fare Collection Worksheet Analysis: Comparison of System Results ${ }^{1}$

\begin{tabular}{|l|c|c|c|c|c|c|}
\hline \multirow{2}{*}{$\begin{array}{c}\text { Transit } \\
\text { System }\end{array}$} & \multicolumn{2}{|c|}{ Annual Value of Time Savings } & \multicolumn{3}{c|}{ Benefit/Cost Ratio } \\
\cline { 2 - 7 } & Pre & Post & $\%$ Chg & Pre & Post & $\%$ Chg \\
\hline PSTA & $\$ 2,910,784$ & $\$ 2,716,732$ & $-7 \%$ & 7.4 & 6.9 & $-7 \%$ \\
\hline HART & $\$ 304,705$ & $\$ 1,618,087$ & $431 \%$ & 1.4 & 7.2 & $414 \%$ \\
\hline LYNX & $\$ 3,287,655$ & $\$ 2,136,976$ & $-35 \%$ & 20.6 & 13.4 & $-35 \%$ \\
\hline SCAT & $\$ 52,019$ & $\$ 131,608^{2}$ & $153 \%$ & 0.7 & $1.7^{2}$ & $143 \%$ \\
\hline AATA & $\$ 0$ & $\$ 810,545^{2}$ & $\mathrm{n} / \mathrm{a}$ & 0.0 & $2.8^{2}$ & $\mathrm{n} / \mathrm{a}$ \\
\hline \multicolumn{1}{|c|}{ Average } & $\$ 1,311,033$ & $\$ 1,482,790$ & $13 \%$ & 6.0 & 6.4 & $6 \%$ \\
\hline
\end{tabular}

${ }^{1}$ All of the information presented in this table is for the "full w eek" case.

${ }^{2}$ Since SCAT and AATA have not implemented the uঙe of electronic fare media yet, their post-implementation results have been estimated using mean values based on the pos-deployment experiences of theotherthreetransit systemsfor average boarding time with electronic fare and the percent of electronic fare use. 
From the data presented in Table 3-17, it also is evident that PSTA's electronic fare collection implementation has resulted in the largest annual value of time savings at more than $\$ 2.7$ million, based on post-deployment user inputs. The other systems time savings values range from approximately $\$ 132,000$ to $\$ 2.1$ million. Conversely, the greatest benefit-to-cost ratio has been achieved by LYNX. This system's analysis indicated that its electronic fare collection system deployment resulted in a benefit/cost ratio of 13.4. The other systems' benefit/cost ratios range from 1.7 to 7.2 .

In Table 3-18, a simil ar comparison is made for the two systems, LYNX and AATA, that currently have $A V L$ technology in place. Overall, it is apparent that the average user time savings resulting from these agencies' AVL systems decreased 58 percent between the expected and achieved figures. Simil arly, the average benefit-to-cost ratio decreased 86 percent. These declines are primarily attributable to LYNX staff's contention that the LYMMO AVL system has not produced any real time savings for its users because of LYMMO's shorter-than-originally-planned headways. However, despite these declines, the average annual time savings related to the deployment of AVL still is approximately $\$ 579,000$, and the average benefit/cost ratio is 1.7 . Given the particular operating characteristics of LYMMO (i.e., frequent downtown circulator), and the fact that AATA's AVL system has been implemented on its entire fleet, it is anticipated that other systemwide AVL implementations would generate benefits results more like those experienced at AATA.

Table 3-18

SCRTS Automatic Vehicle Location Worksheet Analysis: Comparison of System Results ${ }^{1}$

\begin{tabular}{|c|c|c|c|c|c|c|}
\hline \multirow{2}{*}{$\begin{array}{c}\text { Transit } \\
\text { System }\end{array}$} & \multicolumn{2}{|c|}{ Annual Value of Time Savings } & \multicolumn{3}{c|}{ Benefit/Cost Ratio } \\
\cline { 2 - 7 } & Pre & Post & $\%$ Chg & Pre & Post & $\%$ Chg \\
\hline LYNX & $\$ 1,611,256$ & $\$ 0$ & $-100 \%$ & 21.1 & 0.0 & $-100 \%$ \\
\hline AATA & $\$ 1,157,196$ & $\$ 1,157,196$ & $0 \%$ & 3.3 & 3.3 & $0 \%$ \\
\hline Average & $\$ 1,384,226$ & $\$ 578,598$ & $-58 \%$ & 12.2 & 1.7 & $-86 \%$ \\
\hline
\end{tabular}

"All of the information presented in th is table is for the "ful I w eek" case.

Finally, Table 3-19 examinesthe comparison of the pre-and post-implementation results for the three transit-related technologiesincluded in the SCRITSanalysistool. Thedata in thetablefor theelectronic fare collection and AVL technologies reflect system averages compiled previously in Tables 3-17 and 3-18. The bus priority data is representative of LYNX'S LYMMO circulator, since it is the only one of the five transit systemsanalyzed herein that has implemented some level of bus prioritization. 
Table 3-19

SCRITS Worksheet Analysis: Comparison of Technologies ${ }^{1}$

\begin{tabular}{|l|c|c|c|c|c|c|}
\hline \multirow{2}{*}{$\begin{array}{c}\text { Transit } \\
\text { System }\end{array}$} & \multicolumn{2}{|c|}{ Annual Value of Time Savings } & \multicolumn{3}{c|}{ Benefit/Cost Ratio } \\
\cline { 2 - 7 } & Pre & Post & $\%$ Chg & Pre & Post & $\%$ Chg \\
\hline $\begin{array}{l}\text { Eectronic Fare } \\
\text { Collection }\end{array}$ & $\$ 1,311,033$ & $\$ 1,482,790$ & $13 \%$ & 6.0 & 6.4 & $7 \%$ \\
\hline AVL & $\$ 1,384,226$ & $\$ 578,598$ & $-58 \%$ & 12.2 & 1.7 & $-86 \%$ \\
\hline Bus Priority & $\$ 452,565$ & $\$ 179,691$ & $-60 \%$ & 6.4 & 2.4 & $-63 \%$ \\
\hline \multicolumn{1}{|c|}{ Average } & $\$ 1,049,275$ & $\$ 747,026$ & $-29 \%$ & 8.2 & 3.5 & $-57 \%$ \\
\hline
\end{tabular}

${ }^{1}$ All of the information presented in this table isfor the "full week" caseand system averages are used for the electronic fre collection and AVL technologies.

The information in Table 3-19 indicates that the electronic fare collection technology resulted in the highest actual annual value of time savings, $\$ 1,482,790$, based on the user inputs provided by the transit systems, whil e buspriority had the low est user ti me savings $(\$ 179,691)$. Similarly, theelectronic fare collection technology achieved the highest average benefit/cost ratio at 6.4 , while AVL had the lowest, 1.7.

It may be the case that electronic fare collection achieved higher time savings than either AVL or bus priority because of the respective nature of the technologies. With electronic fare media, all bus passengers ultimately benefit because of the faster overall boarding process and the decrease in boarding time as a percent of total bus travel time. For AVL, only those passengersmaking use of the AVL's rea-time information experience any time savings (and then, only for wait time, which doesnot impact bus travel time such that ancill ary benefits can accrue to those passengers $\underline{\text { not }}$ utilizing the realtime information). In addition, for busprioritization, any passenger timesavings that are achieved must be offset by the negative time impact on traffic in or crossing the buscorridor.

However, it also is likely that this result hasbeen impacted by the case study systems respectivelevels of experience with the three technologies. Clearly, these systems have had the greates level of experience with the electronic fare collection technology to date. Thre of the systems have had electronic registering fareboxes and electronic fare media in use for several years and, based on discussions with staff at these systems, there seems to be abetter understanding of this technology and its benefits (potential and/or realized). Thiscomprehension wasreflected in the collection of usr input data, which waseasier and more straightforward for the electronic fare collection worksheet than for either the AVL or bus priority worksheets, where it seemed that much more estimation was necessary. 
Perhaps with greater experience and a better understanding of the AVL and buspriority technologies, improved evaluation results will occur.

\section{Assessment of the SCRITS Tool \& Analysis Process}

Not only will greater experi ence and understanding of the three technologies analyzed herein result in an improved evaluation process, but it is apparent from this effort that increased comprehension of the SCRTS Stool, itself, also will be necessary. One of the primary reasons for selecting the SCRTStool to conduct the analyses described previousy is that it would be simpler to use than IDASand would require a much lower level of user input. Unfortunately, in working with the case study transit systems to complete the worksheet analyses it was determined that SCRTS still is relatively difficult to use because of its required inputs.

While working with the case study systemson their respective SCRTSanalyses, it was found that the necessary user inputs for the various worksheets fell into three categories: information that is known or can be located easily, information that exists but is difficult (or, in some cases, almost impossible) to find, and information that doesnot exist and/or is not collected and must be estimated. Using the electronic fare collecti on worksheet as an example, the systemsdid not have any problemsproviding dataon ridershi $p$, average bus speed, or average passenger trip length. System staff assisting with each analysis knew this information or could easily calcul ate it from NTD statistics or system-developed planning databases. Then there was the information that posed more problemsto acquire, such as the cost and srvice life data for the electronic fare collection system. In each case, the original planning and/or operations contacts had to recruit assistance from individuals in other departments, such as finance or maintenance, to find this information. In some instances, the information was extremely difficult to locate because people who were responsible for it at the time of implementation were no longer at the system and support do cumentation was lacking or unavailable. In other cases, such as for annual operating/maintenance cost and annual labor cost savings, it was discovered that the information was not even collected or maintained on a regular basis. For many of these inputs, then, it was necessary for staff to make educated estimates based on the informati on that was available.

Other user inputs on the electronic fare collection worksheet that perpl exed system staff included average percent of bus travel time devoted to boarding and average passenger boarding times with conventional and el ectronic fare. This also is information that is not collected or maintained in any format. According to most of the system contacts, these and other inputs on the three SCRITS worksheetsare not likely to be collected becaus they are not necessary for the day-to-day operation

of a transit system. It was stressed several times that atransit agency isin the business of getting buses 
on the road to transport people, and not collecting data that they do not bel ieve serves that purpose. As a result, these type of variables needed to be estimated by system staff in order to complete the analyses.

Unfortunately, this need for estimation resulted in another issue that impacted theanal yses: perception versus reality. As exemplified in the HART case sudy, it is the cas that transit staff percption of boarding times does not match what actually occurs in a real-world situation. The systems' inputs for average boarding time for passengers using electronic fare ranged from three to five seconds. However, the brief supplementary survey analysis that HART staff conducted on boarding timesfound that the average boarding time for a person using an electronic fare card is more than seven seconds. A similar result was found when comparing HART's estimated and survey-based boarding times for those passengers using conventional fares. These findings suggest that the SCRTS electronic fare collection analysiswould have had different annual time savingsand benefit/cost ratio values had each system conducted a similar analysis that would have produced more representative boarding times. It is probable that this same issue impacted other uær inputs on the three worksheets, aswell, such as percent of passengers using AVL-based real-time information, average wait time per passenger (with or with out an AVL system), percentage of bus travel time attributable to signal delay, and percentage of traffic that incurs pre-emption delay, among others.

Further exacerbating the estimation problem is lack of experience with a given technology (i.e., those systems that truly are in a pre-implementation phase). In working with AATA and SCAT, which have both implemented electronic fareboxes but are not utilizing electronic fare media yet, it wasfound that estimating necessary user inputs (likeaverage boarding timesand percent of passengerswith electronic fare) was more difficult for these systems than for the others that already had experience with the technology. Since SCRITS is touted asa pre-planning analysis tool, this issue is particul arly perpl exing. In both of these cases, system staff had to rely on their knowledge of the experiences at other transit agencies and/or information from vendors, product documentation, etc., to help in developing their estimatesfor particular user inputs.

Besides these issueswith datacollection/estimation to satisfy the SCRITSuser input requirements, staff at the case sudy systemsalso offered their opinions about the overall SCRTSprocess and its use as an assessment tool, as well. Primarily, there are two major concems about this tool and/or the type of comparative andysis that it engenders. Frst, the systems believe that the SCRITS output, while potentially useful for certain purposes, is not as valuable or useful as it could be because it does not estimate agency benefits. While system saff see the ben efit of being able to explain to their respective oversight boards what benefitsmight accrue to transit passengersif a particular technology were to be 
implemented, it is their informed expectation that, invariably, these boards would want to know the ultimate benefit to the agency. Without such information, in their opinion, the tool loses much of its value in being able to help sell APTS deployment.

The second concern involves the comparability of SCRTSresults across systems One of the benefits of such a tool is the relative standardization that it can provide to the evaluation of APTStechnologies. If a number of systems are compared using the SCRITStool for a particular technology, then it is the case that all of the systems will uti lize the same set of input vari abl es and have their respective benefits results calculated in the samemanner. However, as indicated in the previous discussion on perception versus reality, it is not the case that the process of systems estimating various of their respective user inputs will promote the assurance of "apples to apples" comparability. Unless strict guidelines are established for the collection and/or development of each user inp ut, it will not be possible to conduct comparable analyses across systems. This particular issue is the reason why FTA hasestablished such rigorousreporting guidelines for its National Transit Databas - to ensure that the resulting information is comparable across systems. However, it is still argued by many usersof this particular databas that the information never truly will be comparable becaus of the host of system-level data collection and reporting idiosyncrasies that occur each year that serve to undermine the original intent of FTA's National Transit Database. For this reason, it also is unlikely that strict procedures for compiling SCRTSuser inputs will put to rest completely the transit systems' concernsregarding "comparability across agencies," especially since it appearsthat, for the most part, all transit agencies beli eve that they are inherently different from one another and cannot be compared anyway. As one staff member indicated during one of the phone interviews conducted for this evaluation, "Too many things are unique to each property to compress everything into a few formulas and have it be applicable across the board."

Nevertheless, it must not be discounted that, despite these concerns, staff at the case study systems indicated that they appreciated the SCRTS exercise because it made them think about issues and information related to APTSand the technologies in use at their respective systems that they had not considered before. Because of the nature of their jobs, some of these individuals intimated that their current duties almost require them to operate with blinders on most of the time in order to get everything done for which they are responsible. Being able to think about the SCRITS tool and its inputs, however, enabled them to step back from the everyday issues and tasks of their jobs and get involved in more "bi g picture" thinking. The opportunity to do this was seen asan importantancillary benefit. 


\section{Recom men d ation sfor Perfo rm ance Monitoring Measu res}

As stated previously in this chapter's introduction, it is extremely important for transit systems considering or actually deploying APTS to assess its potential benefits before implementation and to monitor its performance after deployment. These type of analyses are beneficial because they can highlight efficiencies, help justify costs, and provide an agency with important support information as it shares its APTSexperiences with others. The previous sections have detailed benefits analyses for various technology deployments at five different case study transit systems. These analyses have utilized the SCRTSpre-planning analysis tool to derive estimates for annual passenger time savings benefits and benefit/cost ratios for electronic fare collection, automatic vehicle location, and bus priority technologies. In thissection, theconcept of performance criteriaand monitoring is introduced.

The development of performance measurements for APTS technologies is critical because these measures enable an agency to assess how a particular technology is functioning and whether predetermined goals have been met by its deployment. Important to the process of performance monitoring are defining the goals and objectives of the transit system and establishing the measures of effectiveness and efficiency related to those goals and objectives. While the goals and objectives of each transit agency may vary, this section identifies those that are most common and provides examples of how post-deployment measures of effectiveness can be determined.

\section{Defining the Goals and Objectives}

Prior to deploying APTStechnol ogies, most transit systems have preset goals that typi cally are described in transit plans or other documents. These goals usually reflect the interests of all concerned stakeholders, such as transit u sers, op erators, agency admi ni strators, local governmental enti ti es, and private partners. Furthermore, the National ITSArchitecture also has identified goals that pertain to transit ITSand it has had increasing influence over the development of regional, state, and local ITS initiatives, such as FDOT's ITS Strategic Plan. The result is a set of goals which appear standard throughout the country. These goals are ${ }^{33}$ :

- Increase the operational efficiency and capacity of the system.

- Enhance the personal mobility, convenience, and comfort for uærs of the system.

- Improve the safety of the system.

${ }^{33}$ ITS Deployment Guidance for Transit Systems, Technical Edition, U.S. Department of Transportation, Federal Highway Administration, April 1997. 
- Reduce energy consumption and environmental costs.

- Enhance present and future economic productivity of individuals, organizations, and the community.

- Create an environment in which the development and deployment of ITS can flourish.

At some point, represntatives of each of theidentified groupsof stakeholdersparticipatein the shaping of the goalsand determining which objectives will best help to achieve thos goals. Some of themore common objecti ves of transit agenci es are to increase ridership, imp rove on-time performance, reduce travel times, enhance traveler æcurity, and increase intermo dal tran sportation opportunities. It is al so possible that the chosen obj ecti ves may vary depending on transit system type (i.e., demand-response versus fixed-route). Once the objectiveshave been identified, typically, those persons more involved with the management and operation of the transit system develop the specific methods for measuring the effectiveness of the tools used to achieve the objectives - in this cas, the APTSapplications.

\section{Establishing the Measures}

Since APTS deployment is relatively new, there are few definitive guides that identify standard measures of effectiveness and efficiency for specific technologies. Fortunately, though, transit personnel have had extensive experience monitoring the performance of transit service, itself, so the concept of performance measures is not really foreign. For example, a typical route analysis will examine how a route is performing in terms of passenger trips per revenue hour of service, operating expense per hour, and farebox recovery (i.e., the ratio of passenger fare revenue collected on the route to the cost of operating it), among other measures.

For purposes of evaluating APTS, the primary categories of measures are related to user convenience and acceptance, transit system effectiveness, and transit system efficiency. Within these categories are specific measures that allow the evaluation of an APTS technology's performance. The ITS Deployment Guidance for Transit Systems, Technical Edition, identifies suggested "measures of effectiveness," or MOEs, that can be used for the purpose of performance evaluation. These MOES should represent the concerns of the stakeholders and usually measure safety, cost, capacity, satisfaction, and delays in various ways. Examples of measures identified in the publication are:

- number of transit riders per year

- transit vehicle occupancy

- travel times (minutes)

- number of accidents 
- total annual transit miles

- transit revenue

These and other measures are established with specific system goals and objectives in mind. At the onset, a transit agency should identify what the goals and objectivesof its system are and what it hopes to accomplish through the deployment of APTS technologies. The document, Advanced Public Transportation Systems: Eval uation Guidelines, provides an example of a matrix that demonstratesthe relationship between common system objectives and categories of measures. ${ }^{34}$ Table 1 presnts a modified version of the matrix from that publication using the most common objectives of transit agencies.

\section{APTSApplications}

While Table 1 identifies those common objectives and applicable measures of effectiveness, the following section briefly describeswhich APTSapplications can assist in achieving the objectivesand how they might be used in determining the measurements of effectiveness

According to the Economic and Policy Considerations of Advanced Public Transportation Systems (APTS): Assessing the Economic Feasibility of APTS APTSapplications can be categorized as Smart Travel er Technol ogies, Smart Intermo dal Systems, and Smart Vehi cle Technol ogies. ${ }^{35}$ Smart Travel er Technol ogi esare thos that all ow the usersto have access to reliable, real-time informati on either when making plans for using public transportati on or while using it. The main purpose of Smart Traveler applications is to make public transportation more convenient for users, which can have a direct impact on the growth of ridership and user satisfaction. Examples of Smart Traveler applications include advanced/integrated fare payment media, information kiosks, on-bus annunciators, passenger information displays, and computerized passenger information systems.

\footnotetext{
${ }^{34}$ Casey, Robert F. and John Collura, Advanced Public Transportation Systems: Evaluation Guidelines, prepared by the Volpe National Transportation Systems Center for the Office of Technical Assistance, Federal Transit Administration, January 1994.

${ }^{35}$ Ball, William. Economic and Policy Considerations of Advanced Public Transportation Systems (APTS): Assessing the Economic Feasibility of APTS, prepared by the National Urban Transit Institute at the Center for Urban Transportation Research, October 1994.
} 
Table 3-20

Examples of APTS Program Objectives and Performance Measures

\begin{tabular}{|c|c|c|c|c|c|c|c|c|}
\hline \multirow[b]{2}{*}{$\begin{array}{l}\text { Category of } \\
\text { Measure }\end{array}$} & \multicolumn{8}{|c|}{ Objectives } \\
\hline & $\begin{array}{c}\text { Reduce Travel } \\
\text { Time/Improve } \\
\text { On-Time } \\
\text { Performance }\end{array}$ & $\begin{array}{l}\text { Improve On- } \\
\text { Board Safety } \\
\text { \& Security }\end{array}$ & $\begin{array}{l}\text { Increase } \\
\text { ridership }\end{array}$ & $\begin{array}{c}\text { Increase Fare } \\
\text { Payment } \\
\text { Options }\end{array}$ & $\begin{array}{l}\text { Improve } \\
\text { Availability of } \\
\text { Information }\end{array}$ & $\begin{array}{c}\text { Enhance } \\
\text { Opportunities } \\
\text { for Customer } \\
\text { Feedback }\end{array}$ & $\begin{array}{c}\text { Reduce } \\
\text { Transit } \\
\text { System Costs }\end{array}$ & $\begin{array}{c}\text { Increase } \\
\text { Intermodal } \\
\text { Capabilities \& } \\
\text { Opportunities }\end{array}$ \\
\hline $\begin{array}{l}\text { Transit } \\
\text { System } \\
\text { Effectiveness }\end{array}$ & $\begin{array}{l}\text { - \% on-time } \\
\text { - headway } \\
\text { - time by car } \\
\text { - transit travel } \\
\text { time }\end{array}$ & $\begin{array}{l}\text { - accident rate } \\
\text { - incident rate } \\
\text { - crime } \\
\text { incident rate } \\
\text { - farebox } \\
\text { shortages }\end{array}$ & $\begin{array}{l}\text { - increase in } \\
\text { service area }\end{array}$ & $\begin{array}{l}\text { - \# of payment } \\
\text { options } \\
\text { - queue } \\
\text { lengths }\end{array}$ & $\begin{array}{l}\text { - accuracy of } \\
\text { info } \\
\text { - type of } \\
\text { information } \\
\text { relayed }\end{array}$ & $\begin{array}{l}\text { - \# of } \\
\text { opportunities } \\
\text { for feedback } \\
\text { - type of } \\
\text { feedback } \\
\text { opportunities }\end{array}$ & $\begin{array}{l}\text { - \# shared } \\
\text { trips } \\
\text { (demand- } \\
\text { response) }\end{array}$ & $\begin{array}{l}\text { - reduction in } \\
\text { SOV trips } \\
\text { - \# of multi- } \\
\text { mode trips }\end{array}$ \\
\hline $\begin{array}{l}\text { Transit } \\
\text { System } \\
\text { Efficiency }\end{array}$ & $\begin{array}{l}\text { - boarding or } \\
\text { alighting } \\
\text { time }\end{array}$ & $\begin{array}{l}\text { - changes in } \\
\text { vehicle } \\
\text { down-time } \\
\text { changes in } \\
\text { time system } \\
\text { is monitored } \\
\text { by camera, } \\
\text { staff, or } \\
\text { other } \\
\text { methods }\end{array}$ & $\begin{array}{l}\text { - \# trips per } \\
\text { capita } \\
\text { - average } \\
\text { vehicle } \\
\text { occupancy }\end{array}$ & $\begin{array}{l}\text { - \# using each } \\
\text { option }\end{array}$ & $\begin{array}{l}\text { - \# of info } \\
\text { outlets } \\
\text { - \# users of } \\
\text { each outlet } \\
\text { - \# and type of } \\
\text { inquiries }\end{array}$ & $\begin{array}{l}\text { - \# of } \\
\text { responses } \\
\text { received }\end{array}$ & $\begin{array}{l}\text { - change in } \\
\text { cost per trip } \\
\text { - change in } \\
\text { operating } \\
\text { costs } \\
\text { - change in } \\
\text { maintenance } \\
\text { costs }\end{array}$ & $\begin{array}{l}\text { - travelers per } \\
\text { mode } \\
\text { - change in } \\
\text { roadway } \\
\text { LOS }\end{array}$ \\
\hline $\begin{array}{l}\text { Customer } \\
\text { Convenience } \\
\text { and } \\
\text { Satisfaction }\end{array}$ & $\begin{array}{l}\text { - perceptions } \\
\text { regarding } \\
\text { travel time } \\
\text { changes }\end{array}$ & $\begin{array}{l}\text { - rider } \\
\text { perception } \\
\text { regarding } \\
\text { safety }\end{array}$ & $\begin{array}{l}\text { perceptions } \\
\text { regarding } \\
\text { popularity of } \\
\text { transit system } \\
\text { (i.e., is it } \\
\text { used?, are } \\
\text { buses full?) }\end{array}$ & $\begin{array}{l}\text { - rider } \\
\text { perception } \\
\text { on } \\
\text { convenience } \\
\text { - \# users of } \\
\text { new options }\end{array}$ & $\begin{array}{l}\text { - perceptions } \\
\text { regarding } \\
\text { customer } \\
\text { info services } \\
\text { - most popular } \\
\text { info outlet }\end{array}$ & $\begin{array}{l}\text { - perceptions } \\
\text { regarding } \\
\text { ability to } \\
\text { provide } \\
\text { feedback }\end{array}$ & $\begin{array}{l}\text { - perceptions } \\
\text { regarding } \\
\text { level of } \\
\text { service }\end{array}$ & $\begin{array}{l}\text { perceptions } \\
\text { regarding } \\
\text { ease of } \\
\text { traveling } \\
\text { between } \\
\text { modes }\end{array}$ \\
\hline
\end{tabular}


Smart Intermodal Systems can help providers of public transportation offer more intemodal opportunities to users by ensuring that the coordination and integration of services are convenient, userfriendly, and efficient. Such integration is achieved when APTSapplications simplify aspects of intermodal service. For example, Smart Intermodal applications that offer uniform fare media capabi liti es enable travelersto use a single payment technique for varying transportation alternatives. Another example of Smart Intermo dal Systems are computeri zed passenger information systemsthat allow travelersto pre-plan an intermodal trip through use of a telephone or computer.

The thi rd category of APTS applications is Smart Vehicle Technologies. The primary purpose of advanced vehicle technology is to provide moreefficient and effective fleet planning, scheduling, and operations through applications such as AVL systems, automatic passenger counters (APCs), computerized dispatching/scheduling systems, advanced communications systems, and vehicle component monitoring systems. Many Smart Traveler and Smart Intermodal applications are not as effective wi thout the real-time dataprovided by the use of Smart Vehicle Technologies. Conæquently, the integration of applications from all categories of APTStechnologies is important to the successful development and deployment of ITS. Table 2 listssome of the more common APTSapplications and identifies those objectives that they may be instrumental in achieving.

Based on the documented APTS experiences around the country to date, it would appear that ITS technologi es can be quitevaluable to a transit agency in the determination of its system's performance effectiveness. The technologies not only can have an impact on the system's level of effectiveness, itself, but they also have a role in the more accurate collection of the data that ultimately is used to measure performance effectiveness. Effectiveness, as well as efficiency and the level of convenience of the system to its users, are categoriesof measuresthat typically allow a transit system to determine whether the objectives of the agency (and other related sakeholders) are being met. 
Table 3-21

APTS Applications and Measures Matrix

\begin{tabular}{|c|c|c|c|c|c|c|c|c|c|}
\hline \multirow[b]{2}{*}{ Objective } & \multicolumn{9}{|c|}{ APTS Applications } \\
\hline & $\begin{array}{l}\text { Info Kiosks } \\
\text { \& Passenger } \\
\text { Info Displays }\end{array}$ & $\begin{array}{l}\text { Advanced } \\
\text { Fare } \\
\text { Payment } \\
\text { Media }\end{array}$ & $\begin{array}{l}\text { Automated } \\
\text { Vehicle } \\
\text { Locators }\end{array}$ & $\begin{array}{l}\text { Automatic } \\
\text { Passenger } \\
\text { Counters }\end{array}$ & $\begin{array}{l}\text { Computerized } \\
\text { Dispatching/ } \\
\text { Scheduling }\end{array}$ & $\begin{array}{c}\text { Advanced } \\
\text { Communications } \\
\text { Systems }\end{array}$ & $\begin{array}{c}\text { On-Board } \\
\text { Bus } \\
\text { Annunciators }\end{array}$ & $\begin{array}{l}\text { Computerized } \\
\text { Passenger } \\
\text { Information } \\
\text { Systems }\end{array}$ & $\begin{array}{c}\text { Vehicle } \\
\text { Component } \\
\text { Monitoring } \\
\text { Systems }\end{array}$ \\
\hline $\begin{array}{l}\text { Reduce Travel } \\
\text { Time/Improve On- } \\
\text { Time Performance }\end{array}$ & $\bullet$ & $\bullet$ & $\bullet$ & $\bullet$ & $\bullet$ & $\bullet$ & $\bullet$ & $\bullet$ & $\bullet$ \\
\hline $\begin{array}{l}\text { Improve On-Board } \\
\text { Safety/Security }\end{array}$ & & $\bullet$ & $\bullet$ & & $\bullet$ & $\bullet$ & $\bullet$ & & $\bullet$ \\
\hline Increase Ridership & $\bullet$ & $\bullet$ & $\bullet$ & & $\bullet$ & $\bullet$ & $\bullet$ & $\bullet$ & $\bullet$ \\
\hline $\begin{array}{l}\text { Increase Fare } \\
\text { Payment Options }\end{array}$ & $\bullet$ & $\bullet$ & & & & & & $\bullet$ & \\
\hline $\begin{array}{l}\text { Improve Availability } \\
\text { of Information }\end{array}$ & $\bullet$ & & $\bullet$ & & $\bullet$ & $\bullet$ & $\bullet$ & $\bullet$ & \\
\hline $\begin{array}{l}\text { Enhance } \\
\text { Opportunities for } \\
\text { Customer Feedback }\end{array}$ & $\bullet$ & & & & & & & $\bullet$ & \\
\hline $\begin{array}{l}\text { Reduce Transit } \\
\text { System Costs }\end{array}$ & $\bullet$ & $\bullet$ & $\bullet$ & $\bullet$ & $\bullet$ & $\bullet$ & $\bullet$ & $\bullet$ & $\bullet$ \\
\hline $\begin{array}{l}\text { Increase Intermodal } \\
\text { Capabilities }\end{array}$ & $\bullet$ & $\bullet$ & $\bullet$ & $\bullet$ & $\bullet$ & $\bullet$ & $\bullet$ & $\bullet$ & $\bullet$ \\
\hline
\end{tabular}




\section{SU M M ARY OF CH APTER THREE}

Thisthird chapter for the Inventory and Analysis of Advanced Public Transportation Systemsin Florida project has provided an assessment of the annual time savings benefits that five case study transit systems have accrued for their respective passengers through the implementation of one or more of three different APTS technologies electronic fare collection, AVL, and bus priority. The SCRTS spreadsheet-based, pre-planning analysis tool was utilized to conduct the analysis of each system. These analysesexami ned pre-and post-deployment conditionsfor each technology being used, or soon to be utilized, by each system.

In addition, the topic of post-deployment performance measurement and monitoring also was introduced. The development of performance measurements for APTS technologies is extremely important because such measures enable an agency to assess how a particular technology is functioning and whether established system goals and objectives have been met by its deployment. This discussion also provided some examples of, and general recommendations for, performance measures that are applicable to the more common goals and objectives and identified specific APTS applications that may be used to achieve the objectives.

From the overal benefits analysis process, it waslearned that, despite the relative simplicity of SCRTS compared to other similar analysis tools, it is still somewhat difficult to understand - especially some of the required user in puts for each of its technology worksheets. Other drawbacksof this analysistool are that the number of APTS-specific technologies that it is designed to evaluate is extremely limited and it can only estimate the time savings benefits that accrue to a transit agency's passengers, and not any of the potential benefits that might be realized by the agency, itself. Nevertheless, the SCRTStool is readily available for free and is a decided step in the right direction of establishing a standardized benefits analysis process that is easily transferable between systems, regardless of size or operating environment/characteristics, and produces results that can be understood and compared across technologies and/or agencies.

The individual system analyses also provided interesting insights, as well. For the most part, the analyses found that the majority of the APTS deployments at the case study systems have indeed benefitted passengers of those agencies in terms of annual time savings. The resulting benefit-to-cost ratios also have been positive. Unfortunately, the analyses also helped identify a number of issues at the systems related to data col lection and informati on availability, the estimation of u ser inputs for the SCRITS analysis, lack of experience with APTS technologies, and concern about comparability of analysis results across systems. 
Working with the case study systems on their respective SCRTS analyses, it was determined that information for some of the necessary user inputs was extremely difficult to locate and, in some instances, did not even exist or was not collected. Issues contributing to this problem included information being collected/compiled by different personsand/or departmentswith no real processfor centralizing files or data, person(s) originally responsible for information at the time of implementation leaving the agency without passing on any support documentation or data, and staff not having the time and/or wherew ithal to collect i nformati on that doesnot directly servethe transit agency'smain purpose of getting buses on the road to transport people. This issue of missing or incomplete information resulted in many of the case sudy systemshaving to make educated estimates for several of the inputs based on whatever information they did have available.

The need to estimatecertain variablesresulted in another issue that impacted theanalyses: percption versus reality. As exemplified in the HART case sudy related to average boarding times, it is the cas that transit staff perception of particular passenger and/or system characteristics does not match necessarily what actually occurs in a real-world situation. Because of the variability inherent in the estimation process, then, this particular issue can have a significant impact on the desired goal of standardized evaluation processes. Without specific guidance on the calculation or estimation of each user input, true comparability of results across systems/technologies may not be possible.

Further exacerbating this problem with estimation is the lack of experience with APTStechnology at many transit systems, especially those that have not had any deployment opportunities. In working with the two case study systemsthat did not have specific experience with electronicfaremedia, it was noted that the estimation processfor several user inputs(e.g., average boarding time for passenger with electronic fare, percent of passengers with electronic fare) was much more difficult than for thoæ al ready experienced with electronic fare collection. Since SCRTSis touted as a pre-planning analysis tool, this issue is particul arly perpl exing.

Finally, in discussing their thoughts about SCRITS and the analysis process, staff at the case study systemsexpressed their concem over the possibil ity of comparing the benefitsassessment results across systems. Because of the estimation and perception issues, as well as the apparently widespread belief among transit agencies that they are inherently different from one another and cannot be compared in any meaningful fashion, it is questioned whether true "appl es to appl es" comparability will be po ssible.

Despite these issuesand concerns, however, based on the research experience with the five case sudy transit systemsinvolved in this analysis, it would appear that personnel at the systemsare aware of the importance of benefits assessment and measuring the performance of APTS technologies They 
understand the need for establishing verifiable benefits related to APTS deployment so that this information can be used to help sell their systems' potential future APTSapplications to their boards, local officials, and stakeholders. Being able to demonstrate positive performance of existing technologieswill help in this regard, as well. In addi tion, the transit industry, itself, will be well served by the additional APTSevaluation information that will be available to be shared.

Lastly, it is important to note a final positi ve outcome from the analy sis process detailed herein: the opportunity for transit planning and operation staff to pull themselves out of the specific detail focus of their jobs and get involved in more "big picture" thi nking rel ated to the implementation of APTS At any transit agency, it is these individuals that may understand best what applications may help improve aspects of service for passengers or system effecti venessefficiency. They are also in the best position to collect and compile the necessary data for assessing benefits and monitoring technology performance. Assuch, it will be important for transit agencies to facili tate their involvement in most, if not all, aspects of the development and deployment of APTSin order to help ensure success and appropriate assessment. 
Appendix A

Initial APTSInventory Questionnaire 


\section{Advanced Public Transportation Systems Inventory Questionnaire}

\begin{tabular}{|c|c|c|c|c|c|}
\hline \multicolumn{6}{|l|}{ A AGECY NAME: } \\
\hline \multicolumn{6}{|l|}{ RESPONDER NAME: } \\
\hline \multicolumn{6}{|l|}{ TitLE: } \\
\hline \multicolumn{6}{|l|}{ ADDRESS: } \\
\hline \multicolumn{6}{|l|}{ TEL: } \\
\hline \multicolumn{6}{|l|}{ FAX: } \\
\hline \multicolumn{6}{|l|}{ E-MA IL: } \\
\hline \multicolumn{6}{|l|}{$\begin{array}{r}\text { TOTAL NuMbER OF } \\
\text { VEHICLES IN O PERA TION : }\end{array}$} \\
\hline MOD ES O PERA TED: & Fixed Route: & & Demand Respo & nsive: & \\
\hline CAPACITY: & Standing: & & & eating: & \\
\hline \multicolumn{6}{|l|}{ MANUFACTURERS: } \\
\hline ADA AcCess? & Yes: & No: & $\begin{array}{l}\text { Wheelchair } \\
\text { Capacity: }\end{array}$ & & \\
\hline
\end{tabular}

If the an swer to the num bered que stion is "yes" please proceed to part (a) and /or (b) of that question, otherwise, continue on to the next question.

\section{Flemt Management}

\section{Automated Vehicle Location Systems}

1. Does your agency currently have or intend to have an autom ated vebicle location system for its vebicles?

\begin{tabular}{|l|l|}
\hline Yes & No \\
\hline & \\
\hline
\end{tabular}

(a)

\begin{tabular}{|l|l|}
\hline \multicolumn{1}{|c|}{ Technology } & \\
\hline GPS & \\
\hline Signpost/Odometer & \\
\hline Dead-Reckoning & \\
\hline Loran-C & \\
\hline Others (Please Specify) & \\
\hline
\end{tabular}

(b)

\begin{tabular}{|l|l|}
\hline \multicolumn{1}{|c|}{ Status } & \\
\hline Planning & \\
\hline Testing & \\
\hline Implementation/Testing & \\
\hline Implem entation & \\
\hline Fully Operation al & \\
\hline
\end{tabular}

Number and type of vebicles equipped: 


\section{Automatic Passenger Counter}

2. Doesyour agency currently have or intend to have autom atic passenger counters on its vehicles?

\begin{tabular}{|l|l|}
\hline Yes & No \\
\hline & \\
\hline
\end{tabular}

(a)

\begin{tabular}{|l|l|}
\hline \multicolumn{1}{|c|}{ Technology } & \\
\hline Infrared Beam s & \\
\hline Treadle Mats & \\
\hline Infrared Optic Sensors & \\
\hline Ultrasonic Frequency Sensors & \\
\hline Others (Please Specify) & \\
\hline
\end{tabular}

(b)

\begin{tabular}{|l|l|}
\hline \multicolumn{1}{|c|}{ Status } & \\
\hline Planning & \\
\hline Testing & \\
\hline Implem entation/ Testing & \\
\hline Implem entation & \\
\hline Fully Operation al & \\
\hline
\end{tabular}

Num ber and type of vehicles equipped:

\section{Vehicle Component Monitoring System}

3. Doesyour agency currently have or intend to have a vebicle component monitoring system for its vebicles?

\begin{tabular}{|l|l|}
\hline Yes & No \\
\hline & \\
\hline
\end{tabular}

(a)

\begin{tabular}{|l|l|}
\hline \multicolumn{1}{|c|}{ Condition } & \\
\hline High Engine Temperature & \\
\hline Low Oil Pressure & \\
\hline Others (Please Specify) & \\
\hline
\end{tabular}

(b)

\begin{tabular}{|l|l|}
\hline \multicolumn{1}{|c|}{ Status } & \\
\hline Planning & \\
\hline Testing & \\
\hline Implem entation/Testing & \\
\hline Implem entation & \\
\hline Fully Operation al & \\
\hline
\end{tabular}

Number and type of vebicles equipped:

\section{Automated O perations Software}

4. Does your agency currently have or intend to have softw are that integrate sany of the following tran sit operations functions?

\begin{tabular}{|c|c|}
\hline Yes & No \\
\hline & \\
\hline
\end{tabular}

(a)

\begin{tabular}{|l|l|}
\hline \multicolumn{1}{|c|}{ Activities } & \\
\hline Computer Aided Dispatch & \\
\hline Vehicle Performance & \\
\hline Loading & \\
\hline Driver Performance & \\
\hline Schedule Monitoring & \\
\hline Passenger Statistics & \\
\hline System-wide Statistics & \\
\hline Others (Please Specify) & \\
\hline
\end{tabular}

(b)

\begin{tabular}{|l|l|}
\hline \multicolumn{1}{|c|}{ Status } & \\
\hline Planning & \\
\hline Testing & \\
\hline Implem entation/Testing & \\
\hline Implem entation & \\
\hline Fully Operation al & \\
\hline
\end{tabular}




\section{On Board Safety Systems}

5. Doesyour agency currently have or intend to have any on board safety features in its vehicles?

\begin{tabular}{|l|l|}
\hline Yes & No \\
\hline & \\
\hline
\end{tabular}

(a)

\begin{tabular}{|l|l|}
\hline \multicolumn{1}{|c|}{ Features } & \\
\hline Silent Alarms & \\
\hline Passenger Clearance Sensors & \\
\hline Others (Please Specify) & \\
\hline
\end{tabular}

(b)

\begin{tabular}{|l|l|}
\hline \multicolumn{1}{|c|}{ Status } & \\
\hline Planning & \\
\hline Testing & \\
\hline Implem entation/Testing & \\
\hline Implem entation & \\
\hline Fully Operational & \\
\hline
\end{tabular}

Num ber and type of vebicles equipped:

\section{TRAVELR INFORMATION}

\section{Trip Planning Information}

1. Does your agency provide or intend to provide tripplanning inform ation for yourpassengers?

\begin{tabular}{|c|c|}
\hline Yes & No \\
\hline & \\
\hline
\end{tabular}

(a)

\begin{tabular}{|l|l|}
\hline \multicolumn{1}{|c|}{ Location } & \\
\hline Touch-tone Telephones & \\
\hline Internet & \\
\hline FaxMachines & \\
\hline Kiosks & \\
\hline Others (Please Specify) & \\
\hline
\end{tabular}

(b)

\begin{tabular}{|l|l|}
\hline \multicolumn{1}{|c|}{ Status } & \\
\hline Planning & \\
\hline Testing & \\
\hline Implem entation/Testing & \\
\hline Implem entation & \\
\hline Fully Operation al & \\
\hline
\end{tabular}

\section{Trip Planning Information (Single Mode and/or Multimodal)}

2. Does your agency provide or intend to provide trip planning inform ation for single mode and/or multimodal inform ation for your passengers?

\begin{tabular}{|l|l|}
\hline Yes & No \\
\hline & \\
\hline
\end{tabular}

(a)

\begin{tabular}{|l|l|}
\hline \multicolumn{1}{|c|}{ Information } & \\
\hline Schedules, Fares & \\
\hline System Disruption & \\
\hline Carpooling and Parking & \\
\hline Incidents and/or Weather & \\
\hline Routes, Stop Locations & \\
\hline Ride-m atching Registration & \\
\hline Others (Please Specify) & \\
\hline
\end{tabular}

(b)

\begin{tabular}{|l|l|}
\hline \multicolumn{1}{|c|}{ Status } & \\
\hline Planning & \\
\hline Testing & \\
\hline Implem entation/ Testing & \\
\hline Implem entation & \\
\hline Fully Operation al & \\
\hline
\end{tabular}


In-terminal Information Systems

3. Doesyour agency provide or intend to provide in-terminal information for your passengers?

\begin{tabular}{|l|l|}
\hline Yes & No \\
\hline & \\
\hline
\end{tabular}

(a)

\begin{tabular}{|l|l|}
\hline \multicolumn{1}{|c|}{ Technology } & \\
\hline Electronic Signs & \\
\hline Kiosks & \\
\hline Television Monitors & \\
\hline Annun ciators & \\
\hline Others (Please Specify) & \\
\hline
\end{tabular}

(b)

\begin{tabular}{|l|l|}
\hline \multicolumn{1}{|c|}{ Status } & \\
\hline Planning & \\
\hline Testing & \\
\hline Implem entation/Testing & \\
\hline Implem entation & \\
\hline Fully Operation al & \\
\hline
\end{tabular}

\section{In-vehicle Information Systems}

4. Doesyour agency provide or intend to provide in-vehicle information for your passengers?

\begin{tabular}{|l|l|}
\hline Yes & No \\
\hline & \\
\hline
\end{tabular}

(a)

\begin{tabular}{|l|l|}
\hline \multicolumn{1}{|c|}{ Technology } & \\
\hline Electronic Signs & \\
\hline Television Monitors & \\
\hline Annunciators & \\
\hline Others (Please Specify) & \\
\hline
\end{tabular}

(b)

\begin{tabular}{|l|l|}
\hline \multicolumn{1}{|c|}{ Status } & \\
\hline Planning & \\
\hline Testing & \\
\hline Implem entation/Testing & \\
\hline Implem entation & \\
\hline Fully Operation al & \\
\hline
\end{tabular}

Number and type of vebicles equipped:

\section{Eiectro nic Fare Payment}

\section{Automated Fare Payment}

1. Doesyouragency currently have or intend to have automated fare payment system on its vebicles?

\begin{tabular}{|c|c|}
\hline Yes & No \\
\hline & \\
\hline
\end{tabular}

(a)

\begin{tabular}{|l|l|}
\hline \multicolumn{1}{|c|}{ Technology } & \\
\hline Magnetic Strip & \\
\hline Sm art Card & \\
\hline Credit Card & \\
\hline Proximity Cards & \\
\hline Others (Ple ase Specify) & \\
\hline
\end{tabular}

(b)

\begin{tabular}{|l|l|}
\hline \multicolumn{1}{|c|}{ Status } & \\
\hline Planning & \\
\hline Testing & \\
\hline Implem entation/Testing & \\
\hline Implem entation & \\
\hline Fully Operation al & \\
\hline
\end{tabular}

Number and type of vehicles equipped: 


\section{Multi-carrier Reservation and Bill ing Systems}

2. Doesyour agency currently have or intend to have multi-carrier trip reservation and in tegrated billing system s?

\begin{tabular}{|l|l|}
\hline Yes & No \\
\hline & \\
\hline
\end{tabular}

(a)

\begin{tabular}{|l|l|}
\hline \multicolumn{1}{|c|}{ Technology } & \\
\hline Between Different Modes & \\
\hline With ATMand/or Credit Cards & \\
\hline Between Different Providers & \\
\hline Others (Please Specify) & \\
\hline
\end{tabular}

(b)

\begin{tabular}{|l|l|}
\hline \multicolumn{1}{|c|}{ Status } & \\
\hline Planning & \\
\hline Testing & \\
\hline Implem entation/Testing & \\
\hline Implem entation & \\
\hline Fully Operation al & \\
\hline
\end{tabular}

Number and type of vebicles equipped:

\section{iV Transportation Demand Management Technologies}

\section{Advanced Communications}

1. Doesyour agency currently have or intend to have advanced comm unication system forits vehicles?

\begin{tabular}{|l|l|}
\hline Yes & No \\
\hline & \\
\hline
\end{tabular}

(a)

\begin{tabular}{|l|l|}
\hline \multicolumn{1}{|c|}{ Technology } & \\
\hline Analog Land Mobile & \\
\hline Digital & \\
\hline Trunked + Digital & \\
\hline Other + Digital & \\
\hline Others (Please Specify) & \\
\hline
\end{tabular}

(b)

\begin{tabular}{|l|l|}
\hline \multicolumn{1}{|c|}{ Status } & \\
\hline Planning & \\
\hline Testing & \\
\hline Implem entation/Testing & \\
\hline Implem entation & \\
\hline Fully Operation al & \\
\hline
\end{tabular}

Number and type of vebicles equipped:

\section{Automated Service Coordination}

2. Doesyour agency currently have or intend to have any technologies to integrate and coor din ate transportation services in your region? (A "one-stop shopping" for the traveler in your region).

(a)

\begin{tabular}{|l|l|}
\hline \multicolumn{1}{|c|}{ Technology } & \\
\hline Scheduling & \\
\hline Routing & \\
\hline Inform ation Systems & \\
\hline Billing & \\
\hline Others (Please Specify) & \\
\hline
\end{tabular}

(b)

\begin{tabular}{|l|l|}
\hline \multicolumn{1}{|c|}{ Status } & \\
\hline Planning & \\
\hline Testing & \\
\hline Implem entation/Testing & \\
\hline Implem entation & \\
\hline Fully Operation al & \\
\hline
\end{tabular}


Transportation Management Center (TMC)

3. Is the re a TMC in your region? Are you partor intend to be part of this TMC?

\begin{tabular}{|l|l|}
\hline Yes & No \\
\hline & \\
\hline
\end{tabular}

What are the technologies that are used to integrate and distribute transitinform ation from the TMC?

(a)

\begin{tabular}{|l|l|}
\hline \multicolumn{1}{|c|}{ Technology } & \\
\hline Pagers, Telephone & \\
\hline Electronic Signs On Board & \\
\hline Inform ation Kiosks & \\
\hline Cable Television & \\
\hline Others (Please Specify) & \\
\hline
\end{tabular}

(b)

\begin{tabular}{|l|l|}
\hline \multicolumn{1}{|c|}{ Status } & \\
\hline Planning & \\
\hline Testing & \\
\hline Implem entation/Testing & \\
\hline Implem entation & \\
\hline Fully Operation al & \\
\hline
\end{tabular}

\section{Signal Preemption}

4. Doesyour agency currently have or intend to have traffic signal priority on your routes? If yes, how many in tersections?

\begin{tabular}{|c|c|}
\hline Yes & No \\
\hline & \\
\hline
\end{tabular}

(a)

\begin{tabular}{|l|l|}
\hline \multicolumn{1}{|c|}{ Status } & \\
\hline Planning & \\
\hline Testing & \\
\hline Implem entation/Testing & \\
\hline Implem entation & \\
\hline Fully Operation al & \\
\hline
\end{tabular}

\section{Dynamic Ridesharing}

5. Doesyour agency have or intend to have a central database or operation center for an organized dyn am ic ridesharing program? (This form of ridesharing is used to obtain a ride for a single, one way or round trip rather than for trips $m$ ade on a regular basis).

(a)

\begin{tabular}{|l|l|}
\hline \multicolumn{1}{|c|}{ Status } & \\
\hline Planning & \\
\hline Testing & \\
\hline Implem entation/Testing & \\
\hline Implem entation & \\
\hline Fully Operation al & \\
\hline
\end{tabular}

\begin{tabular}{|c|c|}
\hline Yes & No \\
\hline & \\
\hline
\end{tabular}




\section{High Occupancy Vehicle Lane Access}

6. Doesyour agency currently have or intend to have high occupancy ve hicle lane accessfor its vehicles? (Thisis a device/ transponder on the vehicle, which gives

\begin{tabular}{|l|l|}
\hline Yes & No \\
\hline & \\
\hline
\end{tabular}
access to high occupancy vehicle only lanes).

(a)

\begin{tabular}{|l|l|}
\hline \multicolumn{1}{|c|}{ Status } & \\
\hline Planning & \\
\hline Testing & \\
\hline Implem entation/ Testing & \\
\hline Implem entation & \\
\hline Fully Operation al & \\
\hline
\end{tabular}

Number and type of vehicles equipped:

\section{Paratranst Providers}

\section{Automated Paratransit}

1. Doesyouragency currently have or intend to have an automated paratransit system?

\begin{tabular}{|l|l|}
\hline Yes & No \\
\hline & \\
\hline
\end{tabular}

(a)

\begin{tabular}{|l|l|}
\hline \multicolumn{1}{|c|}{ Activities } & \\
\hline Computer Aided Dispatch & \\
\hline Scheduling & \\
\hline Others (Please Specify) & \\
\hline
\end{tabular}

(b)

\begin{tabular}{|l|l|}
\hline \multicolumn{1}{|c|}{ Status } & \\
\hline Planning & \\
\hline Testing & \\
\hline Implem entation/Testing & \\
\hline Implem entation & \\
\hline Fully Operation al & \\
\hline
\end{tabular}

Number and type of vebicles equipped:

\section{VI “OTHER"}

1. Doesyour agency currently have or intend to have any other type of technology for APTS application, which w e hav e over-looked to $m$ en tion in the above que stions.

\begin{tabular}{|c|c|}
\hline Yes & No \\
\hline & \\
\hline
\end{tabular}

What type of technology and for what application?

Number and type of vebicles equipped: 
If you have question s please feel free to contact Shireen Chada at Center for Urban Transportation Research (CUTR). Please send the inv entory que stionn aire back to the address giv en be low no later than March 24, 2000.

Tel:

(813) 9745307

Email: $\quad$ chada@cutr.eng.usf.edu.

Fax: $\quad$ (813) 9745168

Address: Attn: Shireen Chada

Center for Urban Transportation Resear ch

University of South Florida

4202 E Fowler A venue, CUT 100

Tampa, FL 33620-5375 
ApPendix B

Foll ow-Up APTS Inventory Questionnaire 


\section{FOLLOW UP APTSINVENTORY QUESTIONNAIRE}

It is not necessary for you to answer all questions. We would like for you to answer all questions, but if you do not have an opinion on any particular question just put "No Opinion."

For "Staff Opinions", please answer the questions that apply to your transit agency only.

\begin{tabular}{|l|l|}
\hline Agency Name: & \\
\hline Person Interviewed: & \\
\hline Telephone No:: & \\
\hline Email Address: & \\
\hline
\end{tabular}

\section{GenERAL}

1. Did you address APTSin your Transit Development Plans?

2. How much consideration hasbeen given to ITS-Transit in the overall operational scheme?

3. How important is it to incl ude APTS in the planning process?

\begin{tabular}{|l|l|l|l|l|}
\hline Not Important & Somewhat Important & & Very Important \\
\hline
\end{tabular}

4. What level of efficiencies do you expect from APTS?

5. What is the primary motivation for APTS?

\begin{tabular}{|l|l|l|l|l|}
\hline Safety & & Effici ency & & Service Effectiveness \\
\hline
\end{tabular}

6. How do you think APTS will be made more effective in Florida?

7. What factors, in your view, impede the deployment of APTS? How do we overcome these barriers?

8. What isthe role of various players (FDOT Central Office, FDO T Districts, MPOsand local government) in the development and deployment of APTS?

\section{FUNDING}

1. How important is it to provide fundsfor APTSin Public Transportation projects?

\begin{tabular}{|l|l|l|l|l|l|}
\hline Not Important & & Somewhat Important & & Very Important & \\
\hline
\end{tabular}


2. How important is it to seek funding for APTS?

\begin{tabular}{|c|c|c|}
\hline Not Important & Somewhat Important & Very Important \\
\hline
\end{tabular}

3. What percent of the budget should be all ocated to APTS?

4. What specific funding sources have been used for APTS?

\section{INTEGRATION}

1. How important is it for the regional ITS architecture to conform to the national ITS architecture?

\begin{tabular}{|l|l|l|l|l|}
\hline Not Important & & Somewhat Important & & Very Important \\
\hline
\end{tabular}

2. How would you define what conformity is?

3. What do you believe are the implications for APTS as a result of a statew ide ITS strategic plan?

4. Have you ben following the progress of the statewide architecture project?

5. How important is it for individual ITS-Transit projects to fit into overall architecture?

\begin{tabular}{|l|l|l|l|l|}
\hline Not Important & & Somewhat Important & & Very Important \\
\hline
\end{tabular}

6. Should that architecture be statewide, regional or local?

7. Do you think it is important to merge APTS into the regional ITS architecture?

\begin{tabular}{|l|l|l|l|l|}
\hline Not Important & & Somewhat Important & & Very Important \\
\hline
\end{tabular}

8. How can APTSbe integrated into the regional ITS architecture?

9. Do you think transit should be combined with regional transportation services and traffic operations in a regional transportation management center?

10. What specific inter-local agreements and memorandum letters of understanding would be necessary to accomplish this? 
11. Do you think it is important to integrate the following within a route, city, region, or state?

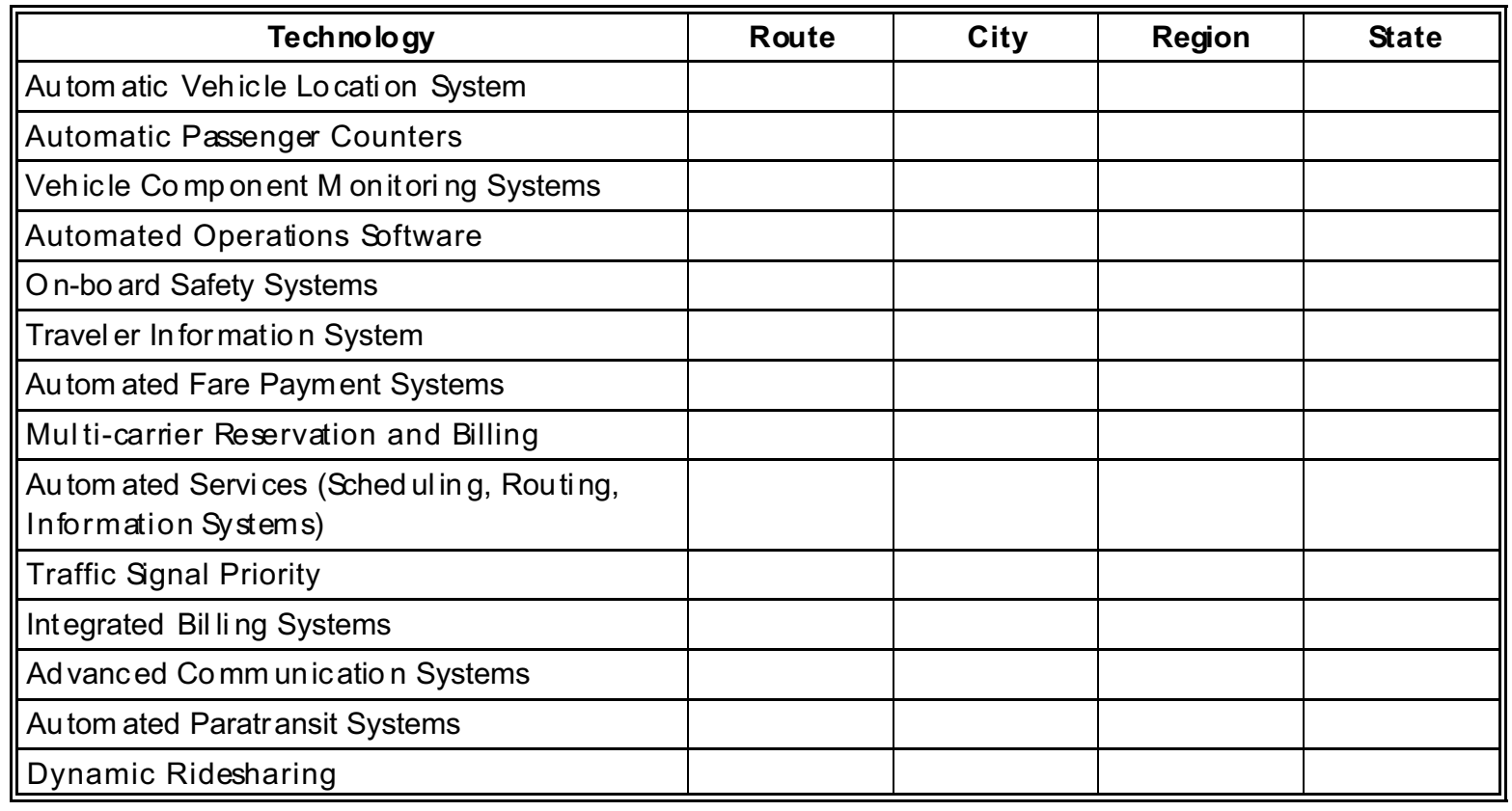

12. Is it important to have traffic signal priority on your routes for transit vehicles?

\begin{tabular}{|l|l|}
\hline Yes & No \\
\hline & \\
\hline
\end{tabular}

\section{EQUIPMENT COMPATIBILITY}

1. Which of the following technologies should there be uniformity across route, city, region, or state?

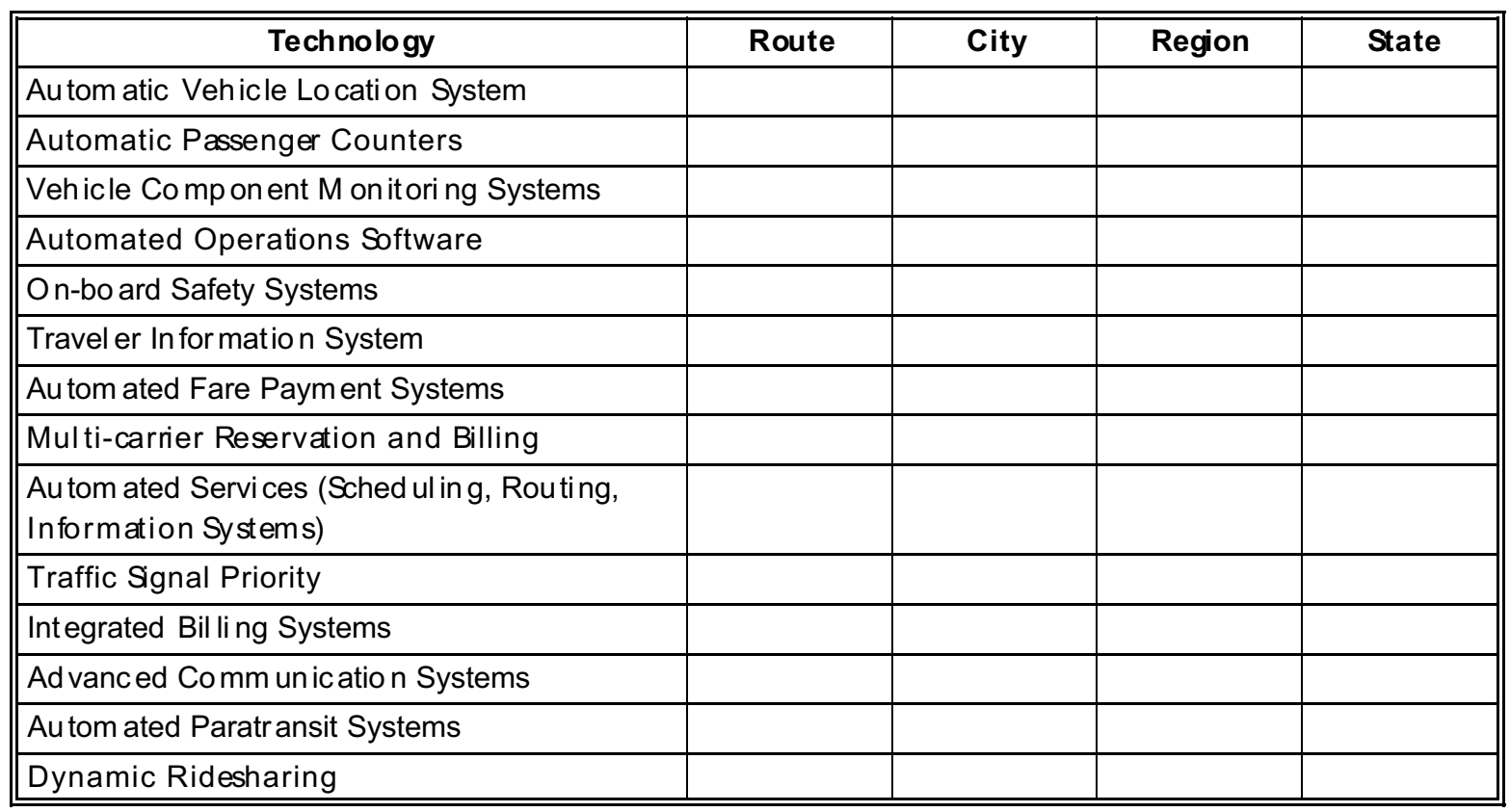




\section{STAFF OPINIONS}

\section{Please give us your opinions on:}

\begin{tabular}{|c|c|c|c|}
\hline \multirow{2}{*}{\begin{tabular}{l}
\multicolumn{1}{c}{ D escription } \\
Automatic Vehicle Location \\
System
\end{tabular}} & Procurement M ethods $^{1}$ & Type & M anufacturers \\
\hline & & & \\
\hline Automatic Passenger Counters & & & \\
\hline $\begin{array}{l}\text { Vehicle Component Monitoring } \\
\text { Systems }\end{array}$ & & & \\
\hline Automated Operations Software & & & \\
\hline On-bo ard Safety Systems & & & \\
\hline Travel er In for mation System & & & \\
\hline Autom ated Fare Payment Systems & & & \\
\hline $\begin{array}{l}\text { Multi-carrier Reservation and } \\
\text { Billing }\end{array}$ & & & \\
\hline $\begin{array}{l}\text { Au tom ated Services (Sched ul in g, } \\
\text { Routing, In formation Systems) }\end{array}$ & & & \\
\hline Traffic Signal Priority & & & \\
\hline Integrated Bil ling Systems & & & \\
\hline $\begin{array}{l}\text { Advanced Communication } \\
\text { Systems }\end{array}$ & & & \\
\hline Au tom ated Paratr ansit Systems & & & \\
\hline Dynamic Ridesharing & & & \\
\hline
\end{tabular}

Note: 1. Products and/or services

\section{Pleas give us your opinions on:}

\begin{tabular}{|c|c|c|}
\hline \multirow{2}{*}{\begin{tabular}{|l|}
\multicolumn{1}{|c|}{ Description } \\
Automatic Vehicle Location \\
System
\end{tabular}} & Perform ance Ratings & Recommendations for Change \\
\hline & & \\
\hline \multicolumn{3}{|l|}{ Automatic Passenger Counters } \\
\hline \multicolumn{3}{|l|}{$\begin{array}{l}\text { Vehicle Component Monitoring } \\
\text { Systems }\end{array}$} \\
\hline \multicolumn{3}{|l|}{ Automated Operations Software } \\
\hline \multicolumn{3}{|l|}{ On-bo ard Safety Systems } \\
\hline \multicolumn{3}{|l|}{ Travel er In for mation System } \\
\hline \multicolumn{3}{|l|}{ Au tom ated Fare Payment Systems } \\
\hline \multicolumn{3}{|l|}{$\begin{array}{l}\text { Multi-carrier Reservation and } \\
\text { Billing }\end{array}$} \\
\hline \multicolumn{3}{|l|}{$\begin{array}{l}\text { Au tom ated Servi ces (Sched ul in g, } \\
\text { Routing, In for mation Systems) }\end{array}$} \\
\hline \multicolumn{3}{|l|}{ Traffic Signal Priority } \\
\hline \multicolumn{3}{|l|}{ Int egrated Bil ling Systems } \\
\hline \multicolumn{3}{|l|}{$\begin{array}{l}\text { Advanced Communication } \\
\text { Systems }\end{array}$} \\
\hline \multicolumn{3}{|l|}{ Au tom ated Paratr ansit Systems } \\
\hline Dynamic Ridesharing & & \\
\hline
\end{tabular}


3. How important is it to have high occupancy vehicle lane access for transit vehicles? (This is a device/transponder on the vehicle, which gives access to high occupancy vehicle only lanes).

\section{Pleas give us your opinions on:}

\begin{tabular}{||l|l|l||}
\hline \multicolumn{1}{|c|}{ Description } & \multicolumn{1}{c||}{ Measurable Benefits } & \multicolumn{1}{c||}{ Problems $^{1}$} \\
\hline Automatic Vehicle Location & & \\
System & & \\
\hline Automatic Passenger Counters & & \\
\hline $\begin{array}{l}\text { Vehicle Component Monitoring } \\
\text { Systems }\end{array}$ & & \\
\hline Automated Operations Software & & \\
\hline On-bo ard Safety Systems & & \\
\hline Travel er In for mation System & & \\
\hline Autom ated Fare Payment Systems & & \\
\hline Multi-carrier Reservation and \\
Billing
\end{tabular}

Note: 1. Are the problems with coordination, compatibility, or standards? (Coordination - Cor; Compatibility - Com; Standards - Std)

\section{Please give us your opinions on:}

\begin{tabular}{|c|c|c|}
\hline Description & Benefits Analysis $^{1}$ & Impacts ${ }^{2}$ \\
\hline \multicolumn{3}{|l|}{$\begin{array}{l}\text { Automatic Vehicle Location } \\
\text { System }\end{array}$} \\
\hline \multicolumn{3}{|l|}{ Automatic Passenger Counters } \\
\hline \multicolumn{3}{|l|}{$\begin{array}{l}\text { Vehicle Component Monitoring } \\
\text { Systems }\end{array}$} \\
\hline \multicolumn{3}{|l|}{ Automated Operations Software } \\
\hline \multicolumn{3}{|l|}{ On-bo ard Safety Systems } \\
\hline \multicolumn{3}{|l|}{ Travel er In for mation System } \\
\hline \multicolumn{3}{|l|}{ Au tom ated Fare Paym ent Systems } \\
\hline \multicolumn{3}{|l|}{$\begin{array}{l}\text { Multi-carrier Reservation and } \\
\text { Billing }\end{array}$} \\
\hline \multicolumn{3}{|l|}{$\begin{array}{l}\text { Au tom ated Services (Sched ul in g, } \\
\text { Routin g, Infor mation Systems) }\end{array}$} \\
\hline \multicolumn{3}{|l|}{ Traffic Signal Priority } \\
\hline \multicolumn{3}{|l|}{ Integrated Bil ling Systems } \\
\hline \multicolumn{3}{|l|}{$\begin{array}{l}\text { Advanced Communication } \\
\text { Systems }\end{array}$} \\
\hline \multicolumn{3}{|l|}{ Au tom ated Paratr ansit Systems } \\
\hline Dynamic Ridesharing & & \\
\hline
\end{tabular}

Notes: 1. Was a benefits andysis done prior to deployment and post deployment? If so, what were the results?

2. What were the impacts to agency's staff and maintenance during operations? 


\section{Pubuc Awaren Ess/Involvement}

1. Are you satisfied with the level of public awareness of APTS?

2. Are you satisfied with the level of public official awareness of APTS?

3. What do you think are appropriate methods to increase public awareness?

\section{PARTNERING}

1. Is your agency currently partnering or intend to partner with a public or private entity? If yes, for what product(s) or service(s)?

2. What opportunities do you think exist for public-public and public-private partnerships for APTS?

\section{RURAl AREAS}

1. What benefits do you see in applying APTS in rural areas?

\section{VISIONSOF THEFUTURE}

1. How would you describe the level of APTSsuccess in your area?

2. If successful, what are the factors for your success?

3. What activities are necessary to assure and maintain success?

4. Do you think the ITS Strategic Plan will encourage more coordination for ITS-Transit projects between local governments and transit agencies?

5. What is your long-term vision of APTSfor the fut ure? 


\section{BusRapid Transit}

(Federal Transit Administration (FTA) is promoting Bus Rapid Transit in the United States through thisinitiative, upgraded busservice will include some or all of the following feat ures: adaptive signal timing; exclusive right-of-ways; queue-jumper intersections; enhanced bus stops/stations; pre-paid fare instrumentsor electronic fare collection systems vehicle location systems, buseswith low floor, wider doors, and greater maneuverability; on-board passenger information systems transit-oriented development land use provisions; and multiple bus service strategies including line haul, skip stop, express, neighborhood distributor, line haul feeders, and circumferential routes.)

6. Do you think Bus Rapid Transit should be integrated into our surface transportation system?

7. Which of the above features should be included in Bus Rapid Transit?

\section{Intell igent Vehicle Initiative}

(The mission of the Intelligent Vehicle Initiative (IV) is to accelerate the development and availability of advanced safety and information systems applied to all types of vehicles Its primary goal is to help driversoperate vehicles more safely and effectively. There are several bus systems that are in varying degrees of demonstrations conceming IVI technology. These include side collision warning, rear collision warning, front collision warning, lane keeping, precision docking etc.)

8. Do you think it is important to incorporate IVI in transit? 
Appendix C

Interview Questionnaire for APTSStakeholders 


\section{INTERVIEW FOR APTSSTAKEHOLDERS}

\begin{tabular}{|l|l|}
\hline Person(s) Interviewed: & \\
\hline Address: & \\
\hline Telephone No.: & \\
\hline Email Address: & \\
\hline
\end{tabular}

\section{INTRODUCTION}

I. Are you familiar with ITS?

\section{Are you aware of what APTS is?}

Advanced Public Transportation Systems (APTS) encompass the application of advanced electronic technologies to the deployment and operation of high occupancy, shared-ride vehicles, including conventional buses, rail vehicles, and the entire range of para-transt vehicles. They hold immense potential for improving mass transportation services and will be used to inform travelers of the alternative schedules that are available for any given trip, including the most advantageous routing.

APTScan also automatically handle trip fares. APTSwill keep the traveler informed, in real time, of any system changes that occur and will respond to changes in the traveler's plans. APTStechnologies will hel $p$ vehicle system admi ni strators manage a safe and efficient fleet and plan servicesto meet a broad range of consumer needs, they will alow the community to manage its roadways with special accommodations for high ocupancy vehicles.

They will, in essence, enable transit authorities to provide a more flexible, cost effective, user friendly service to their customers.

1. ITS-transit is call ed Advanced Public Transportati on Systems (APTS).

2. Advanced Public Transportation Systemsare advanced communication, navigation, computer and information technologiesapplied to Transit.

3. APTSconsists of various parts such as:

a. Fleet Management: It incorporates the many of the vehicle-based APTS technologies and innovationsfor more effective vehicle and fleet pl anning, scheduling and operations. Communication Systems, Geographic Information Systems; Automatic Vehicle Location; Automatic Passenger Counters; Transit Operations Software; Traffic Signal Priority Treatment.

b. Traveler Information: With links to automatic vehicle location systems, traveler information systems are beginning to provide real-time transit information, such as arrival times, departure times, incidents, and delays. Travelerscan access this information through a variety of media. Pre-trip; InTermi nal $/$ ayside; In-Vehi cle.

c. Bectronic Fare Payment Transit, like other service areas, has the desire to reduce the use of cash payments while improving customer convenience. Various cards like smart cards, proximity cards, credit cards, magnetic stripe cards are used in electronic fare payment. 
d. Transportation Demand Management Transportation (TDM ) technologi es are those, whi ch combine innovative approaches and advanced technologiesto better utilize existing infrastructure. This is accomplished through a combination of, among the other things, increased incen ti ves tow ards shared rides, coordination of transportation service providers, and enhanced incident management. There are mainly four TDM technologies. Dynamic Ridesharing; Automated Service Coordination; Transportation Management Centers; High Occupancy Vehicle Facility Monitoring.

\section{Deveopment ANd Deployment}

I. What are your views on ITS?

II. How important is APTScompared to other ITSapplications?

\begin{tabular}{|l|l|l|l|l|}
\hline Not Important & Somewhat Important & & Very Important & $\square$ \\
\hline
\end{tabular}

III. Do you think APTS will improve the performance of public transportation?

\begin{tabular}{|l|l|l|l|l|l|}
\hline Nolmprovements & & Some Improvements & & Significant Improvements \\
\hline
\end{tabular}

IV. How important is it to incl ude APTS in the project development process?

\begin{tabular}{|l|l|l|l|l|}
\hline Not Important & & Some What Important & & Very Important \\
\hline
\end{tabular}

V. Are you promoting any particular APTSprojects?

VI What is your overall view of APTS?

VII. How do you think APTS will be made more effective in Florida?

VIII. What factors, in your view, impede the deployment of APTS? How do we overcome these barriers?

IX. What is the role of various players (FDOT Central Office, FDOT Districts, MPOs and local government) in the development and deployment of APTS?

\section{FUNDING}

I. Should the state and the local governments be in vesting more in APTS?

II. What specific funding sources have been used for APTS? 
III. Do you know how TEA 21 views funding sources for APTS?

The following is a list of some of the views: (Excerpts from interview with William Millar, President of American Public Transit Association).

- TEA 21 puts the federal government' s sal of approval on ITS in general and transit ITS in particular.

- One of TEA 21 's major themes is the importance of open architecture and standards designed to ensure that a region's diverse ITS users have compatible technology, including the transit agency.

- More specifically, TEA 21 makesit clear that ITSisan eligible project cost undera wide variety of federal surface transportation programs, provided that the ITS investments meet the federal open architecture sandards.

- TEA 21 makes it clear that transit-ITS expenditures can come from many programs, especially the flexible highway programs such as the Surface Transportation Program and $C M A Q$, and also the various elements of the transit program.

IV. How important is it to seek funding for APTS?

\begin{tabular}{|l|l|l|l|l|}
\hline Not Important & & Somewhat Important & & Very Important \\
\hline
\end{tabular}

V. Do you think any part of the work program budget should be all ocated to APTS?

\section{INTEGRATION}

I. How important is it for the regional ITS architecture to conform to the national ITS architecture?

\begin{tabular}{|l|l|l|l|l|}
\hline Not Important & & Somewhat Important & & Very Important \\
\hline
\end{tabular}

II. How would you define what conformity is?

III. What do you believe are the implications for APTS as a result of a statew ide ITS strategic plan?

IV. Have you been following the progress of the statewide architecture project?

V. How important is it for individual ITS-Transit projects to fit into overall architecture?

\begin{tabular}{|l|l|l|l|l|}
\hline Not Important & & Somewhat Important & & Very Important \\
\hline
\end{tabular}

VI. Should that architecture be statewide, regional or local? 
VII. Do you think it is important to merge APTS into the regional ITS architecture?

\begin{tabular}{|l|l|l|l|}
\hline Not Important & Somewhat Important & & Very Important \\
\hline
\end{tabular}

VIII. How can APTSbe integrated into the regional ITS architecture?

IX. Do you think transit should be combined with regional transportation services and traffic operations in a regional transportation management center?

X. What specific intertocal agreementsand memorandum lettersof understanding would be necessary to accomplish this?

The fol lowing are some of the advantages of integrating transit and traffic functions in a TMC:

- Reduce jurisdictional issues

- Improve joint incident management

- Develop special event plans

\section{Pubuc Awaren ess/lnvolvement}

I. Are you satisfied with the level of public awareness of APTS?

II. What do you think are appropriate methods to increase public awareness?

\section{PARTNERING}

I. What opportunities do you think exist for public-public and public-private partnerships for APTS?

\section{RURAL AREAS}

I. What benefits do you see in applying APTS in rural areas?

\section{VISIONSOF THEFUTURE}

I. How would you describe the level of APTSsuccess in your area? 
II. What activities are necessary to assure and maintain success?

III. Do you think the ITS Strategic Pan will encourage more coordination for ITS-Transit projects between local governments and transit agencies?

IV. What is your long-term vision of APTSfor the fut ure?

\section{BusRapid Transit}

(Federal Transit Administration (FTA) is promoting Bus Rapid Tran sit in the United States through this initiative, upgraded bus service will include some or all of the following features adaptive signal timing; exclusive right-of-ways; queue-jumper intersections; enhanced bus stops/stations; pre-paid fare instruments or electronic fare collection systems; vehicle location systems, buseswith low floor, wider doors, and greater maneuverability; on-board passenger information systems transit-oriented development land use provisions; and multiple bus service strategiesincluding line haul, skip stop, express, neighborhood distributor, line haul feeders, and circumferential routes)

V. Do you think Bus Rapid Transit should be integrated into our surface transportation system?

VI. Which of the above features should be included in Bus Rapid Transit?

\section{Intell igent Vehicle Initiative}

(The mission of the Intelligent Vehicle Initiative (IV) is to accelerate the development and availability of advanced safety and information systems applied to all types of vehicles Its primary goal is to help drivers operate vehicles more safely and effectively. There are several bus systems that are in varying degrees of demonstrations conceming IVI technology. These include side collision warning, rear colli sion warning, front collision warning, lane keeping, precision docking etc.)

VII. Do you think it is important to incorporate IVI in transit? 
Appendix D

List of Participating Stakeholders 
List of FDOT District 1 stakeholders (meeting attendees):

1. Commissioner David R. Mills, Sarasota County

2. Commissioner Janet Shearer, Polk County

3. Commissioner Jhn Albion, Lee County

4. David Hope, Transit Manager, Collier County BCC

5. Debbie Hunt, Director of Planning \& Public Transportation, FDOT

6. Jay Goodwill, Transit Director, SCAT

7. Jhn Starl ing, District Public Transportation Manger, FDOT.

8. Lisa B. Beever, MPO Coordinator, Charlotte County-Punta Gorda

9. Ralph Mervine, Director of Operations, FDOT

10. Robert Herrington, for Mike Guy, Panning Manager for Sarasota/Manatee MPO

List of FDOT District 2 stakeholders (meeting attendees):

1. Aage Schroder, FDOT, District 2, Director of Panning

2. Lorenzo Alexander, FDO T, District 2, Public Transportation Manager

3. Randy Warden, for Jm McLaughlin, FDOT, District 2, Director of Operations

List of FDOT District 4 stakeholders (meeting attendees):

1. Jeff W eidner, Transit Supervisor

2. Jnathan Overton, District ITSEngineer

3. Mark Plass, Traffic Operations

4. Tahira Faquir, for JamesWolfe, Director of Operations

List of FDOT District 6 stakeholders (meeting attendees):

1. Arvind Kumbhojkar, FDOT, District 6, ITS Administrator

2. Carlos Roa, Miami-Dade MPO, Transportation System Specialist

3. David Fialkoff, MDTA, Chief of Servicesand Mobility

4. David Korros, for Rafael DeArazoza, FDOT, District 6, Planning Manager

5. Gary D onn, FDOT, District 6, Director of Panning

6. Gus Pego, FDOT, District 6, Director of Operations

7. Rene Rodriguez, FDO T, District 6, Public Transportation Manager 
1. Bill Wilshire, FDOT District 7, ITS Engineer

2. Don Skelton, FDOT District 7, Director of Panning and Public Transportation

3. Jerry Karp, FDOT District 7, Planning Department

4. Harry Reid, FDO T District 7, Publ ic Transportation Manager

5. Jhn Temple, FDOT District 7, Director of Operations

List of FDOT Central District stakehol ders (meeting attendees)

1. Wes Watson, Forida Transit Association

2. Liang Hsia, FDO T, Deputy State Traffic Operations Engineer

3. Mary Constiner, FDOT, Transportation Disadvantaged Commission

4. Ike Ubaka, FDOT, Transit Planner

5. Jack Brown, FDO T, State Traffi c Operations Engi neer

6. Howard Glassman, FDOT, MPOAC Executive Director

List of Community Transportation Coordinator stakeholders (survey respondents)

1. Rich Weingarten, Charlotte County Transit Department, Charlotte County

2. Michael D. Perry, Sarasota County Area Transit, Sarasota County

3. Brenda G. Clay, Liberty County Board of County Commissioners, Liberty County

4. Pasco County Public Transportation, Pasco County

5. Jhn Stanley, JTrans, Jackson County

6. James Swisher, Suwannee Valley Transit Authority, Col umbia/Hamilton/Suwannee Counties

7. Tim Banks COMSIS Mobility Services, Inc., Hardee/Highlands/Okeechobee Counties

8. Gary Bryant, Rob Bowman, Carl Kerstan, Good Wheels, Inc., Glades/Hendry Counties

9. Jerry Lamm, Citrus County Transit, Citrus County

10. Steven E Jones, Flagler County Council on Aging, Fagler County

11. Barbara Bertolini Timmerman, Council on Aging of Martin County, Inc., Martin County

12. David Hope, Collier County Board of County Commissioners, Collier County

13. Matt Pearson, Suwannee River Economic Council, Bradford/Dixie/Gil christ/Lafayette Counties

14. Boyd Thompson, Ride Solution, Putnam County

15. Frank Ferry, Clay County Council on Aging, Inc., Clay County 
ApPendix E

List of References for Literature Review 
Anderson, Laurie. Intelligent Transportation Society of America. Legal and Procurement Issues in Forming Public/Private Partnerships in Min nesota. Proceedings from the $5^{\text {th }}$ Annual Meeting of the Intelligent Tran sport ation Society of A merica. Published at http://www.itsa.org. (November $8^{\text {th }}, 1995$ ).

Association of Metropolitan Planning Organizations. National ITS Architecture Consistency (Conformity). Published at http://www.narc.org/ampo/national.htm.

Blackweld er, Glenn; \& Loukakos, Di mitri. Personalized Public Transit. Published at http://www.path.berkeley. edu/ leap/PTO/Personal Pub Transit/in dex.html. (November 7, 2000 ).

Boile, Maria P.; Spasovic, Lazar N.; \& Pignataro, Louis J. "D eveloping a Market-Sensitive Intelligent Transportation Systems Educational Program." Transportation Research Record 1588. Paper number 970437. 120-128.

Chira-Chivala, Ted. "In telligent Technology Benefits Paratransit.” Intellimotion. 8(1)(1999): 8-11.

DBH Consulting. Integrating Intelligent Transportation Systems and M etro politan Tran sport ation Plann ing: Some Integration, Much More Needed. Published at http://www.dbhcon.com/itspaper.htm. (September 29, 1999).

Federal Transit Administration National ITS Architecture Policy on Transit Projects; Notice. 23 CFR Parts 655 and 940; Intell igent Transportation System Architecture and Standards; Final Rule. Federal Register. U.S. Department of Transportation. Federal Highway Administration. 66(5) (January 8, 2001): 1446-1454.

Florida Department of Transportation. New Technology in Mass Transit. Published at http://www.fta.dot.gov/ transcity/its/its.html.

Florida Department of Transportation. Transportation Management Centers. Published at http ://w w w.fta.do t.gov/ li brary/techn ol ogy/A PTS/up date/CH AP5.H TM.

Florida Department of Transportation. Florida Statewide ITS Strategic Plan, Procurement Issue Paper, FINAL. A report prepared by P.B. Farradyne, Inc. January 25, 1999.

Florida Department of Transportation. Florida Statewide ITS Strategic Plan: Int egration of ITS in to the M PO Transportation Planning Process /ssue Paper. A report prepared by T日 Engineers \& Planners. February 7 , 1999.

Florida Department of Transportation. Rural/Inter-Urban ITS Applications Issue Paper. March 8, 1999.

Florida Department of Transportation. Economic Impacts of Intelligent Transportation Systemsin Florida- An Issue Paper, Final Report. A report prepared for Forida DOT by KPMG. April 1999.

Florida Department of Transportation. Florida ITS Strategic Plan: Operations Management, and Main tenance Issues Paper. June 6, 1999.

Florida Department of Transportation. Florida Statewide ITS Strategic Plan. Summary of Survey Results. June 8, 1999.

Florida Department of Transportation. Florida's Intelligent Transportation System Strategic Plan: Fnal Report. August 23, 1999. 
Florida Department of Transportation. Florida's ITSPlanning Guidelines: Integration of ITSinto the Transportation Planning Process. A report prepared by The State of Florida Department of Transportation, Office of the State Transportation Planner in Cooperation with the Metropolitan Planning Organization Advisory Council (http://www.dot.state. fl.us./planning), lune 2000.

Gillen, David; Li, Janling; Dahlgren, Joy; \& Chang, Bva. Assess the Benefits and Costs of ITSProjects Volume 1 Methodology. A rep ort prep ared for Californi a PATH pro gram, In stitu te of Transpo rtati on Studies, University of California, Berkeley. March 1999.

Harris, Richard; Staats, Richard; and Bailey Ronald for Intell igent Transportation Systems Online. ITS Evaluation: A New Framework. Published at http://www.itsonline.com/lmi/isatax.html.

Intelligent Transportation Society of Am erica. Opportunities and Actionsfor Deployment. Publi shed at http://www.itsa.org.

Intelligent Transportation Society of Am erica. Take a 360-Degree Look Around to Locate ITSFunding Sources. Published at http://www.itsa.org. (Septem ber 18, 1998).

Intelligent Transportation Society of America. ITSIntegration and Deployment Funding Nearly $\$ 93$ Million in FY99. Published at http://www.itsa.org. (April 8, 1999).

Intelligent Transportation Society of Am erica. How Do You Use ITS to Im pro ve In cident M anagement. Published at http://www.itsa.org. (Mly 8, 1999).

Intelligent Transportation Society of Am erica. Saving Lives, Time, and Money Using Intelligent Transportation Systems: Opportunities and Actions for Deplo yment. Published at http://www.itsa.org. (February 2000).

Intelligent Transportation Society of Am erica. ITS American's Intell igent Transportation Systems Fair Inform ation and Privacy Principles. Published at http://www.itsa.org. (January 15, 2001).

ITS On line. ITS Architecture Stakeholder Issues. Published at http://www.itsonline.com/stake6.html.

Kane, Anthony R. Intelligent Transportation Society of America. Innovative Procurement Methods. Published at http://www.itsa.org. (O cto ber 6, 1999).

Levy, Melissa. "The Need for Intell igent Transportation Systems in Rural America." Economic Development Digest 11(11) (October 2000): Publi shed at http://www .nado.org/pubs/oct3.html.

Loukakos, Di mitri . Autom atic Vehicle Location. Published at http://www.path.berkeley.edu/ leap/PTO/Pub Trans Manage/avl body.html. (February 26, 2001).

Loukakos, Di mitri. Fare Payment Systems. Published at http://www.path.berkeley.edu/ leap/田/Bectronic Payment/fare payment glance body.html. (Uly 26, 2000).

Loukakos, Di mitri . Public Transportation/Transit. Published at http://www .path .berkeley.ed/ leap/PTO/ index body.html. (February 26, 2001).

Mid-O hio Regional Planning Commission. Executive Summary of ITS Early Deployment Study. Published at http://www.morpc.orgc/trans/cac/Executive\%20 Summ ary\%20ITS.htm.

National ITS Architecture. National ITS Architecture. Published at http://www.odetics.com/itsarch. 
North Carolin a State University Transit Gro up. APTSTechnology Review. Published at http://www.ncsu.edu/ eos/service/ce/research/stone res/tahmed res/ww w/Sec2.html.

Ohio D epartment of Transportation- District 12. Cleveland/Lorain ITSEarly Deployment Planning Study. ITS Strategic Deployment Plan. A report prepared by HN TB Ohio, Inc., and TRW, Inc. September 1996.

Peyrebrune, Henry L. Technology: A Bridge to the States, Opportunities for Intergovernmental Cooperation on Intelligent Transportation Systems. A report prepared for Public Technology, Inc., American Association of State Highw ay and Transportation Officials, and $\mathrm{N}$ ational Association of City Transportation $\mathrm{O}$ fficials. Published at http://www.pti.org/task forces/transportation/do cs/bridge/trans.htm.

PohIman, JM. and Willi ams. EN. for Intelligent Traffic Systems. Intelligent Transportation Society of America. Public/Private Partnering for the Georgia D OT Advanced Traveler In formation Kiosks. Proceedings of the $6^{\text {th }}$ Annual Intelligent Transportation Society of Am erica. Published at http://www.itsa.org. (O cto ber $28,1999)$.

Proper, Allen T. and Maccubb in, Rob. ITS Benefits: Data Needs Up date 2000. A report prepared by Mitretek Systems in Connection with the 12 uly 2000 ITSBenefits Data Needs Workshop, August 29, 2000.

Rodriguez, Daniel A. \& Sussman, bseph M. "Framework for Developing a Regional System Architecture for Intelligent Transportation Systems." Transportation Research Record 1588. Paper number 970893: 77-85.

U.S. Department of Transportation. Federal Transit Administration. Advanced Public Tran sport ation Systems Mobile Show case. A report by Nuria I. Fernandez, Acting Administrator, Federal Transit Administration. Published at http://www.fta.dot.gov/research/fleetits/mobshow.htm.

U.S. Department of Transportation. Intelligent Transportation Systems. Decreased Traffic Congestion. Published at http://www.itsa.dot.gov/cyberdocs/edldocs/4925/body ch0 4 01.html.

U.S. Department of Transportation. Intelligent Transportation Systems. Jint Program Office. Interim Guidance on Conformity with the National ITS Architecture and Standards. Published at http://www.its.dot.gov./ aconform/iguid e.htm.

U.S. Department of Transportation. Federal Transit Adm ini stration. National ITS Program: Where We've Been and Where We're Going. A report prepared by Christine M. Johnson. Publi shed at http://www.tfhrc.gov/ pubrds/pr97-10/p6.htm.

U.S. Department of Transportation. Federal Transit Administration. Transit Intelligent Transportation Systems. A report prepared by Mortimer L. Dow ney, D eputy Secretary of Transportation. Publi shed at http://www.fta.dot. gov/research/fleetlits/its.htm.

U.S. Department of Transportation. Federal Transit Administration. Tran sit Intell igent Transportation Systems National Architecture. Published at http://www.fta.dot.gov/research/fleetits/narch.htm.

U.S. Department of Transportation. Federal Highw ay Admi nistration. Intelligent Transportation Systems Impro ve Travel Safety and Transit Service in Rural Areas. A report prepared by the Federal $\mathrm{H}$ ighw ay Administration and the Federal Transit Administration for use by members of the National Associations Working Group for ITS. Publication number FHWA-OP-00-031. Washington: Governm ent Printing Office. 
U.S. Department of Transportation. Federal Highw ay Administration. Safer, More Eficient Travel with Intelligent Transportation Systems. A report p repared by Susan Lauffer and Walter Kulyk of the Federal $\mathrm{Highw}$ ay $\mathrm{Adm}$ in istration and the Federal Transit $\mathrm{Adm}$ in istration for use by members of the $\mathrm{N}$ ational Association Working Group for ITS. Publication number FHW A-SA-97-087. Washington: Government Printing Office.

U.S. Department of Transportation. Federal Highway Adm ini stration. Public and Private Sector Roles in Intelligent Vehicle-Highway Systems(IVHS) Deployment, volume 3. A report prepared by Walcoff \& Associates. Publication number FHW A-PL-92-024. Washington: Governm ent Pri nting O ffice, August 1992.

U.S. Department of Transportation. Office of Technical Assistance and Safety. Advanced Public Transportation Systems Program: A Component of the Departmental IVHS Initiative. Advanced Public Transport ation Systems: Evaluation Guidelines. A report prepared by the Volpe National Transportation Systems Center. Publi cation num ber DO T-T-94-10. Washington: Government Printing O ffice, January 1994.

U.S. Department of Transportation. Federal Transit Administration. Review of and Prelim in ary Guidelines Integrating Transit into Transportation Management Centers. A report prepared for the Volpe $\mathrm{N}$ ational Transportation Systems Center by Carol L. Schweiger, EG\& G D ynatrend Published at http://ww w.fta.dot.gov/ library/planning/IVHS/ivhs. html. Publication number D OT-94-25. Washington: Governm ent Printing O ffice, January 1994.

U.S. Dep artm ent of Transportation. Federal Transit Adm in istration. Advanced Public Transportati on Systems Program: A Component of the Departmental ITSInitiative. Institutional and Policy Issuesin Adopting Advanced Public Transportation Systems Technology. A report prepared for the US DOT by the Institute of Public Policy, George Mason University. Publication number DO T-T-97-19. Washington: Government Printing Office, September 1995.

U.S. Department of Transportation. Research and Special Programs Admin istration. Project Memorandum: Intelligent Transportation Systems (ITS) Program. Analysis of U.S. DOT -Sponsored Reportson NonTechnical Issues. A report prepared by Dawn M. Lafrance-Linden, Anne C. Tallon, and Allan J DeBlasio of the Volpe National Transportation Systems Center. December 1995.

U.S. Department of Transportation. Federal Transit Administration. Office of Mobility Innovation. Benefits Assessment of Advanced Public Transportation Systems (APTS). A report prepared for the Office of Mobility Innovation by the Volpe National Transportation Systems Center. Publication num ber FHW A-PO-96-0031. Washington: Government Printing Office, July 30, 1996.

U.S. Department of Transportation. Federal Highway Administration. bint Program Office for Intelligent Transportation Systems. Appendix E: Nontechnical Constraints and Barriers to the Implementation of Intelligent Transportation Systems: 1996 Report to Congress. 1997.

U.S. Department of Transportation. ITS Deployment Guidance for Transit Systems Executive Edition. A report prepared by P.B. Farradyne, Inc. April 1997.

U.S. Department of Transportation. Federal Highway Adm inistration. ITSDeployment Guidance for Transit Systems Technical Edition. A report prepared by P.B. Farradyne, Inc. April 1997.

U.S. Department of Transportation. National ITS Architecture Transit Guidelin es Executive Summary. A report prepared by P.B. Farradyne, Inc. Publication number FHW A-PO-97-0016. Washington: Government Printing Office, April 1997. 
U.S. Department of Transportation. Federal Highw ay Administration. Innovative Contracting Practicesfor ITS: Executive Summary. A report p repared by L.S.Gall egos \& Associ ates Inc for the Federal $\mathrm{H}$ ighw ay Admi nistration. Published at http://www.itsdocs.fhwa.dot.gov/jpodocs/rept mis/1fw01!.htm. (April 1997).

U.S. Department of Transportation. Federal Highw ay Administration. A Guide to Developing a Regional ITS/CVO Coordination Plan. A report prepared by Cambridge Systematics, Inc. for the Federal $\mathrm{H}$ ighw ay Administration. August 1997.

U.S. Department of Transportation. Federal Highw ay Administration. FHWA Federal-Aid ITS Procurement Regulations and Contracting Options. A report prepared by Booz Allen \& Hamilton, Inc for the TurnerFairbank Highway Research Center. Publication number FHW A-RD-97-145. Washington: Government Printing Office, October 1997.

U.S. Department of Transportation. Federal Highw ay Administration. Technology in Rural Transportation "Simple Solutions". A report prepared by Castle Rock Consultants for Turner-Fairbank H ighw ay Research Center. Publication number FHW A-RD-97-108. Washington: Government Printing Office, October 1997.

U.S. Department of Transportation. Intelligent Transportation Systems: Commercial Vehicle ITS Publication number FHW A-PO-98-020. Washington: Government Printing Office, 1998.

U.S. Department of Transportation. Intelligent Transportation Systems: Intelligent Vehicle Initiative. Publication number FHW A-PO-98-021. Washington: Government Printing Office, 1998.

U.S. Department of Transportation. Intelligent Transportation Systems: ITS Standards. Publ ication number FHW A-PO-98-028. Washington: Government Printing Office, 1998.

U.S. Department of Transportation. Intelligent Transportation Systems: Metropolitan ITS. Publication number FHW A-PO-98-023. Washington: Government Printing Office, 1998.

U.S. Department of Transportation. Intell igent Transportation Systems: Nation al ITS Archit ecture. Publication number FHW A-PO-98-019. Washington: Government Printing Office, 1998.

U.S. Department of Transportation. Intell igent Transportation Systems: Rural ITS. Publication number FHW A-PO-98-022. Washington: Government Printing Office, 1998.

U.S. Department of Transportation. Federal Transit Administration. Transportation Planning and ITS Putting the Pieces Together. A report prepared by Sarah J. Siw ek \& Associ ates for the Federal $\mathrm{H}$ ighw ay Administration. Publication number FHW A-PD-98-026. Washington: Government Printing Office, 1998.

U.S. Department of Transportation. Federal Transit Administration. Advanced Public Transportation Systems: The State of the Art, Update '98. A report prepared by Vol pe $\mathrm{N}$ atio nal Transportati on Systems Center. Publication number FTA-MA-26-7007-98-1. Washington: Government Printing Office, January 1998.

U.S. Department of Transportation. Federal Highw ay Administration. Intelligent Tran sport ation System s: Real World Benefits. A report prepared by Apogee/Hagler Bially. Publication num ber FHW A-PO-98-018. Washington: Government Printing Office, January 1998.

U.S. Department of Transportation. Federal Highw ay Administration. ITS/CVO Funding Strategies for States. A report prepared by Cambridge Systematics, Inc. for the Federal Highway Administration. March 1998.

U.S. Department of Transportation. Intelligent Transportation Systems bint Program Office. Developing Intelligent Transportation Systems Using the National ITSArchitecture: An Executive Edition for Senior Transportation Managers. A report prepared by Mitretek, Inc. Mly 1998. 
U.S. Department of Transportation. Federal Highway Adm inistration. ITS bint Program Office. Natio nal ITS Architecture Consistency: Summ ary Findings. A report prepared by $\mathrm{V}$ ol pe $\mathrm{N}$ atio nal Transpo rtati on Systems Center. Publi shed at http://www.itsdocs.fhwa.dot.gov/jpodocs/proceedn/41q01!.htm. Jly 1998.

U.S. Department of Transportation. Intelligent Transportation Systems bint Program Office. Developing Traveler Information Systems Using the National ITS Architecture. A report prepared by Mitretek Systems and TransCore Inc. Publication number FHW A-PO-98-031. Washington: Governm ent Printing O ffice, August 1998.

U.S. Department of Transportation. Federal Highw ay Admi nistration. ITS bint Program Office. Benefits of Integrated Technologies and the National ITS Architecture. Outreach materials for National Associations Working Group Publications. A repo rt p repared by Volpe $\mathrm{N}$ ational Tran sportation Systems Cen ter. Publi shed at http://www.its.dot.gov/archconsis/nawgmats.htm. August 1998.

U.S. Department of Transportation. Federal Highw ay Administration. Rural Public Transportation Technologies: User Needs and Applications. A report prepared by Turner-Fairbank Highw ay Research Center. Publication number FHW A-RD-98-146. Washington: Government Printing Office, September 1998.

U.S. Department of Transportation. Federal Transit Administration. Advanced Public Tran sport ation Systems Deployment in the United States. A report prepared by Robert F. Casey of the Volpe National Transportation Systems Center. Publ ic ation num ber FTA-M A-26-70 07-99-1. W ashin gton: Governm ent Printing O ffice, January 1999.

U.S. Department of Transportation. Research and Special Programs Admin istration. Successful Appro aches to Deploying a Metropol itan Intelligent Transportation System. A report p repared by Volpe $\mathrm{N}$ ational Transportation Systems Center. Document number FHW A-PO-99-032. Washington: Government Printing Office, March 1999.

U.S. Department of Transportation. ITS bint Program Office. ITSPCB Program. Building Professional Capacity in ITS: Documentation and An alysis of Training and Education N eeds in Support of ITS Development. A report prepared by Thomas F. Humphrey. April 1999.

U.S. Department of Transportation. Federal Highw ay Admi nistration. Intelligent Tran sport ation Systems Improve Travel Safety and Transit Service in Rural Areas. A report produced by the Federal $\mathrm{H}$ ig hw ay Ad mi ni stration for use by members of the Natio nal Associations Working Group for ITS. Publication num ber FHW A-RD-99-102. Washington: Government Printing Office, April 1999.

U.S. Department of Transportation. Federal Highw ay Administration. Rural ITS. A report prepared by Turner-Fairbank Highway Research Center. Publication number FHW A-RD-99-102. Washington: Government Printing Office, April 1999.

U.S. Department of Transportation. Federal Highw ay Administration. ITS bint Program Office. Intelligent Transportation Systems Benefits: 1999 Update. A repo rt p repared by Mitretek Systems, Inc. Published at http://www.its.fhwa.dot.gov/cyberdocs/welco me.htm. (May 1999). EDL Docu ment N umber 8323.

Publication number FHW A-OP-99-012.Washington: Government Printing Office, May 1999.

U.S. Department of Transportation. Federal Highw ay Administration. Procuring ITS Projects A report prepared by Anthony R. Kane for Forida DO T. Publi shed at http://www.its.dot.gov/procure/memo-a.htm. (Octo ber 6, 1999).

U.S. Department of Transportation. Federal Highw ay Administration. What's Yours, Mine, and Ours: Overcoming Intellectual Property Rights Issues. A report prepared by Christine M. Johnson and Edw ard L. Thomas. Publication Number FHW A-OP-99-021. Washington: Government Printing Office, August 2000. 
U.S. Department of Transportation. Research and Special Programs Admin istration. Incorporating ITS Solutions into the Metropolitan Transportation Planning Process: Overcoming Institutional Barriers. A report prepared by Eizabeth Deysher, David W. Jackson, and Allan $\rfloor$ DeBlasio of the Volpe National Transportation Systems Center. November 2000.

Virgin ia Transportation Research Council. Expected Safety Benefits of Implementing Intelligent

Transportation Systems in Virginia: A Synthesis of the Literature. A report prepared by Jack D. Jernigan, Senior Research Scientist for U.S. Department of Transportation. Publi cation num ber FHWA/VTRC 99-R2.

Washington: Government Printing Office, 1998.

W eissenberger, Stein. "Why ITS Projects Should be Small." Intellimotion. 8(1)(1999). 